\title{
Electrical substrate for cardiac resynchronization therapy : identification and treatment
}

Citation for published version (APA):

Strik, M. O. (2013). Electrical substrate for cardiac resynchronization therapy : identification and treatment. [Doctoral Thesis, Maastricht University]. Uitgeverij BOXPress. https://doi.org/10.26481/dis.20131206ms

Document status and date:

Published: 01/01/2013

DOI:

10.26481/dis.20131206ms

Document Version:

Publisher's PDF, also known as Version of record

\section{Please check the document version of this publication:}

- A submitted manuscript is the version of the article upon submission and before peer-review. There can be important differences between the submitted version and the official published version of record.

People interested in the research are advised to contact the author for the final version of the publication, or visit the DOI to the publisher's website.

- The final author version and the galley proof are versions of the publication after peer review.

- The final published version features the final layout of the paper including the volume, issue and page numbers.

Link to publication

\footnotetext{
General rights rights.

- You may freely distribute the URL identifying the publication in the public portal. please follow below link for the End User Agreement:

www.umlib.nl/taverne-license

Take down policy

If you believe that this document breaches copyright please contact us at:

repository@maastrichtuniversity.nl

providing details and we will investigate your claim.
}

Copyright and moral rights for the publications made accessible in the public portal are retained by the authors and/or other copyright owners and it is a condition of accessing publications that users recognise and abide by the legal requirements associated with these

- Users may download and print one copy of any publication from the public portal for the purpose of private study or research.

- You may not further distribute the material or use it for any profit-making activity or commercial gain

If the publication is distributed under the terms of Article $25 \mathrm{fa}$ of the Dutch Copyright Act, indicated by the "Taverne" license above, 


\section{Electrical Substrate for \\ Cardiac Resynchronization Therapy Identification and Treatment}

Marc Oliver Strik 



\title{
Electrical Substrate for
}

\section{Cardiac Resynchronization Therapy Identification and Treatment}

\author{
Proefschrift \\ ter verkrijging van de graad van doctor aan de Universiteit Maastricht, \\ op gezag van de Rector Magnificus, prof. dr. L.L.G. Soete, \\ volgens het besluit van het College van Decanen, in het openbaar te verdedigen \\ op vrijdag 6 december 2013 om 10.00 uur \\ door
}

Marc Oliver Strik

geboren op 28 november 1984

te Sousse, Tunesië 


\section{Promotores:}

Prof. dr. F.W. Prinzen

Prof. dr. A. Auricchio (Fondazione Cardiocentro Ticino, Lugano, Switzerland)

\section{Beoordelingscommissie:}

Prof. dr. U. Schotten (voorzitter)

Prof. dr. H.-P. Brunner-La Rocca

Prof. dr. H.J.G.M. Crijns

Prof. dr. T. Delhaas

Prof. dr. M.A. Vos (Universiteit Utrecht)

Parts of the research described in this thesis were performed within the framework of CTMM, the Center for Translational Molecular Medicine (www.ctmm.nl), project COHFAR (grant 01C-203), and supported by the Dutch Heart Foundation, Medtronic and EBR Systems.

Financial support for the publication of this thesis as provided by the following sponsors, is gratefully acknowledged
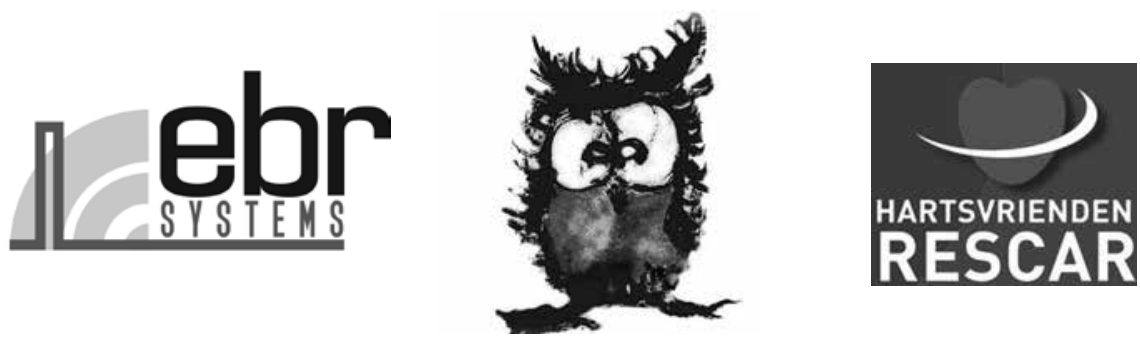
Klein en blond samen met je papa de wereld rond.

Iejoor is joun grote knuffeldier, met hem beb je immens veel plezier. Ik hoop iedere dag dat je zo lief en zo mooi als je mama worden mag.

Aan Adeline 


\section{ISBN/EAN:}

978-90-8891-696-0

\section{Cover:}

Hugo Miggels

\section{Lay-out:}

Marc Strik

Published by:

Uitgeverij BOXPress, 's-Hertogenbosch

Printed by:

Proefschriftmaken.nl || Uitgeverij BOXPress 


\section{Table of contents}

Chapter 1 General Introduction: 9

Background and General Aim of the Thesis

Chapter 2 Electrical Ventricular Activation during Left Bundle Branch Block and Resynchronization

Chapter 3 Animal Models of Dyssynchrony

Chapter 4 Endocardial Mapping in the Dyssynchronous Canine Left Ventricle: Comparison of Non-Contact and Contact electrograms

Chapter 5 Transseptal Conduction as an Important Determinant for Cardiac Resynchronization Therapy; as Revealed by Extensive Electrical Mapping in the Dyssynchronous Canine Heart

Chapter 6 The Interplay of Electrical Wave Fronts as Determinant of the Response to Cardiac Resynchronization Therapy in Dyssynchronous Canine Hearts

Chapter 7 Acute Electrical and Hemodynamic Effects of Multi-Left Ventricular Pacing for CRT in the Dyssynchronous Canine Heart

Chapter 8 Endocardial Left Ventricular Pacing Improves Cardiac Resynchronization Therapy in Chronic Asynchronous Infarction and Heart Failure Models

Chapter 9 General Discussion

Summary

Samenvatting

Dankwoord \& Acknowledgements $\quad 201$

About the Author $\quad 207$

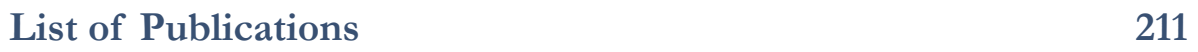



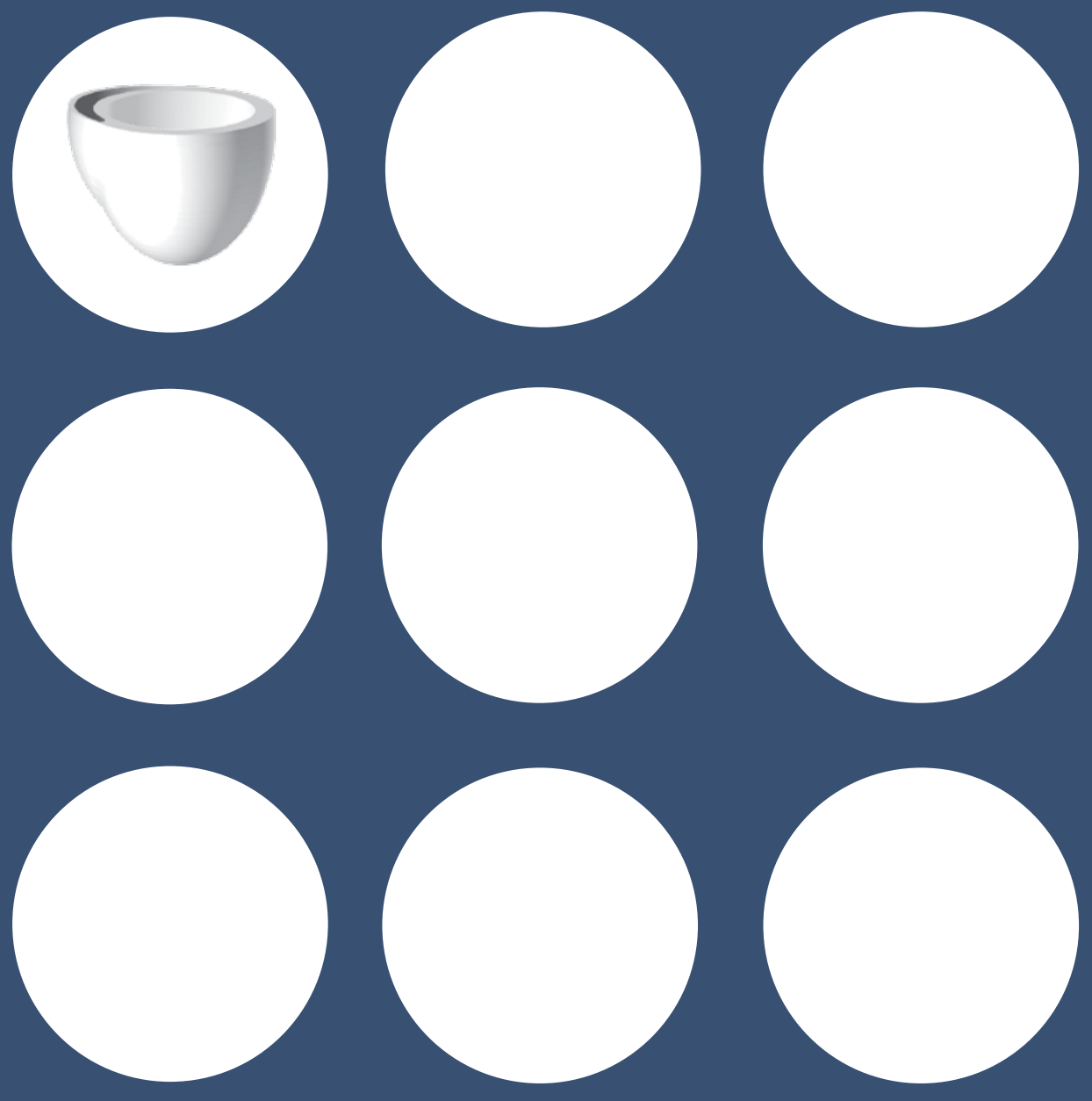

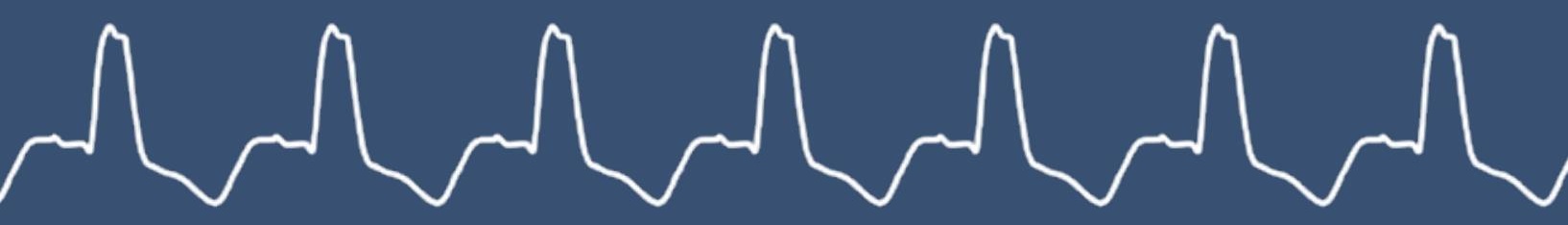




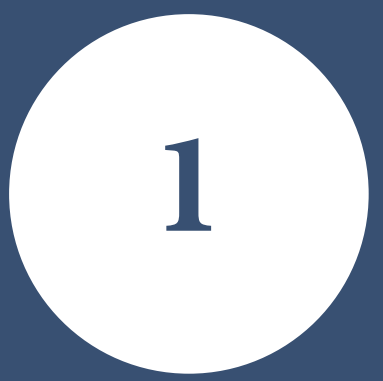

\section{General Introduction:}

\section{Background and}

\section{General Aim of the Thesis}

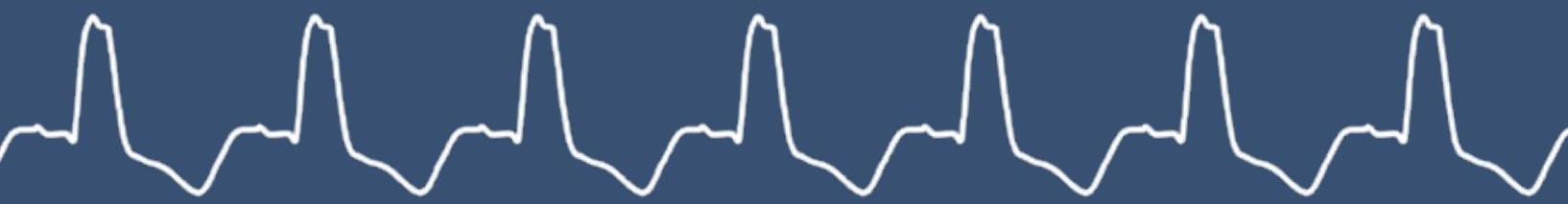




\section{Introduction}

Under normal conditions, each heartbeat is initiated by the sinus node: a structure located in the right atrium which functions as the physiological pacemaker. Emerging from this sinus node, an electrical activation wave front propagates over the atrial walls, is slowed down in the atrioventricular node and is then rapidly conducted via the specialized His-Purkinje fibers towards the right ventricle (RV, through the right bundle branch) and left ventricle (LV, through the left bundle branch). Because ventricular cardiac myocytes are directly connected to Purkinje fiber endings, physiological ventricular depolarization occurs very fast, often within one hundred milliseconds. ${ }^{1}$ A near synchronous activation is considered imperative to maintain normal cardiac pump function. ${ }^{2}$

\section{Dyssynchronous activation of the ventricles}

In certain conditions, such as during left bundle branch block (LBBB) or RV pacing, the LV is not rapidly activated through the left bundle branch. In these circumstances, ventricular activation occurs from right to left and from myocyte-tomyocyte which is considerably slower and results in marked regional differences. ${ }^{3-5}$ This condition, also termed mechanical dyssynchrony, is associated with impairment of LV function, adverse structural remodeling, and increased risk for heart failure..$^{6-8}$ Intrinsic or pacing-induced dyssynchrony are pathobiological entities which should be treated in order to prevent or treat cardiac deterioration.

\section{Cardiac resynchronization therapy}

As its name suggests, cardiac resynchronization therapy (CRT) aims to restore synchronous electrical activation of the ventricles. CRT is most often performed through simultaneous biventricular pacing with an additional atrial lead to accomplish near-physiological atrioventricular delays. In the past decade, CRT has become an important treatment for symptomatic heart failure patients with reduced LV ejection fraction and increased QRS duration, most often with electrocardiographic evidence of LBBB. Large clinical trials have shown that CRT is more effective than any pharmaceutical agent in lowering morbidity and mortality in this patient group.' ${ }^{13}$ However, up to half of patients do not show clinical and/or echocardiographic signs of response. ${ }^{14}$ In-depth analyses of these studies have revealed for instance that patients with "true" LBBB are much more likely to respond to the therapy. ${ }^{15}$, ${ }^{16}$ In addition, echocardiographic-based approaches to better identify dyssynchrony have so far failed to improve CRT patient selection on a large scale. ${ }^{17}$ 
A need exists for increased understanding of the detrimental effects of electrical asynchrony and beneficial effects of resynchronization as both aspects have been oversimplified in the past. The heterogeneity in response and the amount of nonresponders could also be decreased by improving match between substrate (electrical and/or morphological) and therapy. Moving away from conventional simultaneous biventricular pacing towards novel strategies such as stimulating the LV at alternative sites or optimizing lead stimulation-timings are expected to increase CRT efficacy.

\section{Aim of the thesis}

The general aims of the research presented in this thesis are twofold:

1. To improve understanding of electrical activation of the dyssynchronous and resynchronized heart.

2. To apply newly gained insights in order to deliver tools for increasing the efficacy of cardiac resynchronization therapy.

\section{Toward increased understanding of dyssynchrony and CRT}

To improve understanding of electrical ventricular activation during dyssynchrony and resynchronization, extensive electrical mapping studies are imperative. High temporal and spatial resolution is essential with simultaneous measurement of endocardial and epicardial potentials during an extensive range of activation patterns in an in vivo heart. This information would need to be acquired in a singlebeat as the range of observed activation patterns would be extensive. Unfortunately, such detailed electrical mapping in humans is impossible because of its invasive and extensive nature and thus an adequate animal model is required. Even though multiple asynchronous animal models exist, the canine heart is most ideal for this purpose as the conduction system, but also the mechanical properties, are very comparable to that of the human heart.

In an in vivo canine experiment, it is possible to place a large amount of contact electrodes on the epicardium. This is not possible, however, on the endocardium because an extensive transmural approach would jeopardize myocardial wall function. The use of a multipolar non-contact mapping catheter placed into the left ventricle via retrograde approach enables single-beat measurement of multiple endocardial potentials. This method could be validated and matched to the epicardium by using a limited amount of transmural endocardial contact electrodes. When epicardial and 
endocardial potentials are matched successfully, three-dimensional activation time maps can be created for the purpose of increased understanding of dyssynchrony and resynchronization.

\section{Toward increased efficacy of CRT}

A detailed electrical mapping in the dyssynchronous canine heart enables the evaluation of novel pacing modalities for the purpose of increasing CRT efficacy. Because CRT aims to resynchronize the heart by adding an activation wave front originating from an LV epicardial electrode, we sought to investigate the added benefit of adding more activation wave fronts to LV activation. Secondly, instead of LV epicardial pacing during CRT, we attempted to explore LV endocardial pacing and its effect on acute systolic LV function. The effects of myocardial infarction and heart failure on the added benefit of endocardial LV pacing were also investigated as it is important for improved translation to the clinical situation. Finally, we attempted to optimize conventional CRT in a tailored approach by testing the ability of electrical mapping (extensive contact mapping and surface electrocardiography) to predict acute CRT response.

\section{Outline of the thesis}

The general background and introduction to the studies presented in this thesis are divided into two chapters (chapter 2 and chapter 3). An overview of existing knowledge concerning the electrical activation of the dyssynchronous and resynchronized ventricles in humans is provided in chapter 2 . The rationale for the use of animal models of dyssynchrony to investigate dyssynchrony and resynchronization is given in chapter 3 . This chapter focuses on the canine model of dyssynchrony; the induction of dyssynchrony and addition of substrate such as myocardial infarction and heart failure.

The rationale for and validation of non-contact mapping is presented in chapter 4 . The validation study was performed in order to evaluate non-contact mapping as a potential tool to answer research questions proposed in later chapters. In chapter $\mathbf{5}$, the combination of non-contact and contact mapping was used to investigate electrical mechanisms of resynchronization. Simultaneous biventricular pacing, but also single-site LV pacing and pacing at various stimulation timings was performed to explore endocardial and epicardial activation patterns. In this chapter, transseptal conduction was of special interest because it was hypothesized to be of major importance in CRT. 
In chapter 6, we investigated whether electrical resynchronization or improved filling was primarily responsible for acutely optimizing contractility during alteration of lead-stimulation timings.

The studies with the objective to improve match between substrate and deliverance of CRT are presented in chapters 7-8. Because the benefits of conventional CRT rely on the added activation wave front originating from the LV pacing lead, we evaluated the effect of adding more epicardial pacing sites in chapter 7. Our group previously showed that during CRT, endocardial LV pacing is superior to conventional epicardial LV pacing in the canine heart with acute dyssynchrony. ${ }^{18}$ In chapter 8 , the use of three-dimensional electrical mapping, and myocardial infarction and heart failure models increases the scope of these observations.

In the last chapter of this thesis (chapter 9), the findings of the abovementioned studies are linked and put in broader perspective. The first part of the general discussion concerns what can be learned from electrical activation in the dyssynchronous and resynchronized heart. In the second part, better pacingstrategies and their clinical implications are discussed. 


\section{References}

1. Massing GK, James TN. Anatomical configuration of the his bundle and bundle branches in the human heart. Circulation. 1976;53:609-621.

2. Wiggers CJ. The muscular reactions of the mammalian ventricles to artificial surface stimuli. American Journal of Physiology -- Legacy Content. 1925;73:346-378.

3. Little WC, Reeves RC, Arciniegas J, Katholi RE, Rogers EW. Mechanism of abnormal interventricular septal motion during delayed left ventricular activation. Circulation. 1982;65:1486-1491.

4. Prinzen FW, Augustijn CH, Allessie MA, Arts T, Delhaas T, Reneman RS. The time sequence of electrical and mechanical activation during spontaneous beating and ectopic stimulation. European heart journal. 1992;13:535-543.

5. van Oosterhout MF, Prinzen FW, Arts T, Schreuder JJ, Vanagt WY, Cleutjens JP, Reneman RS. Asynchronous electrical activation induces asymmetrical hypertrophy of the left ventricular wall. Circulation. 1998;98:588-595.

6. Sweeney MO, Hellkamp AS, Ellenbogen KA, Greenspon AJ, Freedman RA, Lee KL, Lamas GA. Adverse effect of ventricular pacing on heart failure and atrial fibrillation among patients with normal baseline qrs duration in a clinical trial of pacemaker therapy for sinus node dysfunction. Circulation. 2003;107:2932-2937.

7. Vernooy K, Dijkman B, Cheriex EC, Prinzen FW, Crijns HJ. Ventricular remodeling during long-term right ventricular pacing following his bundle ablation. Am J Cardiol. 2006;97:1223-1227.

8. Vernooy K, Verbeek XA, Peschar M, Crijns HJ, Arts T, Cornelussen RN, Prinzen FW. Left bundle branch block induces ventricular remodelling and functional septal hypoperfusion. European heart journal. 2005;26:91-98.

9. Abraham WT, Fisher WG, Smith AL, Delurgio DB, Leon AR, Loh E, Kocovic DZ, Packer M, Clavell AL, Hayes DL, Ellestad M, Trupp RJ, Underwood J, Pickering F, Truex C, McAtee P, Messenger J, Evaluation MSGMIRC. Cardiac resynchronization in chronic heart failure. The New England journal of medicine. 2002;346:1845-1853.

10. Bristow MR, Saxon LA, Boehmer J, Krueger S, Kass DA, De Marco T, Carson P, DiCarlo L, DeMets D, White BG, DeVries DW, Feldman AM. Cardiacresynchronization therapy with or without an implantable defibrillator in advanced chronic heart failure. The New England journal of medicine. 2004;350:2140-2150.

11. Cazeau S, Leclercq C, Lavergne T, Walker S, Varma C, Linde C, Garrigue S, Kappenberger L, Haywood GA, Santini M, Bailleul C, Daubert JC. Effects of multisite biventricular pacing in patients with heart failure and intraventricular conduction delay. The New England journal of medicine. 2001;344:873-880. 
12. Moss AJ, Hall WJ, Cannom DS, Klein H, Brown MW, Daubert JP, Estes NA, 3rd, Foster E, Greenberg H, Higgins SL, Pfeffer MA, Solomon SD, Wilber D, Zareba W. Cardiac-resynchronization therapy for the prevention of heart-failure events. The New England journal of medicine. 2009;361:1329-1338.

13. Tang AS, Wells GA, Talajic M, Arnold MO, Sheldon R, Connolly S, Hohnloser SH, Nichol G, Birnie DH, Sapp JL, Yee R, Healey JS, Rouleau JL. Cardiacresynchronization therapy for mild-to-moderate heart failure. The New England journal of medicine. 2010

14. Daubert JC, Saxon L, Adamson PB, Auricchio A, Berger RD, Beshai JF, Breithard O, Brignole M, Cleland J, DeLurgio DB, Dickstein K, Exner DV, Gold M, Grimm RA, Hayes DL, Israel C, Leclercq C, Linde C, Lindenfeld J, Merkely B, Mont L, Murgatroyd F, Prinzen F, Saba SF, Shinbane JS, Singh J, Tang AS, Vardas PE, Wilkoff BL, Zamorano JL, Anand I, Blomstrom-Lundqvist C, Boehmer JP, Calkins H, Cazeau S, Delgado V, Estes NA, Haines D, Kusumoto F, Leyva P, Ruschitzka F, Stevenson LW, Torp-Pedersen CT. 2012 ehra/hrs expert consensus statement on cardiac resynchronization therapy in heart failure: Implant and follow-up recommendations and management. Europace. 2012;14:1236-1286.

15. Bilchick KC, Kamath S, DiMarco JP, Stukenborg GJ. Bundle-branch block morphology and other predictors of outcome after cardiac resynchronization therapy in medicare patients. Circulation. 2010;122:2022-2030.

16. Hsing JM, Selzman KA, Leclercq C, Pires LA, McLaughlin MG, McRae SE, Peterson BJ, Zimetbaum PJ. Paced left ventricular qrs width and ecg parameters predict outcomes after cardiac resynchronization therapy: Prospect-ecg substudy. Circ Arrbythm Electrophysiol. 2011;4:851-857.

17. Chung ES, Leon AR, Tavazzi L, Sun JP, Nihoyannopoulos P, Merlino J, Abraham WT, Ghio S, Leclercq C, Bax JJ, Yu CM, Gorcsan J, 3rd, St John Sutton M, De Sutter J, Murillo J. Results of the predictors of response to crt (prospect) trial. Circulation. 2008;117:2608-2616.

18. van Deursen C, van Geldorp IE, Rademakers LM, van Hunnik A, Kuiper M, Klersy C, Auricchio A, Prinzen FW. Left ventricular endocardial pacing improves resynchronization therapy in canine left bundle-branch hearts. Circ Arrbythm Electrophysiol. 2009;2:580-587. 

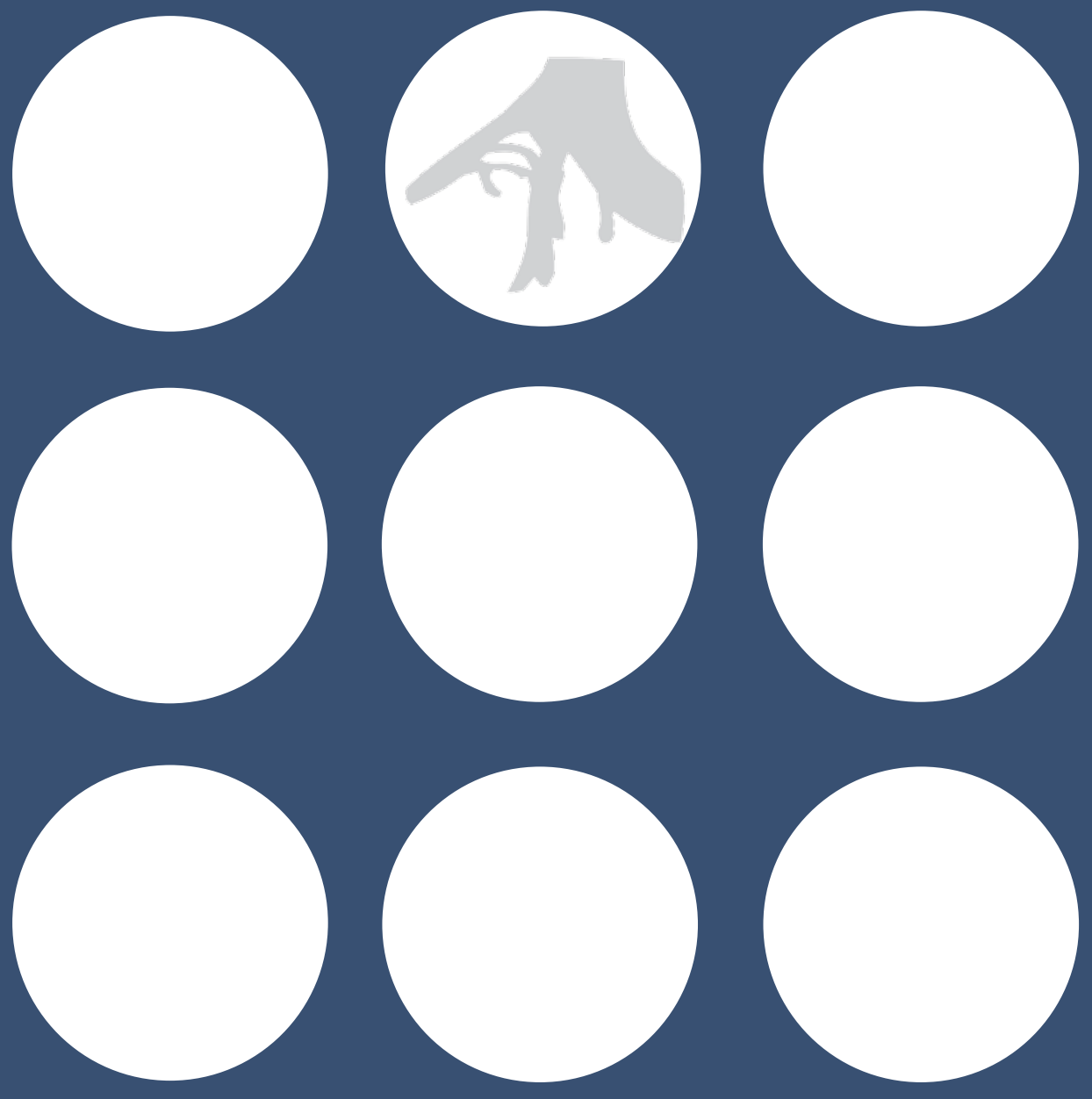

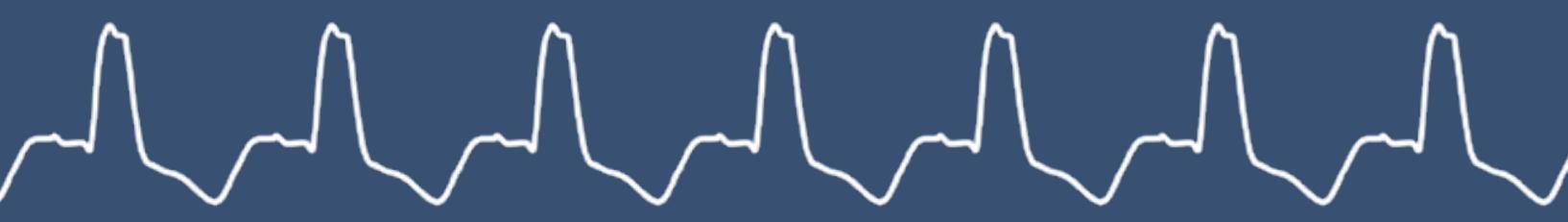




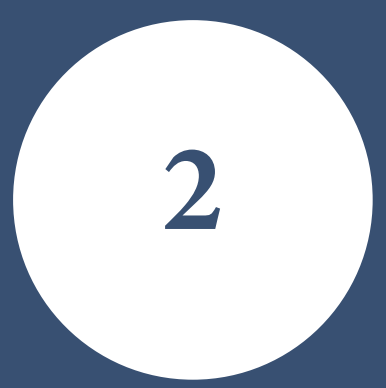

\section{Electrical Ventricular Activation During Left Bundle Branch Block and Resynchronization}

Based on:

Strik M, Regoli F, Auricchio A, Prinzen FW.

Electrical and mechanical ventricular activation during left bundle branch block and resynchronization.

J Cardiovasc Transl Res. 2012;5:117-126

Strik M, Ploux S, Vernooy K, Prinzen FW.

Cardiac resynchronization therapy: Refocus on the electrical substrate.

Circ J. 2011;75:1297-1304

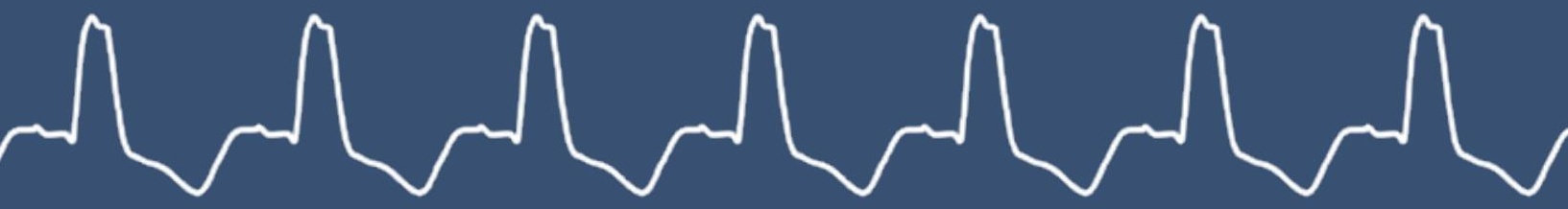




\section{Introduction}

To maintain normal cardiac pump function, a near synchronous electrical activation sequence of both ventricles is imperative. This synchronous activation applies to multiple anatomic levels: within atria, between atria and ventricles, between ventricles, and especially within the left ventricle (LV). Right-sided pre-excitation, such as during left bundle branch block (LBBB) and right ventricular (RV) pacing, induces dyssynchrony, which instantly decreases cardiac pump function and is a risk factor for development of heart failure. ${ }^{1}$ Before the widespread application of Cardiac Resynchronization Therapy (CRT), little was known about the pathophysiology of the conduction disease and its adverse effects on ventricular contractility. Large CRT trials have shown that approximately one third of implanted patients do not show clinical or echocardiographic response. ${ }^{2-4}$ Furthermore, further analysis of these studies show that the amount of responders was considerably higher in patients with $\mathrm{LBBB}$ as compared with patients without this conduction disease. ${ }^{5}$ These aspects have revamped major interest in LBBB. This interest is further enforced by the difficulties of echocardiographic mechanical dyssynchrony measurements to adequately predict CRT response.

Insight in electrical activation during LBBB and ventricular pacing during CRT has steadily increased over the last few years. LBBB appears to be the hallmark conduction disease that is treatable by CRT independently from etiology, as evidenced by efficacy of CRT in canine hearts with isolated LBBB and in CRT patients with LBBB compared to CRT patients with other conduction disorders. ${ }^{6}$, ${ }^{7}$ It is also becoming increasingly apparent that the site of LV stimulation, the electrical and mechanical activation patterns and the presence of little or no scar are all critical for CRT success.

In this chapter, electrical activation patterns during LBBB and CRT are discussed. Why these aspects are important for the delivery of a successful therapy is also shown. 


\section{Early investigations}

In 1910, Eppinger and Tothberger reported distinctive changes in QRS morphology after the destruction of only a small region in the interventricular septum in canine hearts. ${ }^{8}$ Since the esophageal-to-rectal leads in the dogs were directly extrapolated to leads II and III in human patients, LBBB was erroneously diagnosed as right bundle branch block (RBBB) and vice versa for 25 years. This misinterpretation illustrates the fact that the conduction disease was not considered important, and LBBB was solely considered a sign of poor prognosis. Later it was discovered that most patients with LBBB who died shortly after diagnosis, died of underlying heart disease and that the conduction disease on its own was not as dangerous as previously believed.

It was not until 1972 that the anatomy of the left bundle branch (LBB) was described in more detail. A histopathological study in human patients without known cardiac disease, showed that the LBB is a continuation of the His bundle and initiates between the non-coronary and right-coronary aortic cusps. It runs as a 6 to $10 \mathrm{~mm}$ wide ribbon-like structure under the septal endocardium in inferior and anterior directions. ${ }^{9}$ The fibers of the LBB fibers then separate to form fasciculi into anterior, posterior and often septal radiations. That the anatomical distribution of the LBB exists in considerable variation is shown in Figure 1. Ultimately, the peripheral Purkinje fibers are coupled with individual (sub)endocardial myocardial cells which allows fast depolarization of the $\mathrm{LV}^{10}$

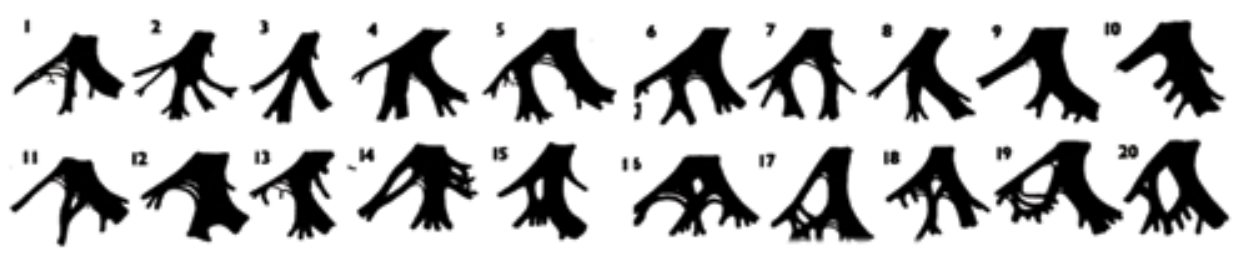

Figure 1: Diagrammatic sketches of the left-sided conduction system as observed in 20 normal hearts. Histopathological study performed by Demoulin in 1972.

In isolated human hearts with an intact LBB, extensive electrical mapping showed up to three LV endocardial breakthrough sites which resulted in a rapid electrical activation of the LV. ${ }^{11}$ Narula reported in 1977 that by distal His-Bundle pacing, he was able to abolish the electrocardiographic signs of LBBB in 25 patients, thereby 'curing' the conduction disease. In these LBBB patients, the lesions were apparently located very proximal in the rapid conduction system, just below the AV-node. ${ }^{12}$ 


\section{Cardiac mapping}

Investigation of the electrical activation during normal conduction and LBBB can be performed in vivo in patients, most often using invasive cardiac mapping by conventional point-by-point technique, or 3-dimensional electroanatomical reconstruction contact $\left(\mathrm{CARTO}^{\circledR}\right)$ and non-contact mapping $\left(\right.$ EnSite $\left.^{\circledR}\right)$ techniques. Figure 2 shows examples of RV and LV endocardial contact mapping using $\mathrm{CARTO}^{\circledR}$ in a patient with normal conduction (top pane) or in three patients with LBBB (bottom).

\section{Normal Conduction}

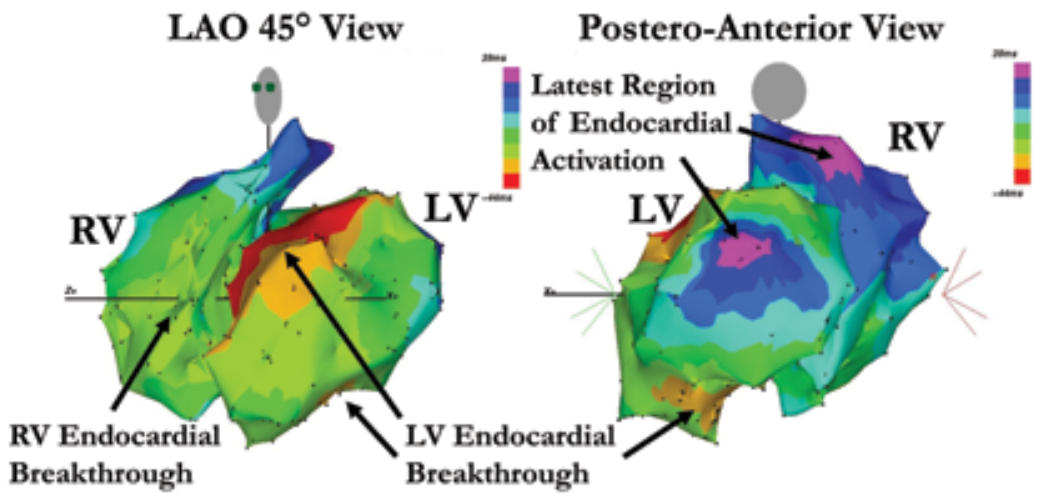

\section{Left Bundle Branch Block} $\left(\mathrm{LAO} 45^{\circ}\right)$

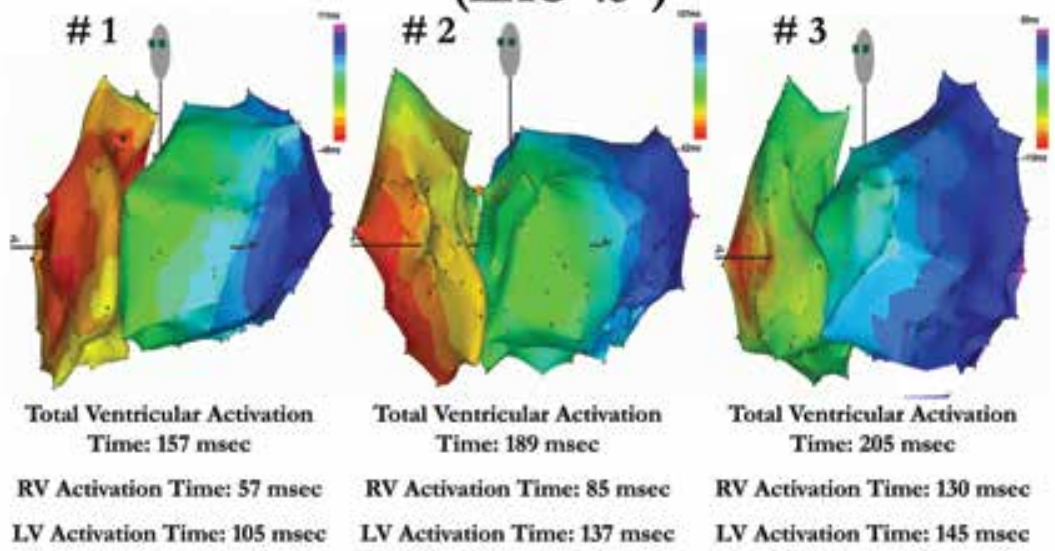

Figure 2. Endocardial activation pattern derived by CARTO $^{\circledR}$ mapping in one normal heart (top panel) and in three hearts with LBBB (bottom panel). Please note that the colorbar-range differs between patients. 
During normal conduction the endocardium of both ventricles were depolarized within 40 milliseconds with multiple breakthroughs in the septum at the LV side and the latest activated region at the posterobasal region (Figure $2 A$ ). In patients with LBBB (Figure 2B) onset of ventricular activation is located within the RV and the activation wave front then propagates slowly from cardiomyocyte to cardiomyocyte towards the latest activated region at the LV posterolateral wall. During LBBB, endocardial activation is a multitude slower than during normal conduction and varies between patients, as shown by differences in total, RV and LV activation times. LV endocardial breakthrough is heterogeneous and may occur at different septal regions. ${ }^{13,14}$ In some patients, breakthrough occurred in the mid-septal region, which could suggest activation by slow conduction through the LBB, in some others via right-to-left transseptal activation. ${ }^{13}$ In addition to differences in LV endocardial activation time and site(s) of breakthrough, the activation pattern also differs between patients. First described by Auricchio et al in 2004, endocardial noncontact mapping (the principles of which are described in more detail in chapter 4) revealed lines of conduction block in 23 of 24 LBBB patients. ${ }^{20}$ The virtual electrograms in the vicinity of block showed typical signs such as split potentials and emergence of an R' wave (see example in Figure 3). The etiology of these blocklines remain unknown. Obviously, these patients suffer from heart failure with dilated and/or infarcted ventricles but a structural heart disease is not a determing factor for the location of the lines of block because the blocklines change or disappear when ventricular activation is altered (e.g. during ventricular pacing), suggesting a functional nature.
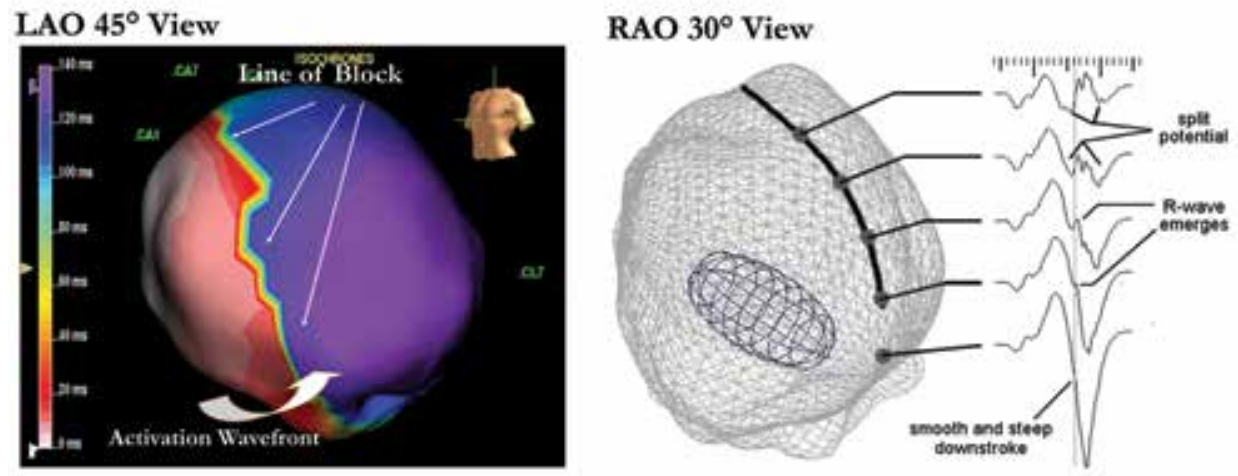

Figure 3. Endocardial activation pattern derived by EnSite ${ }^{\circledR}$ mapping in a heart with LBBB showing line of block with the activation wave front propagating over the apex (left panel) and schematic overview with examples of virtual electrograms showing split potential and emergence of $R^{\prime}$ wave (right panel). 
While mentioned techniques are highly invasive, recent developments in cardiac mapping enabled investigating electrical activation using non-invasive mapping. Electrocardiographic imaging (ECGi) is a non-contact mapping technique, using the same principles of solving the inverse problem as the EnSite ${ }^{\circledR}$ system, but instead of a "inside-out" approach, it uses a "outside-in" approach by estimating epicardial activation from body surface potentials. Using ECGi, multiple epicardial conduction patterns were found in CRT candidates with LBBB of which two examples are shown in Figure 4. Interestingly, lines of functional conduction block were also found in LBBB patients using the ECGi technique (Example \#2 - Figure 4).

Example \# 1

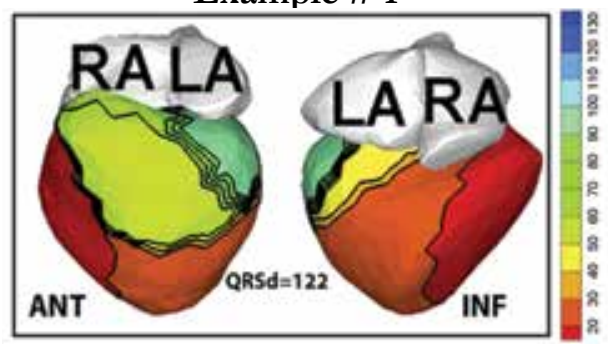

Example \# 2

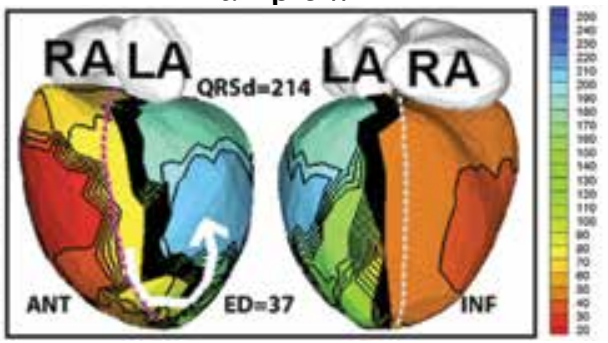

Figure 4. Epicardial isochrone maps during native rhythm in two patients with LBBB. The approximate valve region is covered by gray. Activation times are given with respect to QRS onset. QRSd: QRS duration. LA = left atrium.. RA = right atrium, ANT = anterior, INF = inferior

Clinical studies show considerable differences in activation patterns between patients. These varying conduction patterns could be caused by one or more of the following aspects: (1) the varying structure of the LBB, (2) variability in the location of the LBB 'block', being either a proximal lesion or a more distal and diffuse disease, (3) LV hypertrophy and fibrosis as associated cellular uncoupling can result in increasing QRS duration and an LBBB-like QRS morphology. ${ }^{16}$ The heterogeneous activation patterns seen in heart failure patients with LBBB might in part explain why CRT leads to varying amount of response. In addition, the mentioned data accentuate the need for patient tailored therapy by carefully selecting the site of pacing and pacing settings. However, presence of co-morbidities and the lack of knowledge concerning the duration and extent of the lesion (or lesions) limits the use of clinical data to investigate the pathophysiology of electrical asynchrony. These limitations stimulated us to specifically investigate the effects of isolated LBBB and pacing therapies in the animal models, discussed more extensively in chapter $\mathbf{3}$ and to use techniques for highly detailed electrophysiological measurements, mentioned in chapters 4 and $\mathbf{5}$. 


\section{The surface electrocardiogram and its role in clinical trials}

The key clinical investigational technique to detect and evaluate the extent of ventricular conduction delay remains the surface electrocardiogram.

To diagnose LBBB in patients, specific ECG criteria exist ${ }^{17}$ :

1. QRS duration $\geq 120 \mathrm{~ms}$ in adults.

2. Broad notched or slurred $\mathrm{R}$ wave in leads $\mathrm{I}, \mathrm{aVL}, \mathrm{V} 5$, and $\mathrm{V} 6$ and an occasional RS pattern in V5 and V6 attributed to displaced transition of QRS complex.

3. Absent q waves in leads I, V5, and V6, but in the lead aVL, a narrow q wave may be present in the absence of myocardial pathology.

4. $\quad \mathrm{R}$ peak time greater than $60 \mathrm{~ms}$ in leads $\mathrm{V} 5$ and $\mathrm{V} 6$ but normal in leads V1, $\mathrm{V} 2$, and $\mathrm{V} 3$, when small initial $\mathrm{r}$ waves can be discerned in the above leads.

5. $\quad$ ST and $\mathrm{T}$ waves usually opposite in direction to QRS.

6. Positive $\mathrm{T}$ wave in leads with upright $\mathrm{QRS}$ may be normal (positive concordance).

7. Depressed ST segment and/or negative $\mathrm{T}$ wave in leads with negative QRS (negative concordance) are abnormal

Note that although scar in the septum causes Q waves in V1 to V3 when normal conduction is present, the same scar causes large $\mathrm{R}$ waves in $\mathrm{V} 1$ to $\mathrm{V} 3$ in the presence of LBBB because of unopposed electrical forces in the RV free wall. ${ }^{18}$ When these criteria are not met it is likely that patients have RBBB or slowed conduction by LV hypertrophy.

Clinical studies have typically implanted CRT device in patients with a QRS duration of at least $120 \mathrm{~ms}$. The criterion means that many patients with right bundle branch block or other conduction disease were also included. On top of that, one third of patients diagnosed with LBBB by conventional electrocardiographic criteria may not have true complete LBBB, but likely have a combination of left ventricular hypertrophy and left anterior fascicular block. ${ }^{19,20} \mathrm{~A}$ recent electrical mapping study showed that 'true LBBB' was only seen in patients with a QRS duration exceeding $130 \mathrm{~ms}$ (female) or $140 \mathrm{~ms}$ (male). ${ }^{21}$

The REVERSE (Resynchronization Reverses Remodeling in Systolic Left Ventricular Dysfunction) study failed to show a significant difference in their primary endpoint (percentage worsening in the heart failure clinical composite response score), except for the patients with QRS duration $>152 \mathrm{~ms}(\mathrm{n}=307)$, for whom there was a clear 
difference (Odds Ratio 0.42, C.I. 0.22-0.81). ${ }^{22}$ In the MADIT-CRT (Multicenter Automatic Defibrillator Implantation Trial with Cardiac Resynchronization Therapy) trial, CRT-D resulted in a $52 \%$ decrease in risk of death or heart failure in the subgroup of patients with QRS duration $\geq 150 \mathrm{~ms}(\mathrm{n}=1175)$ as compared to ICD-only patients. ${ }^{23,24}$ This astonishing result in the $>150 \mathrm{~ms}$ subgroup is the reason why the trial met its primary endpoint for all CRT-D patients, despite the subgroup of 645 patients with QRS duration $<150 \mathrm{~ms}$ that did not show a reduction. Similarly, a recent MADIT-CRT sub-analysis investigated patients with LBBB at baseline $(n=1281)$ and found a decrease of $53 \%$ in mentioned endpoints in patients with CRT-D (Figure 5).
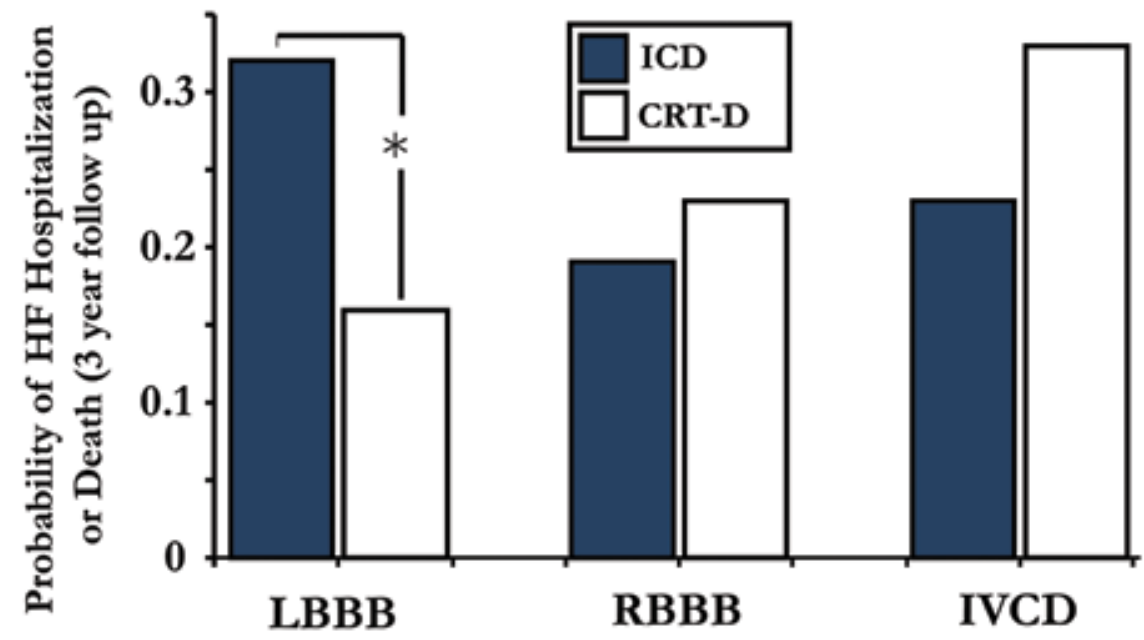

RBBB

IVCD

Figure 5: Probability of heart failure hospitalization or death after three years of follow-up in MADIT-CRT. ${ }^{25}$ Patients are grouped according to therapy (ICD only, white bars and CRT-D, black bars), and conduction disorder as derived from the ECG. $*=p<0.001$. IVCD: interventricular conduction disease.

These data, in combination with a neutral effect in RBBB patients and a trend to worsening in the subgroups of patients with IVCD, stress the importance of LBBB as electrical substrate that is amenable to CRT. ${ }^{25}$ In addition, the risk of ventricular tachycardia, ventricular fibrillation, or death was decreased significantly in CRT-D patients with LBBB but not in non-LBBB patients. In accordance, RAFT (Resynchronization-Defibrillation for Ambulatory Heart Failure Trial) reported reductions in mortality or hospitalization for heart failure only for the subgroup of patients who had QRS duration $>150 \mathrm{~ms}$ or LBBB. ${ }^{26}$ As discussed, in all major clinical trials, risk for composite clinical events was greatly diminished by CRT in patients 
with severely prolonged QRS duration (at baseline) while this not in patients with moderate QRS duration widening (see overview in Figure O). A recent retrospective analysis of the Medicare Implantable Cardioverter-Defibrillator Registry (2005 to 2006) showed that almost one third of the $\approx 15.000$ CRT-D patients had RBBB or intraventricular conduction delay, rather than LBBB. ${ }^{7}$ After three years, $40.3 \%$ of patients with $\mathrm{RBBB}$ and $34.2 \%$ of patients with intraventricular conduction delay had died, as opposed to $29.7 \%$ of patients with intraventricular conduction delay had died, as opposed to $29.7 \%$ of patients with LBBB. Mentioned insights have moved the ESC and AHA guidelines to be more restrictive in their class I recommendation to patients with $\mathrm{LBBB}$ morphology on their electrocardiogram. ${ }^{27}$

\section{QRS duration widening}

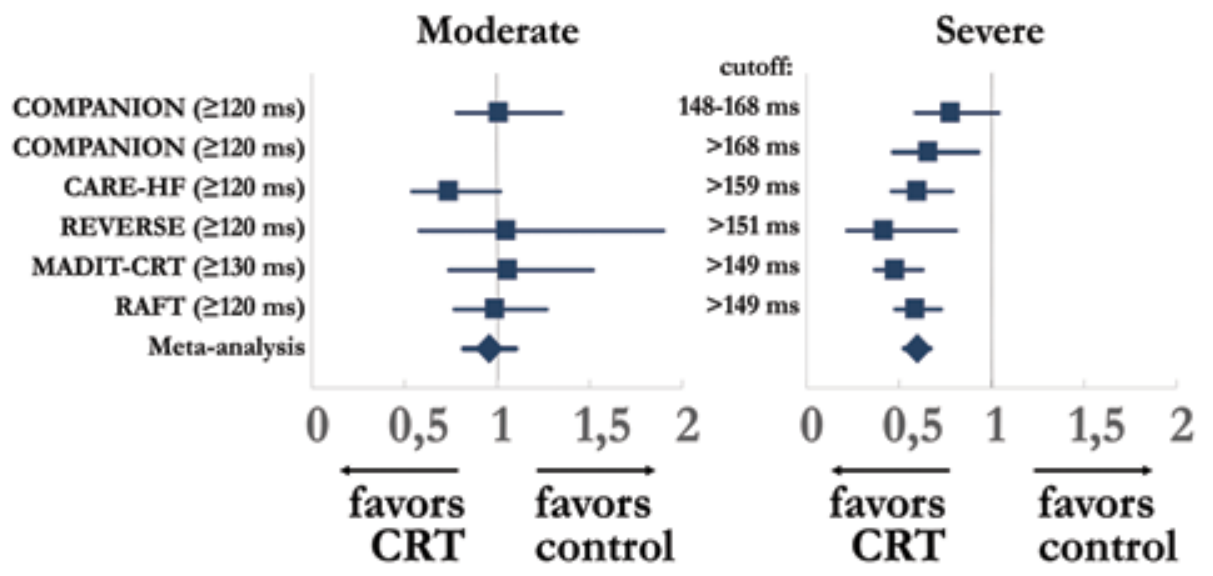

Figure 6. Effect of CRT on composite clinical events in patients with moderately versus severely prolonged QRS interval (cut-off values per study are given).

The aforementioned findings give rise to the notion that an 'adequate amount' of conduction delay needs to be present for CRT to be efficient. Whether additional factors such as LV systolic dysfunction need to co-exist with electrical asynchrony for CRT to be successful, is important for understanding the therapy and better selection of CRT candidates. Recently, multiple clinical trials have confirmed this idea by showing comparable CRT efficacy in heart failure patients who were not severely symptomatic (NYHA class I and II) or in non-failing patients with already implanted RV pacemakers. $^{26,28,29}$ The MIRACLE ICD II (Multicenter InSync Randomized Clinical Evaluation II) trial showed that CRT for six months in NYHA II patients lead to improvement in cardiac structure and function, together with improvement in NYHA class and clinical composite response score. ${ }^{30}$ Reductions 
of LV dimensions were also seen in the mildly symptomatic HF subgroup (NYHA class I and II) of the CONTAK-CD (CONTAK-Cardiac Defibrillator) trial. ${ }^{31}$ Initial results of the REVERSE trial were disappointing as the difference in the percentage of NYHA I-II patients who worsened in clinical composite score after 12 months in ICD-CRT patients versus ICD-only patients failed to reach significance $(16 \%$ versus $21 \%, \mathrm{p}=0.10) .{ }^{22}$ However, after a follow-up of 24 months in a subgroup of European patients the difference did become significant with worsening in 19\% of CRT patients versus 34\% in control patients $(p=0.01) .{ }^{28}$ For both follow-up periods, CRT resulted in reduction in HF hospitalization and greater improvements in cardiac structure and function. In the MADIT-CRT trial a $41 \%$ reduction in heart failure events during an average follow-up of 2.4 years was seen in favor of the CRT-ICD patients. ${ }^{24,29}$ Finally, the RAFT study followed 1438 NYHA II patients for an average of 40 months and found a $29 \%$ reduction in all-cause mortality and a $30 \%$ reduction in hospitalization for heart failure. ${ }^{26}$ Given the electrical similarity of the spontaneously occurring and the RV pacing induced LBBB, several centers have explored the feasibility of 'upgrading' patients without heart failure with already implanted RV pacemakers to biventricular (BiV) ones or, in the case of a new implant, to use BiV pacing from the beginning in select patients. Although large prospective randomized controlled studies are currently lacking, there are several retrospective observational series or small prospective trials demonstrating a clinical benefit of upgrading to biventricular pacing, regardless of QRS duration and even in patients with normal LV ejection fraction. ${ }^{32-35}$

The mentioned clinical studies remind us that underlying electrical substrate can be treated, also in the absence of heart failure symptoms, thus preventing or delaying the development of heart failure. These insights have recently lead for the ESC and AHA guidelines to extend their class I recommendations for CRT implantation to patients with NYHA class II. ${ }^{27,36}$

\section{More specific electrical measures of dyssynchrony}

In the past decade, most efforts focused on finding dyssynchrony parameters to predict CRT response were based on echocardiography. Interestingly, recent studies have revamped the interest in using the surface ECG for exactly that purpose. An example is the PROSPECT trial where multiple echocardiography derived dyssynchrony parameters were investigated, followed by a sub-study where various ECG parameters were tested. ${ }^{37,38}$ In fact, LBBB morphology was the only parameter that was predictive for both volumetric and clinical response after six 
months (defined by LV end-systolic volume reduction of $\geq 15 \%$ and improvement in Clinical Composite Score, respectively). In addition, a broad QRS complex during single-site LV pacing was predictive of failure of volumetric response $(\mathrm{OR}=0.86$ per $10 \mathrm{~ms}$ increment). In non-ischemic patients, an LV paced QRS width of $\leq 200$ ms was 5 times more likely to be associated with a positive response than having an LV paced QRS width greater than $200 \mathrm{~ms}$, while no such difference was found in ischemic patients. The authors of this article postulate that LV paced QRS width may be an indirect method of identifying a region near scar or an area of poor conduction.

Sweeney and colleagues carefully inspected standard 12-lead electrocardiograms of 202 LBBB patients indicated for CRT. ${ }^{39}$ Based on the comparisons of baseline and post-implant electrocardiograms the authors introduced new measurements, which predicted CRT response (defined as at least 10\% reduction in end-systolic volume as derived by echocardiography at 6 months). A notch, which occurred after 40 ms of QRS onset, was regarded as the transition from RV to LV depolarization and the time difference between this notch and the end of QRS was indicated as the LV activation time $\left(\operatorname{LVAT}_{\max }\right)$. QRS duration was weakly associated with reverse remodeling probability and this relationship was replaced by LVAT $_{\max }$ in the multivariable model. A longer LVAT $_{\max }$ at baseline was predictive of CRT response (OR 1.30 for each $10 \mathrm{~ms}$ increase up to $125, \mathrm{p}=0.001$ ). The Selvester QRS score was used to quantify LV scar and a higher score was detrimental to volumetric response (OR 0.49 for each 1-point increase from 0 to $4, \mathrm{p}=0.002) .{ }^{21}$ The appearance of anterior forces in the precordial leads after implantation (change in $\mathrm{R}$ amplitude in $\mathrm{V}_{1}$ and $\mathrm{V}_{2}$ in expected direction) was also predictive of CRT response. An alternative method to estimate LV electrical asynchrony is by calculating the delay between QRS onset and LV lead depolarization. Varma et al. found in heart failure patients that this delay exceeded $100 \mathrm{~ms}$ in $87 \%$ of LBBB patients as compared to $45 \%$ of RBBB patients, even though there was no difference in QRS duration. ${ }^{40}$ Singh et al showed that CRT patients with a reduced LV lead electrical delay $(<50 \%$ of QRS duration) before pacing was associated with worse clinical outcome at 12 months. ${ }^{41}$

The surface ECG could therefore be used to predict which CRT candidates will responds to the therapy but possibly also to optimize lead stimulation timings after the device has been implanted. Optimizing the CRT-device is important as the degree of response is heterogeneous and up to half of implanted patients fail to respond. ${ }^{2,3}$ Current procedures for CRT optimization commonly use assessment of 
systolic function and diastolic filling patterns by echocardiography (aortic outflow or mitral inflow measurements). Disadvantages of these procedures are that they are time consuming and have yet failed to prove their accuracy. ${ }^{42}$ Lead stimulation algorithms derived from lead-sensed timings have also not yet shown a significant improvement in CRT efficacy. ${ }^{43,44}$

Optimal "resynchronization" refers to electrically correcting abnormal conduction by introducing electrical wave fronts from the RV electrode, LV electrode and intrinsic activation through the right bundle branch. Apparently, the interplay between the three electrical activation wave fronts is more complex than initially anticipated and its effects on CRT response remains incompletely understood. ${ }^{45}$ In previous experiments we have shown that in canine hearts with experimental $\mathrm{LBBB}$, the maximal vector amplitude of the QRS complex halfway between the values during LV pacing at short AV-interval and during LBBB coincided with optimal systolic function. ${ }^{46}$ However, the interaction between the three activation wave fronts during extensive alteration of lead-stimulation timings is incompletely understood. In chapter 6, it is our aim to evaluate the interplay of the three activation wave fronts and the role of altering ventricular filling on LV function. In order to investigate these effects, electrical mapping and hemodynamic measurements were performed in the established canine models of LBBB and AV-block. Improving electrical resynchronization can also be performed by other ways than optimizing lead-stimulation timing such as by adding LV epicardial pacing sites (chapter 7) or by pacing on the LV endocardium (chapter 8 ).

\section{Conclusions}

LBBB results in asynchronous electrical activation, but considerable differences in activation patterns exist between patients. Presence of comorbidities and the lack of knowledge concerning the duration and extent of the lesion (or lesions) limits the use of clinical data to investigate the pathophysiology of electrical asynchrony. These limitations stimulated us to specifically investigate the effects of isolated LBBB and pacing therapies in animal models, as discussed more extensively in the next chapter.

\section{Acknowledgments}

This research was performed within the framework of CTMM, the Center for Translational Molecular Medicine (www.ctmm.nl), project COHFAR (grant 01C-203), and supported by the Dutch Heart Foundation. 


\section{References}

1. Sweeney MO, Prinzen FW. A new paradigm for physiologic ventricular pacing. $J \mathrm{Am}$ Coll Cardiol. 2006;47:282-288.

2. Cleland JG, Daubert JC, Erdmann E, Freemantle N, Gras D, Kappenberger L, Tavazzi L. The effect of cardiac resynchronization on morbidity and mortality in heart failure. The New England journal of medicine. 2005;352:1539-1549.

3. Abraham WT, Fisher WG, Smith AL, Delurgio DB, Leon AR, Loh E, Kocovic DZ, Packer M, Clavell AL, Hayes DL, Ellestad M, Trupp RJ, Underwood J, Pickering F, Truex C, McAtee P, Messenger J, Evaluation MSGMIRC. Cardiac resynchronization in chronic heart failure. The New England journal of medicine. 2002;346:1845-1853.

4. Bristow MR, Saxon LA, Boehmer J, Krueger S, Kass DA, De Marco T, Carson P, DiCarlo L, DeMets D, White BG, DeVries DW, Feldman AM. Cardiac-resynchronization therapy with or without an implantable defibrillator in advanced chronic heart failure. The New England journal of medicine. 2004;350:2140-2150.

5. Strik M, Ploux S, Vernooy K, Prinzen FW. Cardiac resynchronization therapy: Refocus on the electrical substrate. Circ J. 2011;75:1297-1304.

6. Vernooy K, Cornelussen RN, Verbeek XA, Vanagt WY, van Hunnik A, Kuiper M, Arts T, Crijns HJ, Prinzen FW. Cardiac resynchronization therapy cures dyssynchronopathy in canine left bundle-branch block hearts. European heart journal. 2007;28:2148-2155.

7. Bilchick KC, Kamath S, DiMarco JP, Stukenborg GJ. Bundle-branch block morphology and other predictors of outcome after cardiac resynchronization therapy in medicare patients. Circulation. 2010;122:2022-2030.

8. Eppinger H, Rothberger J. Ueber die folgen der durchschneidung der tawaraschen schenkel des reizleitungssystems. Zeitschrift für klinische Medizin. 1910;70:1-20.

9. Demoulin JC, Kulbertus HE. Histopathological examination of concept of left hemiblock. Br Heart J. 1972;34:807-814.

10. Massing GK, James TN. Anatomical configuration of the his bundle and bundle branches in the human heart. Circulation. 1976;53:609-621.

11. Durrer D, van Dam RT, Freud GE, Janse MJ, Meijler FL, Arzbaecher RC. Total excitation of the isolated human heart. Circulation. 1970;41:899-912.

12. Narula OS. Longitudinal dissociation in the his bundle. Bundle branch block due to asynchronous conduction within the his bundle in man. Circulation. 1977;56:9961006.

13. Rodriguez LM, Timmermans C, Nabar A, Beatty G, Wellens HJ. Variable patterns of septal activation in patients with left bundle branch block and heart failure. $J$ Cardiovasc Electrophysiol. 2003;14:135-141.

14. Auricchio A, Fantoni C, Regoli F, Carbucicchio C, Goette A, Geller C, Kloss M, Klein H. Characterization of left ventricular activation in patients with heart failure and left bundle-branch block. Circulation. 2004;109:1133-1139.

15. Jia P, Ramanathan C, Ghanem RN, Ryu K, Varma N, Rudy Y. Electrocardiographic imaging of cardiac resynchronization therapy in heart failure: Observation of variable electrophysiologic responses. Heart Rhythm. 2006;3:296-310.

16. Bacharova L, Mateasik A, Krause R, Prinzen FW, Auricchio A, Potse M. The effect of reduced intercellular coupling on electrocardiographic signs of left ventricular hypertrophy. Journal of electrocardiology. 2011;44:571-576. 
17. Surawicz B, Childers R, Deal BJ, Gettes LS, Bailey JJ, Gorgels A, Hancock EW, Josephson M, Kligfield P, Kors JA, Macfarlane P, Mason JW, Mirvis DM, Okin P, Pahlm O, Rautaharju PM, van Herpen G, Wagner GS, Wellens H. Aha/accf/hrs recommendations for the standardization and interpretation of the electrocardiogram: Part iii: Intraventricular conduction disturbances. J Am Coll Cardiol. 2009;53:976-981.

18. Strauss DG, Selvester RH, Lima JA, Arheden H, Miller JM, Gerstenblith G, Marban E, Weiss RG, Tomaselli GF, Wagner GS, Wu KC. Ecg quantification of myocardial scar in cardiomyopathy patients with or without conduction defects: Correlation with cardiac magnetic resonance and arrhythmogenesis. Circ Arrhythm Electrophysiol. 2008;1:327-336.

19. Vassallo JA, Cassidy DM, Marchlinski FE, Buxton AE, Waxman HL, Doherty JU, Josephson ME. Endocardial activation of left bundle branch block. Circulation. 1984;69:914-923.

20. Grant RP, Dodge HT. Mechanisms of qrs complex prolongation in man; left ventricular conduction disturbances. Am J Med. 1956;20:834-852.

21. Strauss DG, Selvester RH. The qrs complex--a biomarker that "images" the heart: Qrs scores to quantify myocardial scar in the presence of normal and abnormal ventricular conduction. Journal of electrocardiology. 2009;42:85-96.

22. Linde C, Abraham WT, Gold MR, St John Sutton M, Ghio S, Daubert C. Randomized trial of cardiac resynchronization in mildly symptomatic heart failure patients and in asymptomatic patients with left ventricular dysfunction and previous heart failure symptoms. J Am Coll Cardiol. 2008;52:1834-1843.

23. Moss AJ. What we have learned from the family of multicenter automatic defibrillator implantation trials. Circ J. 2010;74:1038-1041.

24. Moss AJ, Hall WJ, Cannom DS, Klein H, Brown MW, Daubert JP, Estes NA, 3rd, Foster E, Greenberg H, Higgins SL, Pfeffer MA, Solomon SD, Wilber D, Zareba W. Cardiac-resynchronization therapy for the prevention of heart-failure events. The New England journal of medicine. 2009;361:1329-1338.

25. Zareba W, Klein H, Cygankiewicz I, Hall WJ, McNitt S, Brown M, Cannom D, Daubert JP, Eldar M, Gold MR, Goldberger JJ, Goldenberg I, Lichstein E, Pitschner H, Rashtian M, Solomon S, Viskin S, Wang P, Moss AJ. Effectiveness of cardiac resynchronization therapy by qrs morphology in the multicenter automatic defibrillator implantation trial-cardiac resynchronization therapy (madit-crt). Circulation. 2011;123:1061-1072.

26. Tang AS, Wells GA, Talajic M, Arnold MO, Sheldon R, Connolly S, Hohnloser SH, Nichol G, Birnie DH, Sapp JL, Yee R, Healey JS, Rouleau JL. Cardiac-resynchronization therapy for mild-to-moderate heart failure. The New England journal of medicine. 2010

27. Tracy CM, Epstein AE, Darbar D, DiMarco JP, Dunbar SB, Estes NA, 3rd, Ferguson TB, Jr., Hammill SC, Karasik PE, Link MS, Marine JE, Schoenfeld MH, Shanker AJ, Silka MJ, Stevenson LW, Stevenson WG, Varosy PD, Ellenbogen KA, Freedman RA, Gettes LS, Gillinov AM, Gregoratos G, Hayes DL, Page RL, Stevenson LW, Sweeney MO. $2012 \mathrm{accf} / \mathrm{aha} / \mathrm{hrs}$ focused update of the 2008 guidelines for devicebased therapy of cardiac rhythm abnormalities: A report of the american college of cardiology foundation/american heart association task force on practice guidelines. Circulation. 2012;126:1784-1800. 
28. Daubert C, Gold MR, Abraham WT, Ghio S, Hassager C, Goode G, Szili-Torok T, Linde C. Prevention of disease progression by cardiac resynchronization therapy in patients with asymptomatic or mildly symptomatic left ventricular dysfunction: Insights from the european cohort of the reverse (resynchronization reverses remodeling in systolic left ventricular dysfunction) trial. J Am Coll Cardiol. 2009;54:18371846.

29. Solomon SD, Foster E, Bourgoun M, Shah A, Viloria E, Brown MW, Hall WJ, Pfeffer MA, Moss AJ. Effect of cardiac resynchronization therapy on reverse remodeling and relation to outcome: Multicenter automatic defibrillator implantation trial: Cardiac resynchronization therapy. Circulation. 2010;122:985-992.

30. Abraham WT, Young JB, Leon AR, Adler S, Bank AJ, Hall SA, Lieberman R, Liem LB, O'Connell JB, Schroeder JS, Wheelan KR. Effects of cardiac resynchronization on disease progression in patients with left ventricular systolic dysfunction, an indication for an implantable cardioverter-defibrillator, and mildly symptomatic chronic heart failure. Circulation. 2004;110:2864-2868.

31. Higgins SL, Hummel JD, Niazi IK, Giudici MC, Worley SJ, Saxon LA, Boehmer JP, Higginbotham MB, De Marco T, Foster E, Yong PG. Cardiac resynchronization therapy for the treatment of heart failure in patients with intraventricular conduction delay and malignant ventricular tachyarrhythmias. J Am Coll Cardiol. 2003;42:1454-1459.

32. van Geldorp IE, Vernooy K, Delhaas T, Prins MH, Crijns HJ, Prinzen FW, Dijkman B. Beneficial effects of biventricular pacing in chronically right ventricular paced patients with mild cardiomyopathy. Europace. 2010;12:223-229.

33. Paparella G, Sciarra L, Capulzini L, Francesconi A, De Asmundis C, Sarkozy A, Cazzin R, Brugada P. Long-term effects of upgrading to biventricular pacing: Differences with cardiac resynchronization therapy as primary indication. Pacing Clin Electrophysiol. 2010;33:841-849.

34. Vatankulu MA, Goktekin O, Kaya MG, Ayhan S, Kucukdurmaz Z, Sutton R, Henein M. Effect of long-term resynchronization therapy on left ventricular remodeling in pacemaker patients upgraded to biventricular devices. Am J Cardiol. 2009;103:1280-1284.

35. Yu CM, Chan JY, Zhang Q, Omar R, Yip GW, Hussin A, Fang F, Lam KH, Chan HC, Fung JW. Biventricular pacing in patients with bradycardia and normal ejection fraction. The New England journal of medicine. 2009;361:2123-2134.

36. Dickstein K, Vardas PE, Auricchio A, Daubert JC, Linde C, McMurray J, Ponikowski P, Priori SG, Sutton R, van Veldhuisen DJ, Vahanian A, Bax J, Ceconi C, Dean V, Filippatos G, Funck-Brentano C, Hobbs R, Kearney P, McDonagh T, Popescu BA, Reiner Z, Sechtem U, Sirnes PA, Tendera M, Vardas P, Widimsky P, Anker SD, Blanc JJ, Gasparini M, Hoes AW, Israel CW, Kalarus Z, Merkely B, Swedberg K, Camm AJ. 2010 focused update of esc guidelines on device therapy in heart failure: An update of the 2008 esc guidelines for the diagnosis and treatment of acute and chronic heart failure and the 2007 esc guidelines for cardiac and resynchronization therapy. Developed with the special contribution of the heart failure association and the european heart rhythm association. European heart journal. 2010;31:2677-2687.

37. Hsing JM, Selzman KA, Leclercq C, Pires LA, McLaughlin MG, McRae SE, Peterson BJ, Zimetbaum PJ. Paced left ventricular qrs width and ecg parameters predict 
outcomes after cardiac resynchronization therapy: Prospect-ecg sub-study. Circ Arrhythm Electrophysiol. 2011

38. Chung ES, Leon AR, Tavazzi L, Sun JP, Nihoyannopoulos P, Merlino J, Abraham W'T, Ghio S, Leclercq C, Bax JJ, Yu CM, Gorcsan J, 3rd, St John Sutton M, De Sutter J, Murillo J. Results of the predictors of response to crt (prospect) trial. Circulation. 2008;117:2608-2616.

39. Sweeney MO, van Bommel RJ, Schalij MJ, Borleffs CJ, Hellkamp AS, Bax JJ. Analysis of ventricular activation using surface electrocardiography to predict left ventricular reverse volumetric remodeling during cardiac resynchronization therapy. Circulation. 2010;121:626-634.

40. Varma N. Left ventricular conduction delays and relation to qrs configuration in patients with left ventricular dysfunction. Am J Cardiol. 2009;103:1578-1585.

41. Singh JP, Fan D, Heist EK, Alabiad CR, Taub C, Reddy V, Mansour M, Picard MH, Ruskin JN, Mela T. Left ventricular lead electrical delay predicts response to cardiac resynchronization therapy. Heart Rhythm. 2006;3:1285-1292.

42. Pabari PA, Willson K, Stegemann B, van Geldorp IE, Kyriacou A, Moraldo M, Mayet J, Hughes AD, Francis DP. When is an optimization not an optimization? Evaluation of clinical implications of information content (signal-to-noise ratio) in optimization of cardiac resynchronization therapy, and how to measure and maximize it. Heart Fail Rev. 2010

43. Ellenbogen KA, Gold MR, Meyer TE, Fernndez Lozano I, Mittal S, Waggoner AD, Lemke B, Singh JP, Spinale FG, Van Eyk JE, Whitehill J, Weiner S, Bedi M, Rapkin J, Stein KM. Primary results from the smartdelay determined av optimization: A comparison to other av delay methods used in cardiac resynchronization therapy (smart-av) trial: A randomized trial comparing empirical, echocardiography-guided, and algorithmic atrioventricular delay programming in cardiac resynchronization therapy. Circulation. 2010;122:2660-2668.

44. Martin DO, Lemke B, Birnie D, Krum H, Lee KF, Aonuma K, Gasparini M, Starling RC, Milasinovic G, Rogers T, Sambelashvili A, Houmsse M, Gorcsan J, 3rd. Investigation of a novel algorithm for synchronized left-ventricular pacing and ambulatory optimization of cardiac resynchronization therapy: Results of the adaptive crt trial. Heart Rhythm. 2012

45. Strik M, Regoli F, Auricchio A, Prinzen F. Electrical and mechanical ventricular activation during left bundle branch block and resynchronization. J Cardiovasc Transl Res. 2012;5:117-126.

46. van Deursen CJ, Strik M, Rademakers LM, van Hunnik A, Kuiper M, Wecke L, Crijns HJ, Vernooy K, Prinzen FW. Vectorcardiography as a tool for easy optimization of cardiac resynchronization therapy in canine left bundle branch block hearts. Circ Arrbythm Electrophysiol. 2012;5:544-552. 
Electrical Activation 

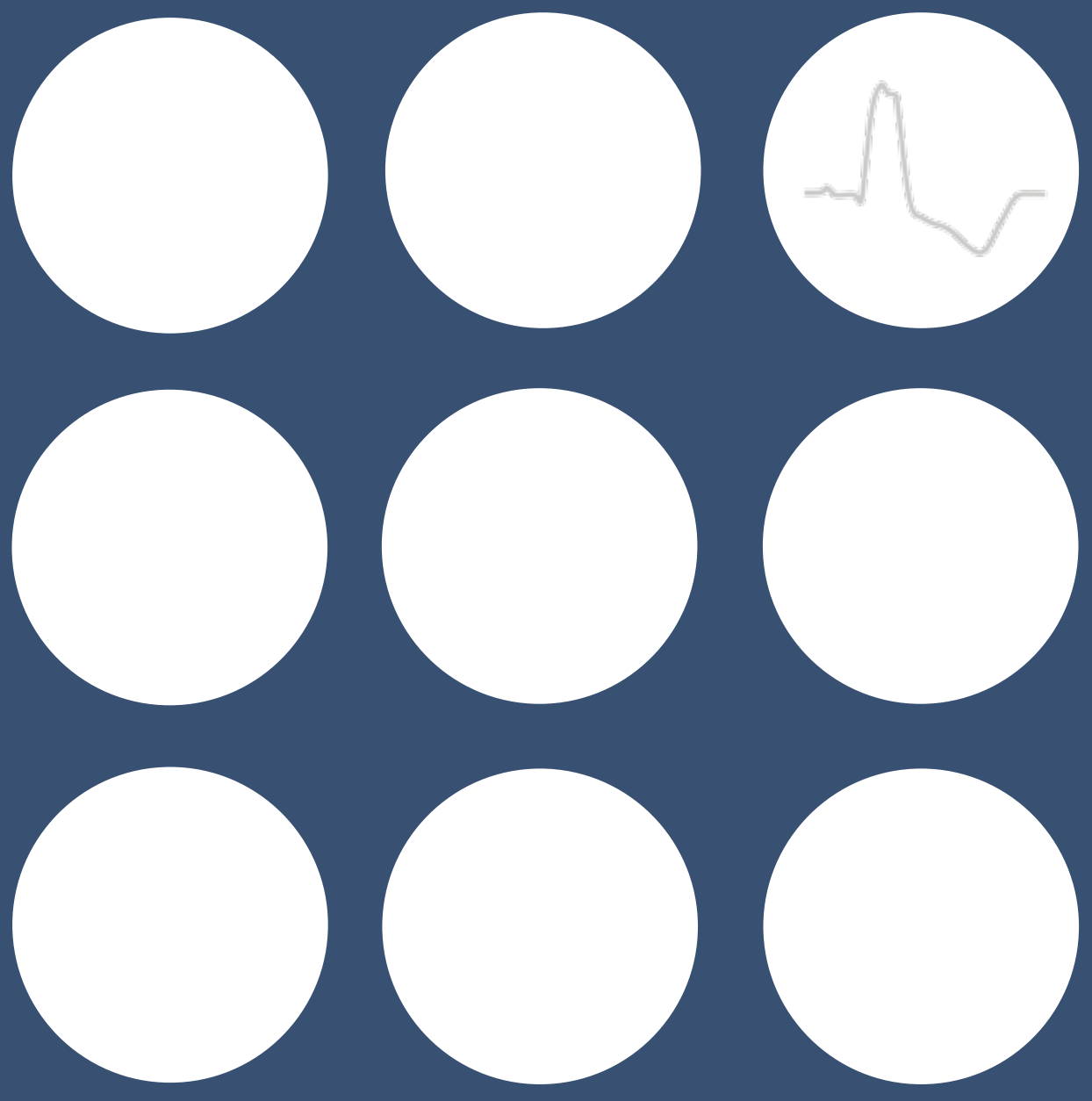

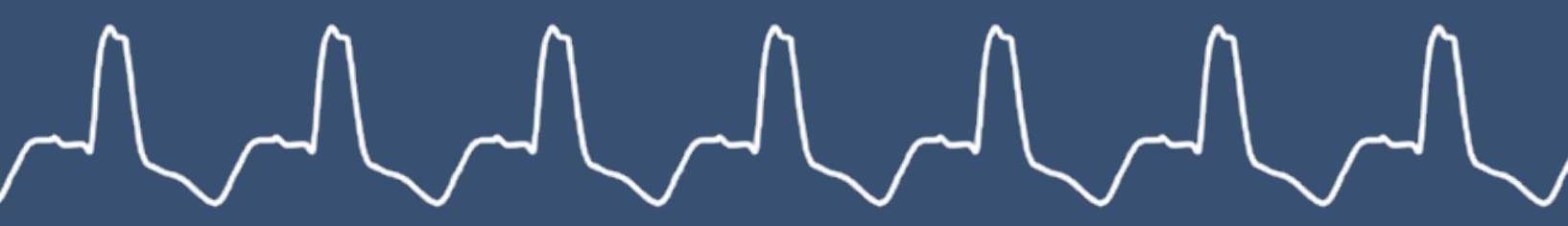




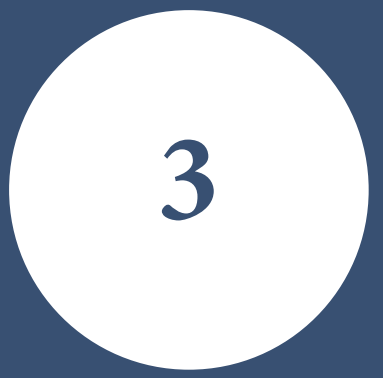

\section{Animal Models of Dyssynchrony}

\section{Based on:}

Strik M, van Middendorp LB, Vernooy K.

Animal models of dyssynchrony.

J Cardiovasc Transl Res. 2012;5:135-145

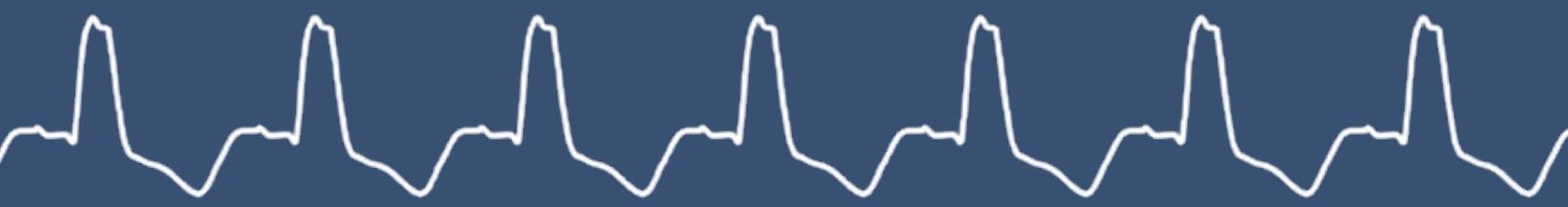




\section{Introduction}

Previous chapters signified the need for increased understanding of electrical asynchrony and resynchronization. However, presence of co morbidities and the lack of knowledge concerning the duration and extent of the lesion (or lesions) limits the use of clinical data to investigate the electro-pathophysiology of LBBB and CRT. The goal of the present chapter is to review how animal models of dyssynchrony can help clarify the pathophysiology of dyssynchrony and further improve the treatment of dyssynchrony by CRT.

\section{Animal models of dyssynchrony}

More than one century have passed since the observation of large and specific changes in QRS morphology after making a small incision in the left or right surface of the interventricular septum in canine hearts. ${ }^{1}$ The first dyssynchronous animal model was hereby established and was in fact a dyssynchrony model by proximal lesion of the bundle branches. Since then, LBBB has been described in humans but also in monkeys and pigs., ${ }^{2}$ Investigating LBBB in animals may apply less to the human situation, as there are inter-species differences in anatomy of the left bundle branch. For example in hearts from ox and sheep, the bundles are significantly thicker and their branches extend much more towards the epicardium. ${ }^{4}$ In rabbit hearts the left 'bundle' is composed of groups of fine sheets covering the subendocardial tissue. ${ }^{5}$ Since the extent of electrical asynchrony in dogs is comparable to humans (where a doubling of QRS duration is seen) the canine heart is considered the most suitable animal model for investigating LBBB. In contrast, RV pacing and LBBB increases QRS duration only 50\% in pigs $^{3}$ and even less in goats (observations from our lab).

For obvious reasons, animal experiments have presented more detailed information than clinical studies, but they suffer from limitations such as the fact that most animal studies are performed in (initially) young and healthy animals and that various preparations have been used, which differ from the clinical and intact human situation. Because of it required open heart surgery, an animal model based on intraventricular incisions was not suitable to investigate the hemodynamic effects of $\mathrm{LBBB}$ and later research focused on dyssynchrony based on ventricular pacing.

In 1925, Wiggers described that artificial stimulation of the canine left ventricle 1) slows down the rise of intraventricular pressure, 2) lengthens the isometric contraction phase, 3) lowers the maximal systolic pressure and 4) increases the 
duration of systole. ${ }^{6}$ Even though it was clear that dyssynchrony has adverse effects on cardiac pump function, major interest in the pathophysiology of dyssynchrony developed only after these effects were revealed in large groups of patients who underwent permanent RV pacing. ${ }^{4}$ Similar to LBBB, RV pacing induces delays in transseptal and intraventricular conduction which explains why the hemodynamic effects of altered ventricular activation during RV pacing and LBBB are comparable. However, one can think of important differences between the two situations. RV apex pacing disturbs RV activation since pacing induces slow intramyocardial conduction instead of fast conduction through the Purkinje fibers. Secondly, the site of stimulation-induced breakthrough could differ from the site of intrinsic breakthrough. Therefore, transseptal LV depolarization through the interventricular septum is expected to differ from LBBB.

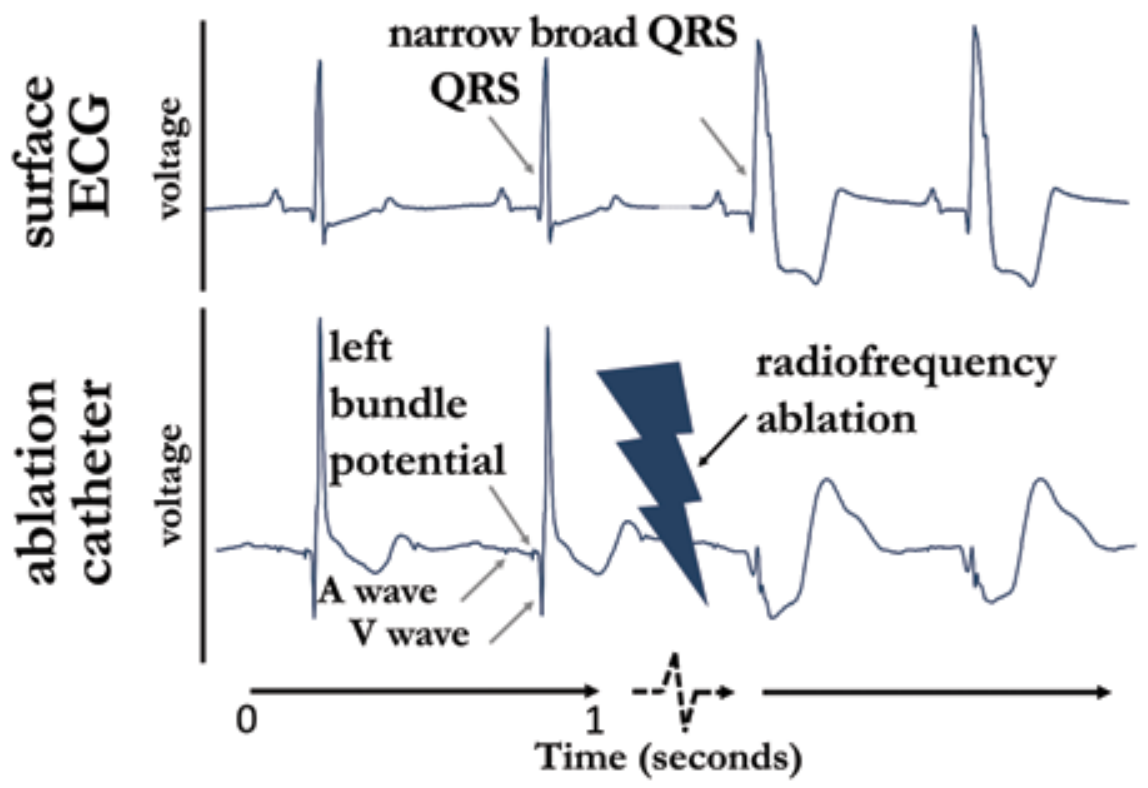

Figure 1. Creation of left bundle branch through radiofrequency ablation: on the electrogram derived from an ablation catheter in proximity of the left bundle branch (bottom tracing), the left bundle branch potential is observed as a sharp deflection between the $A$ wave and $V$ wave. Radiofrequency ablation then resulted in a proximal LBBB as evidenced by QRS complex broadening and typical changes in QRS and $T$ complex morphology in the surface ECG (top tracing).

To investigate the effects of LBBB and CRT, an LBBB model was developed in canine hearts. ${ }^{7-9}$ A steerable ablation catheter was introduced into the LV through the aortic valve and then positioned against the basal septum using fluoroscopy. 
Guided by the local endocardial electrogram derived from the tip of the catheter, when the ablation catheter is in the proximity of the left bundle branch, the left bundle branch potential appears as a sharp deflection between A wave and V wave (bottom tracing, Figure 1). ${ }^{9}$ Subsequently, radiofrequency ablation is started at this location, which results in a proximal lesion of the left bundle branch. The top tracing shows a simultaneously recorded surface electrocardiogram with narrow QRS-complex before ablation and broad QRS-complex after ablation together with typical changes in morphology of the QRS and T wave, indicating LBBB.

Examples of hemodynamic consequences induced by LBBB are shown in Figure 2. The increased time offset in normalized LV and RV pressure curves indicate an increase in mechanical interventricular asynchrony (center panels) and septal versus lateral strain patterns show that onset of $\mathrm{LV}$ shortening is regionally delayed (later negative deflection of curve in lateral wall, right panels), signifying increased intraventricular dyssynchrony. In agreement to the observations of Wiggers, dyssynchronous contraction also reduces ejection time and slows rates of rise and fall of LV and aortic pressure and increases duration of isovolumic contraction and relaxation. ${ }^{10,11}$
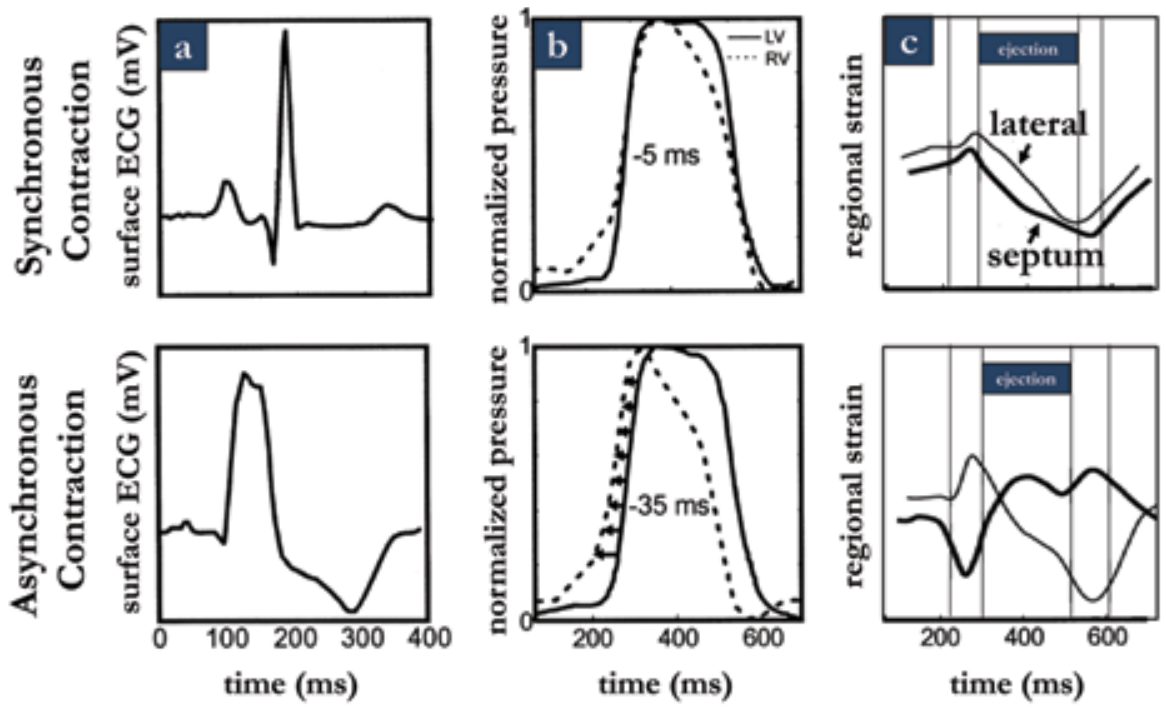

Figure 2: Effects of synchronous (top) and asynchronous (bottom) ventricular activation. (A) Asynchronous electromechanical activation induces increased QRS duration (B) mechanical interventricular asynchrony and (C) onset of LV shortening (strain) is regionally delayed (negative deflection of curve). Adapted with permission from Verbeek et al. ${ }^{9}$ 
During in vivo canine experiments, over one hundred simultaneous epicardial contact potentials can be derived by placing electrodes around the ventricles. Results from these studies are described in chapters 5 to 8 . In addition, endocardial potentials of the LV can be derived by transmural contact electrodes or by non-contact mapping $\left(E_{n S i t e}{ }^{\circledR}\right)$, the methodology of which is described in chapters 4 and 5. Furthermore, for a subset of these experiments the simultaneously acquired epicardial and endocardial activation data were combined in order to construct three-dimensional maps of activation. Examples of three-dimensional depolarization time maps in a canine heart before and after induction of LBBB are shown in Figure 3. In a canine heart with intact conduction, the His-Purkinje fibers allow for rapid propagation of the impulse from the atrioventricular node towards all regions of the heart.

normal conduction

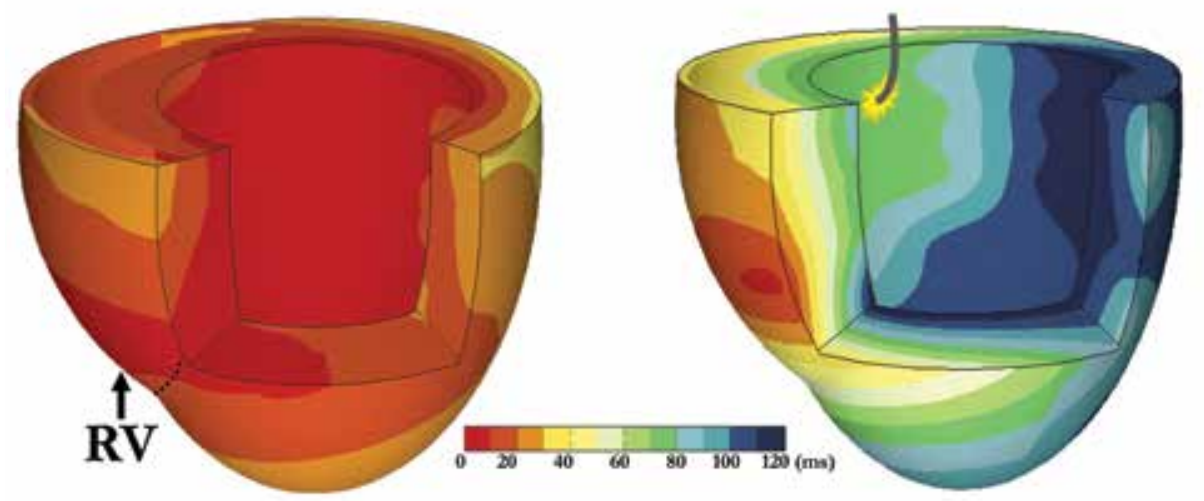

Figure 3: Typical examples of 3D electrical activation in canine hearts during normal conduction (left panel) and after creation of left bundle branch block (right panel). Plotted activation times were derived from $\approx 110$ epicardial and transmural endocardial contact electrodes and referenced to the onset of the $Q$ wave. ${ }^{13}$

As is shown in the left panel, most of the ventricles is depolarized within 50 milliseconds (red, orange or yellow colors). After ablation of the LBB (right panel), the activation pattern changes drastically. Onset of electrical activation now occurs inside the right ventricle and the electrical wave front slowly propagates through the interventricular septum towards the lateral wall of the LV. ${ }^{12}$ As LV depolarization occurs from cardiac myocyte to cardiac myocyte instead of via specialized purkinje fibers, biventricular depolarization exceeds 100 milliseconds and thus more than doubles as compared with normal conduction. 


\section{Electromechanical delay}

Myocardial contraction does not immediately follow depolarization and the delay between local electrical activation and shortening, or electro-mechanical delay, was found to be approximately 30 milliseconds in normal canine hearts. ${ }^{14}$ More advanced measurements (MRI tagging) at many sites in asynchronous ventricles showed that timing differences in shortening are larger than in electrical activation. ${ }^{15}$ This larger mechanical asynchrony is presumably explained completely by its definition: the onset of shortening. Recent studies in canine hearts indicate that when the onset of active force generation rather than the onset of shortening is used to define mechanical activation, electro-mechanical delay is equal throughout the asynchronous heart and directly reflects the timing of electrical activation. ${ }^{16}$

The discrepancy between onset of active force generation and onset of shortening is explained by the fact that early activated regions can start to shorten immediately upon activation, because cavity pressure is low and all other muscle fibers are passive, while this is not valid for late activated regions. The prolonged electromechanical delay in the later activated region could not be explained by increased excitation-contraction coupling time or increased pressure at the time of local depolarization. However, the higher rate of rise of LV pressure $(\mathrm{d} P / \mathrm{d} t)$ that late activated regions have to oppose prolongs the interval when force generation is accelerated to a rate superior to load rise, resulting in delayed onset of shortening. ${ }^{17}$ Moreover, the septum contracts against a reduced load resulting in a faster than normal shortening during the isovolumic phase. This phenomenon can be used as an echocardiographic marker for dyssynchrony and is possibly able to predict response to CRT. ${ }^{18}$ Additionally, early septal contraction pre-stretches the left ventricular free wall, and when this regions starts to contract after its delayed onset of shortening, it will stretch the septum again. ${ }^{19}$

This combination of delayed onset of shortening, early septal shortening and reciprocated stretching causes a less effective contraction and reduces the rate in rise of pressure. The early fiber shortening in early activated regions and pronounced shortening in late activated regions found in canine dyssynchrony models was also found in LBBB patients. ${ }^{17,20,21}$ Since $\mathrm{LV} \mathrm{d} P / \mathrm{d} t$ reflects $\mathrm{LV}$ function and contractility, the magnitude of mechanical dyssynchrony may vary over time in a given patients when there are changes in LV function. ${ }^{17}$ 


\section{Structural remodeling}

The ventricular wall is capable of adapting to changes in workload by changing the extracellular matrix composition and by hypertrophy of cardiac myocytes. It is not entirely clear which mechanisms are responsible for initiating these changes, but neurohumoral feedback and altered cardiac load have been ascribed to play an important role. Within the LV wall, an asynchronous electrical activation causes a redistribution of mechanical work, perfusion, and oxygen demand. ${ }^{20,22}$ Ventricular pacing results in reductions in regional myocardial perfusion and oxygen consumption near the pacing site. Moreover, the larger mechanical load in late activated regions leads, in the long run, to increased wall thickness in regions opposing the site of pacing, while early-activated wall segments tend to become thinner. ${ }^{19,20,23}$ The latter is even more the case in canine hearts, which were paced at the RV, while pressure overload was induced by aortic banding. In this model no added hypertrophy was seen in the late-activated wall, but a clear inhibition of hypertrophy in the early activated septum. ${ }^{24}$ The generally more pronounced hypertrophy in the pre-stretched regions indicates that the local mechanical load is an important stimulus in this remodeling process. ${ }^{23}$ Abnormal contraction also induces abnormal relaxation by premature relaxation in early-activated regions and delayed relaxation in late activated regions. ${ }^{4}$

\section{Myocardial perfusion and metabolism}

To investigate regional myocardial blood flow, the microsphere deposition method can be used, the gold standard for regional blood flow measurements. After injection of radioactive or fluorescent microspheres, deposition is measured and thereby provides information on regional perfusion. ${ }^{25}$ During sinus rhythm blood flow is homogeneous and equally distributed. However in the dyssynchronous heart, early activated regions consistently show a reduced myocardial blood flow, while higher flow is observed in late activated regions. ${ }^{20,26}$ Closely related to myocardial blood flow is myocardial oxygen consumption $\left(\mathrm{MVO}_{2}\right)$. Not surprisingly $\mathrm{MVO}_{2}$ shows a similar distribution as myocardial blood flow, where early-activated regions show a reduction in $\mathrm{MVO}_{2}$ and a near normal oxygen consumption is observed in the latest activated regions. ${ }^{26}$ Oxygen extraction from the blood is not altered in the different regions and remains stable over a wide physiological range. Therefore it is speculated that the local changes in workload, due to dyssynchronous contraction, changes the local oxygen demand and thereby local perfusion. 
In humans, dyssynchrony has usually a silent onset and is often first diagnosed when patients present themselves with other cardiovascular problems. Frequently non-invasive myocardial imaging is performed to diagnose perfusion defects due to coronary artery disease. However septal perfusion defects are frequently found in patients with LBBB in the absence of any significant coronary artery disease. ${ }^{27,28}$ As argued above, the data from animal studies suggest that this effect in patients is probably due to reduced oxygen demand, caused by the underlying electrical substrate. An alternative hypothesis of the septal underperfusion in dyssynchronous hearts is that perfusion is hampered by the abnormal contraction, which augments intramyocardial pressure and shortens the diastolic period, where coronary perfusion occurs. ${ }^{29-31}$ Changes in myocardial blood flow and workload are paralleled by changes in metabolism. In dogs with dyssynchronous hearts, glucose uptake in the septum is markedly reduced in a similar fashion as the redistribution in myocardial blood flow. ${ }^{29}$ In patients with dyssynchrony, a relative reduction of glucose uptake in the septum compared to the lateral wall is observed as assessed by fluorodeoxyglucose positron emission tomography imaging. However, the perceived reduction in glucose uptake in the septum may also be due to an increase in absolute glucose uptake in the lateral wall, caused by an increase in work load and higher energy demand in that wall. ${ }^{32}$

\section{Cardiac resynchronization therapy in animal models}

Immediately upon inducing LBBB in the canine hearts, $\mathrm{LV} \mathrm{d} P / \mathrm{d} t_{\max }$ decreased by $22 \%$ and adverse effects as described in earlier animal models of pacing induced dyssynchrony are reproduced. ${ }^{33}$ Interestingly, biventricular pacing in the LBBB heart immediately causes an almost normalization of the strain pattern (Figure 4) and increases $\mathrm{LV} \mathrm{d} P / \mathrm{d} t_{\max }$ to $86 \pm 5 \%$ of pre-LBBB followed by a slight further improvement to $89 \pm 5 \%$ of pre-LBBB values after eight weeks of CRT. Therefore, the data from this animal study indicate that CRT clearly improves cardiac pump function in the LBBB hearts, but does not return it completely to pre-LBBB values. This could be explained by the fact that the physiological sequence of activation and contraction are never completely restored during CRT, remaining less efficient than through the Purkinje system. ${ }^{34}$ Asymmetric hypertrophy, as seen during chronic LV pacing, also applies to the situation of LBBB. ${ }^{35}$ Eight weeks after creation of LBBB, wall mass of the lateral wall and LV cavity size increased by $\approx 30 \%$, whereas mass of the septum barely changed. ${ }^{35}$ After eight weeks of CRT, LV cavity size and regional differences in hypertrophy normalized to pre-LBBB levels. The observations made in these dog models are readily translatable to the human situation. In patients 
with LBBB the effect of asynchronous activation on regional hypertrophy was comparable to that observed in dogs. Nonetheless, the effects of CRT are less pronounced in patients possibly due to the large heterogeneity and confounding factors such as hypertrophy, fibrosis, infarction and dilatation that are so often present in these patient groups. ${ }^{32,36}$

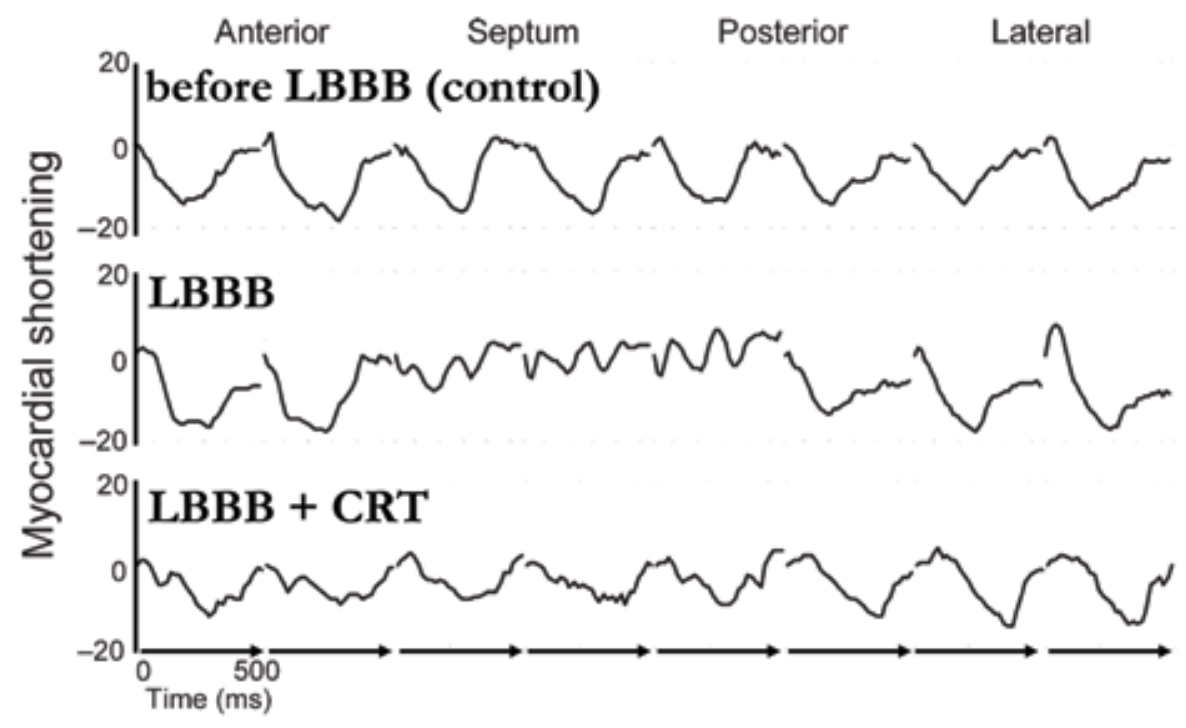

Figure 4: Typical example of myocardial circumferential shortening (\%) tracings in eight regions along the mid-basal LV circumference. Note the abnormal shortening patterns during LBBB and the normalization during CRT (LBBB+CRT).From ${ }^{33}$

The aforementioned findings give rise to the notion that dyssynchronous ventricular activation by LBBB on its own is sufficient for CRT to be efficient. The described animal models contain dyssynchronous activation either by ventricular pacing or by proximal ablation of the left bundle branch and, unlike CRT candidates, these models do not suffer from co-morbidities complicating their conduction defect. It is important to understand the effects of additional factors such as LV systolic dysfunction for better selection of CRT candidates and to improve response to treatment. In healthy canine hearts, isolated LBBB induces electrical and mechanical dyssynchrony that eventually will lead to loss of LV pump function and ventricular remodeling. In these hearts, CRT largely reversed global and regional function and structural abnormalities, indicating that LBBB as electrical substrate is sufficient for acute and long-term response to CRT. ${ }^{37}$ Recently, multiple clinical trials have indeed shown high CRT efficacy in heart failure patients who were not severely symptomatic (NYHA class I and II). ${ }^{38-42}$ 


\section{Role of infarction in CRT}

While, based on these studies, inclusion criteria for CRT may be extended to patients without severe symptomatic heart failure, still a significant number of patients complying with the current guidelines do not respond to CRT. To this regard, most clinical studies show that the number of non-responders is highest in patients who suffer from ischemic heart disease. One possible mechanism is that there is insufficient viable tissue to allow an increase in contractility by CRT. Another possible mechanism lies in modification of the electrical substrate where the extent of resynchronization would be limited as a result of slow-conducting or non-conducting regions. This would mean that a good response to CRT in patients with ischemic heart disease not only requires clear conduction disease, but also the capability to properly resynchronize the heart. An important feature in this regard is the site of pacing as pacing in the vicinity of scar tissue is considered to compromise conduction.

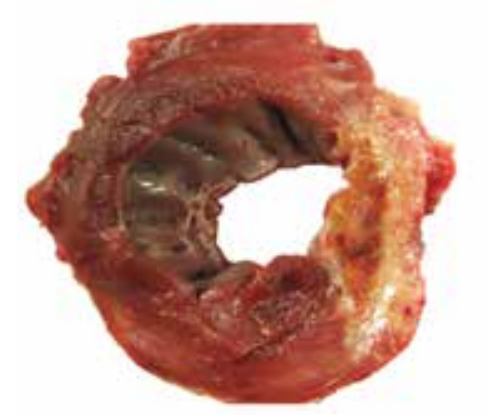

Figure 5: Short-axis slice at the mid-level of LV demonstrating transmural myocardial infarction of the canine LV lateral wall in the LBBB with additional infarction model (for details see text).

To investigate this idea, an animal model was developed where asynchronous activation by proximal left bundle branch ablation was combined with myocardial infarction. ${ }^{43}$ Transmural myocardial infarction was created by embolization of the left anterior descending (LAD) or circumflex (LCX) artery using a suspension of polyvinyl alcohol foam particles. Four weeks later LBBB was induced and another week later measurements on electrical activation and hemodynamics were performed. TTC staining showed that all infarctions were transmural with an infarct size of $19.9 \pm 6.0 \%$ (range 14-32\%) of LV mass (see typical example in Figure 5). ${ }^{43}$

Figure 6 shows examples of how an LAD or LCX infarction can influence electrical resynchronization in dogs with LBBB. An important feature in this regard is the site of pacing as pacing in the vicinity of scar tissue can compromise conduction. Achieving the maximal benefit in infarcted dyssynchronous hearts required accurate positioning of the LV pacing lead and more precise timing of LV stimulation. ${ }^{43}$ 


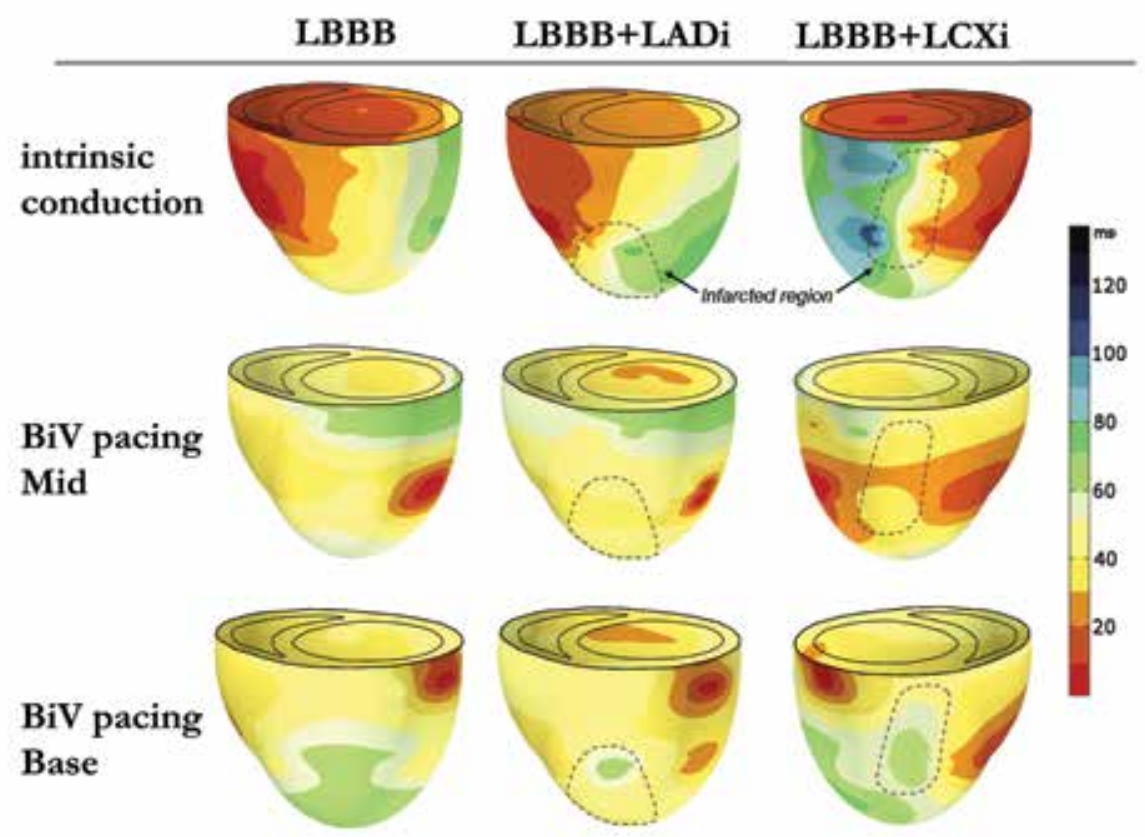

Figure 6. 3D reconstruction of epicardial electrical activation during intrinsic conduction (LBBB) and BiV pacing (RV apex and $L V$ free wall) in hearts with $L B B B$ (left), LBBB + LAD infarction (middle) and LBBB + LCX infarction (right). ${ }^{43}$

In infarcted hearts, the optimal pacing site did not coincide with the region of latest activation but rather a region distant from the infarction and more basal or apical than the preferred pacing site in non-infarcted hearts. The optimal LV pacing position in infarcted dyssynchronous hearts appears to be determined by the fastest pathway of activation wave front from LV and RV electrodes. This study ${ }^{43}$ indicated that in hearts with LAD occlusion, the infarction is located apically and basal pacing allows the activation wave front to bypass the infarcted area. In contrast, the midlateral position is best in case of LCX infarctions since the activation wave front can easily propagate over the lateral wall and apex. Whether LBBB hearts with myocardial infarction can also benefit from endocardial LV pacing during CRT as in hearts with isolated LBBB is described in chapter 8.

The preclinical data indicate that it is important to know the location of the infarction but in many CRT candidates, this is not known since scar imaging before device implantation is not regularly performed. Even if scar imaging is not feasible, acute hemodynamic or electrocardiographic testing during pacemaker implantation could help to optimize CRT response in patients with underlying ischemic disease. 


\section{Role of dilation on benefit of (endocardial) CRT}

Besides ventricular conduction delay and possibly myocardial infarction, many CRT candidates suffer from dilated cardiomyopathy. Even though dyssynchrony alone is sufficient for CRT to be successful, inducing heart failure in addition to electrical asynchrony can be essential to test certain hypotheses. For example it was found that in canine hearts with isolated LBBB, endocardial LV pacing during CRT consistently improved systolic LV pump function, reduced electrical asynchrony and decreased dispersion of repolarization, as compared to epicardial LV pacing at the same site. ${ }^{44}$ Three possible mechanisms explaining the more rapid electrical activation during endocardial CRT in this model were proposed: 1) shorter path length of conduction, 2) faster endocardial than epicardial conduction as well as 3) faster conduction from endocardium to epicardium than vice versa. While all three factors may contribute in the setting of LBBB in otherwise healthy canine hearts, ventricular dilatation and wall thinning would reduce the difference in conduction path length between endocardium and epicardium, potentially reducing the advantages of endocardial CRT in patients with dilated cardiomyopathy. Better understanding of the various factors determining the benefits of endocardial CRT in multiple animal models can also be used to propose explanations to ambivalent results reported from the few small clinical studies. ${ }^{45-47}$

For this purpose, we performed a study (chapter 8) to investigate the efficacy of endocardial CRT in canine LBBB hearts combined with dilated cardiomyopathy. ${ }^{48}$ The results were compared with endocardial CRT in dogs with acute LBBB and in dogs with chronic LBBB and infarction (model as described above). To obtain dilated cardiomyopathy, the apex of the right ventricle was paced at a rate of 220 beats per minute for 4 weeks, as described earlier by other groups. ${ }^{49,50}$ Pacing induced tachycardia results in severe LV dilatation and decreases LV systolic function to levels similar to those found in heart failure patients. However, evaluating chronic effects of CRT in this model is only possible when tachycardia is maintained during resynchronization as the heart would recover independently from therapy. This model has been used in the past to explore genetic alterations induced by dyssynchrony and the capability of CRT (at the same high rate) to restore these alterations. ${ }^{51}$ This model provided some interesting data, showing that even though heart rate remained high and hemodynamics hardly improved, electrical resynchronization and mechanical recoordination resulted in extensive cellular and molecular recovery. ${ }^{52,53}$ 
To investigate chronic effects of CRT under physiological heart rates in LBBB and dilated cardiomyopathy, an alternative heart failure model is necessary. Therefore we have recently commenced the development of a chronic model of heart failure and dyssynchrony in our lab by inducing LBBB and mitral regurgitation in canine hearts. The model is based on a known canine mitral regurgitation model in absence of LBBB which was used to investigate atrial fibrillation. ${ }^{54}$ Mitral regurgitation was induced using a customized electrophysiology catheter with a hook at the distal tip which was introduced into the left ventricle via the aortic valve. After grasping one or more chorda(e), the hook was withdrawn into a sheet and cauterized to partially obliterate the mitral suspension. This process was repeated until echocardiographic and fluoroscopic evaluation indicated severe mitral regurgitation.

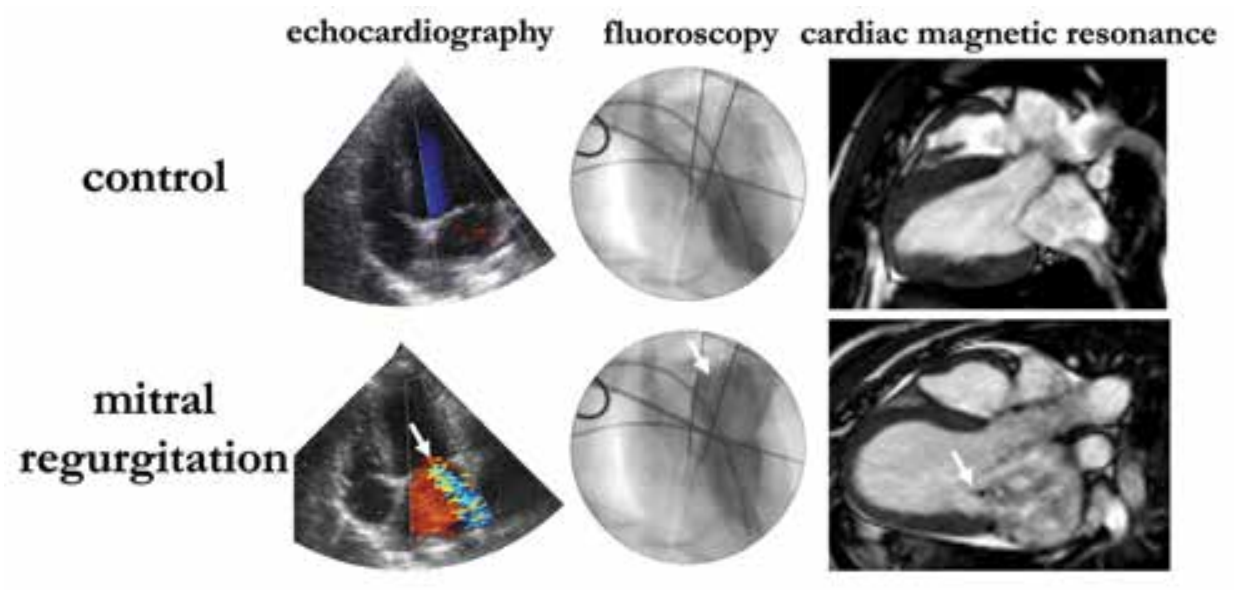

Figure 7 Examples of echocardiography, fluoroscopy and cardiac MRI in canine hearts before and after creation of mitral regurgitation. The cardiac MRI was performed 5 months after creating mitral regurgitation. Arrows point to the regurgitant blood flow into the left atrium.

Figure 7 shows typical examples of mitral regurgitation on echocardiography, fluoroscopy and cardiac MRI in canine hearts. One month after the procedure, LBBB was induced by radiofrequency ablation of the left bundle branch. Upon creation of mitral regurgitation, heart rate and LV end-diastolic pressure increased, accompanied by a modest decrease in maximal LV pressure. LV contractility decreased more gradually and after five months (including creation of LBBB after one month) ultimately decreased to $\approx 57 \%$ of baseline. Clearly left atrial dilatation and pericardial fluid are seen on the cardiac MRI, indicating heart failure. Signs and symptoms of heart failure were also clinically present in the dogs. 
Meanwhile, LV end-diastolic pressure doubled compared to baseline values and peak systolic pressure decreased to $\approx 83 \%$ of baseline (preliminary data). Figure 8 shows an example of left ventricular dilatation over time in a dog with mitral regurgitation and LBBB. Note the rather steep increase in the first weeks after superimposing LBBB upon mitral regurgitation.

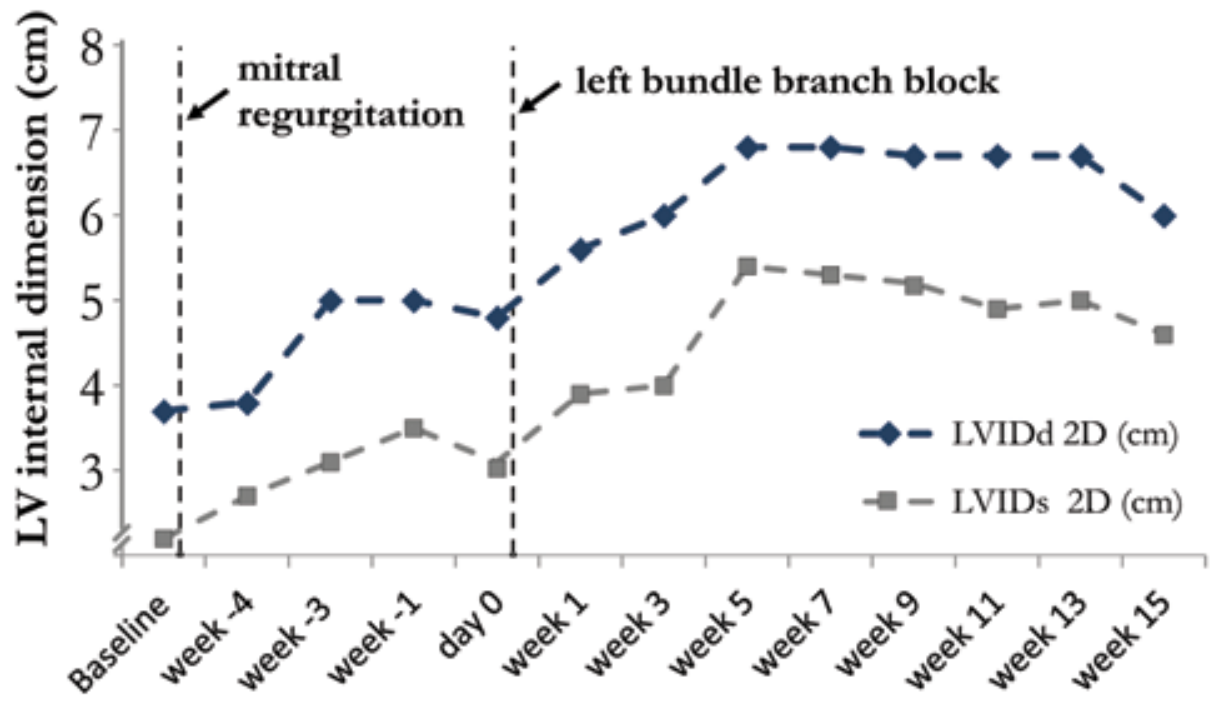

Figure 8. Bi-weekly ehocardiographic follow-up of left ventricular internal diameters of a dog with mitral regurgitation. At day zero, four weeks after creation of mitral regurgitation, the left bundle branch is ablated. Note the steep increase in end diastolic and end systolic internal diameter of the left ventricle after superimposing LBBB upon mitral regurgitation.

Beyond the scope of this thesis, we expect that this model will be useful to compare effects of isolated dyssynchrony with dyssynchrony complicated by heart failure. Of particular interest are biomarkers sensitive to dyssynchrony and regional differences in wall structure and protein synthesis.

As delineated in an overview of discussed canine models of dyssynchrony and their effects on left ventricular characteristics (Table 1), we believe that this novel dyssynchrony model is the animal model which resembles the pathophysiology of CRT patients the closest, especially since mitral regurgitation is also an important component of the dyssynchronous heart. 
Table 1. Canine models of dyssynchrony and associated left ventricular changes in hypertrophy, dilatation, $\mathrm{EF}$ and $\mathrm{dP} / \mathrm{dt}_{\max }$.

\begin{tabular}{|c|c|c|c|c|c|}
\hline & $\begin{array}{c}\text { heart } \\
\text { rate }\end{array}$ & $\begin{array}{c}\text { wall } \\
\text { thickening }\end{array}$ & $\begin{array}{c}\text { dilata- } \\
\text { tion }\end{array}$ & $\begin{array}{l}\text { ejection } \\
\text { fraction }\end{array}$ & $\begin{array}{c}\mathrm{LV} \\
\mathbf{d P} / \mathbf{d t}_{\max }\end{array}$ \\
\hline LV pacing p $^{13,23}$ & $=$ & septal wall & $=1+$ & $=/-$ & $=/-$ \\
\hline LBBB / RV pacing ${ }^{24,35}$ & $=$ & $\begin{array}{c}\text { lateral } \\
\text { wall }\end{array}$ & + & - & - \\
\hline added $\mathrm{AoS}^{55}$ & $=$ & ++ & $=$ & + & + \\
\hline added $\mathrm{MI}^{43,56}$ & $=$ & + & + & - & - \\
\hline added $\mathbf{M R}^{33,57}$ & $=1+$ & - & ++ & $+^{*}$ & - \\
\hline added atrial tachypacing ${ }^{51}$ & ++ & - & ++ & - & - \\
\hline
\end{tabular}

AoS; aortic stenosis, MI; myocardial infarction, MR; mitral regurgitation, * including backflow to left atrium

\section{Conclusion}

Animal models are of great importance in understanding the events and consequences of dyssynchrony and resynchronization. Depending on the hypothesis to be tested, multiple well-established and novel animal models of dyssynchrony exist. Detailed animal experiments demonstrate that ventricular dyssynchrony is a complex disease, which can and needs to be treated in a better way than it is often performed today.

\section{Acknowledgments}

This research was performed within the framework of CTMM, the Center for Translational Molecular Medicine (www.ctmm.nl), project COHFAR (grant 01C-203), and supported by the Dutch Heart Foundation. 


\section{References}

1. Eppinger H, Rothberger J. Ueber die folgen der durchschneidung der tawaraschen schenkel des reizleitungssystems,. Ztsch Klin Med 1910;70:1.

2. Roberts GH, Crawford JH, Abramson DI. Experimental bundle branch block in the monkey. J Clin Invest. 1935;14:867-870.

3. Marrouche NF, Pavia SV, Zhuang S, Kim YJ, Tabata T, Wallick D, Saad E, AbdulKarim A, Schweikert R, Saliba W, Tchou P, Natale A. Nonexcitatory stimulus delivery improves left ventricular function in hearts with left bundle branch block. J Cardiovasc Electrophysiol. 2002;13:691-695.

4. Prinzen FW, Peschar M. Relation between the pacing induced sequence of activation and left ventricular pump function in animals. Pacing Clin Electrophysiol. 2002;25:484-498.

5. Bojsen-Moller F, Tranum-Jensen J. Rabbit heart nodal tissue, sinuatrial ring bundle and atrioventricular connexions indentified as a neuromuscular system. $J$ Anat. 1972;112:367-382.

6. Wiggers CJ. The muscular reactions of the mammalian ventricles to artificial surface stimuli. American Journal of Physiology -- Legacy Content. 1925;73:346-378.

7. Verbeek XA, Vernooy K, Peschar M, Van Der Nagel T, Van Hunnik A, Prinzen FW. Quantification of interventricular asynchrony during lbbb and ventricular pacing. American journal of physiology. Heart and circulatory physiology. 2002;283:H13701378.

8. Liu L, Tockman B, Girouard S, Pastore J, Walcott G, KenKnight B, Spinelli J. Left ventricular resynchronization therapy in a canine model of left bundle branch block. Am J Physiol Heart Circ Physiol. 2002;282:H2238-2244.

9. Verbeek XA, Vernooy K, Peschar M, Cornelussen RN, Prinzen FW. Intra-ventricular resynchronization for optimal left ventricular function during pacing in experimental left bundle branch block. J Am Coll Cardiol. 2003;42:558-567.

10. Prinzen FW, Van Oosterhout MF, Vanagt WY, Storm C, Reneman RS. Optimization of ventricular function by improving the activation sequence during ventricular pacing. Pacing Clin Electrophysiol. 1998;21:2256-2260.

11. Zile MR, Blaustein AS, Shimizu G, Gaasch WH. Right ventricular pacing reduces the rate of left ventricular relaxation and filling. J Am Coll Cardiol. 1987;10:702709.

12. Vassallo JA, Cassidy DM, Marchlinski FE, Buxton AE, Waxman HL, Doherty JU, Josephson ME. Endocardial activation of left bundle branch block. Circulation. 1984;69:914-923.

13. Mills RW, Cornelussen RN, Mulligan LJ, Strik M, Rademakers LM, Skadsberg ND, van Hunnik A, Kuiper M, Lampert A, Delhaas T, Prinzen FW. Left ventricular septal and left ventricular apical pacing chronically maintain cardiac contractile coordination, pump function and efficiency. Circ Arrbythm Electrophysiol. 2009;2:571579.

14. Prinzen FW, Augustijn CH, Allessie MA, Arts T, Delhaas T, Reneman RS. The time sequence of electrical and mechanical activation during spontaneous beating and ectopic stimulation. European heart journal. 1992;13:535-543.

15. Wyman BT, Hunter WC, Prinzen FW, McVeigh ER. Mapping propagation of mechanical activation in the paced heart with mri tagging. Am J Physiol. 
1999;276:H881-891.

16. Russell K, Opdahl A, Remme EW, Gjesdal O, Skulstad H, Kongsgaard E, Edvardsen T, Smiseth OA. Evaluation of left ventricular dyssynchrony by onset of active myocardial force generation: A novel method that differentiates between electrical and mechanical etiologies. Circulation. Cardiovascular imaging. 2010;3:405-414.

17. Russell K, Smiseth OA, Gjesdal O, Qvigstad E, Norseng PA, Sjaastad I, Opdahl A, Skulstad H, Edvardsen T, Remme EW. Mechanism of prolonged electromechanical delay in late activated myocardium during left bundle branch block. American Journal of Physiology. 2011

18. Parsai C, Bijnens B, Sutherland GR, Baltabaeva A, Claus P, Marciniak M, Paul V, Scheffer M, Donal E, Derumeaux G, Anderson L. Toward understanding response to cardiac resynchronization therapy: Left ventricular dyssynchrony is only one of multiple mechanisms. Eur Heart J. 2009;30:940-949.

19. Baller D, Wolpers HG, Zipfel J, Bretschneider HJ, Hellige G. Comparison of the effects of right atrial, right ventricular apex and atrioventricular sequential pacing on myocardial oxygen consumption and cardiac efficiency: A laboratory investigation. Pacing Clin Electrophysiol. 1988;11:394-403.

20. Prinzen FW, Augustijn CH, Arts T, Allessie MA, Reneman RS. Redistribution of myocardial fiber strain and blood flow by asynchronous activation. Am J Physiol. 1990;259:H300-308.

21. Breithardt OA, Stellbrink C, Herbots L, Claus P, Sinha AM, Bijnens B, Hanrath P, Sutherland GR. Cardiac resynchronization therapy can reverse abnormal myocardial strain distribution in patients with heart failure and left bundle branch block. $J$ Am Coll Cardiol. 2003;42:486-494.

22. Prinzen FW, Hunter WC, Wyman BT, McVeigh ER. Mapping of regional myocardial strain and work during ventricular pacing: Experimental study using magnetic resonance imaging tagging. J Am Coll Cardiol. 1999;33:1735-1742.

23. van Oosterhout MF, Prinzen FW, Arts T, Schreuder JJ, Vanagt WY, Cleutjens JP, Reneman RS. Asynchronous electrical activation induces asymmetrical hypertrophy of the left ventricular wall. Circulation. 1998;98:588-595.

24. van Oosterhout MF, Arts T, Muijtjens AM, Reneman RS, Prinzen FW. Remodeling by ventricular pacing in hypertrophying dog hearts. Cardiovascular research. 2001;49:771-778.

25. Prinzen FW, Bassingthwaighte JB. Blood flow distributions by microsphere deposition methods. Cardiovascular research. 2000;45:13-21.

26. van Oosterhout MF, Arts T, Bassingthwaighte JB, Reneman RS, Prinzen FW. Relation between local myocardial growth and blood flow during chronic ventricular pacing. Cardiovasc Res. 2002;53:831-840.

27. Matzer L, Kiat H, Friedman JD, Van Train K, Maddahi J, Berman DS. A new approach to the assessment of tomographic thallium-201 scintigraphy in patients with left bundle branch block. Journal of the American College of Cardiology. 1991;17:1309-1317.

28. Hayat SA, Dwivedi G, Jacobsen A, Lim TK, Kinsey C, Senior R. Effects of left bundle-branch block on cardiac structure, function, perfusion, and perfusion reserve: Implications for myocardial contrast echocardiography versus radionuclide perfusion imaging for the detection of coronary artery disease. Circulation. 
2008;117:1832-1841.

29. Ono S, Nohara R, Kambara H, Okuda K, Kawai C. Regional myocardial perfusion and glucose metabolism in experimental left bundle branch block. Circulation. 1992;85:1125-1131.

30. Altehoefer C, vom Dahl J, Bares R, Stocklin GL, Bull U. Metabolic mismatch of septal beta-oxidation and glucose utilization in left bundle branch block assessed with pet. Journal of nuclear medicine : official publication, Society of Nuclear Medicine. 1995;36:2056-2059.

31. Zanco P, Desideri A, Mobilia G, Cargnel S, Milan E, Celegon L, Buchberger R, Ferlin G. Effects of left bundle branch block on myocardial fdg pet in patients without significant coronary artery stenoses. Journal of nuclear medicine : official publication, Society of Nuclear Medicine. 2000;41:973-977.

32. Masci PG, Marinelli M, Piacenti M, Lorenzoni V, Positano V, Lombardi M, L'Abbate A, Neglia D. Myocardial structural, perfusion, and metabolic correlates of left bundle branch block mechanical derangement in patients with dilated cardiomyopathy: A tagged cardiac magnetic resonance and positron emission tomography study. Circulation. Cardiovascular imaging. 2010;3:482-490.

33. Vernooy K, Cornelussen RN, Verbeek XA, Vanagt WY, van Hunnik A, Kuiper M, Arts T, Crijns HJ, Prinzen FW. Cardiac resynchronization therapy cures dyssynchronopathy in canine left bundle-branch block hearts. European heart journal. 2007;28:2148-2155.

34. Wyman BT, Hunter WC, Prinzen FW, Faris OP, McVeigh ER. Effects of singleand biventricular pacing on temporal and spatial dynamics of ventricular contraction. American journal of physiology. Heart and circulatory physiology. 2002;282:H372379.

35. Vernooy K, Verbeek XA, Peschar M, Crijns HJ, Arts T, Cornelussen RN, Prinzen FW. Left bundle branch block induces ventricular remodelling and functional septal hypoperfusion. European heart journal. 2005;26:91-98.

36. Prinzen FW, Cheriex EC, Delhaas T, van Oosterhout MF, Arts T, Wellens HJ, Reneman RS. Asymmetric thickness of the left ventricular wall resulting from asynchronous electric activation: A study in dogs with ventricular pacing and in patients with left bundle branch block. American heart journal. 1995;130:1045-1053.

37. Strik M, Ploux S, Vernooy K, Prinzen FW. Cardiac resynchronization therapy: Refocus on the electrical substrate. Circ J. 2011;75:1297-1304.

38. Abraham WT, Young JB, Leon AR, Adler S, Bank AJ, Hall SA, Lieberman R, Liem LB, O’Connell JB, Schroeder JS, Wheelan KR. Effects of cardiac resynchronization on disease progression in patients with left ventricular systolic dysfunction, an indication for an implantable cardioverter-defibrillator, and mildly symptomatic chronic heart failure. Circulation. 2004;110:2864-2868.

39. Linde C, Abraham WT, Gold MR, St John Sutton M, Ghio S, Daubert C. Randomized trial of cardiac resynchronization in mildly symptomatic heart failure patients and in asymptomatic patients with left ventricular dysfunction and previous heart failure symptoms. J Am Coll Cardiol. 2008;52:1834-1843.

40. Tang AS, Wells GA, Talajic M, Arnold MO, Sheldon R, Connolly S, Hohnloser SH, Nichol G, Birnie DH, Sapp JL, Yee R, Healey JS, Rouleau JL. Cardiac-resynchronization therapy for mild-to-moderate heart failure. The New England journal of 
medicine. 2010

41. Solomon SD, Foster E, Bourgoun M, Shah A, Viloria E, Brown MW, Hall WJ, Pfeffer MA, Moss AJ. Effect of cardiac resynchronization therapy on reverse remodeling and relation to outcome: Multicenter automatic defibrillator implantation trial: Cardiac resynchronization therapy. Circulation. 2010;122:985-992.

42. van Geldorp IE, Vernooy K, Delhaas T, Prins MH, Crijns HJ, Prinzen FW, Dijkman B. Beneficial effects of biventricular pacing in chronically RV paced patients with mild cardiomyopathy. Europace. 2010;12:223-229.

43. Rademakers LM, van Kerckhoven R, van Deursen CJ, Strik M, van Hunnik A, Kuiper M, Lampert A, Klersy C, Leyva F, Auricchio A, Maessen JG, Prinzen FW. Myocardial infarction does not preclude electrical and hemodynamic benefits of cardiac resynchronization therapy in dyssynchronous canine hearts. Circ Arrhythm Electrophysiol. 2010;3:361-368.

44. van Deursen C, van Geldorp IE, Rademakers LM, van Hunnik A, Kuiper M, Klersy C, Auricchio A, Prinzen FW. Left ventricular endocardial pacing improves resynchronization therapy in canine left bundle-branch hearts. Circ Arrbythm Electrophysiol. 2009;2:580-587.

45. Derval N, Steendijk P, Gula LJ, Deplagne A, Laborderie J, Sacher F, Knecht S, Wright M, Nault I, Ploux S, Ritter P, Bordachar P, Lafitte S, Reant P, Klein GJ, Narayan SM, Garrigue S, Hocini M, Haissaguerre M, Clementy J, Jais P. Optimizing hemodynamics in heart failure patients by systematic screening of left ventricular pacing sites: The lateral left ventricular wall and the coronary sinus are rarely the best sites. J Am Coll Cardiol. 2010;55:566-575.

46. Spragg DD, Dong J, Fetics BJ, Helm R, Marine JE, Cheng A, Henrikson CA, Kass DA, Berger RD. Optimal left ventricular endocardial pacing sites for cardiac resynchronization therapy in patients with ischemic cardiomyopathy. $J$ Am Coll Cardiol. 2010;56:774-781.

47. Ginks MR, Lambiase PD, Duckett SG, Bostock J, Chinchapatnam P, Rhode K, McPhail MJ, Simon M, Bucknall C, Carr-White G, Razavi R, Rinaldi CA. A simultaneous $\mathrm{x}$-mri and non contact mapping study of the acute hemodynamic effect of left ventricular endocardial and epicardial cardiac resynchronization therapy in humans. Circulation. Heart failure. 2011;4:170-179.

48. Strik M, Rademakers LM, van Deursen CJ, van Hunnik A, Kuiper M, Klersy C, Auricchio A, Prinzen FW. Endocardial left ventricular pacing improves cardiac resynchronization therapy in chronic asynchronous infarction and heart failure models. Circ Arrhythm Electrophysiol. 2011

49. Helm RH, Byrne M, Helm PA, Daya SK, Osman NF, Tunin R, Halperin HR, Berger RD, Kass DA, Lardo AC. Three-dimensional mapping of optimal left ventricular pacing site for cardiac resynchronization. Circulation. 2007;115:953-961.

50. Prabhu SD, Freeman GL. Effect of tachycardia heart failure on the restitution of left ventricular function in closed-chest dogs. Circulation. 1995;91:176-185.

51. Barth AS, Aiba T, Halperin V, DiSilvestre D, Chakir K, Colantuoni C, Tunin RS, Dimaano VL, Yu W, Abraham TP, Kass DA, Tomaselli GF. Cardiac resynchronization therapy corrects dyssynchrony-induced regional gene expression changes on a genomic level. Circulation. Cardiovascular genetics. 2009;2:371-378.

52. Aiba T, Hesketh GG, Barth AS, Liu T, Daya S, Chakir K, Dimaano VL, Abraham 
TP, O’Rourke B, Akar FG, Kass DA, Tomaselli GF. Electrophysiological consequences of dyssynchronous heart failure and its restoration by resynchronization therapy. Circulation. 2009;119:1220-1230.

53. Chakir K, Daya SK, Aiba T, Tunin RS, Dimaano VL, Abraham TP, JaquesRobinson KM, Lai EW, Pacak K, Zhu WZ, Xiao RP, Tomaselli GF, Kass DA. Mechanisms of enhanced beta-adrenergic reserve from cardiac resynchronization therapy. Circulation. 2009;119:1231-1240.

54. Verheule S, Wilson E, Everett Tt, Shanbhag S, Golden C, Olgin J. Alterations in atrial electrophysiology and tissue structure in a canine model of chronic atrial dilatation due to mitral regurgitation. Circulation. 2003;107:2615-2622.

55. Hori Y, Tsubaki M, Katou A, Ono Y, Yonezawa T, Li X, Higuchi SI. Evaluation of nt-pro bnp and ct-anp as markers of concentric hypertrophy in dogs with a model of compensated aortic stenosis. J Vet Intern Med. 2008;22:1118-1123.

56. Mathieu M, El Oumeiri B, Touihri K, Hadad I, Mahmoudabady M, Thoma P, Metens T, Bartunek J, Heyndrickx GR, Brimioulle S, Naeije R, Mc Entee K. Ventricular-arterial uncoupling in heart failure with preserved ejection fraction after myocardial infarction in dogs - invasive versus echocardiographic evaluation. BMC Cardiovasc Disord. 2010;10:32.

57. Urabe Y, Mann DL, Kent RL, Nakano K, Tomanek RJ, Carabello BA, Cooper Gt. Cellular and ventricular contractile dysfunction in experimental canine mitral regurgitation. Circ Res. 1992;70:131-147. 
Animal Models of Dyssynchrony 

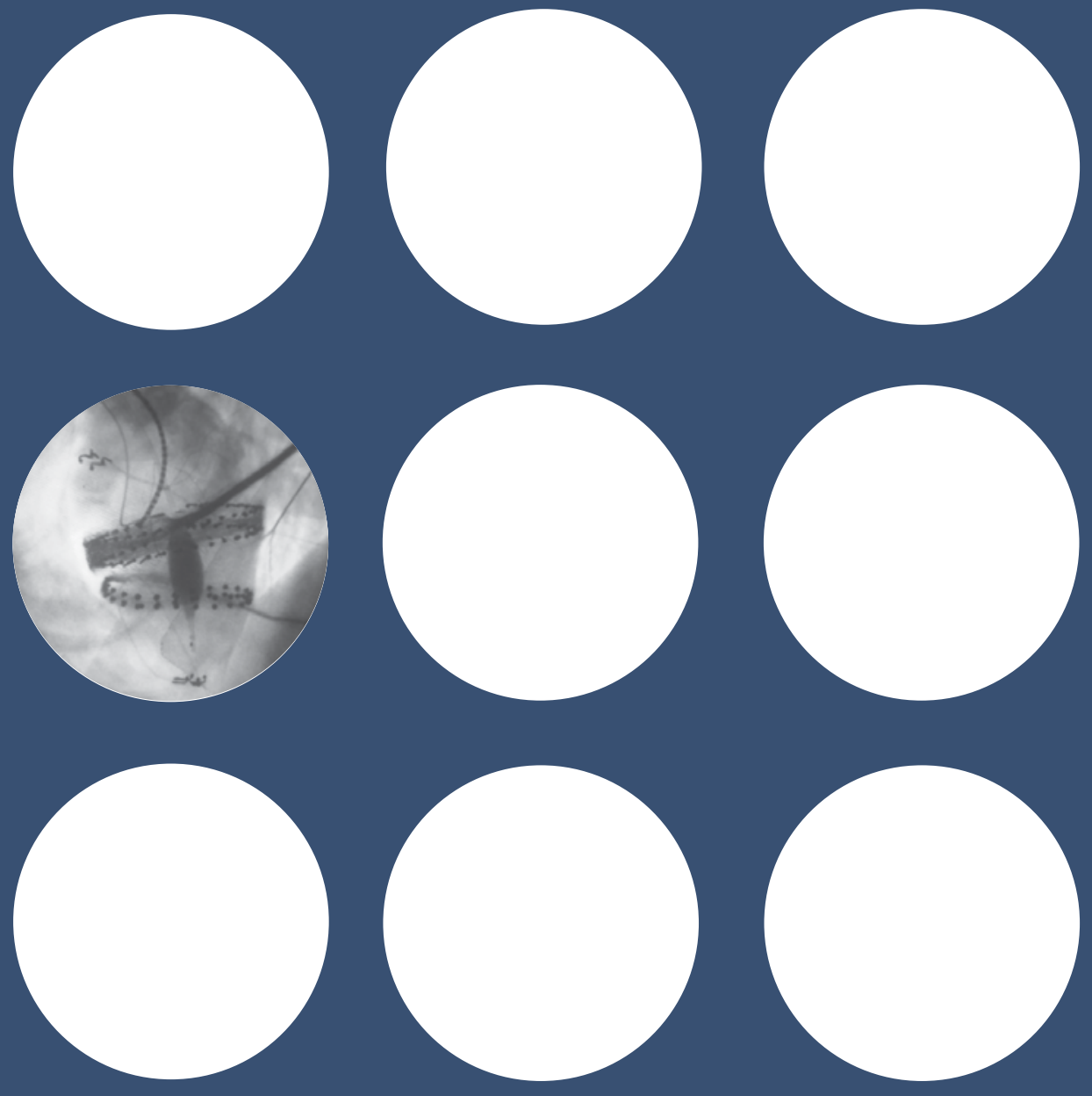

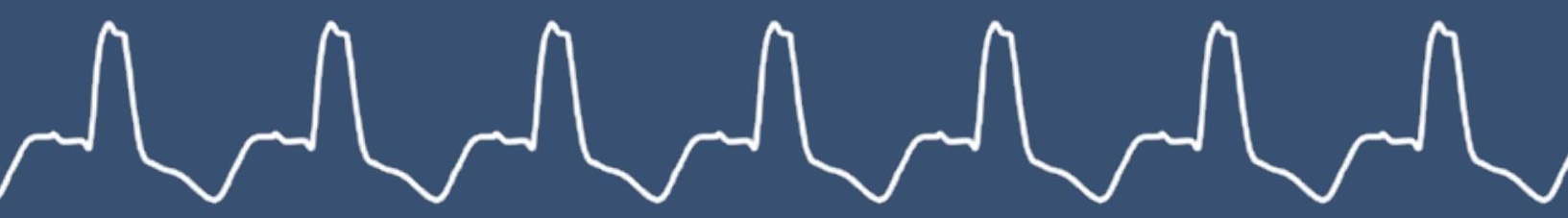




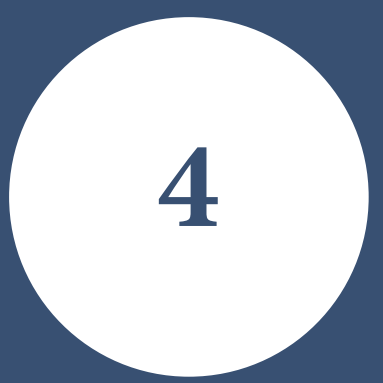

\section{Endocardial Mapping in the Dyssynchronous Canine Left Ventricle: Comparison of Non-Contact and Contact Electrograms}

Published in part as supplemental material to:

Strik M, van Deursen CJ, van Middendorp LB, van Hunnik A, Kuiper M, Auricchio A, Prinzen FW.

Transseptal Conduction as an Important Determinant for Cardiac Resynchronization Therapy, as Revealed by Extensive Electrical Mapping in the Dyssynchronous Canine Heart

Circ Arrhythm Electrophysiol. 2013 Aug 1;6(4):682-9

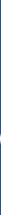


Chapter 4

\section{Abstract}

\section{Introduction}

Cardiac Resynchronization Therapy (CRT) through biventricular (BiV) or left ventricular (LV) pacing is an important tool in managing selected patients with heart failure (HF) and left bundle branch block (LBBB). In order to investigate the electrical activation of the LV endocardium during conventional and novel forms of CRT, non-contact (NC) mapping might prove to be a viable tool. We investigated the accuracy of $\mathrm{NC}$ mapping by comparing it with direct contact (C) mapping in dyssynchronous canine hearts.

\section{Methods}

In anesthetized dogs with acute LBBB ( $\mathrm{n}=5)$ or chronic LBBB with tachypacinginduced $\mathrm{HF}(\mathrm{n}=5), \mathrm{AAI}$ and DDD ( $\mathrm{LV}$ and $\mathrm{BiV}$ ) pacing was performed using pacing electrodes in the right atrium, right ventricular apex and at 8 epicardial LV locations. Signals from 8 endocardial C electrodes and from matching NC electrodes (EnSite ${ }^{\circledR}$ ) were recorded simultaneously and stored. NC mapping was validated by comparing $\mathrm{NC}$ with $\mathrm{C}$ electrograms using depolarization time differences and morphology cross correlation of ventricular deflections.

\section{Results}

1766 paired $\mathrm{NC}$ and $\mathrm{C}$ electrodes were tested showing a good correlation between morphology of $\mathrm{C}$ and $\mathrm{NC}$ signals $(0.87 \pm 0.12)$ and a good match of calculated depolarization times $(9.66 \pm 7.23 \mathrm{~ms}$ with a bias of $-2.77 \mathrm{~ms})$. There was no significant difference in morphology cross-correlation or depolarization time difference between LBBB and LBBB+HF dogs, pacing modes, LV pacing sites or location of electrode pairs.

\section{Conclusions}

Non-contact mapping adequately registers endocardial potentials and can be used to investigate asynchronous activation and resynchronization. 


\section{Introduction}

Under physiological conditions, rhythmical excitation of the left ventricle (LV) occurs through activation of the rapidly conducting left bundle branch. ${ }^{1}$ Left bundle branch block (LBBB) is a conduction disease where LV depolarization is greatly disturbed as the onset and pattern of electrical activation are altered. ${ }^{2}$ One or more activation wave fronts initiate from the right bundle branch in the RV and slowly propagate through the interventricular septum towards the LV. Cardiac Resynchronization Therapy (CRT) attempts to partly restore electrical activation by electrically stimulating both ventricles simultaneously. In selected heart failure patients, CRT leads to improved symptoms and decreased mortality. ${ }^{3,4}$ Unfortunately, CRT results in heterogeneous response and up to a third of treated patients do not improve. Improved insight in electrical activation of the left ventricular during electrical asynchrony and resynchronization is required to increase CRT efficacy. The EnSite ${ }^{\circledR}$ system is an invasive non-contact mapping system which allows the evaluation of endocardial electrical activation of a single heart chamber. ${ }^{5-7}$ Since multiple potentials throughout the LV can be measured in a single heartbeat and stored for offline analysis, this mapping system enables comparison of multiple pacing modalities.

In the present study, we investigated the accuracy of non-contact mapping to adequately detect endocardial potentials. Therefore we performed simultaneous non-contact and contact mapping studies in the canine LBBB model during CRT.

\section{Methods}

Animal handling was performed according to the Dutch Law on Animal Experimentation and the European Directive for the Protection of Vertebrate Animals Used for Experimental and Other Scientific Purposes. The protocol was approved by the Animal Experimental Committee of Maastricht University.

The experiments were performed on 10 adult mongrel dogs weighing 28-31 kg of either sex and unknown age. Animals were induced by intravenous pentothal administration and anesthetized by continuous infusion of midazolam $(0.25 \mathrm{mg} /$ $\mathrm{kg} / \mathrm{h}$ iv) and sufentanyl ( $3 \mu \mathrm{g} / \mathrm{kg} / \mathrm{h}$ iv). During sterile surgery, LBBB was induced by radiofrequency ablation. ${ }^{8}$ Two distinct groups were created: dogs with acute left bundle-branch block (LBBB, $n=5$ ) and dogs with chronic LBBB and heart failure $(\mathrm{LBBB}+\mathrm{HF}, \mathrm{n}=5)$. Heart failure was induced by four weeks of tachypacing and monitored by weekly echocardiography.? 


\section{Mapping protocol}

Non-contact mapping was performed using a multi-electrode array (MEA) which consists of a network of 64 polyimide-insulated wires with laser-etched electrodes mounted on a 9 French catheter with inflatable balloon. Figure 1 shows a MEA in a deflated (left panel) and inflated (center panel) state; a single electrode is also shown (far right panel).
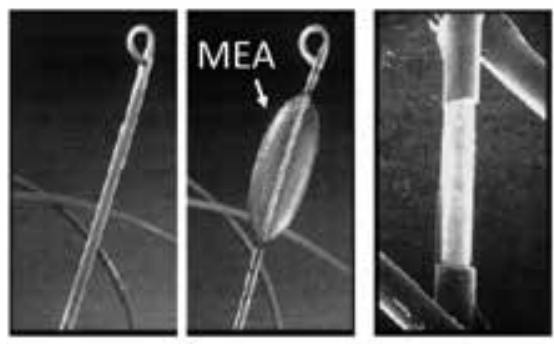

Figure 1. Distal end of the array catheter. Left and middle, catheter before and after balloon inflation. Right: magnified view of 1 of the 64 electrodes on the array surface.

The MEA was deployed in the LV through a retro-aortic approach. A standard electropotential (EP) catheter was inserted into the heart chamber under fluoroscopy and was moved throughout the chamber whilst the ring electrodes of the MEA localized its distal tip during diastole. Intracavitary locations were disposed and the most distant locations of the acquired positions were collected in order to construct a geometric model of the endocardium, (Figure 2, left panel). The non-contact mapping combined the smoothed endocardial contour (Figure 2, center panel) and the far-field potentials as measured on the MEA to calculate virtual electrograms as if they were derived from the endocardium. Subsequently, 2048 virtual electrograms measured by the MEA were distributed and 'drawn' on the superimposed grid (Figure 2, right panel).

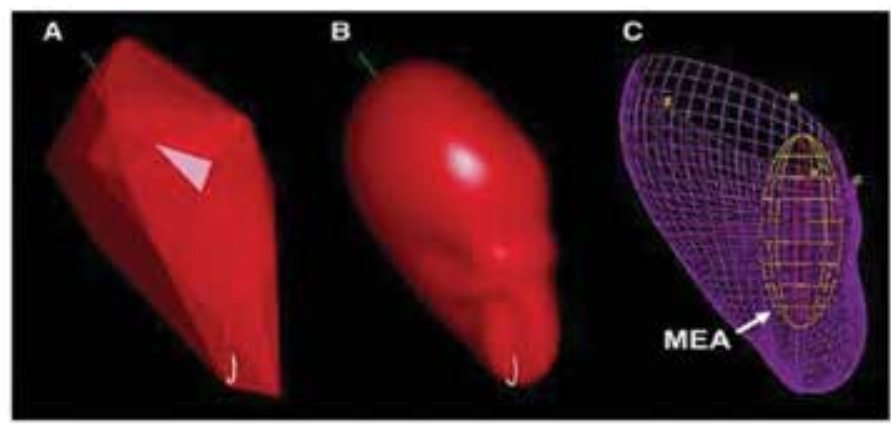

Figure 2: The virtual endocardium is created by tracing the endocardial surface with a conventional catheter while the system tracks its position. The geometry has been partially defined (A); then completed and smoothed (B); and finally converted into an anatomically contoured, wire-frame three-dimensional model (C). 
To enable comparison to direct contact mapping, custom-made plunge electrodes were inserted through the LV myocardium at the apex, lateral apex and at anterior, lateral and posterior sites at the base and mid level. A schematic overview of the MEA and contact electrodes is shown in Figure 3. The location of these endocardial electrodes were localized by the MEA and matched with non-contact electrodes. For epicardial measurements, two epicardial multi-electrode bands were placed below the base and around the equator of the left ventricle. The bands consisted of over one hundred epicardial contact electrodes. Eight epicardial electrodes across the endocardial plunge electrodes were used to stimulate the LV. Two catheter manometers were placed into the LV and RV cavities to obtain LV and RV pressure measurements. Electrocardiograms were derived from the limb leads.

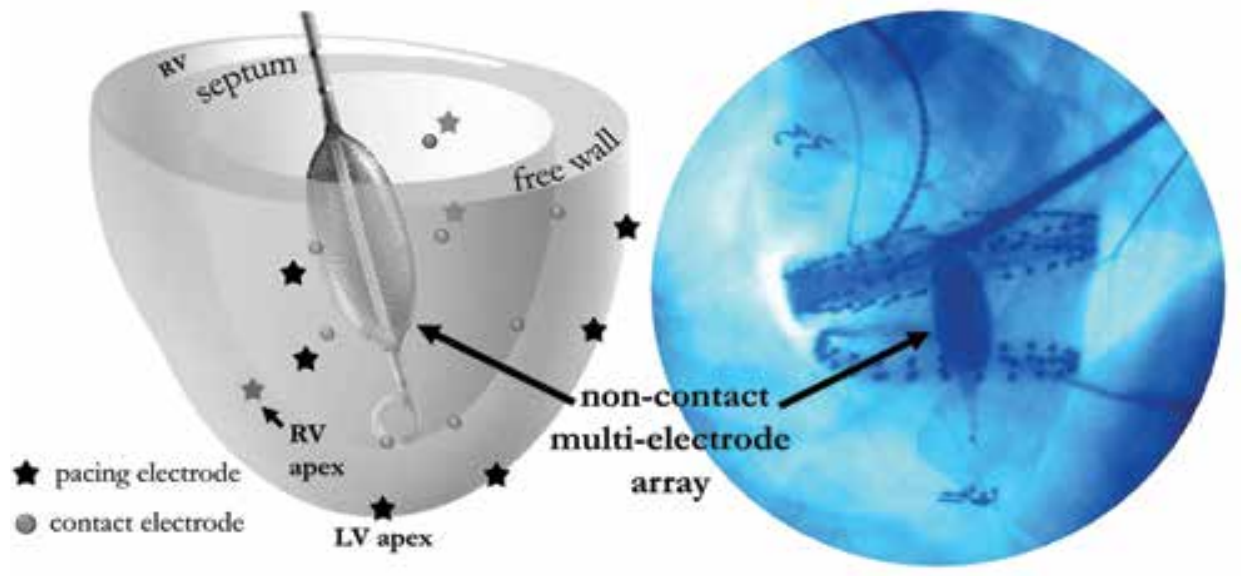

Figure 3: Schematic (left panel) and fluoroscopic (right panel) set-up of pacing sites, non-contact multi-electrode array and contact electrodes.

\section{Pacing protocol}

Baseline (atrial pacing) measurements were followed by simultaneous biventricular pacing (RV apical pacing) and single-site LV pacing. The LV was paced at the epicardium at anterior, lateral and posterior regions of basal and mid LV, apicolateral and apical. The atrioventricular interval was programmed to guarantee complete capture of ventricular activation from the pacing electrodes and atrial pacing occurred at a rate $\sim 10$ beats higher than intrinsic heart rate.

\section{Data analysis}

For each measurement, all non-contact and contact endocardial electrograms were exported. As the EnSite ${ }^{\circledR}$ sampling rate equaled $1200 \mathrm{~Hz}$; every data point 
represented 0.833 milliseconds. Using a custom algorithm (Matlab R2007a), the virtual electrograms were converted to the same sampling rate as the epicardial mapping system $(1000 \mathrm{~Hz})$. The electrograms were imported into standard analyzing software (Microsoft Excel 2007) and the activation time was determined by calculating the point of maximum negative deflection $(\max -\mathrm{dV} / \mathrm{dt})$, indicating local depolarization. For all cardiac mapping electrodes, depolarization times were calculated as the time difference between onset of the $\mathrm{Q}$ wave (during baseline) or ventricular pacing artifact (during pacing) and the time of steepest negative deflection in the electrogram.

The validation study compared endocardial contact and matched non-contact electrodes and consisted of two parts: 1) calculating the depolarization timing difference and 2) cross correlating the electrogram morphologies of ventricular deflections. Depolarization time difference was expressed by average absolute difference \pm S.D. and by the method suggested by Bland and Altman: non-absolute mean difference as 'bias' and upper and lower limits of agreement defined as 'bias \pm 1.96 SD'. For the morphological validation, a 120 millisecond timeframe was selected including the ventricular deflection ("QRS" complex) from the contact and non-contact electrogram. A cross-correlation was then performed by shifting signals in time to assure maximum QRS morphology matching.

\section{Results}

\section{Validating non-contact mapping with contact mapping}

Out of the 1920 possible comparisons between contact and non-contact electrodes (10 dogs x 3 pacing modes x $8 \mathrm{LV}$ epicardial pacing sites x 8 electrode pairs), depolarization time difference was calculated for 1766 electrode pairs $(92 \%)$. Unsuccessful data acquisition was related to problems with contact mapping: unacceptable quality of electrogram or non-endocardial location of plunge electrode at post mortal evaluation.

For all experiments, mean absolute depolarization time difference was 9.66 \pm 7.23 ms. Figure 4 shows the Bland-Altman plot with a bias of -2.77 ms with upper limit of agreement ( +1.96 S.D.) of $+20.3 \mathrm{~ms}$ and lower limit of agreement of $-25.8 \mathrm{~ms}$ (-1.96 S.D.). The negative bias signified slight earlier estimation of depolarization times with non-contact mapping as compared with contact mapping. There was no significant difference in activation time difference between $\mathrm{LBBB}$ or $\mathrm{LBBB}+\mathrm{HF}$ 
dogs, pacing modes, LV pacing sites or electrode pair location. For all experiments, morphologic cross correlation between contact and non-contact electrograms was $0.87 \pm 0.12$. Figure 5 shows typical examples of morphology cross correlation between ventricular deflections of contact electrodes (left panels) and non-contact electrodes (right panels). Also for morphologic cross correlation, there was no significant difference between the models, pacing modes, LV pacing sites or location of electrode pairs.

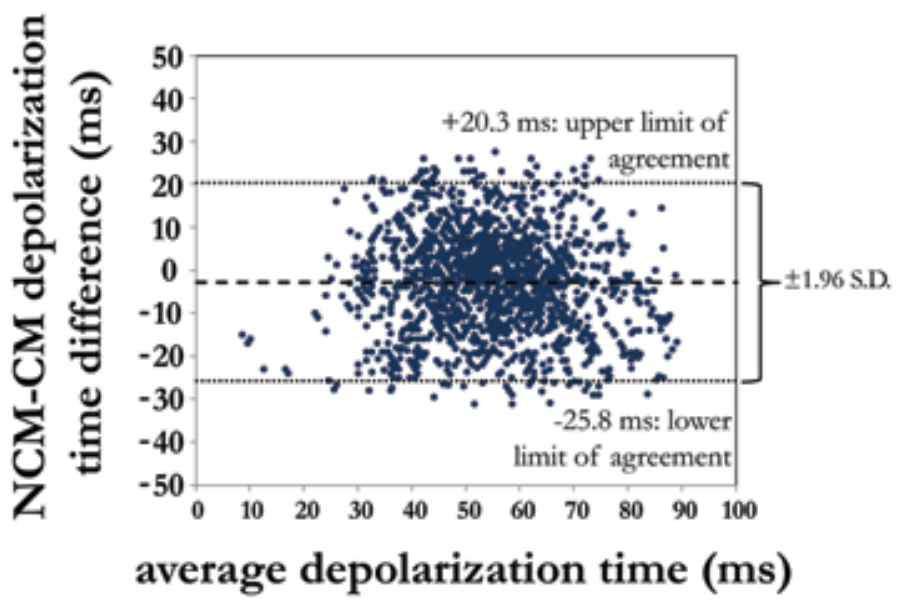

Figure 4. The difference between depolarization times as determined by non-contact and contact is displayed against the average of measurements. NCM: non-contact mapping (EnSite $\left.{ }^{\circledR}\right)$; CM: contact mapping.

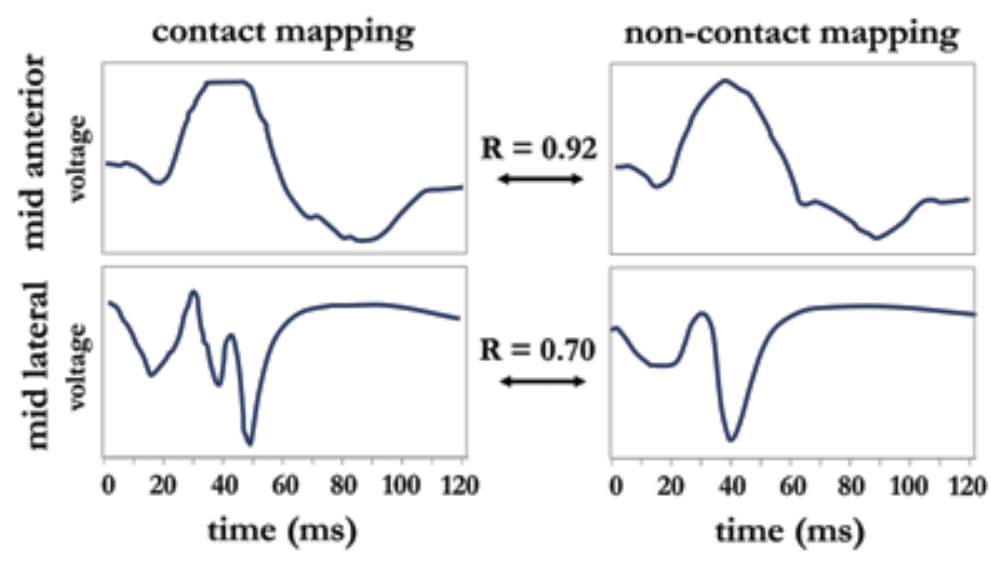

Figure 5. Examples of QRS morphology cross correlation between contact mapping and non-contact mapping. Cross correlation is higher for the mid anterior electrograms (top panels, $R=0.98$ ) than for the mid lateral electrograms (bottom panels, $R=0.70$ ), but the characteristic shapes are comparable between both examples. 


\section{Lines of conduction block}

Endocardial activation time maps reveal lines of functional block similar to those in many LBBB patients (Figure O). These lines of block were seen in non-failing and failing dog hearts during baseline atrial pacing (LBBB) and were typically located over the anterior and posterior wall (left panel). During LV pacing at various sites, these lines of block shifted in location, indicating a functional nature. Even though LV apical pacing resulted in the least amount of conduction block, there was no clear relation between amount of conduction block and LV pacing site or systolic parameters such as $\mathrm{LVd} P / \mathrm{d} t_{\max }$.

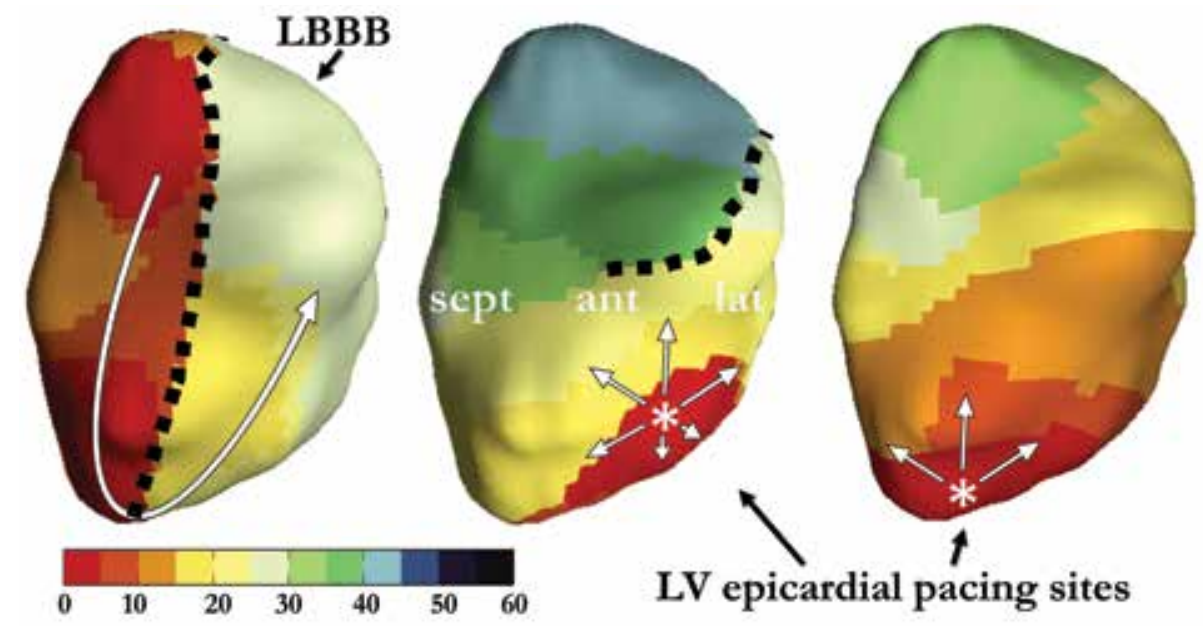

Figure 6: LV endocardial electrical activation maps as derived using non-contact mapping (EnSite $\left.{ }^{\circledR}\right)$ in canine LBBB hearts. The left panel shows an example of a line of conduction block during LBBB where the electrical activation follows a $\mathrm{U}$ shaped pattern around the apex of the LV. When the depolarization pattern changes due to LV epicardial pacing, the lines of conduction block change or disappear.

\section{Discussion}

The depolarization time difference (both absolute, bias and limits of agreement) and morphological cross-correlation results are indicative of good agreement between the methods and suggest that non-contact mapping adequately registers endocardial activation. Morphologic cross correlation between contact and non-contact electrograms from the current study matched well with earlier human validation studies $(0.88 \pm 0.15$ and $0.83 \pm 0.16) .{ }^{1,2}$ In the only validation study performed in canine hearts, morphology cross correlation was $0.97 .^{3}$ This result is higher than current and older validation studies and might be explained through the limited 
variation in LV pacing regions used in the study (only anterior and anterolateral regions). Schilling et al calculated a non-absolute average timing difference of $-1.94 \pm 7.12 \mathrm{~ms}$ for distances at $<34 \mathrm{~mm}$ (from electrode to MEA), $-14.16 \pm 19.29$ $\mathrm{ms}$ at $>34 \mathrm{~mm}$ and for nonequatorial points electrogram timing difference was $-8.97 \pm 15.75 \mathrm{~ms} .{ }^{1}$ Even though our results were not grouped as according to the distance to the MEA, overall bias was comparable and also showed slightly earlier estimation of depolarization of non-contact mapping.
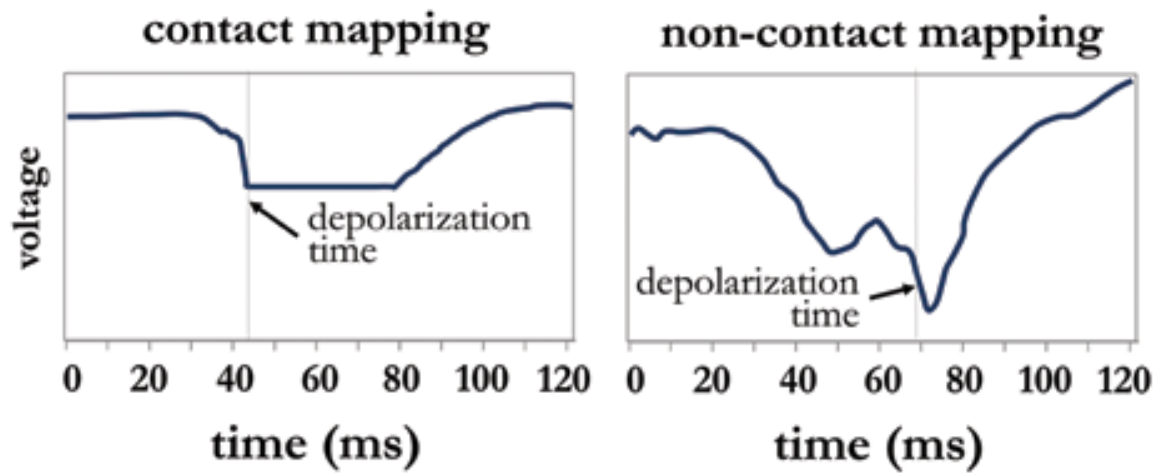

Figure 7. "QRS" complexes of corresponding contact and non-contact electrodes are shown with depolarization times (dotted lines). A difference of approximately $30 \mathrm{~ms}$ is seen between mapping systems due to voltage clipping.

Thiagalingam et al performed a validation study comparing thousands of electrograms in paced ovine left ventricles and found a mean absolute activation timing difference of $4.3 \pm 3.4 \mathrm{~ms}$ which shows higher accuracy compared with the current experiment. ${ }^{2}$ This may partly be explained by their use of 50-electrode grids which allows more detailed defining of the LV endocardial contour. In addition, a portion of contact electrograms in our experiment were subjected to voltage clipping. This introduced possible error in the allocation of depolarization time in the case of possible fractionated electrograms (underestimation). Since activation times are chosen at the point of maximal negative deflection, data clipping leads to false depolarization time selection, most often at a time point before clipping. An example is shown in Figure 7, where clipping resulted in a depolarization time difference of 25 milliseconds.

\section{Lines of conduction block}

Lines of conduction block are seen in most LBBB patients as shown by endocardial $\left(\right.$ EnSite $\left.^{\circledR}\right)$ and epicardial (ECGi) non-contact mapping studies (see examples in Chapter 2). ${ }^{5,} 10$ The electrical wave front originating from the RV propagates over 
the LV apex in a "U-shaped" manner around anterior and posterior lines of block. Our mapping study also revealed lines of functional block, similar to those in many LBBB patients. In these otherwise healthy LBBB hearts the observed lines of block are modified by LV pacing at different sites. The implications of these lines of block have been investigated in a small observational study where non-contact mapping was performed in 23 CRT candidates. ${ }^{11}$ Twelve of the 18 patients who had lines of conduction block before implantation were volumetric CRT responders at 3 months as opposed to 1 of the 8 patients who had homogeneous endocardial conduction $(p=0.01)$. This study confirmed that the benefit of CRT is more dependent on specific LV activation patterns rather than on total LV activation time, which could explain why LVATmax beyond $125 \mathrm{~ms}$, and in some studies QRS duration, are poor individual predictors of response. ${ }^{12,13}$ Combining the observations in the canine model with the aforementioned patient studies suggests that at least a sizeable number of CRT candidates with LBBB has a proximal lesion.

\section{Limitations}

The design of this study meant that the comparison of non-contact electrograms with contact electrograms depended on both the reconstruction algorithm and the accuracy of the catheter-location system. This study is limited by its inability to determine whether errors seen were due to the reconstruction process or the location system. However, although previous in vitro data have supported the accuracy of the locator system and construction of the virtual endocardium, no study has yet compared the virtual endocardium with the true anatomy of the cardiac chamber. As the non-contact mapping system integrates the locator and electrogram reconstruction technologies, this study addresses the performance of the system as a whole.

\section{Conclusion}

Non-contact mapping adequately registers endocardial potentials and can be used to investigate asynchronous activation and resynchronization.

\section{Funding sources}

This research was performed within the framework of CTMM, the Center for Translational Molecular Medicine (www.ctmm.nl), project COHFAR (grant 01C-203), and supported by the Dutch Heart Foundation. 


\section{References}

1. Durrer D, van Dam RT, Freud GE, Janse MJ, Meijler FL, Arzbaecher RC. Total excitation of the isolated human heart. Circulation. 1970;41:899-912

2. Vernooy K, Verbeek XA, Peschar M, Crijns HJ, Arts T, Cornelussen RN, Prinzen FW. Left bundle branch block induces ventricular remodelling and functional septal hypoperfusion. Eur Heart J. 2005;26:91-98

3. Bristow MR, Saxon LA, Boehmer J, Krueger S, Kass DA, De Marco T, Carson P, DiCarlo L, DeMets D, White BG, DeVries DW, Feldman AM. Cardiacresynchronization therapy with or without an implantable defibrillator in advanced chronic heart failure. The New England journal of medicine. 2004;350:2140-2150

4. Cleland JG, Daubert JC, Erdmann E, Freemantle N, Gras D, Kappenberger L, Tavazzi L. The effect of cardiac resynchronization on morbidity and mortality in heart failure. The New England journal of medicine. 2005;352:1539-1549

5. Auricchio A, Fantoni C, Regoli F, Carbucicchio C, Goette A, Geller C, Kloss M, Klein $\mathrm{H}$. Characterization of left ventricular activation in patients with heart failure and left bundle-branch block. Circulation. 2004;109:1133-1139

6. Thiagalingam A, Wallace EM, Boyd AC, Eipper VE, Campbell CR, Byth K, Ross DL, Kovoor P. Noncontact mapping of the left ventricle: Insights from validation with transmural contact mapping. Pacing Clin Electrophysiol. 2004;27:570-578

7. Schilling RJ, Peters NS, Davies DW. Simultaneous endocardial mapping in the human left ventricle using a noncontact catheter: Comparison of contact and reconstructed electrograms during sinus rhythm. Circulation. 1998;98:887-898

8. Verbeek XA, Vernooy K, Peschar M, Van Der Nagel T, Van Hunnik A, Prinzen FW. Quantification of interventricular asynchrony during $\mathrm{lbbb}$ and ventricular pacing. Am J Physiol Heart Circ Physiol. 2002;283:H1370-1378

9. Strik M, Rademakers LM, van Deursen CJ, van Hunnik A, Kuiper M, Klersy C, Auricchio A, Prinzen FW. Endocardial left ventricular pacing improves cardiac resynchronization therapy in chronic asynchronous infarction and heart failure models. Circ Arrbythm Electrophysiol. 2012;5:191-200

10. Jia P, Ramanathan C, Ghanem RN, Ryu K, Varma N, Rudy Y. Electrocardiographic imaging of cardiac resynchronization therapy in heart failure: Observation of variable electrophysiologic responses. Heart Rhythm. 2006;3:296-310

11. Fung JW, Chan JY, Yip GW, Chan HC, Chan WW, Zhang Q, Yu CM. Effect of left ventricular endocardial activation pattern on echocardiographic and clinical response to cardiac resynchronization therapy. Heart. 2007;93:432-437

12. Mollema SA, Bleeker GB, van der Wall EE, Schalij MJ, Bax JJ. Usefulness of qrs duration to predict response to cardiac resynchronization therapy in patients with end-stage heart failure. Am J Cardiol. 2007;100:1665-1670

13. Sweeney MO, van Bommel RJ, Schalij MJ, Borleffs CJ, Hellkamp AS, Bax JJ. Analysis of ventricular activation using surface electrocardiography to predict left ventricular reverse volumetric remodeling during cardiac resynchronization therapy. Circulation. 2010;121:626-634 

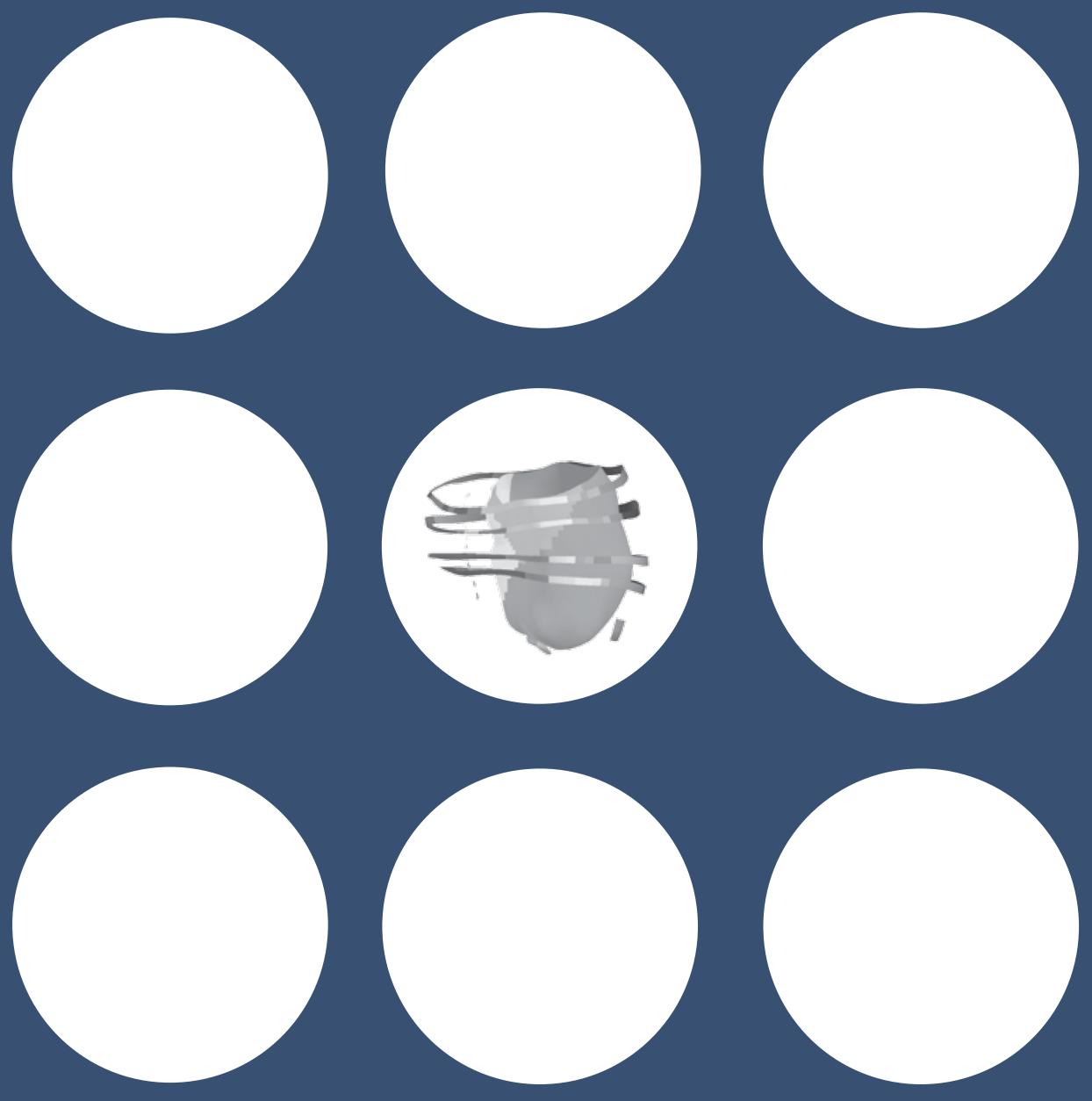

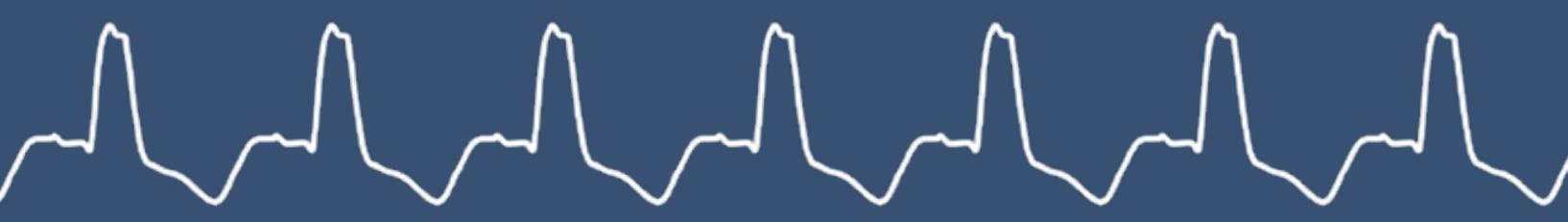




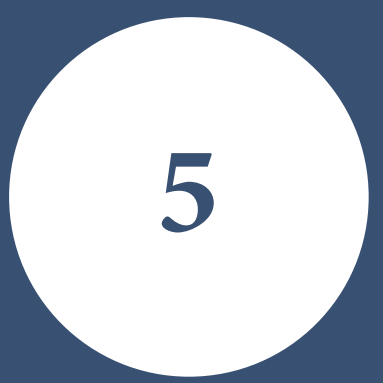

\section{Transseptal Conduction as an Important Determinant for Cardiac Resynchronization Therapy, as Revealed by Extensive Electrical Mapping in the Dyssynchronous Canine Heart}

Strik M, van Deursen CJ, van Middendorp LB, van Hunnik A, Kuiper M, Auricchio A, Prinzen FW.

Circ Arrhythm Electrophysiol. 2013 Aug 1;6(4):682-9

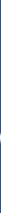




\section{Abstract}

\section{Background}

Simple conceptual ideas about Cardiac Resynchronization Therapy (CRT) assume that biventricular $(\mathrm{BiV})$ pacing results in collision of right (RV) and left ventricular (LV) pacing derived wave fronts. However, this concept is contradicted by the minor reduction in QRS duration usually observed. We investigated the electrical mechanisms of CRT by performing detailed electrical mapping during extensive pacing protocols in dyssynchronous canine hearts.

\section{Methods and Results}

Studies were performed in anesthetized dogs with acute left bundle branch block (LBBB, $n=10)$ and chronic LBBB with tachypacing-induced heart failure $(\mathrm{LBBB}+\mathrm{HF}, \mathrm{n}=6)$. Activation times (AT) were measured using LV endocardial contact and non-contact mapping and epicardial contact mapping. BiV-pacing reduced QRS duration by $21 \pm 10 \%$ in LBBB but only by $5 \pm 12 \%$ in $\mathrm{LBBB}+\mathrm{HF}$ hearts. Transseptal impulse conduction was significantly slower in LBBB $+\mathrm{HF}$ than in LBBB hearts (67 \pm 9 vs $44 \pm 16 \mathrm{~ms}$, respectively) and in both groups significantly slower than transmural LV conduction ( $\approx 30 \mathrm{~ms})$. In both groups QRS duration and vector and the epicardial AT vector amplitude and angle were significantly different between LV- and BiV-pacing, while the endocardial AT vector was similar. During variation of AV-delay during LV-pacing and VV-delay during BiV-pacing, the optimal hemodynamic effect was achieved when epicardial AT and QRS vectors were minimal and endocardial AT vector indicated LV pre-excitation.

\section{Conclusion}

Due to slow transseptal conduction the LV electrical activation sequence is similar in LV- and BiV-pacing, especially in failing hearts. Optimal hemodynamic CRT response coincides with minimal epicardial asynchrony and QRS vector and LV pre-excitation. 


\section{Introduction}

In heart failure patients with abnormal ventricular conduction, Cardiac Resynchronization Therapy (CRT) improves left ventricular (LV) systolic pump function, reverses adverse LV remodeling, and improves clinical symptoms and outcome. ${ }^{1,2}$ Beneficiary effects of CRT are generally considered to act through decreasing dispersion of LV activation by fusion/collision of activation wave fronts migrating from the LV and right ventricular (RV) pacing electrodes. This at first sight logical concept is, however, violated by multiple observations. Firstly, if during left bundle branch block (LBBB) LV activation occurs from the septum to the free wall and during biventricular $(\mathrm{BiV})$ pacing from both sides to each other, one would expect a decrease in electrical activation of approximately $50 \%$. However, BiVpacing reduces QRS-duration by less than 20\%. ${ }^{3}$ Secondly, single-site LV-pacing at a short atrioventricular (AV) interval is known to increase QRS-duration but provides a similar acute and chronic effect to conventional biventricular pacing. ${ }^{4}$ Also, multiple clinical trials failed to show a different effect on cardiac function, mortality and hospitalization between single-site LV-pacing and BiV-pacing. ${ }^{2,5,6}$

These data indicate that there is still limited understanding of the mechanism of CRT. One of the complicating factors in understanding CRT is the conduction velocity in the various parts of the ventricular wall, which is assumed to be uniform in the abovementioned concept. In a large group of patients, activation times across the septum ranged from almost zero to more than 100 milliseconds. ${ }^{7}$ Septal conduction is difficult to measure and its role on CRT is unknown.

The aim of the present study was to investigate the electrophysiological mechanisms underlying the hemodynamic effects of CRT in canine hearts with LBBB, all or not in combination with heart failure. To this purpose we related the hemodynamic effects of CRT with detailed electrical activation measurements during various pacing modes.

\section{Methods}

Animal handling was performed according to the Dutch Law on Animal Experimentation and the European Directive for the Protection of Vertebrate Animals used for Experimental and Other Scientific Purposes (86/609/EU). The protocol was approved by the Experimental Animal Committee of Maastricht University. 


\section{Experimental setup and pacing protocol}

The experiments were performed on 16 adult mongrel dogs of either sex and unknown age, with a weight of $29 \pm 3 \mathrm{~kg}$. Animals were induced by intravenous pentothal administration and anesthetized by continuous infusion of midazolam $(0.25 \mathrm{mg} / \mathrm{kg} / \mathrm{h})$ and sufentanyl $(3 \mu \mathrm{g} / \mathrm{kg} / \mathrm{h})$. During sterile surgery, LBBB was induced by radiofrequency ablation. ${ }^{8}$

Two distinct groups were created: dogs with acute left bundle-branch block (LBBB, $\mathrm{n}=10)$ and dogs with chronic LBBB and heart failure $(\mathrm{LBBB}+\mathrm{HF}, \mathrm{n}=6)$. Heart failure was induced by four weeks of tachypacing (right atrium and RV apex) and monitored by weekly echocardiography. ${ }^{9}$ Since the LBBB+HF model was regarded as the closest equivalent to CRT patients, $\mathrm{AV}$ and VV optimization was also performed in this group.

A pacing lead was transvenously inserted into the right atrium. After thoracotomy, over one hundred contact electrodes were placed around the heart and through the myocardial wall (see Figure 1 for experimental set-up). ${ }^{9-12}$ An octapolar electrodecatheter (Daig Livewire TC, Minnetonka, MN) was used for septal mapping and RV apical pacing. Non-contact mapping of the LV endocardium (EnSite $3000^{\circledR}$ ) was performed in six LBBB dogs and six LBBB+HF dogs. Non-contact mapping analysis and validation is described chapter 4 . Examples of matched non-contact and contact electrograms used for validation are shown in Figure 1. One 7F cathetertip manometer (CD-Leycom Zoetermeer, the Netherlands) was used to measure $\mathrm{RV}$ pressure whereas a $7 \mathrm{~F}$ combined catheter-tip manometer and conductance catheter was used to measure LV pressure and volume. Mechanical interventricular dyssynchrony (MIVD) was determined as the time delay between normalized upslopes of simultaneously recorded LV and RV pressure curves. ${ }^{8}$

Recordings of baseline atrial pacing (AAI) and $\mathrm{LV} / \mathrm{BiV}$ pacing (DDD, at an AVinterval ensuring full capture) included two respiratory cycles, was performed at a rate approximately 10 beats per minute above the intrinsic sinoatrial rate and was commenced after at least twenty beats to allow for steady state measurements. To investigate the behavior of electrical propagation wave fronts more extensively, the LV was also stimulated at anterior and posterior regions. CRT optimization was performed in the LBBB+HF group through LV lateral wall pacing at increasing AV-intervals $(30-250 \mathrm{~ms})$. Sequential biventricular pacing was then performed at the optimal AV-interval from $90 \mathrm{~ms} L V$ pre-excitation to $90 \mathrm{~ms}$ RV pre-excitation. 

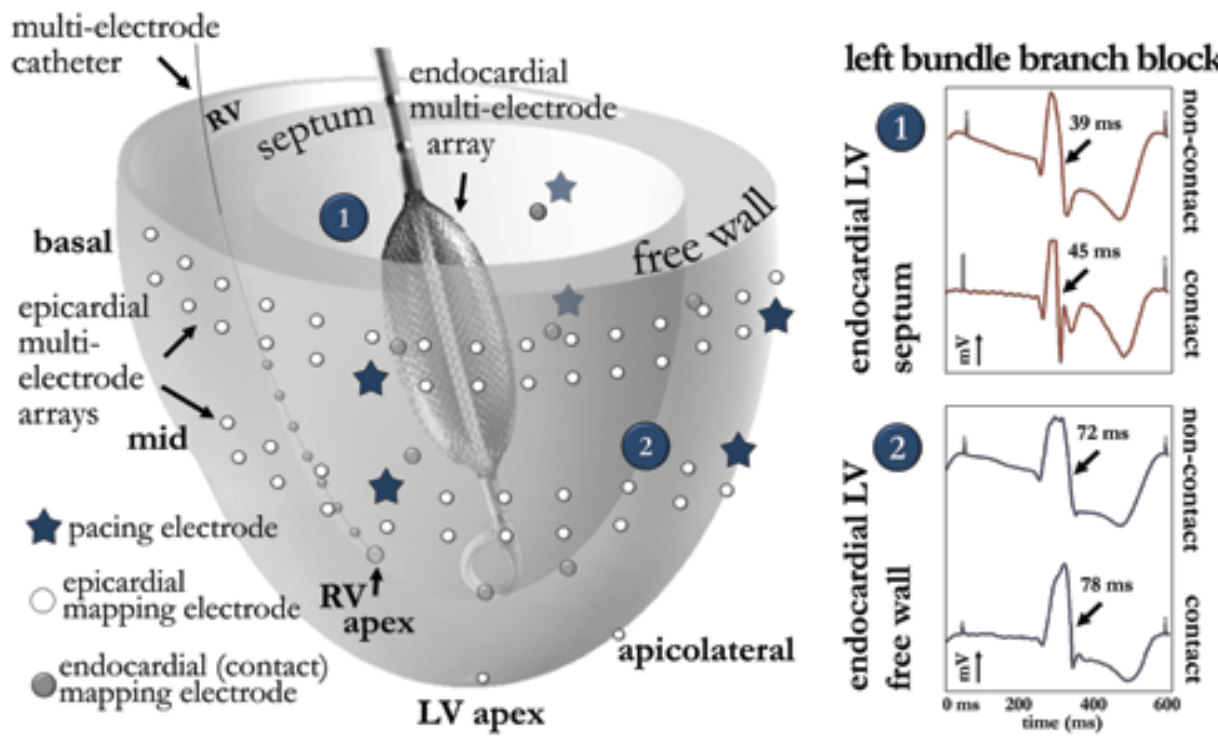

Figure 1. Schematic experimental set-up (left panel) with pacing electrodes (stars), epicardial mapping electrodes around the ventricles (white dots), endocardial plunge electrodes (grey dots) and the endocardial multi-electrode array. Right panel shows matched non-contact and contact electrogram examples with local depolarization times at the LV septum (1) and LV free wall (2) during left bundle branch block in a non-failing heart.

\section{Measurements of vectorcardiography, electrical activation and} hemodynamics

The surface ECG was used to calculate QRS duration and maximal QRS-vector amplitude $\left(\mathrm{VA}_{\mathrm{QRS}}\right) \cdot{ }^{13}$ The value halfway of $\mathrm{VA}_{\mathrm{QRS}}$ determined from LBBB and during LV-pacing at a short AV-interval has been shown to predict maximal contractility response during AV/VV optimization. ${ }^{13}$ For cardiac mapping electrodes, local depolarization times were calculated as the time difference between onset of the Q-wave (during baseline) or ventricular pacing artifact and the time of steepest negative deflection in the electrogram. Using custom MATLAB software (MathWorks, Natick, MA), the depolarization times could then be plotted on corresponding anatomical locations and on matched interpolated models. ${ }^{12}$ Activation times (AT) were defined as the maximum depolarization time difference and were calculated for all electrodes and separately for the endocardial LV (all non-contact electrodes, all endocardial contact electrodes and septum-to-free wall contact electrodes). In addition, transseptal conduction was calculated as earliest RV septal depolarization time during LV septal pacing. 
In addition to calculating activation times, AT vectors were calculated in the shortaxis direction to express temporal and spatial asynchrony in more detail. ${ }^{14}$ Using the center of the LV as a reference, for each electrode a sub-vector was appointed using the depolarization time as amplitude and anatomical location for direction. The LV and RV epicardial contact sub-vectors were then summed to construct the epicardial AT vector $\left(\mathrm{ATV}_{\text {epi }}\right)$ and the LV endocardial non-contact sub-vectors were summed for constructing the endocardial AT vector $\left(\mathrm{ATV}_{\text {endo }}\right)$. AT vectors measure the spatial imbalance indicative of electrical depolarization between opposite sides. Larger AT vector values indicate a greater electrical asynchrony and the angle of the AT vector expresses the main direction of conduction. Angles were measured from the reference vector between the $\mathrm{LV}$ free wall $\left(180^{\circ}\right)$ and $\mathrm{RV}$ free wall $\left(0^{\circ}\right)$ and anterior angles were considered positive. Hemodynamic data analysis was performed as described previously. ${ }^{11}$

\section{Statistical analysis}

Statistical analyses were performed using SPSS software version 18 (SPSS Inc.). Continuous data were presented as mean \pm standard deviation, and discrete variables as counts and percentages. A series of general linear regression models were used to compare pacing modes and experimental models for the several endpoints, with identity or logistic link function according to the dependent variable assessed. To account for intra-individual correlation of measurements (panel data), Huber-White robust standard-errors were calculated. Correlations were evaluated with Pearson correlation coefficient. Comparison between the predicted and the observed optimal $\mathrm{AV} / \mathrm{VV}$ interval was performed by Wilcoxon signed-rank tests. A $P$-value $<0.05$ was considered statistically significant.

\section{Results}

In the $\mathrm{LBBB}+\mathrm{HF}$ group, $\mathrm{LV}$ ejection fraction decreased from $56 \pm 6 \%$ at baseline to $15 \pm 2 \%$ after four weeks of rapid pacing. $\mathrm{LV} \mathrm{d} P / \mathrm{d} t_{\max }$ was almost $50 \%$ lower in the $\mathrm{LBBB}+\mathrm{HF}$ than in the acute LBBB group ( $\mathrm{p}<0.05$ for both comparisons).

\section{Effects of pacing on conduction}

For all LBBB hearts, QRS duration was approximately $120 \mathrm{~ms}$, which was significantly increased by LV-pacing. BiV-pacing reduced QRS duration by $21 \pm 10 \%$ in the LBBB hearts but only by $5 \pm 12 \%$ in the LBBB + HF hearts $(p<0.05$ for both comparisons, Figure 2). 

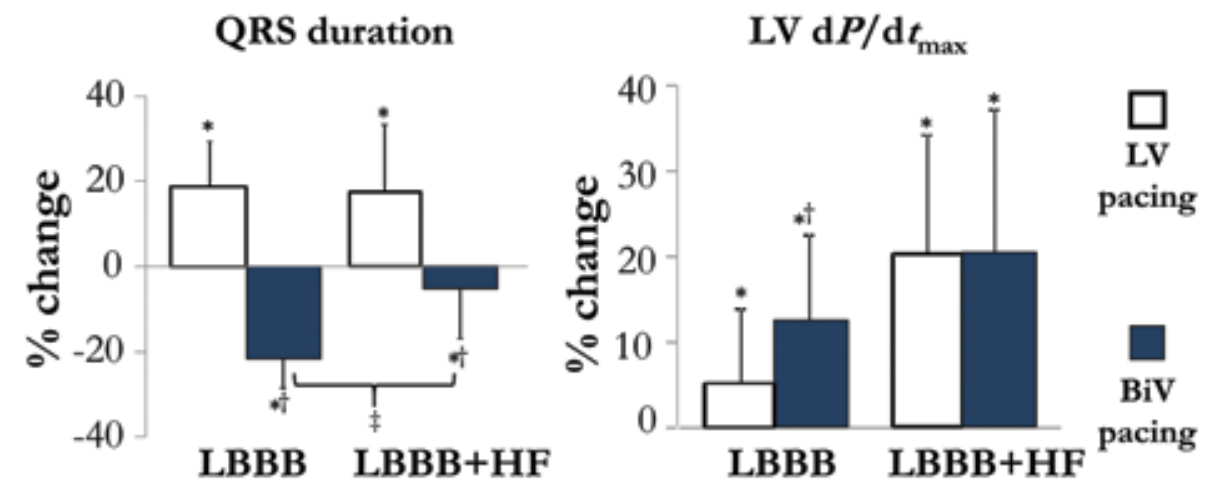

Figure 2. Percent change in QRS duration (left panel) and LVdP/dtmax (right panel) during LV-pacing and simultaneous BiV-pacing in dogs with acute LBBB and chronic LBBB + HF. ${ }^{*} \mathrm{p}<0.05$ compared with baseline. $\mathrm{tp}_{\mathrm{p}}<0.05$ compared with $\mathrm{LV}$. $\ddagger \mathrm{p}<0.05$ compared with LBBB dogs. Presented are mean values \pm SD.

A LBBB

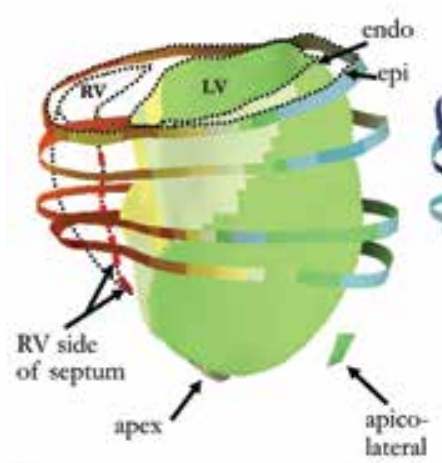

B

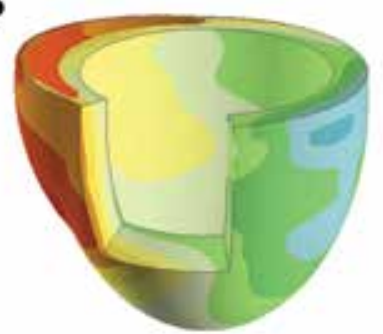

\section{LV pacing}

AV delay $70 \mathrm{~ms}$
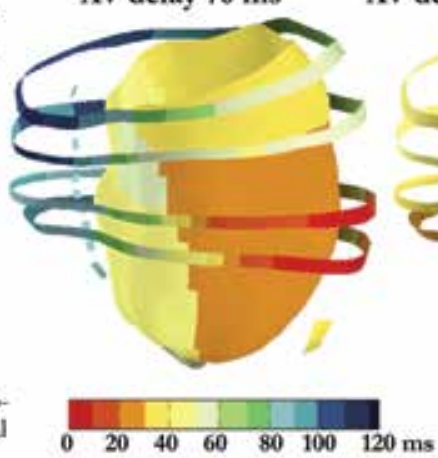

BiV pacing

AV delay $70 \mathrm{~ms}-\mathrm{VV}$ delay $0 \mathrm{~ms}$

Figure 3. Examples of three-dimensional electrical maps in hearts from the LBBB + HF group during baseline atrial pacing (left panels), LV-pacing (center panels) and BiV-pacing (right panels). The top panels show depolarization times (in anterior-posterior view) plotted at their anatomical locations while the bottom panels show biventricular models with interpolated depolarization time maps. 
Figure 3 shows examples of electrode depolarization times plotted at corresponding anatomical locations (top panels) and on interpolated models (bottom panels). During LBBB (left panels), the electrical wave front originated in the RV and slowly propagated through the interventricular septum towards the basolateral wall of the LV. During LV-pacing (middle panels) activation of the RV side of the septum and the RV free wall was delayed while during BiV-pacing (right panels) two wave fronts are visible. However, the LV endocardial electrical activation pattern was similar during LV and BiV-pacing (Figure 3).

The reduction in QRS duration by BiV-pacing was mainly attributable to a more homogeneous epicardial depolarization as both contact and non-contact mapping showed that LV endocardial AT did not decrease during BiV-pacing (see Table 1). This is further substantiated by LV endocardial depolarization times at the septum and the opposing free wall as shown in Figure 4. During both LV and BiV-pacing the LV septal endocardium was activated consistently later than the LV free wall. This finding is explained by measurements of true transseptal conduction, as measured during LV septal pacing. Transseptal activation time was significantly longer than transmural free wall conduction time.
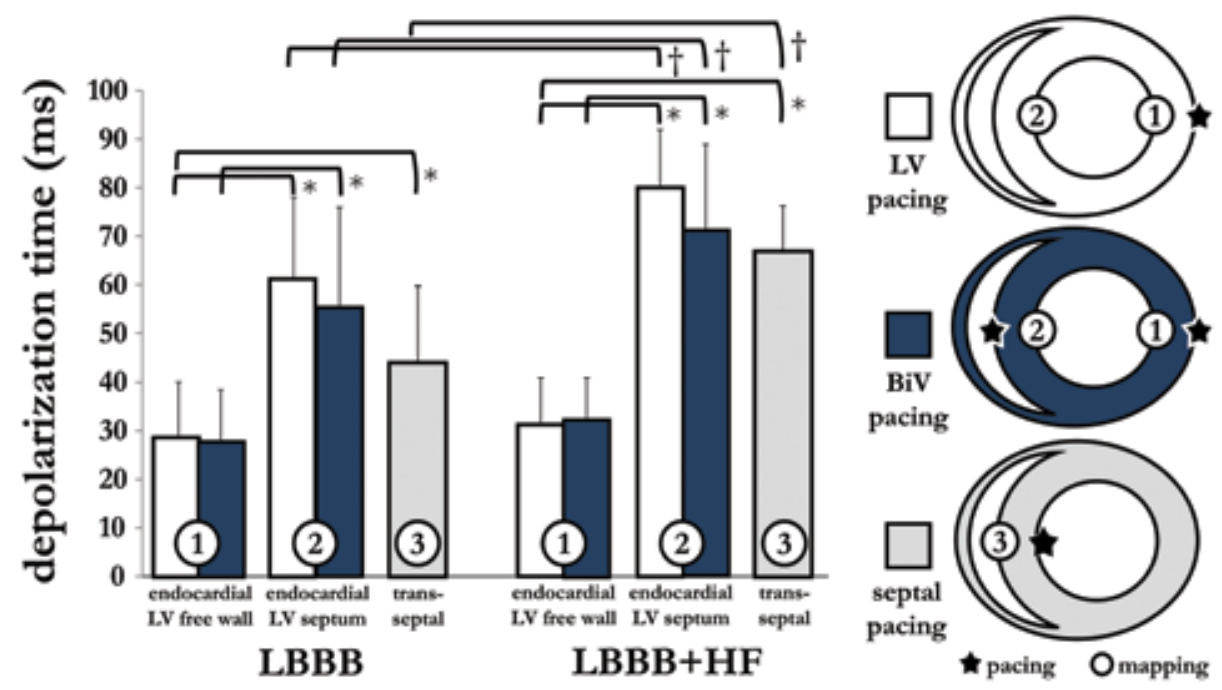

Figure 4. Depolarization times of LV endocardial free wall and septum during LV (white bars) and BiV-pacing (blue bars) in dogs from the acute LBBB and LBBB+HF groups. The grey bars denote transseptal activation times (defined as time required to cross the septum during $L V$ septal pacing). ${ }^{*} \mathrm{p}<0.05$ compared with free wall. $\nmid \mathrm{p}<0.05$ compared with $\mathrm{LBBB}$. Presented are mean values \pm SD. 


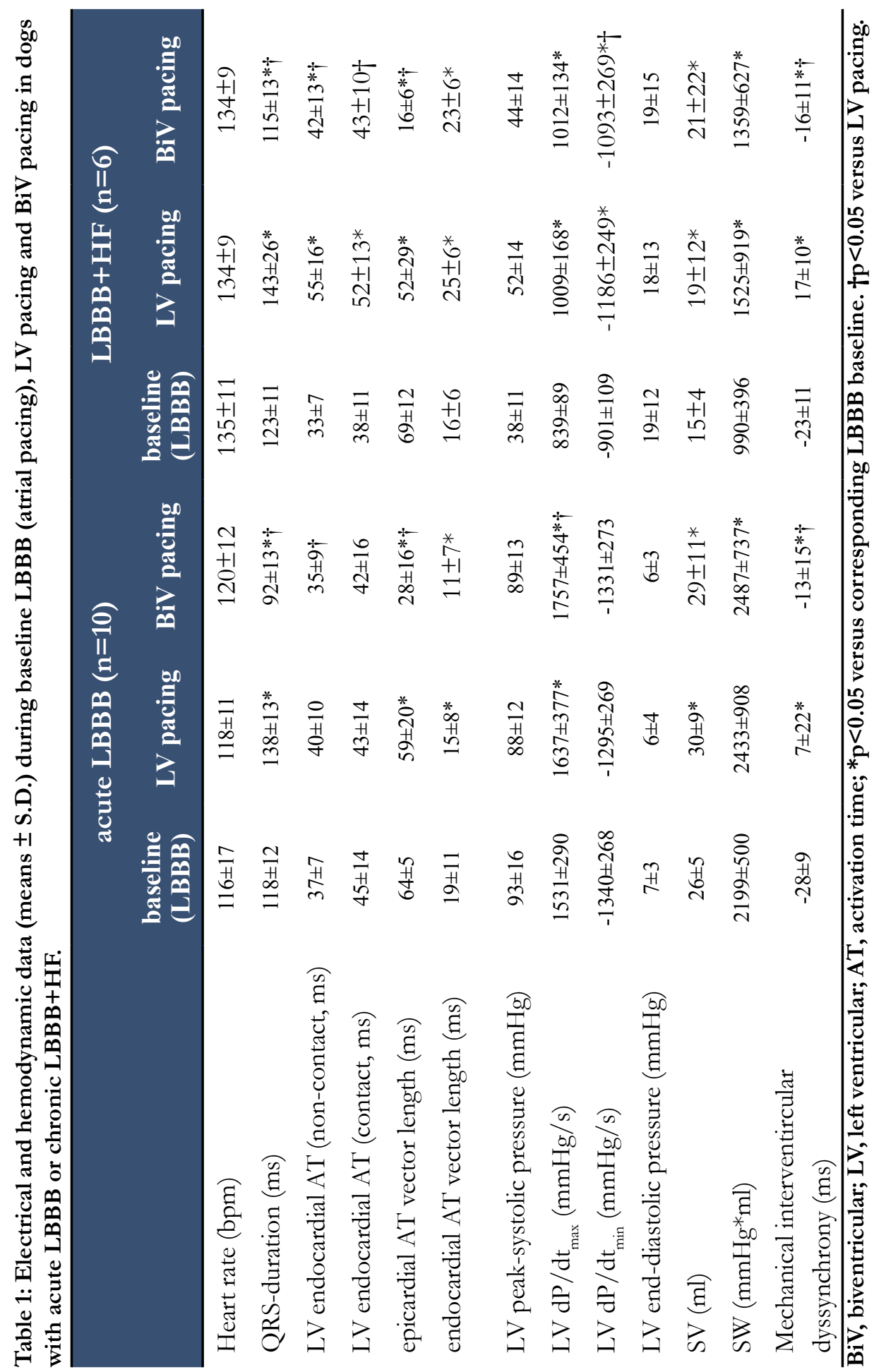


Moreover, in the $\mathrm{LBBB}+\mathrm{HF}$ group, transseptal conduction was approximately $50 \%$ more delayed than in the acute LBBB group (67 \pm 9 ms versus $44 \pm 16 \mathrm{~ms}$ respectively, $\mathrm{p}=0.02)$. This transseptal conduction slowing occurred despite the fact that the septum was significantly thinner in the $\mathrm{LBBB}+\mathrm{HF}$ than in the LBBB hearts as measured by M-mode echocardiography $(0.86 \pm 0.12 \mathrm{~cm}$ versus $1.31 \pm 0.09$ $\mathrm{cm}, \mathrm{p}<0.05)$. A significant inverse correlation was observed between transseptal conduction time and the percentage reduction in $\mathrm{QRS}$ duration $(\mathrm{R}=0.61, \mathrm{p}<0.05)$.

\section{Epicardial and endocardial activation vectors}

Typical examples of $\mathrm{ATV}_{\text {epi }}$ and $\mathrm{ATV}_{\text {endo }}$ are shown in Figure 5. During baseline $\mathrm{LBBB}, \mathrm{ATV}_{\text {endo }}$ and $\mathrm{ATV}_{\text {epi }}$ point away from the early activated septum towards the late-activated $\mathrm{LV}$ free wall $\left(\approx 180^{\circ}\right)$, indicating predominant $\mathrm{RV}$-to-LV conduction. By pacing the LV lateral wall the AT vectors shifted away from this region and pointed towards the RV. During simultaneous BiV-pacing, ATV epi $_{\text {angle and }}$ amplitude were in between those for LBBB and LV-pacing. However, ATV $\mathrm{endo}_{\text {angle }}$ and amplitude were comparable for BiV and LV-pacing.

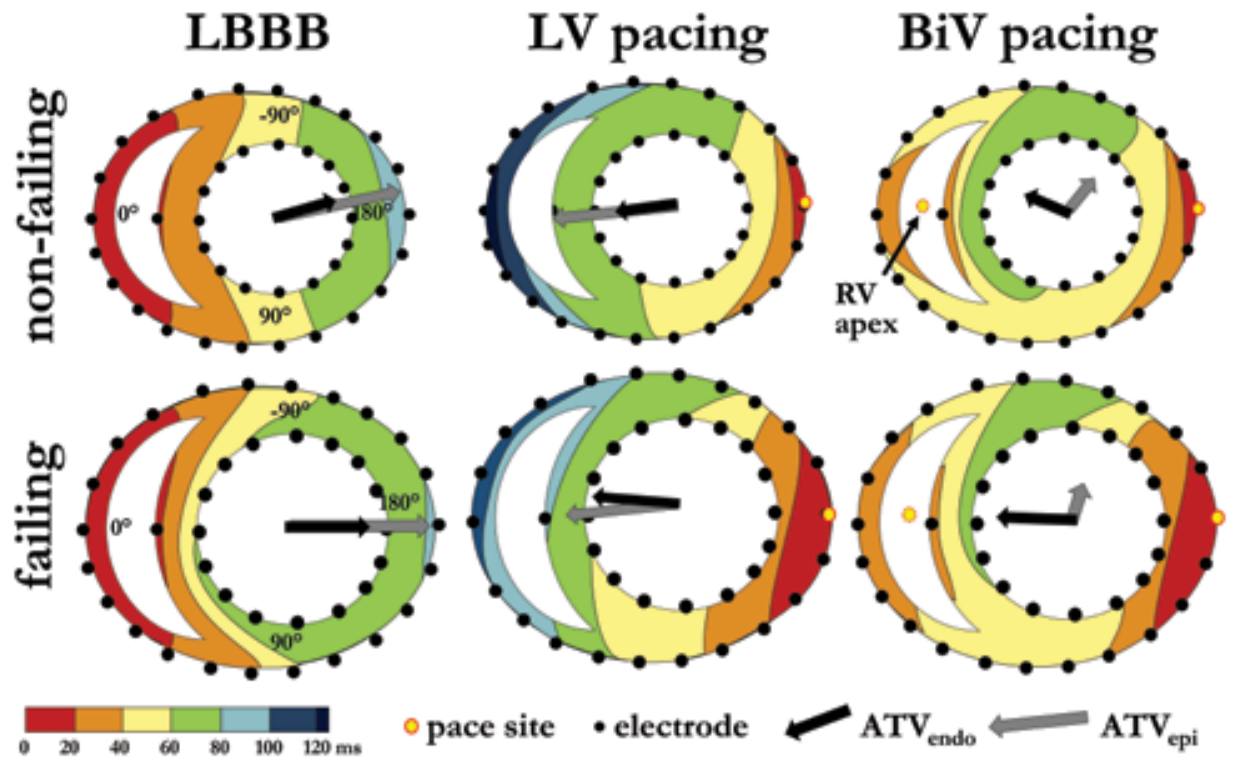

Figure 5. Depolarization time maps in the short axis plane of the heart from the acute LBBB (upper row) and the LBBB+HF group (lower row) during baseline LBBB (left panels), LV-pacing (middle panels) and biventricular pacing (right panels). Pacing sites are represented by the yellow dots. The arrows indicate ATV $\mathrm{epi}_{\text {and }}$ ATV $_{\text {endo }}$. 
LBBB
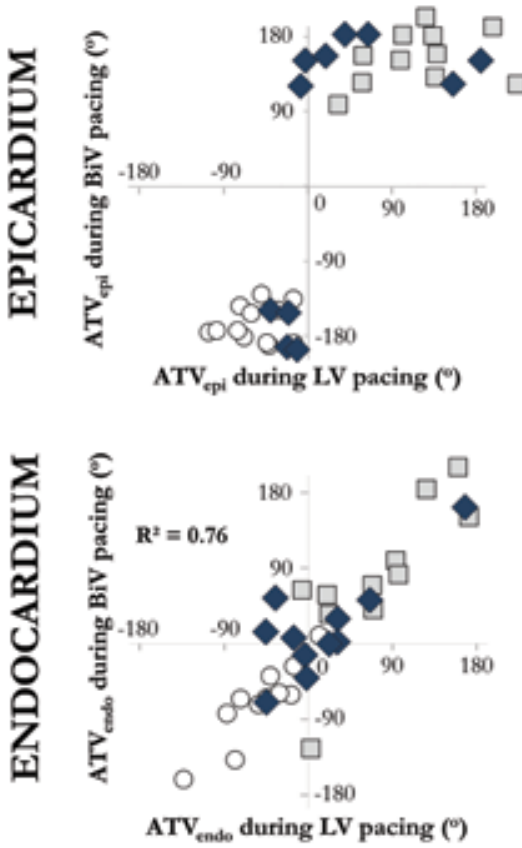

$\mathrm{LBBB}+\mathrm{HF}$
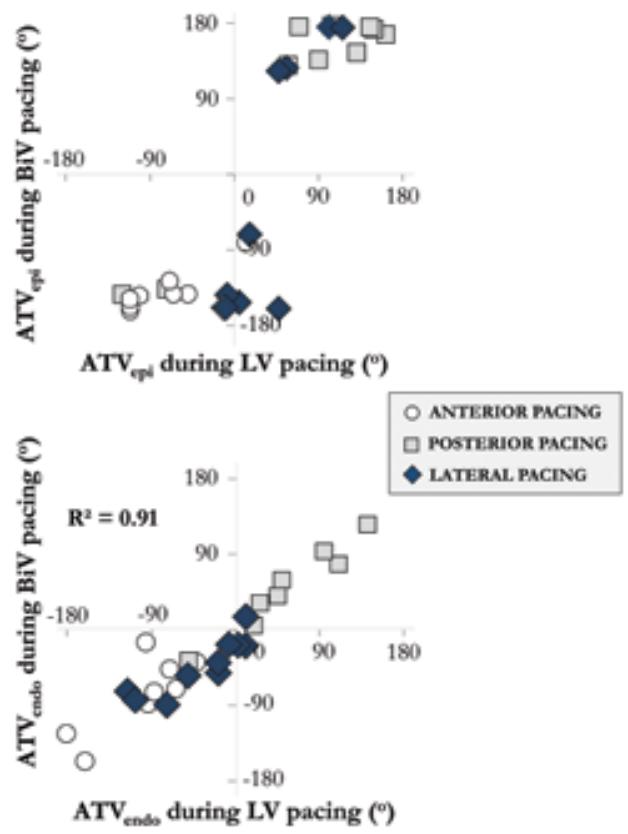

Figure 6. Angles of ATVepi (top panels) and ATVendo (bottom panels) during BiV-pacing (vertical axis) plotted as a function of the corresponding angles during LV-pacing (horizontal axis) in LBBB dogs (left panels) and LBBB+HF dogs (right panels).

Figure 6 shows epicardial vector angles (top panels) and endocardial vector angles (bottom panels) with angles during LV pacing on the $\mathrm{X}$-axis and angles during $\mathrm{BiV}$ pacing on the $\mathrm{Y}$-axis for all experiments. For all animals and for all $\mathrm{LV}$-pacing regions, the switch from LV-pacing to BiV-pacing caused clear changes in the direction of the $\mathrm{ATV}_{\text {epi }}$ angles, but not for $\mathrm{ATV}_{\text {endo }}$ angles. The latter is also expressed by the high correlation between $\mathrm{ATV}_{\text {endo }}$ during $\mathrm{LV}$ and BiV-pacing $\left(\mathrm{LBBB}: \mathrm{R}^{2}=0.76\right.$, $\mathrm{LBBB}+\mathrm{HF}: \mathrm{R}^{2}=0.91, \mathrm{p}<0.05$ for both correlations).

\section{Hemodynamic effects of pacing}

Both $\mathrm{BiV}$ and $\mathrm{LV}$-pacing resulted in a significant improvement in $\mathrm{LV} \mathrm{d} P / \mathrm{d} t_{\max }$ compared with baseline atrial pacing $(\mathrm{p}<0.05$, Figure 2). BiV-pacing resulted in a larger $\mathrm{LV} \mathrm{d} P / \mathrm{d} t_{\max }$ increase than LV-pacing $(\mathrm{p}<0.05)$ in the LBBB dogs. In the $\mathrm{LBBB}+\mathrm{HF}$ group, BiV-pacing and LV-pacing both resulted in $\approx 21 \%$ increase in $\mathrm{LV}$ $\mathrm{d} P / \mathrm{d} t_{\text {max }}(\mathrm{p}=\mathrm{NS}$ between BiV and LV-pacing). 


\section{Atrioventricular and ventriculo-ventricular optimization}

Figure 7 presents examples of electrical maps made during LV-pacing at various AV-intervals. At an AV-interval of $60 \mathrm{~ms}$ the activation was entirely dominated by LV-pacing, resulting in large $A T V_{\text {endo }}$ and $A T V_{\text {epi }}$ amplitudes. At an AV-interval of $120 \mathrm{~ms}$, intrinsic activation through the right bundle branch caused synchronous activation of the RV, resulting in a minimal $\mathrm{ATV}_{\mathrm{epi}}$ amplitude of $9 \mathrm{~ms}$. However, at this AV-interval $\mathrm{ATV}_{\text {endo }}$ amplitude was not changed yet, due to the lack of transseptal breakthrough. This breakthrough occurred at a longer AV-interval, so that at an $\mathrm{AV}$-interval of $160 \mathrm{~ms} \mathrm{ATV}_{\text {endo }}$ amplitude was minimal. Conversely, at this AV-interval, the intrinsic wave front fully activated the RV and a large part of the anterior and posterior wall of the LV, thereby increasing $\mathrm{ATV}_{\text {epi }}$ to $38 \mathrm{~ms}$. At an AVinterval of $200 \mathrm{~ms}$, LV capture was lost entirely and resulting in a LBBB activation pattern.

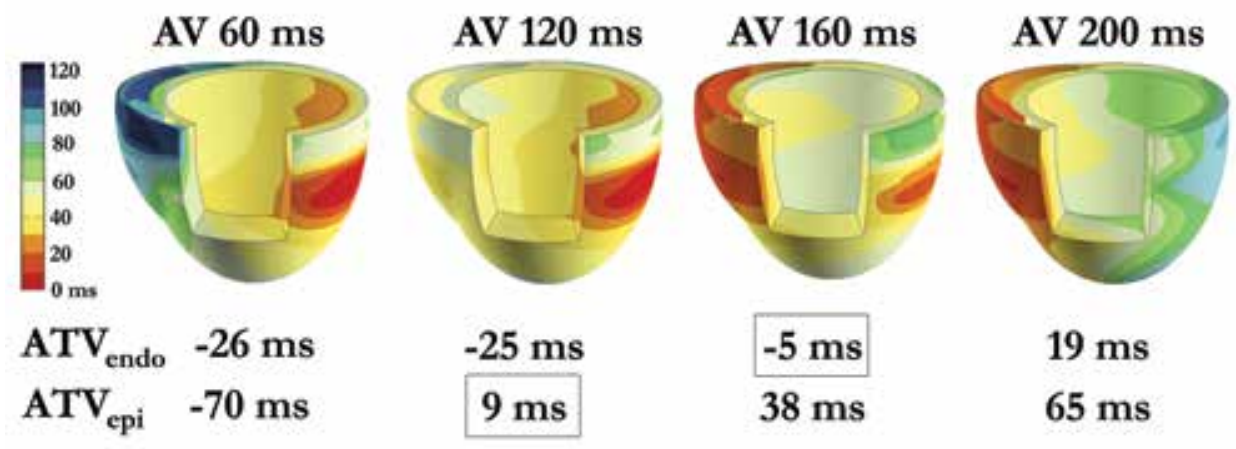

Figure 7. Examples of three-dimensional electrical depolarization time maps and ATVepi and ATVendo behavior during LV-pacing at increasing AV-intervals in a LBBB+HF heart.

Figure $8 A$ displays the changes in $\mathrm{ATV}_{\text {epi }}, \mathrm{ATV}_{\text {endo }}$ and vector amplitude of the QRS complex of the surface ECG ( $\mathrm{VA}_{\mathrm{QRS}}$ ), while pacing at various $\mathrm{AV}$-intervals (during LV-only pacing) and VV-intervals (during BiV-pacing). The optimal $\mathrm{LVdP} / \mathrm{dt}_{\max }$ consistently occurred at an interval where $\mathrm{ATV}_{\mathrm{epi}}$ and $\mathrm{VA} \mathrm{QRS}_{\mathrm{Q}}$ were at values halfway between those during LBBB and LV-pacing, supporting data from a previous study. ${ }^{13}$ During AV-optimization the average interval-offset was $2 \pm 11 \mathrm{~ms}$ for $\mathrm{VA}_{\mathrm{QRS}}$ and $-9 \pm 24 \mathrm{~ms}$ for $\mathrm{ATV}_{\text {epi }}(\mathrm{p}=\mathrm{N}$.S. for both comparisons). During VV-optimization, maximal response was predicted with an offset of $-4 \pm 9 \mathrm{~ms}$ for $\mathrm{VA}_{\mathrm{QRS}}$ and $2 \pm 8 \mathrm{~ms}$ for $\mathrm{ATV}_{\text {epi }}\left(\mathrm{p}=\mathrm{N}\right.$.S. for both comparisons). In contrast, halfway $A T V_{\text {endo }}$ vector amplitudes occurred during longer AV-intervals and during RV pre-excitation (in VV-optimization). 
Figure $8 \mathrm{~B}$ shows that for all $\mathrm{AV}$ - and VV-optimizations, there was a significant difference between the optimal $\mathrm{AV} / \mathrm{VV}$-interval and the $\mathrm{AV} / \mathrm{VV}$-interval resulting in minimal ATV ${ }_{\text {endo }}$ amplitude. While these $\mathrm{ATV}_{\text {endo }}$ values were derived from noncontact mapping, similar findings were obtained using septum and lateral wall plunge electrodes. Figure 9 shows the values of $\mathrm{LVd} P / \mathrm{d} t_{\max }$, programmed A-LV-interval, $\mathrm{ATV}_{\text {epi }}, \mathrm{ATV}_{\text {endo }}$ and $\mathrm{VA}_{\mathrm{QRS}}$ during LBBB, LV-pacing at short AV-interval, optimal AV-interval and optimal VV-interval. Optimizing the AV-interval during LV-pacing resulted in an average $\mathrm{LV} \mathrm{d} P / \mathrm{d} t_{\max }$ increase to $\approx 26 \%$ above baseline $\mathrm{LBBB}(\mathrm{p}<0.05$ as compared to baseline and LV-pacing at short AV-interval). Optimizing the VVinterval increased $\mathrm{LV} \mathrm{d} P / \mathrm{d} t_{\max }$ to $\approx 33 \%$ above baseline $\mathrm{LBBB}(\mathrm{p}<0.05$ as compared to baseline and simultaneous BiV-pacing).

A

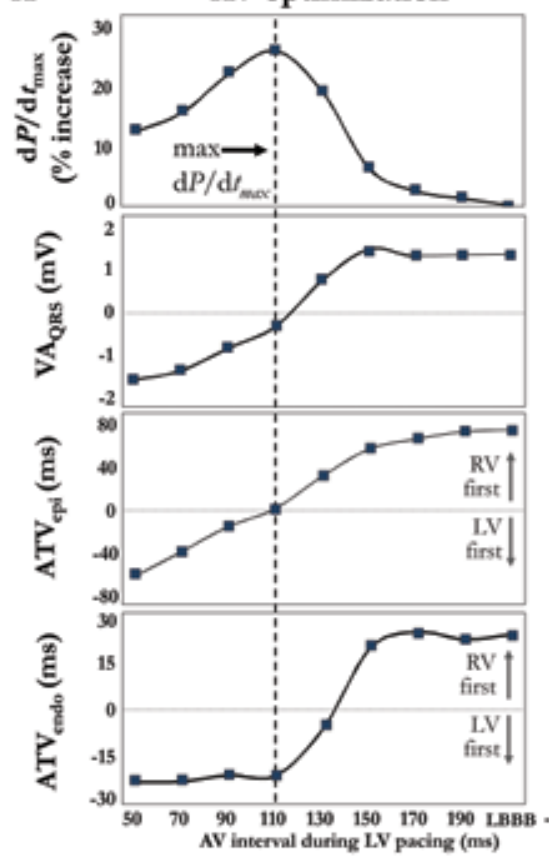

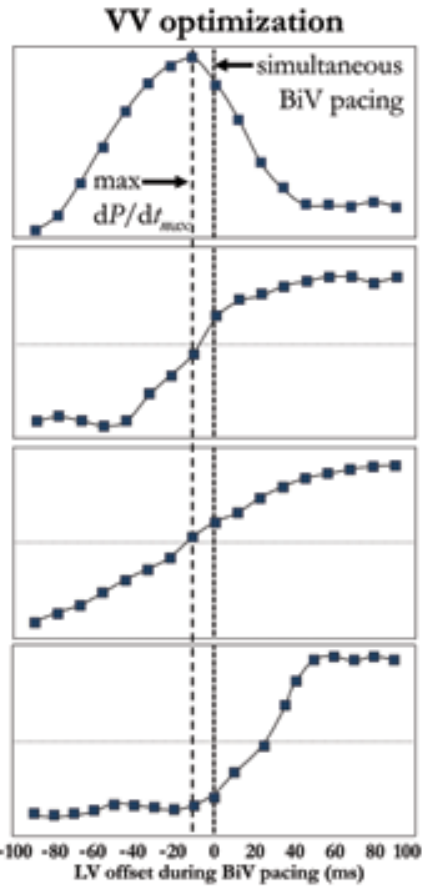

B average

offset

(predicted optimum)

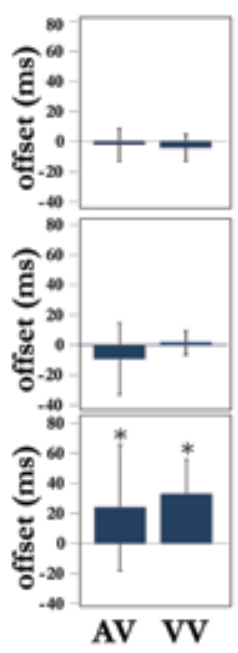

Figure 8. A) Typical example of relation between AV-interval (left panels) or VVinterval (right panels) and change in $\mathrm{LV} \mathrm{dP/dtmax,} \mathrm{QRS} \mathrm{vector} \mathrm{amplitude} \mathrm{from}$ the surface ECG $\left(\mathrm{VA}_{\mathrm{QRS}}\right), \mathrm{ATV}_{\text {epi }}$ and $\mathrm{ATV}$ endo measured in an $\mathrm{LBBB}+\mathrm{HF}$ heart. The dashed line represents the optimal AV/VV-interval (the setting which resulted in the maximal increase in $\mathrm{LV} \mathrm{dP} / \mathrm{dtmax}$ ). B) Average offset between predicted and observed optima for AV- and VV-optimization. ${ }^{*} \mathrm{p}<0.05$ as compared with observed optimal setting. 


\section{Discussion}

The findings of the present animal study shed new light on the electrical mechanisms of CRT. For the first time it is demonstrated that BiV-pacing does not result in collision of pacing-induced wave fronts in between the septum and the LV free wall due to slow transseptal conduction. Septal conduction is slower than LV transmural conduction in hearts with acute LBBB and even more prolonged in failing LBBB hearts. Slow septal conduction is associated with a relatively small reduction in QRS duration by BiV-pacing, as seen in clinical CRT trials. ${ }^{3}$ Optimal hemodynamic CRT response during $\mathrm{LV}$-fusion or sequential BiV-pacing is achieved under conditions where epicardial $\mathrm{RV}+\mathrm{LV}$ asynchrony is minimal, which coincides with a left-toright activation of most of the $\mathrm{LV}$ wall.

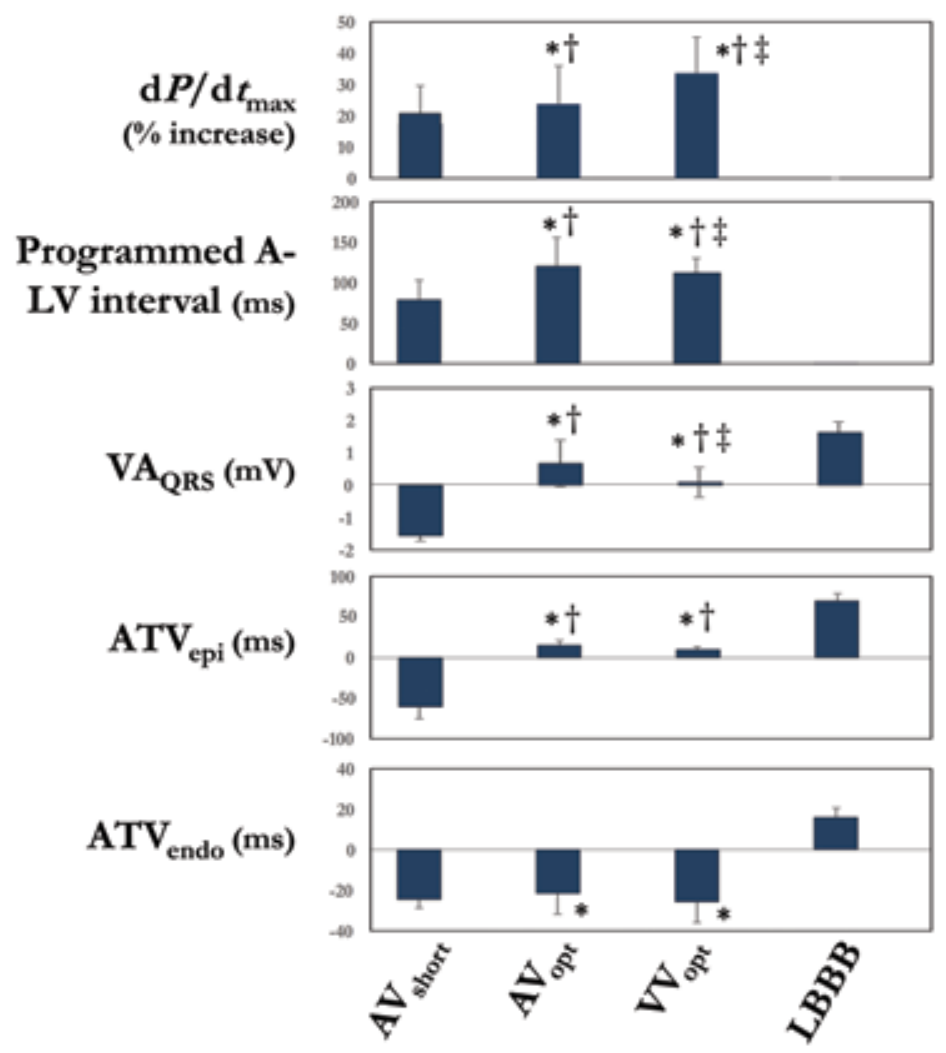

Figure 9. Average changes in LVdP/dt ${ }_{\text {max }}(\%)$, programmd A-LV interval (ms), $\mathrm{VA}_{\mathrm{QRS}}(\mathrm{ms}), \mathrm{ATV}_{\text {epi }}(\mathrm{ms})$, and $\mathrm{ATV}_{\text {endo }}$ (ms) during LV-pacing at short AV-interval $\left(\mathrm{AV}_{\text {short }}\right)$, optimized $\mathrm{AV}$-interval $\left(\mathrm{AV}_{\mathrm{opt}}\right)$, optimized $\mathrm{VV}$-interval $\left(\mathrm{VV}_{\mathrm{opt}}\right)$ and LBBB in hearts with $\mathrm{LBBB}+\mathrm{HF} .{ }^{*} \mathrm{p}<0.05$ as compared with $\mathrm{AV}_{\text {short }}{ }^{\circ}+0.05$ as compared with LBBB. $\ddagger<0.05 \mathrm{VV}_{\text {opt }}$ vs $\mathrm{AV}_{\text {opt }}$. 


\section{Slow transseptal conduction}

Information about transseptal conduction in LBBB hearts in the literature is scarce, because most electrical mapping studies measure either the epicardium or the endocardium. Vasallo et al measured transseptal conduction by determining the time from onset of $\mathrm{Q}$ wave to $\mathrm{LV}$-breakthrough during catheter mapping while Auricchio et al used biventricular contact mapping. ${ }^{15,16}$ These investigators showed a wide range of transseptal conduction times in patients, from almost zero to $\approx 100$ ms. Interestingly, there appears to be a separation between $30 \%$ of this patient population with very short and $70 \%$ with long transseptal conduction times. ${ }^{15}$ The long transseptal conduction times observed appear to be in line with the delayed septal conduction found in dogs with proximal LBBB. Importantly, we show that conduction in the septum slows down further during 4 weeks of dyssynchronous heart failure. As for the possible cause of this transseptal conduction slowing, factors such as ischemia and hypertrophy are unlikely to play a role in the tachypacing model. A possible explanation for slow septal conduction may be a more vertical orientation of the laminar sheets with myocytes, as demonstrated by Helm et al in the same dyssynchronous heart failure model. ${ }^{17}$

Preliminary results from our lab show that, in seven dogs with four months of LBBB and normal sinus rhythm, endocardial LV septum activation times during BiV-pacing were similarly increased as in the LBBB $+\mathrm{HF}$ group. This suggests that slow transseptal conduction may be related with longer-lasting asynchrony, rather than tachypacing-induced dilation. Spach et al observed that cell-cell delay increases with decreasing cell diameter ${ }^{18}$, a situation that occurs in the early activated regions of dyssynchronous hearts (in our case, the septum). ${ }^{19}$ Data in the literature on a possible role of remodeling of ion channels, such as connexins and sodium channels, on slowing of septal conduction are scarce. This is primarily due to the fact that only the LV lateral or anterior wall was investigated. ${ }^{20,21}$ A paper reporting on RV and LV samples showed no significant change in Cx43 and SCN5A expression in rabbits that were paced in the RV (comparable with LBBB) as compared to control rabbits. $^{22}$

The present findings on transseptal conduction may explain several hemodynamic aspects of CRT. First of all, several patient studies and data derived from a canine model of dyssynchronous heart failure showed that LV and BiV-pacing may have the same benefits for hemodynamics. ${ }^{2,5,6,23}$ Findings in this study may also explain the paradoxical findings by Leclerq et al, who showed that in an animal 
model quite similar to our $\mathrm{LBBB}+\mathrm{HF}$ model, $\mathrm{LV}$ and BiV-pacing result in similar pump function and even regional mechanics, despite a dyssynchronous electrical activation. ${ }^{23}$ The "mismatch" between their electrical and mechanical measurements may be explained by the fact that local strains can be considered as an average of transmural mechanics, whereas electrical dyssynchrony was measured exclusively at the epicardium. Slow septal conduction causes, under several conditions, a dissociation between epicardial and endocardial conduction patterns as illustrated by the changes in $\mathrm{ATV}_{\text {epi, }}$, but not $\mathrm{ATV}_{\text {endo }}$, when comparing LV-pacing with BiVpacing. The observation that the changes in $\mathrm{ATV}_{\mathrm{epi}}$ correspond with those in the QRS vector of the surface ECG indicates that the latter mainly represents epicardial electrical phenomena.

The fact that $L V$ and $\mathrm{BiV}$-pacing at a relatively short AV-interval provide a similar increase in pump function does not mean that this is the maximal improvement to be achieved. The present study shows that the largest hemodynamic improvement is achieved during optimal interventricular resynchronization, coinciding with LV pre-excitation which agrees with earlier observation in our canine model and clinical studies. ${ }^{4,12,24}$

\section{Potential clinical implications}

The main implication of the present study is that it provides a mechanism why contribution of RV pacing in simultaneous BiV-pacing is negligible. This has already been suggested during "fusion" LV-pacing, but it may also hold for LV-pacing at shorter AV-intervals, especially in failing hearts. The present study shows that the biventricular epicardium and LV endocardium may contain considerably different electrical information. While detailed LV endocardial mapping unravels similarities between pacing modes, epicardial mapping appears to provide more useful information in CRT optimization. This is important in the light of the increasing use of endocardial mapping ${ }^{15,25}$ and ECG-imaging for epicardial mapping ${ }^{26,27}$.

In addition, further support is provided that morphology of the QRS complex of the surface ECG is determined primarily by epicardial electrical phenomena. This finding is important also for practical reasons as ECG vectorcardiography and ECG-imaging are non-invasive, low-cost, and widely available techniques. 


\section{Limitations}

A limitation of this study is that it was performed in canine hearts, and therefore should be extrapolated to the situation in patients with caution. However, in the decade that this model exists ${ }^{8}$, several principles of CRT have been proven applicable to patients, such as the remodeling processes both at the tissue $e^{28}$ and the molecular ${ }^{29}$ level and optimization of $\mathrm{AV}$ and VV-delays ${ }^{4}$. Due to the smaller heart size in dogs, there are quantitative differences between the dog and human heart, but the qualitative effects may well apply to the human heart. This study investigated acute hemodynamic improvement while these effects may not (completely) translate into chronic outcome. ${ }^{30}$ However, the GREATER-EARTH trial reported no differences in reverse remodeling between pacing modalities after 6 months, suggesting that acute similarities may persist into the chronic phase. ${ }^{6}$

\section{Conclusion}

Through simultaneous endocardial and epicardial electrical mapping in dyssynchronous canine hearts we established that transseptal conduction in LBBB hearts is slow, especially in failing hearts. Due to this slow transseptal conduction biventricular pacing does not result in collision of RV and LV-pacing induced wave fronts within the LV wall and the LV activation sequence is not different between LV and BiV-pacing, Optimal hemodynamic CRT response is achieved when interventricular asynchrony is minimal, which coincides with LV pre-excitation.

\section{Acknowledgements}

The authors are indebted to Peter Bakker (St. Jude Medical) for his assistance in operating the EnSite 3000 system.

\section{Funding sources}

This research was performed within the framework of CTMM, the Center for Translational Molecular Medicine (www.ctmm.nl), project COHFAR (grant 01C-203), and supported by the Dutch Heart Foundation. 


\section{References}

1. Cleland JG, Daubert JC, Erdmann E, Freemantle N, Gras D, Kappenberger L, Tavazzi L. The effect of cardiac resynchronization on morbidity and mortality in heart failure. The New England journal of medicine. 2005;352:1539-1549

2. Auricchio A, Stellbrink C, Sack S, Block M, Vogt J, Bakker P, Huth C, Schondube F, Wolfhard U, Bocker D, Krahnefeld O, Kirkels H. Long-term clinical effect of hemodynamically optimized cardiac resynchronization therapy in patients with heart failure and ventricular conduction delay. J Am Coll Cardiol. 2002;39:20262033

3. Gervais R, Leclercq C, Shankar A, Jacobs S, Eiskjaer H, Johannessen A, Freemantle N, Cleland JG, Tavazzi L, Daubert C. Surface electrocardiogram to predict outcome in candidates for cardiac resynchronization therapy: A sub-analysis of the care-hf trial. Eur J Heart Fail. 2009;11:699-705

4. Verbeek XA, Auricchio A, Yu Y, Ding J, Pochet T, Vernooy K, Kramer A, Spinelli J, Prinzen FW. Tailoring cardiac resynchronization therapy using interventricular asynchrony. Validation of a simple model. American journal of physiology. Heart and circulatory physiology. 2006;290:H968-977

5. Rao RK, Kumar UN, Schafer J, Viloria E, De Lurgio D, Foster E. Reduced ventricular volumes and improved systolic function with cardiac resynchronization therapy: A randomized trial comparing simultaneous biventricular pacing, sequential biventricular pacing, and left ventricular pacing. Circulation. 2007;115:2136-2144

6. Thibault B, Ducharme A, Harel F, White M, O’Meara E, Guertin MC, Lavoie J, Frasure-Smith N, Dubuc M, Guerra P, Macle L, Rivard L, Roy D, Talajic M, Khairy P. Left ventricular versus simultaneous biventricular pacing in patients with heart failure and a qrs complex $>=120$ milliseconds. Circulation. 2011;124:2874-2881

7. Prinzen FW, Auricchio A. Is echocardiographic assessment of dyssynchrony useful to select candidates for cardiac resynchronization therapy? Echocardiography is not useful before cardiac resynchronization therapy if qrs duration is available. Circulation. Cardiovascular imaging. 2008;1:70-77; discussion 78

8. Verbeek XA, Vernooy K, Peschar M, Van Der Nagel T, Van Hunnik A, Prinzen FW. Quantification of interventricular asynchrony during lbbb and ventricular pacing. American journal of physiology. Heart and circulatory physiology. 2002;283:H13701378

9. Strik M, Rademakers LM, van Deursen CJ, van Hunnik A, Kuiper M, Klersy C, Auricchio A, Prinzen FW. Endocardial left ventricular pacing improves cardiac resynchronization therapy in chronic asynchronous infarction and heart failure models. Circ Arrbythm Electrophysiol. 2012;5:191-200 
10. Rademakers LM, van Kerckhoven R, van Deursen CJ, Strik M, van Hunnik A, Kuiper M, Lampert A, Klersy C, Leyva F, Auricchio A, Maessen JG, Prinzen FW. Myocardial infarction does not preclude electrical and hemodynamic benefits of cardiac resynchronization therapy in dyssynchronous canine hearts. Circ Arrbythm Electrophysiol. 2010;3:361-368

11. van Deursen C, van Geldorp IE, Rademakers LM, van Hunnik A, Kuiper M, Klersy C, Auricchio A, Prinzen FW. Left ventricular endocardial pacing improves resynchronization therapy in canine left bundle-branch hearts. Circ Arrbythm Electrophysiol. 2009;2:580-587

12. Mills RW, Cornelussen RN, Mulligan LJ, Strik M, Rademakers LM, Skadsberg ND, van Hunnik A, Kuiper M, Lampert A, Delhaas T, Prinzen FW. Left ventricular septal and left ventricular apical pacing chronically maintain cardiac contractile coordination, pump function and efficiency. Circ Arrbythm Electrophysiol. 2009;2:571579

13. van Deursen CJ, Strik M, Rademakers LM, van Hunnik A, Kuiper M, Wecke L, Crijns HJ, Vernooy K, Prinzen FW. Vectorcardiography as a tool for easy optimization of cardiac resynchronization therapy in canine left bundle branch block hearts. Circ Arrbythm Electrophysiol. 2012;5:544-552

14. Verbeek XA, Vernooy K, Peschar M, Cornelussen RN, Prinzen FW. Intraventricular resynchronization for optimal left ventricular function during pacing in experimental left bundle branch block. J Am Coll Cardiol. 2003;42:558-567

15. Auricchio A, Fantoni C, Regoli F, Carbucicchio C, Goette A, Geller C, Kloss M, Klein $\mathrm{H}$. Characterization of left ventricular activation in patients with heart failure and left bundle-branch block. Circulation. 2004;109:1133-1139

16. Vassallo JA, Cassidy DM, Marchlinski FE, Buxton AE, Waxman HL, Doherty JU, Josephson ME. Endocardial activation of left bundle branch block. Circulation. 1984;69:914-923

17. Helm PA, Younes L, Beg MF, Ennis DB, Leclercq C, Faris OP, McVeigh E, Kass D, Miller MI, Winslow RL. Evidence of structural remodeling in the dyssynchronous failing heart. Circulation research. 2006;98:125-132

18. Spach MS, Heidlage JF, Dolber PC, Barr RC. Electrophysiological effects of remodeling cardiac gap junctions and cell size: Experimental and model studies of normal cardiac growth. Circulation research. 2000;86:302-311

19. van Oosterhout MF, Prinzen FW, Arts T, Schreuder JJ, Vanagt WY, Cleutjens JP, Reneman RS. Asynchronous electrical activation induces asymmetrical hypertrophy of the left ventricular wall. Circulation. 1998;98:588-595

20. Spragg DD, Akar FG, Helm RH, Tunin RS, Tomaselli GF, Kass DA. Abnormal 
conduction and repolarization in late-activated myocardium of dyssynchronously contracting hearts. Cardiovasc Res. 2005;67:77-86

21. Aiba T, Tomaselli G. Electrical remodeling in dyssynchrony and resynchronization. J Cardiovasc Transl Res. 2012;5:170-179

22. Saba S, Mehdi H, Mathier MA, Islam MZ, Salama G, London B. Effect of right ventricular versus biventricular pacing on electrical remodeling in the normal heart. Circ Arrbythm Electrophysiol. 2010;3:79-87

23. Leclercq C, Faris O, Tunin R, Johnson J, Kato R, Evans F, Spinelli J, Halperin H, McVeigh E, Kass DA. Systolic improvement and mechanical resynchronization does not require electrical synchrony in the dilated failing heart with left bundlebranch block. Circulation. 2002;106:1760-1763

24. Bogaard MD, Meine M, Tuinenburg AE, Maskara B, Loh P, Doevendans PA. Cardiac resynchronization therapy beyond nominal settings: Who needs individual programming of the atrioventricular and interventricular delay? Europace. 2012;14:1746-1753

25. Ginks MR, Shetty AK, Lambiase PD, Duckett SG, Bostock J, Peacock JL, Rhode KS, Bucknall C, Gill J, Taggart P, Leclercq C, Carr-White GS, Razavi R, Rinaldi CA. Benefits of endocardial and multi-site pacing are dependent on the type of $\mathrm{lv}$ electrical activation pattern and presence of ischemic heart disease: Insights from electro-anatomical mapping. Circ Arrbythm Electrophysiol. 2012;5:889-897

26. Jia P, Ramanathan C, Ghanem RN, Ryu K, Varma N, Rudy Y. Electrocardiographic imaging of cardiac resynchronization therapy in heart failure: Observation of variable electrophysiologic responses. Heart Rhythm. 2006;3:296-310

27. Ghosh S, Silva JN, Canham RM, Bowman TM, Zhang J, Rhee EK, Woodard PK, Rudy Y. Electrophysiological substrate and intraventricular lv dyssynchrony in non-ischemic heart failure patients undergoing cardiac resynchronization therapy. Heart Rhythm. 2011;8:692-699

28. Strik M, Regoli F, Auricchio A, Prinzen F. Electrical and mechanical ventricular activation during left bundle branch block and resynchronization. J Cardiovasc Transl Res. 2012;5:117-126

29. Vanderheyden M, Penicka M, Bartunek J. Cellular electrophysiological abnormalities in dyssynchronous hearts and during crt. J Cardiovasc Transl Res. 2012;5:127-134

30. Bogaard MD, Houthuizen P, Bracke FA, Doevendans PA, Prinzen FW, Meine M, van Gelder BM. Baseline left ventricular dp/dtmax rather than the acute improvement in $\mathrm{dp} / \mathrm{dtmax}$ predicts clinical outcome in patients with cardiac resynchronization therapy. Eur J Heart Fail. 2011;13:1126-1132 
Transseptal Conduction 

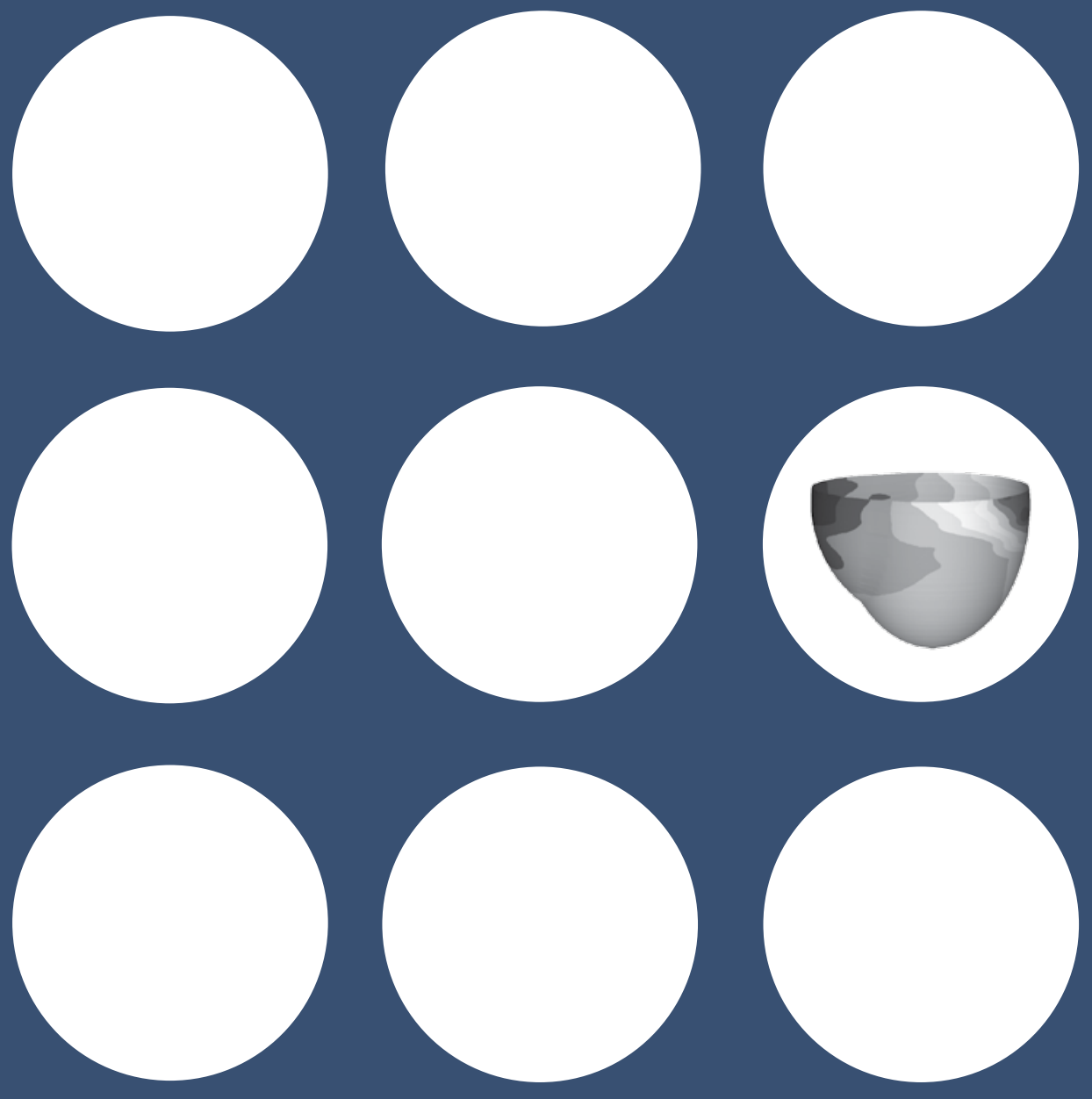

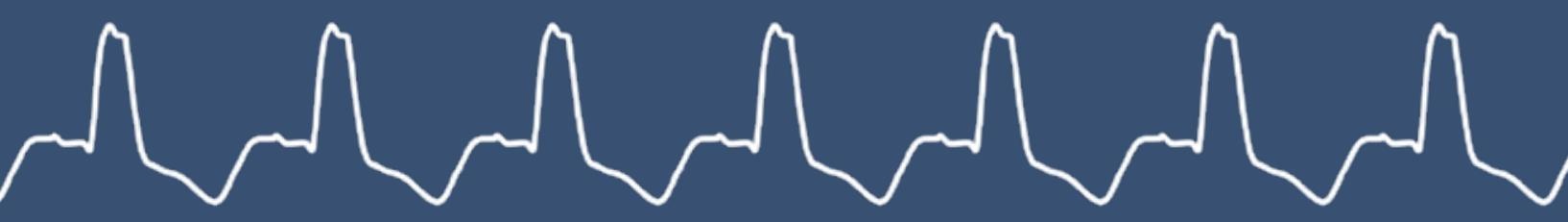




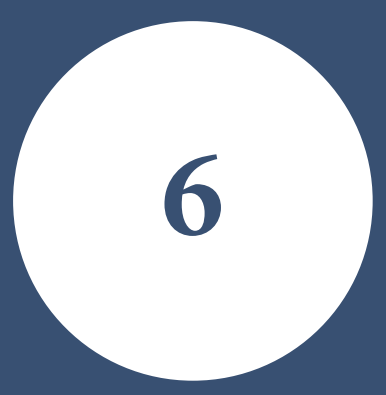

\section{The Interplay of Electrical Wave Fronts as Determinant of the Response to Cardiac Resynchronization Therapy in Dyssynchronous Canine Hearts}

Strik M, van Middendorp LB, Houthuizen P, Ploux S, van Hunnik A, Kuiper M, Auricchio A, Prinzen FW

Circ Arrhythm Electrophysiol. 2013 Sep 18.

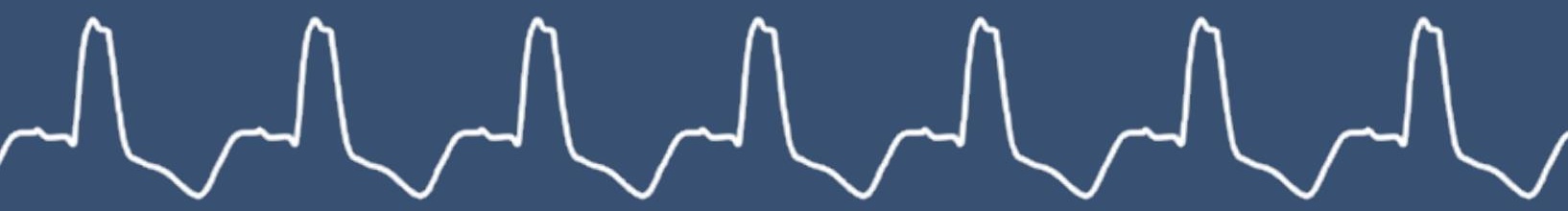




\section{Abstract}

\section{Background}

The relative contribution of electromechanical synchronization and ventricular filling to the optimal hemodynamic effect in cardiac resynchronization therapy (CRT) during adjustment of stimulation-timings is incompletely understood. We investigated whether optimal hemodynamic effect in CRT requires collision of pacing-induced and intrinsic activation waves and/or optimal filling of the left ventricle $(\mathrm{LV})$.

\section{Methods}

CRT was performed in dogs with chronic left bundle branch block (LBBB, $\mathrm{n}=8$ ) or atrioventricular (AV) block $(\mathrm{n}=6)$ through atrial $(\mathrm{A})$, right ventricular $(\mathrm{RV})$ apex and LV-basolateral pacing. 100 randomized combinations of A-LV/A-RV intervals were tested. Total activation time (TAT) was calculated from $>100$ contact mapping electrodes. Mechanical interventricular dyssynchrony (MIVD) was determined as the time delay between upslopes of LV and RV pressure curves. Settings providing an increase in $\mathrm{LVdP} / \mathrm{dtmax}$ of $\geq 90 \%$ of the maximum $\mathrm{LVdP} / \mathrm{dtmax}$ value were defined as optimal (CRTopt). Filling was assessed by changes in LV end-diastolic volume (EDV; conductance catheter technique).

\section{Results}

In all hearts, $\mathrm{CRT}_{\text {opt }}$ was observed during multiple settings, providing an average $\mathrm{LVdP} / \mathrm{dt}_{\text {max }}$ increase of $\approx 15 \%$. In AV-block hearts, $\mathrm{CRT}_{\text {opt }}$ exclusively depended on interventricular-interval and not on AV-interval. In LBBB hearts, $\mathrm{CRT}_{\text {opt }}$ occurred at A-LV intervals that allowed fusion of $L V$ pacing-derived activation with right bundle derived activation. In all animals $\mathrm{CRT}_{\text {opt }}$ occurred at settings resulting in the largest decrease in TAT and MIVD, while LV EDV hardly changed.

\section{Conclusion}

In LBBB and AV-block hearts, optimal hemodynamic effect of CRT depends on optimal interplay between pacing-induced and intrinsic activation waves and the corresponding mechanical resynchronization rather than filling. 


\section{Introduction}

In chronic heart failure patients with delayed ventricular activation (most often in the form of left bundle branch block, LBBB) and decreased left ventricular (LV) ejection fraction $(<35 \%)$, cardiac resynchronization therapy (CRT) has been shown to improve cardiac pump function, symptoms, hospitalizations, and survival. ${ }^{1}$ Optimizing the CRT-device is important, as CRT response is heterogeneous among patients and up to half of implanted patients fail to respond to the therapy. During optimization the timing between atrial pacing or sensing and stimulation of RV and LV (A-RV and A-LV intervals) is varied. However, the exact mechanism behind CRT optimization is not well understood. In hearts with LBBB, ventricular activation is preserved via the right bundle branch. ${ }^{2}$ During CRT, ventricular activation may result from fusion of three activation wave fronts generated by 1) intrinsic conduction, 2) the RV pacing lead and 3) the LV pacing lead. At certain AVintervals, the activation front generated by the RV pacing lead dominates and it fully collides with the one generated by the LV lead. In patients with complete AV-block, one component (activation via right bundle branch) is inexistent; this is an ideal situation to clarify the importance and relative role of activation generated via right bundle as well as whether ventricular filling is determinant to the hemodynamic outcome of CRT. As consequence of the different mechanism of optimization of CRT, different protocols are being employed for optimization of CRT, using either filling (E-A-wave separation, diastolic filling times) or systolic parameters with respect to the latter either externally measured indices, like aortic velocitytime integral and systolic blood pressure are being used as well as device-based algorithm using signals from lead electrograms or accelerometer sensors. ${ }^{3-5}$ Clearly, better insight in the mechanisms of CRT optimization may help to further improve the clinical approaches to create the largest benefit of CRT. This is particularly true in consideration of a possible expansion of the indication to CRT after the BLOCK-HF study supporting previous single center observations that biventricular pacing may be preferred over RV-pacing in patients with heart failure. ${ }^{6}$

It was the aim of the present study to evaluate the acute hemodynamic response during CRT optimization, focusing on the fusion of the activation wave fronts originating from pacing electrodes and/or intrinsic conduction, the effects of $\mathrm{AV}$ intervals on ventricular filling and the resulting changes in LV pump function. In order to investigate these effects, electrical mapping and hemodynamic measurements were performed in the established canine models ${ }^{7}$ of $\mathrm{LBBB}$ and AV-block during extensive CRT optimization. Comparison between these two animal models will 
indicate the role of intrinsic conduction in optimization and may show whether CRT optimization protocol can be similar in both patients with complete AV block and those presenting ventricular conduction disturbance as LBBB.

\section{Methods}

Animal handling was performed according to the Dutch Law on Animal Experimentation and the European Directive for the Protection of Vertebrate Animals Used for Experimental and Other Scientific Purposes. The protocol was approved by the Animal Experimental Committee of Maastricht University.

\section{Experimental setup and pacing protocol}

The experiments were performed on 14 adult mongrel dogs of either sex and unknown age. Animals were induced by intravenous pentothal administration and anesthetized by continuous infusion of midazolam $(0.25 \mathrm{mg} / \mathrm{kg} / \mathrm{h}$ i.v. $)$ and sufentanyl $(3 \mu \mathrm{g} / \mathrm{kg} / \mathrm{h}$ i.v.). Radiofrequency ablation was used to create LBBB in 8 dogs and complete AV-block in 6 dogs. ${ }^{8}$ In the LBBB dogs, CRT studies were performed 16 weeks after ablation, to allow for ventricular remodeling to occur. ${ }^{8}$ One 7F catheter tip manometer (CD-Leycom Zoetermeer, the Netherlands) was used to measure RV pressure whereas a 7F combined catheter-tip manometer and conductance catheter was used to measure LV pressure and volume. A pacing lead was transvenously inserted into the right atrium. After thoracotomy, two multielectrode bands holding 102 contact electrodes were placed around the heart which measured local LV and RV epicardial electrograms, a basal posterolateral electrode was selected for LV pacing., 10 An additional electrode was placed at the apex. A multi-electrode catheter (Daig Livewire TC, Minnetonka, MN) placed in the RV was used for mapping and its most distal electrode was used for RV apical pacing. A schematic overview of the experiment is shown in igure 1A. For baseline measurements, atrial pacing occurred at a rate approximately 10 beats per minute above the intrinsic sinoatrial rate (see figure $1 \mathrm{~B}$ for an example of an $\mathrm{LVdP} / \mathrm{dt}$ tracing). In the AV-block dogs, additional RV apical pacing was used for baseline measurements (at an AV-interval of $125 \mathrm{~ms}$ ). AV-intervals were then programmed individually for the RV and the LV, ranging from 50 to $230 \mathrm{~ms}$ in randomized steps of $20 \mathrm{~ms}$, resulting in one hundred possible combinations of A-LV and A-RV intervals. Baseline recordings were performed before every four settings (as shown in Figure 1C) which were used to calculate relative changes. Hemodynamic and electrocardiographic data were recorded for a minimum of two respiratory cycles. 
A Schematic set-up of pacing system \& $\mathrm{LVd} P / \mathrm{d} t$ measurements
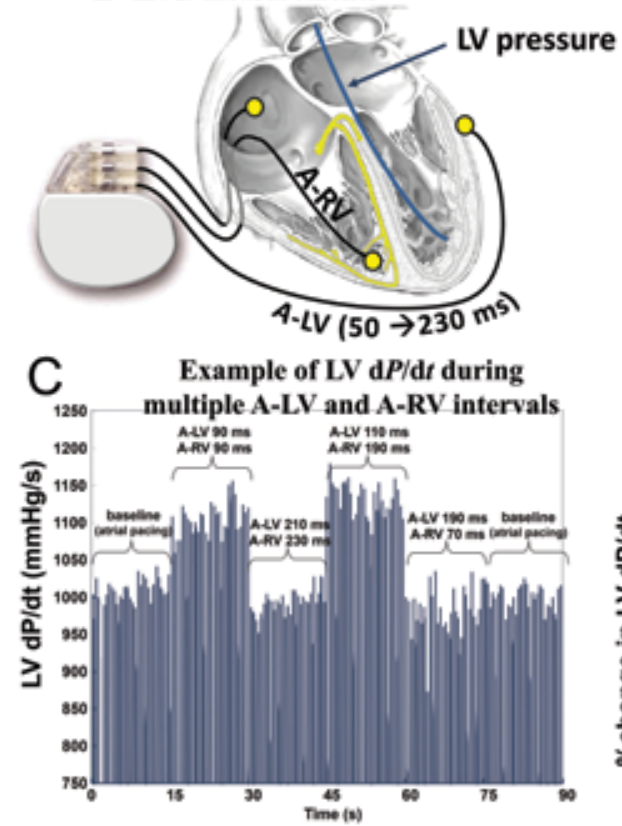

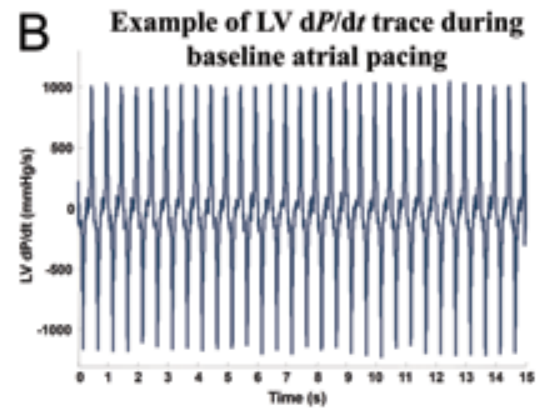

D \%change in $L V \mathrm{~d} P / \mathrm{d} t_{\max }$ for all $\mathrm{A}-\mathrm{LV}$ and $A-R V$ intervals in a single subject

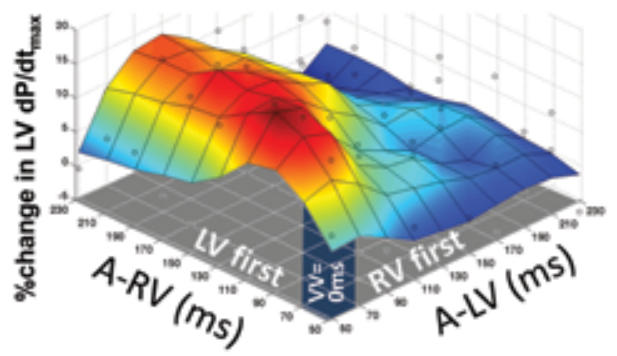

Figure 1. Methods for measuring relative change in $\mathrm{LVdP} / \mathrm{dt}_{\text {max }}$ for $100 \mathrm{~A}-\mathrm{RV} / \mathrm{A}$ LV intervals. (A) Set-up of pacing leads and pressure-catheter. (B) Example of an $\mathrm{LVdP} / \mathrm{dt}$ tracing during baseline atrial pacing (C) and during four A-RV/A-LV interval-combinations flanked by baseline recordings. (D) A quadratic fit was applied to the $\mathrm{LVdP} / \mathrm{dt}_{\text {max }}$ data (black circles) to minimize measurement variation effects.

\section{Data analysis}

From the surface-ECG, PR and QRS durations were determined. Depolarization times were calculated for all cardiac mapping electrodes with total activation time (TAT) defined as the maximal depolarization time difference and electrical resynchronization was expressed as the percentage decrease in TAT when compared with baseline. ${ }^{9}$ Electrical activation maps were created by plotting the depolarization times on models of cardiac shape using custom MATLAB software (MathWorks, Natick, MA). ${ }^{9,10}$ Mechanical interventricular dyssynchrony (MIVD) was determined as the absolute time delay between normalized upslopes of simultaneously recorded LV and RV pressure curves. ${ }^{8}$ Stroke work was calculated as the area of the pressurevolume diagram. Electrical resynchronization, MIVD and relative change in LVdP/ $\mathrm{dt}_{\max }$ and stroke work were plotted in relation to the A-LV/A-RV interval in contour plots. Quadratic fitting was applied to account for measurement variability (Figure 1D). ${ }^{11}$ Simultaneous $\mathrm{LV}$ and RV pacing at an AV-interval of $110 \mathrm{~ms}\left(\mathrm{CRT}_{110}\right)$ 
ensured full biventricular capture in all dogs and was regarded as "out-of-the-box" CRT. When a setting resulted in a percentage $\mathrm{LVdP} / \mathrm{dt}_{\max }$ increase of at least $90 \%$ of the maximal $\mathrm{LVdP} / \mathrm{dt}_{\max }$ value, the setting was identified as optimal $\left(\mathrm{CRT}_{\text {opt }}\right)$.

\section{Statistical analysis}

Continuous data are presented as mean \pm standard deviation (SD) and median with first and third quartiles (Q1-Q3). Continuous variables were compared using the Wilcoxon rank sum test or Mann-Whitney $U$ test for dependent or independent observations respectively. A P-value $<0.05$ was considered statistically significant. Statistics were performed using MATLAB (MathWorks, Natick, MA).

\section{Results}

The baseline characteristics of the LBBB group and the complete AV-block group are described in Table 1. There were no significant differences found in measures of ventricular dyssynchrony or systolic pump function between the two groups. PRduration was shorter in the dogs with complete AV-block $(p=0.03)$ as AV-interval during RV apex pacing was set at $125 \mathrm{~ms}$ while intrinsic PR-duration in the LBBB dogs ranged from 108 to $218 \mathrm{~ms}$ (median $162 \mathrm{~ms}$ ).

Table 1. Baseline electrocardiographic and hemodynamic characteristics from LBBB dogs during atrial pacing $(n=8)$ and AV-block dogs during atrial $+R V$ pacing $(n-6)$.

\begin{tabular}{|c|c|c|c|}
\hline & $\begin{array}{c}\text { LBBB } \\
(n=8)\end{array}$ & $\begin{array}{c}\text { AV-block } \\
(n=6)\end{array}$ & P-value \\
\hline Heart rate (bpm) & $119 \pm 15$ & $113 \pm 13$ & 0.57 \\
\hline Total activation time $(\mathrm{ms})$ & $98 \pm 10$ & $103 \pm 10$ & 0.24 \\
\hline PR time (ms) & $162 \pm 34$ & $125^{*}$ & 0.03 \\
\hline QRS duration (ms) & $108 \pm 8$ & $112 \pm 10$ & 0.23 \\
\hline QTc duration (ms) & $398 \pm 21$ & $417 \pm 32$ & 0.35 \\
\hline $\mathrm{LV} \mathrm{P}_{\max }(\mathrm{mmHg})$ & $84 \pm 8$ & $79 \pm 7$ & 0.41 \\
\hline $\mathrm{LV} \mathrm{d} P / \mathrm{d} t_{\max }(\mathrm{mmHg} / \mathrm{s})$ & $1299 \pm 289$ & $1240 \pm 172$ & 0.57 \\
\hline $\mathrm{LV} \mathrm{d} P / \mathrm{d} t_{\min }(\mathrm{mmHg} / \mathrm{s})$ & $-1240 \pm 130$ & $-977 \pm 275^{*}$ & 0.03 \\
\hline LV EDP (mmHg) & $9 \pm 3$ & $7 \pm 2$ & 0.23 \\
\hline LV EDV (ml) & $66 \pm 26$ & $72 \pm 42$ & 0.95 \\
\hline LV SV (ml) & $26 \pm 11$ & $24 \pm 7$ & 0.75 \\
\hline LV SW (mmHg*ml) & $2016 \pm 994$ & $1571 \pm 501$ & 0.41 \\
\hline Mechanical interventricular dyssynchrony (ms) & $-33 \pm 4$ & $-26 \pm 15$ & 0.28 \\
\hline
\end{tabular}

Means \pm S.D. are given; ${ }^{*} \mathrm{p}<0.05$ as compared with LBBB 


\section{Electrophysiological effects of altering stimulation timings in CRT}

Figure 2 shows electrical contact maps acquired from an LBBB dog during four settings; atrial pacing without ventricular capture (LBBB), single-site LV pacing, "out-of-the-box" CRT (CRT ${ }_{110}$, A-LV and A-RV $110 \mathrm{~ms}$ ) and CRTopt (A-LV 110 ms, A-RV $180 \mathrm{~ms}$ ). During A-LV and A-RV of $230 \mathrm{~ms}$ ventricular capture is lost (indicated by the dashed lines) and a typical LBBB electrical activation pattern was observed with most delayed activation in the LV free wall (top-left panel). During single-site LV pacing at a short AV-interval (top-right panel), the activation pattern as observed during $\mathrm{LBBB}$ was largely reversed, with latest activation of the RV free wall. The reversed activation pattern coincided with an increase in TAT during LV-pacing (121 ms) as compared with LBBB (98 ms), also indicated by the larger and darker blue latest activation region. During $\mathrm{CRT}_{110}$ two activation wave fronts originating from the stimulated RV and LV electrodes fuse and resynchronized the heart as evidenced by a decrease of TAT to $79 \mathrm{~ms}$. In the $\mathrm{CRT}_{\text {opt }}$ example, RV capture is lost (A-RV $180 \mathrm{~ms}$ ) but the LV activation wave front (A-LV $110 \mathrm{~ms}$ ) fuses with an intrinsic activation wave from the right bundle. The electrical activation wave fronts resulted in an alternative electrical resynchronization of the heart with a TAT decrease to $78 \mathrm{~ms}$, comparable to simultaneous biventricular pacing.

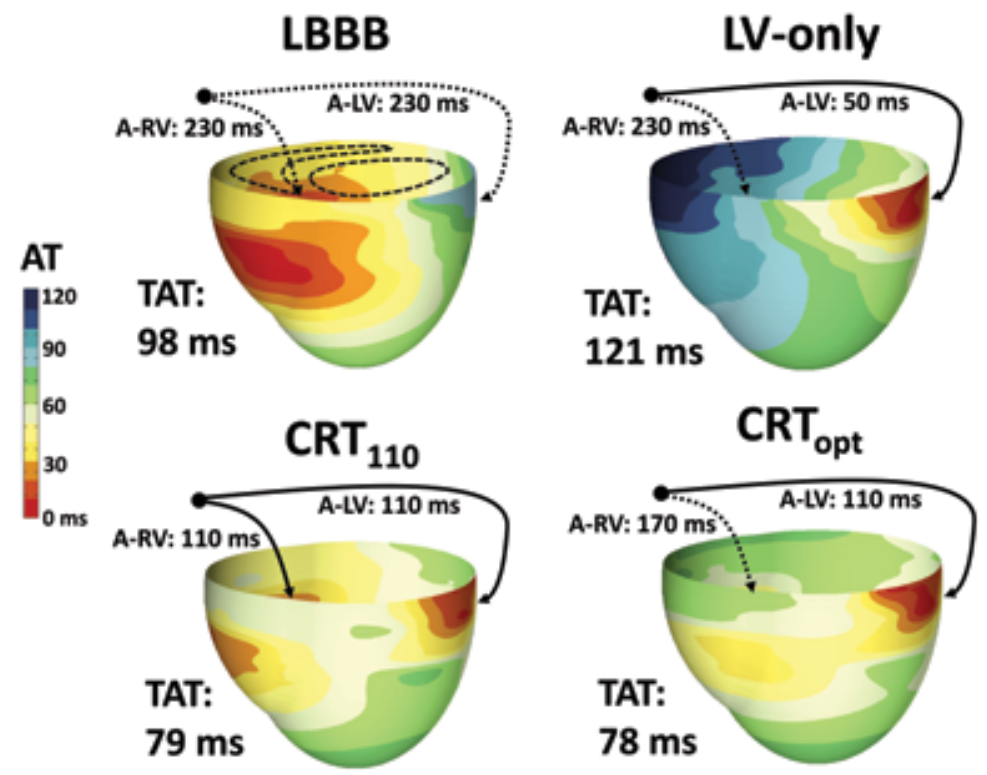

Figure 2. Electrical activation maps during $\mathrm{LBBB}, \mathrm{LV}$ pacing at short AV-interval (A-LV = $50 \mathrm{~ms})$, simultaneous biventricular pacing at short AV-interval (CRT50, $A-L V$ and $A-R V=50 \mathrm{~ms}$ ) and CRTopt. The solid arrows indicate ventricular capture while the dashed arrows indicate loss-of-capture. TAT; total activation time. 
The top panel of Figure 3 displays electrical resynchronization, defined as the $\%$ reduction in TAT, for all 100 settings. LV-pacing at short A-LV increased electrical dispersion while biventricular pacing at short AV-intervals resulted in a greater homogeneous electrical activation. Intrinsic conduction through the AV-node and right bundle was possible, enabling fusion between LV pacing-induced wave front and intrinsic conduction. This is shown by the "leftward" turn where pacing at an A-LV interval resulting in at least partial LV capture and a delayed A-RV interval resulting in loss of RV capture allows similar electrical resynchronization as biventricular pacing at short AV-interval. In a dog with AV-block, electrical resynchronization was identical over a range of AV-intervals and a set offset between A-LV and A-RV (Figure 3, top right panel). Since there was no conduction possible through the bundle branches, only the interventricular delay (offset A-LV and A-RV) determined TAT. On average, TAT could be decreased by an average of 22\% (median of 20\%, Q1-Q3: 17\% - 25\%) during the optimization protocol, a decrease that was similar to that in LBBB dogs: mean value $22 \%$ (median $24 \%$, Q1-Q3: 19\% - 26\%, p=0.67 between the two groups).

A
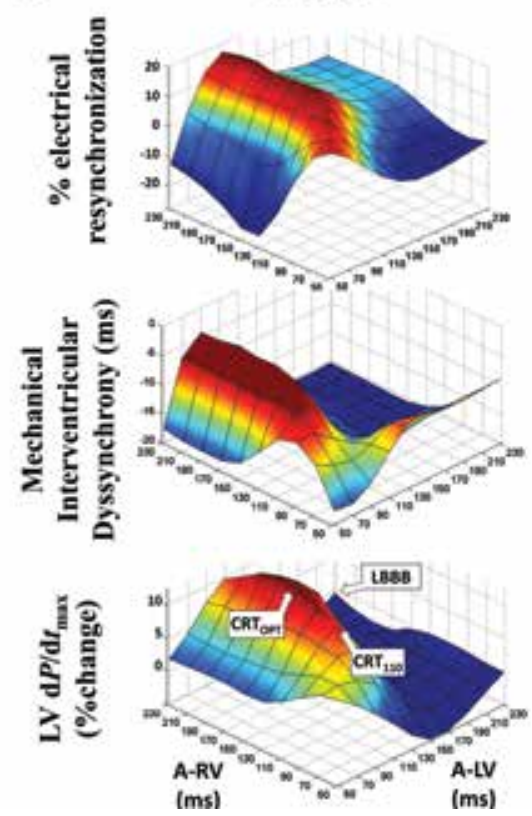

B AV-block

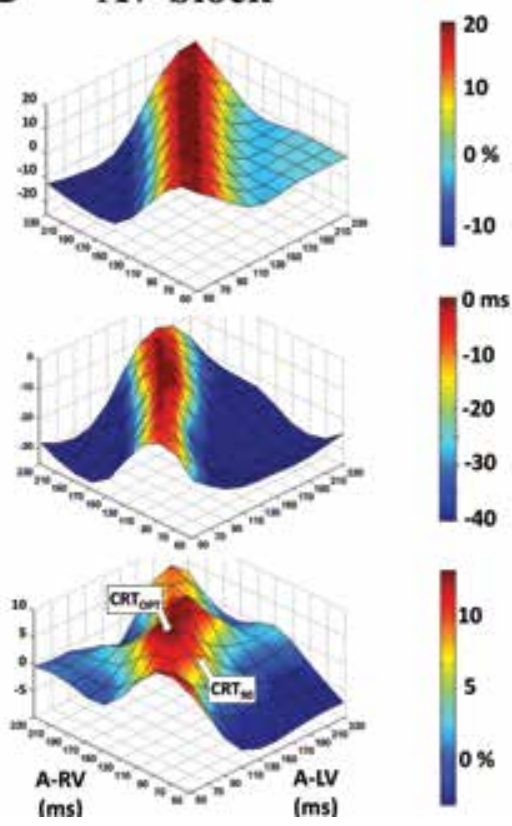

Figure 3. Surface plots of electrical resynchronization (top) inversed mechanical interventricular dyssynchrony (middle) and percentage change in $\mathbf{L V d P} / \mathrm{dt}_{\text {max }}$ (bottom) during one-hundred possibilities of A-LV and A-RV interval-combinations as compared to baseline measurements from a single experiment in a dog with $A$ ) LBBB and B) complete AV block. 


\section{Hemodynamic effects of altering stimulation timings in CRT}

The pattern of mechanical interventricular dyssynchrony (MIVD, Figure 3) matched well with that of electrical resynchronization. MIVD could be diminished to less negative values during biventricular capture and during LV "fusion-pacing" in the LBBB heart. Consequently, the ridge of minimal MIVD showed a similar leftward turn as seen during electrical resynchronization. In the LBBB hearts, CRT at the "out-of-the-box" setting $\left(\mathrm{CRT}_{110}\right)$ increased $\mathrm{LVd} P / \mathrm{d} t_{\max }$ by $10 \pm 4 \%$ (median 11\%, Q1-Q3: 8\% - 13\%) as compared with baseline atrial pacing $(\mathrm{p}=0.008)$. The optimization protocol effectuated a further increase in $\mathrm{LVdP} / \mathrm{dt}_{\max }$ to $15 \pm 4 \%$ above baseline (median 16\%, Q1-Q3: 11\% - 19\%, p=0.008 vs. baseline and vs. CRT ${ }_{110}$ ). The LVdP/dt ${ }_{\max }$ surface plot showed a "ridge" of optima rather than a sharp peak, indicating that CRT ${ }_{\text {opt }}$ could be reached at multiple settings. CRT $T_{\text {opt }}$ settings were found during biventricular pacing, but also during LV pre-excitation at longer AVintervals where the leftward ridge indicate fusion between pacing induced activation wave front(s) and the intrinsic activation wave front. For all LBBB experiments, optimal acute response was found during simultaneous biventricular pacing $(n=4)$, LV pre-excitation (20 ms, $n=3 ; 40 \mathrm{~ms}, \mathrm{n}=1$ ) or $\mathrm{RV}$ pre-excitation (20 ms, $\mathrm{n}=1$ ). The leftward ridge (fusion with intrinsic conduction) occurred during A-LV intervals ranging from 70 to $190 \mathrm{~ms}$. Between experiments, the number of A-LV/A-RV interval combinations, which resulted in $\mathrm{CRT}_{\mathrm{OPT}}$ varied between 2 to 6 combinations out of a possible 100 (median of 4 combinations).
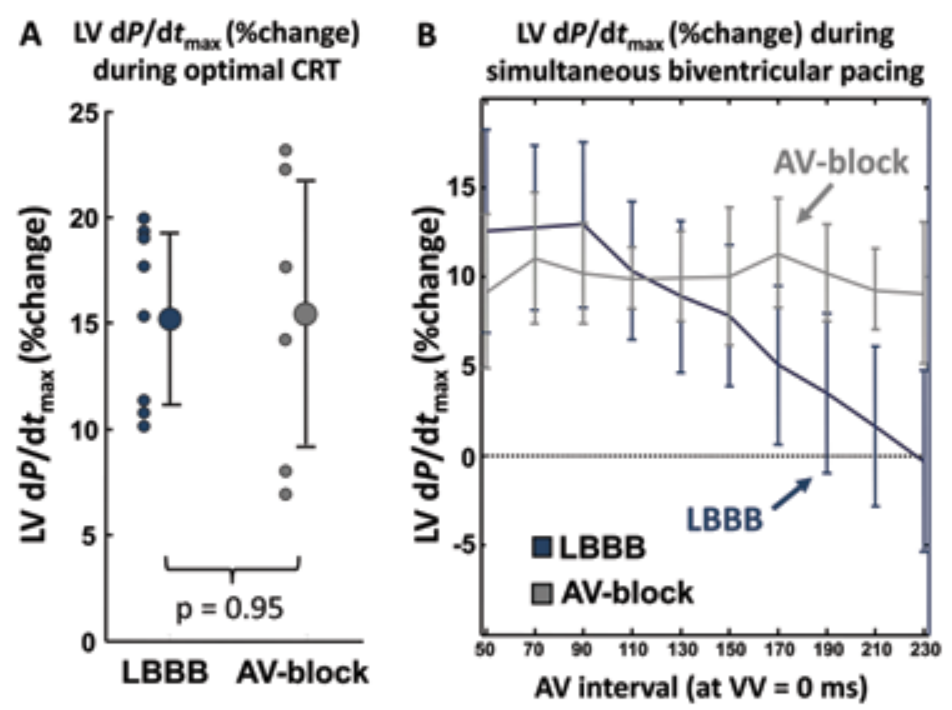

Figure 4. $\% \mathrm{LVdP} / \mathrm{dt}_{\max }$ increase in LBBB and AV-block dogs at A) CRT ${ }_{\text {opt }}$ and B) during biventricular pacing at increasing AV-intervals. Means \pm S.D. are shown. 
Contrary to observations in LBBB, in hearts with complete AV-block changes were similar for a fixed VV-interval over a large range of AV-intervals. The optimal settings for the example shown in Figure 3 (right panels) were consistently seen at $20 \mathrm{~ms}$ LV pre-excitation, expressed in the surface plot as a straight ridge. For all AV-block experiments, the $\mathrm{LVdP} / \mathrm{dt}_{\max }$ increase at $\mathrm{CRT}_{\text {opt }}$ was $15 \pm 6 \%$ (median 14\%, Q1-Q3: 9\% - 21\%) compared with RV pacing ( $\mathrm{p}=0.03)$, an increase similar to what was found in the LBBB dogs $(\mathrm{p}=$ N.S., Figure $4 A$ ). In all AV-block hearts $\mathrm{LVdP} / \mathrm{dt}_{\max }$ showed optima at LV pre-excitation ranging from 20 to $40 \mathrm{~ms}$, over the whole range of $\mathrm{AV}$-intervals. Figure $4 \mathrm{~B}$ indicates the importance of ventricular synchronization and the limited influence of atrial contraction on $\mathrm{LVdP} / \mathrm{dt}_{\max }$ in the range of $\mathrm{AV}$-intervals tested.
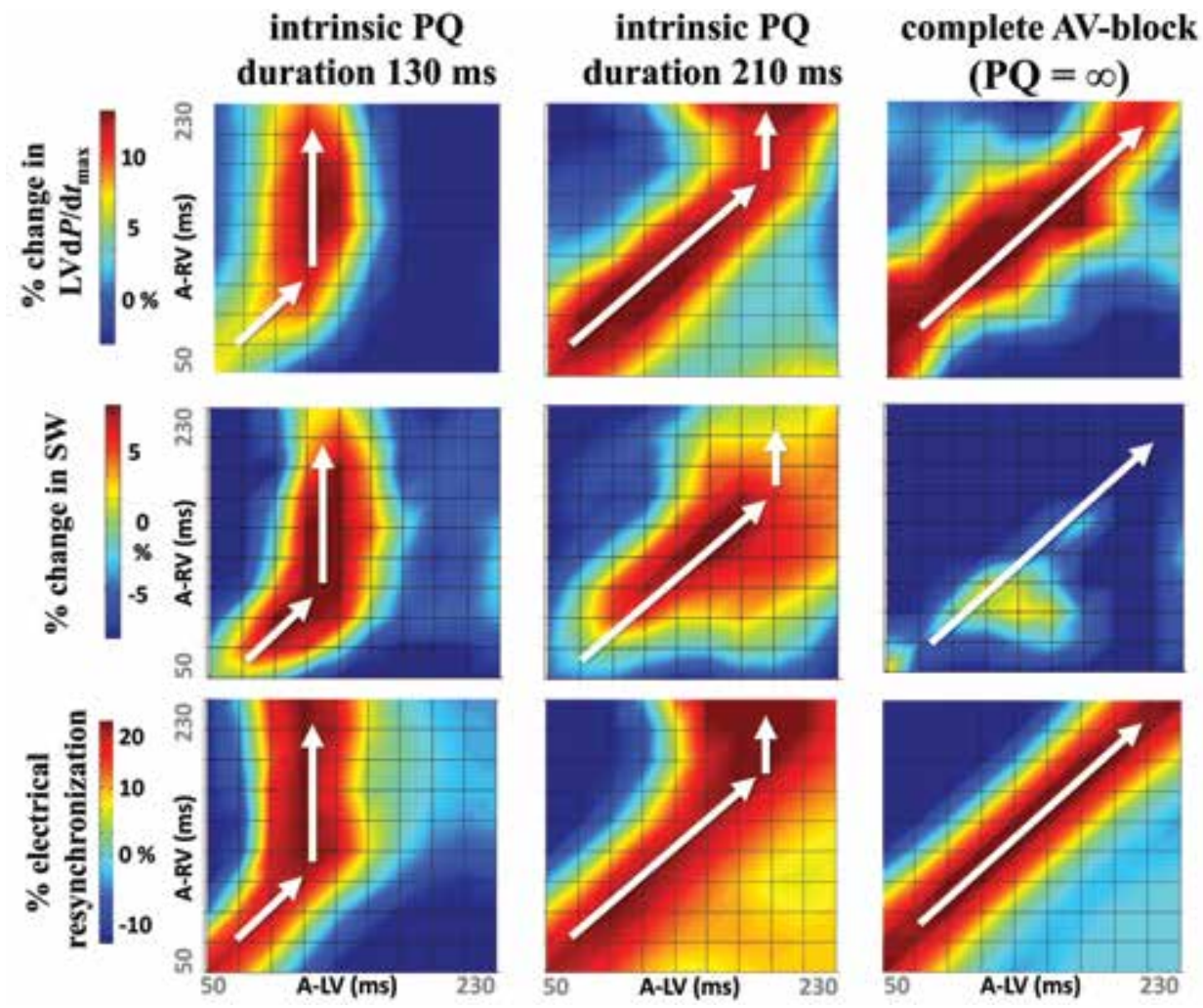

Figure 5. Surface plots of percentage change in LVdP/dtmax (top panels) and electrical resynchronization (bottom panels) during one-hundred possibilities of A-LV and A-RV interval-combinations in three experiments with varying underlying intrinsic AV-conduction: ranging from PQ duration of $143 \mathrm{~ms}$ (left panel, same experiment as Figure 2 and $3 A$ ) to $201 \mathrm{~ms}$ (center panel) to complete AV-block (right panel, same experiment as Figure $3 B$ ). 
Figure 5 shows that the "ridge" of highest $\mathrm{LVd} P / \mathrm{d} t_{\max }$ values (top panels) matched with that of highest stroke work (middle panels) and of lowest TAT (bottom panels) in two LBBB and one AV-block experiment. In addition, the "leftward turn" in $\mathrm{LVd} P / \mathrm{d} t_{\text {max }}$ seen in the LBBB hearts (left and center panels) was also observed for stroke work and TAT, which strongly indicates contribution of intrinsic conduction at these settings. The location of the leftward turn in the matrix was mainly dependent on PQ-interval during baseline LBBB. The individual behavior for all 14 experiments are depicted in Figure 6 for TAT, Figure 7 for $\mathrm{LVdP} / \mathrm{dt}_{\max }$ and Figure 8 for SW.

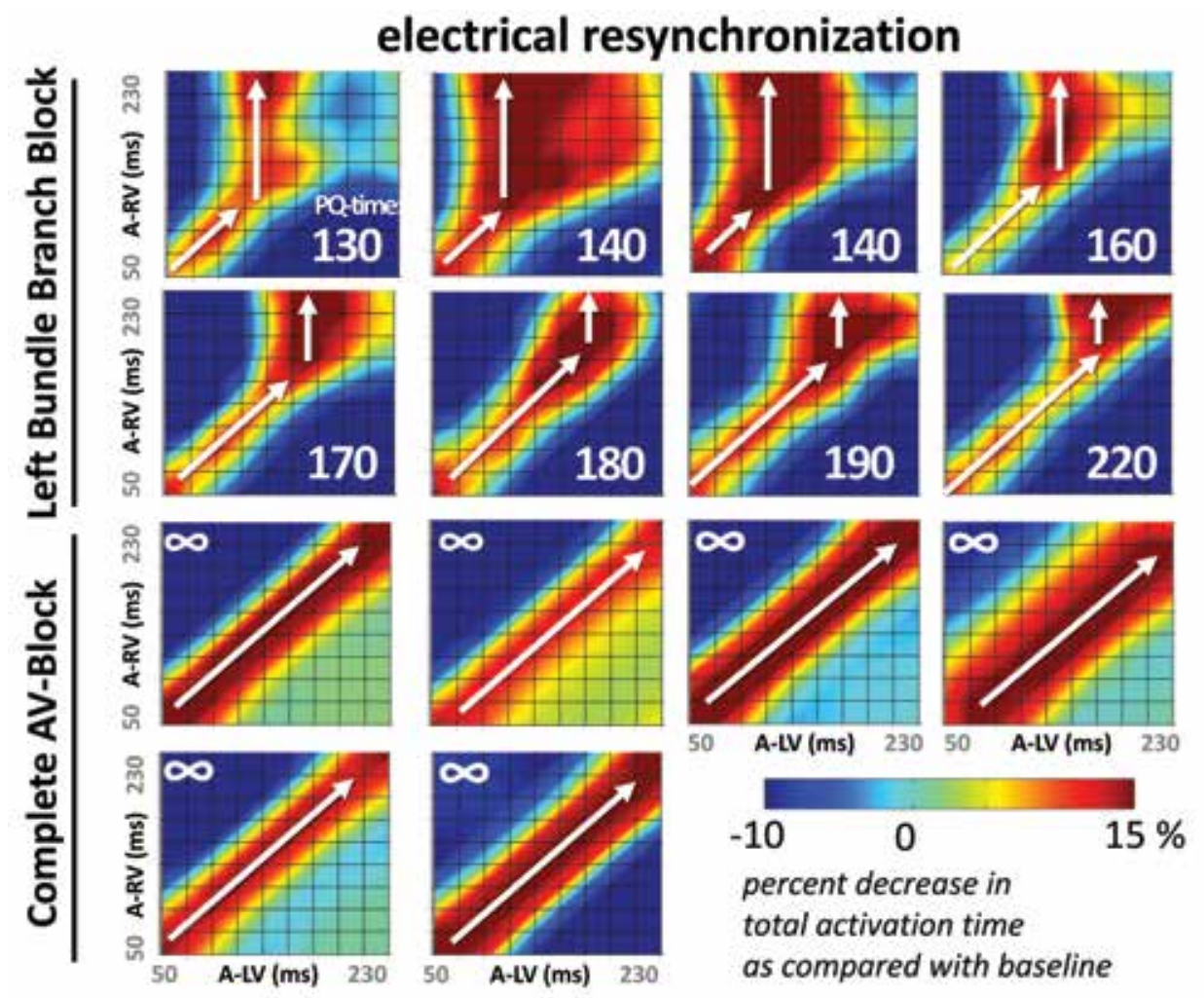

Figure 6. Contour plots of electrical resynchronization (percentage decrease in TAT) of all experiments grouped by LBBB or AV-block dogs and sorted according to intrinsic PQ-duration. Arrows show ridge of optima. 


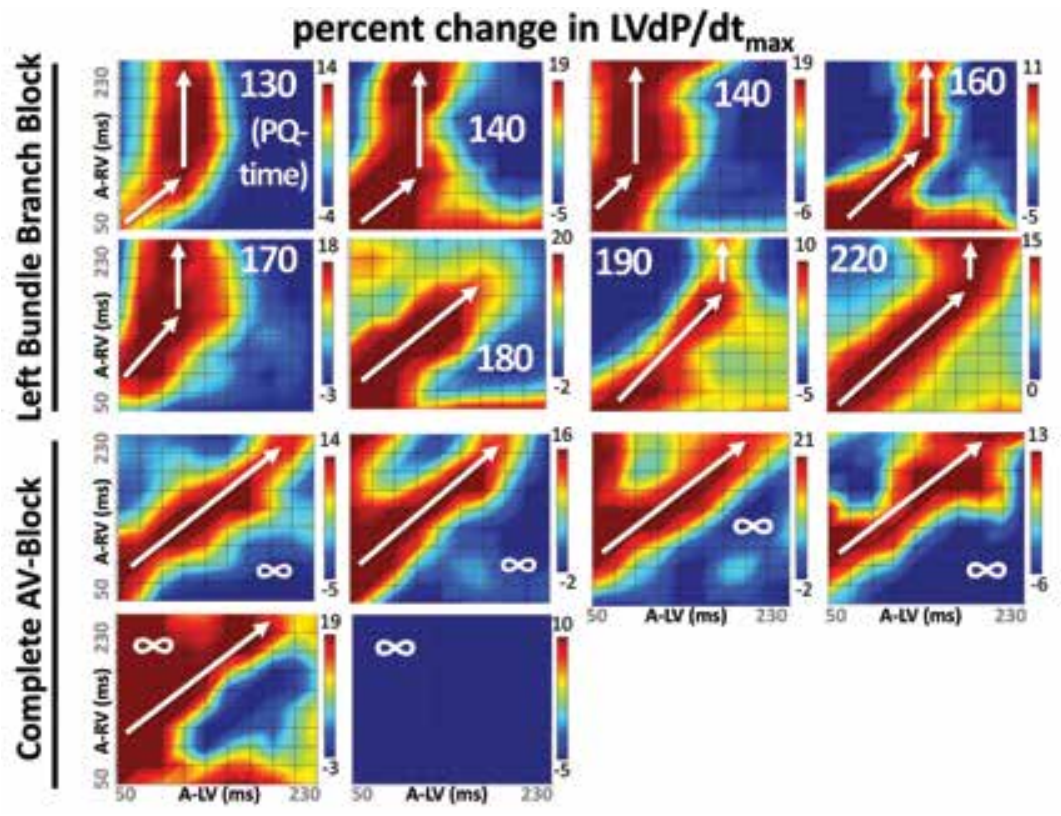

Figure 7. Contour plots of $\%$ change in $L V d P / d_{\text {max }}$ of all experiments grouped by LBBB or AV-block dogs and sorted according to intrinsic PQ-duration. Arrows show ridge of optima

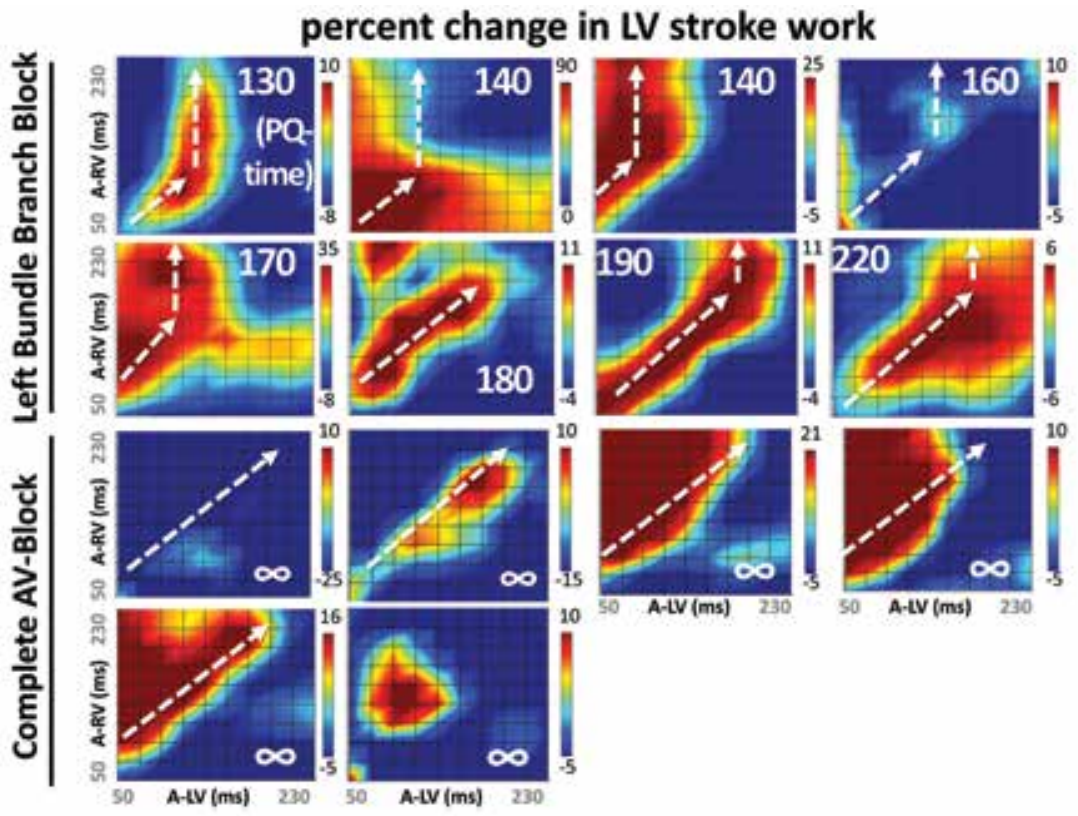

Figure 8. Contour plots of percentage change in stroke work of all experiments grouped by LBBB or AV-block dogs and sorted according to intrinsic PQ-duration. Dashed arrows show ridge of $\mathrm{LVdP} / \mathrm{dt}_{\text {max }}$ optima (Figure 7). 
A LBBB B AV-block
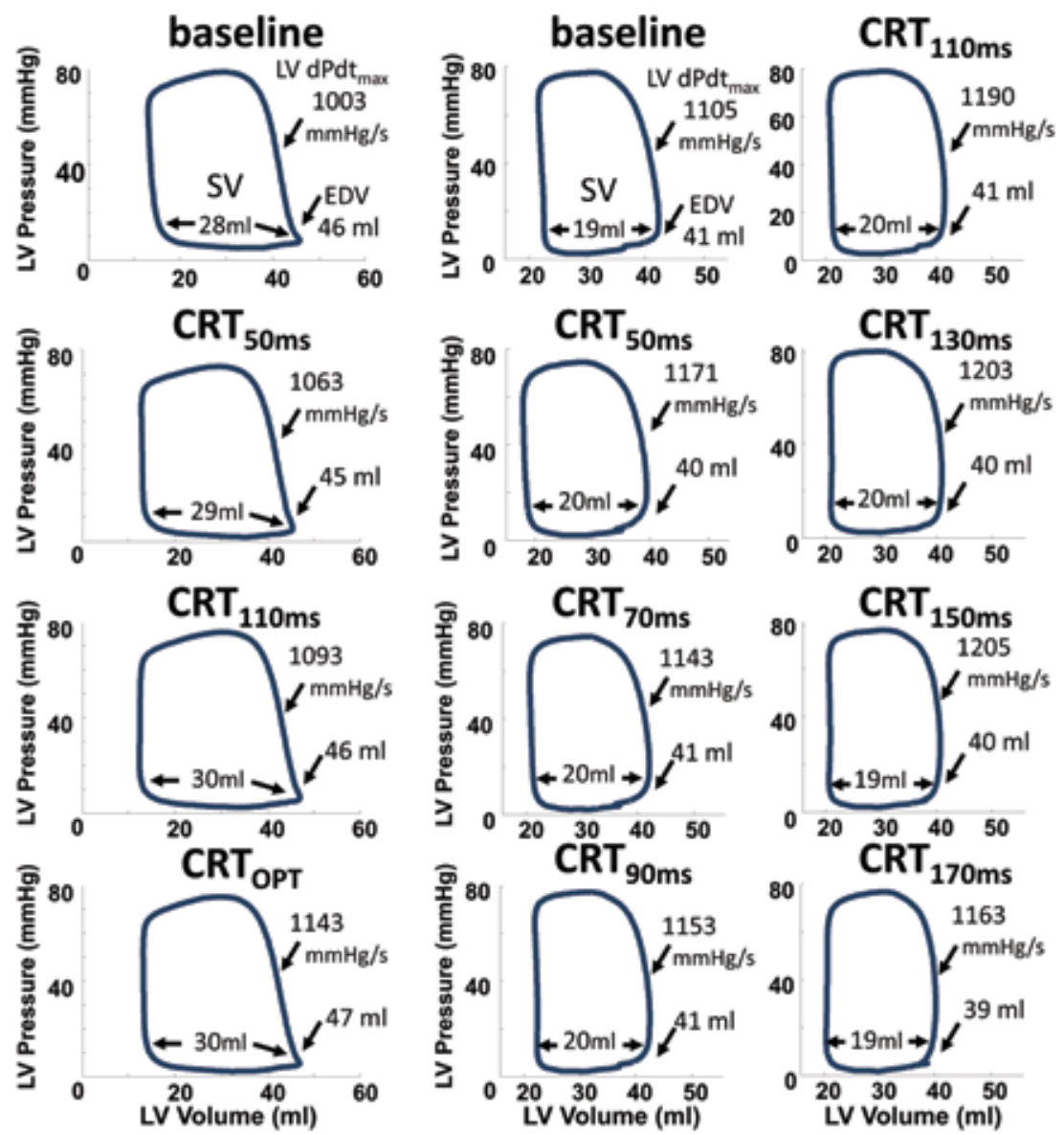

Figure 9. Examples of pressure-volume loops during baseline and CRT with increasing AV-interval in a dog with LBBB (blue loops in left panels, same experiment as in Figure 2A) or AV-block (red loops in center and right panels, same experiment as in Figure 2B).

\section{Effects of AV/VV intervals on LV filling}

In dogs with LBBB the differences in LV EDV between baseline atrial pacing, CRT at shortest $\mathrm{AV}$-interval $(50 \mathrm{~ms})$, at $\mathrm{CRT}_{110}$ and $\mathrm{CRT}_{\mathrm{opt}}$ were small, while changes in $\mathrm{LVdP} / \mathrm{dt}_{\max }$ were apparent (Figure 9A). Also in dogs with complete AV-block, simultaneous biventricular pacing over a wide range of $\mathrm{AV}$-intervals did not induce notable changes in LV EDV (Figure 9B). For most experiments, EDV remained stable over a wide range of $\mathrm{AV}$-intervals (Figure 10) and did not show parabola patterns such as for $\mathrm{LVdP} / \mathrm{dt}_{\max }$. 


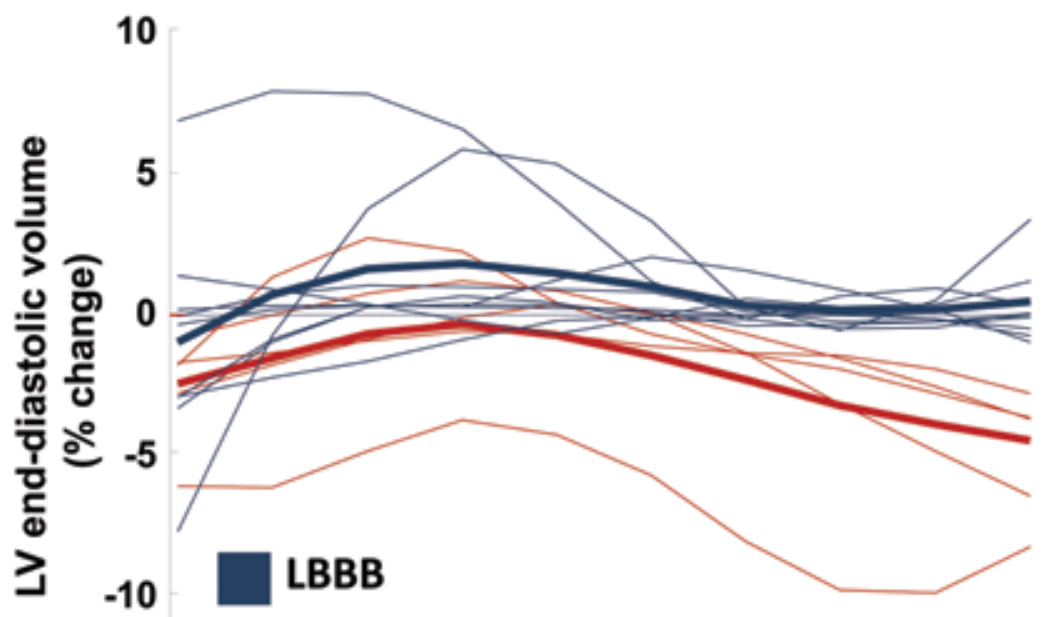

\section{AV block}

\section{$\begin{array}{llllllllll}50 & 70 & 90 & 110 & 130 & 150 & 170 & 190 & 210 & 230\end{array}$ $\mathrm{AV}$ delay (at $\mathrm{VV}=0 \mathrm{~ms}$ )}

Figure 10. Average \% change in LV EDV in LBBB (blue color) and AV-block dogs (red color) during simultaneous biventricular pacing at increasing AV-intervals. EDV; end-diastolic volume

\section{Discussion}

The present animal study shows that in hearts with AV-block, the best hemodynamic response, as quantified by $\mathrm{LVdP} / \mathrm{dt}_{\text {max }}$, is achieved at a fixed $\mathrm{VV}$-interval over a wide range of $\mathrm{AV}$-intervals, whereas in hearts with $\mathrm{LBBB}$ the optimal response can also be achieved during $\mathrm{AV}$-intervals that allow contribution from intrinsic activation. The common denominator in both models is that optimal acute hemodynamic response during CRT is achieved by proper electrical and mechanical resynchronization rather than by improvement in filling. These findings may help to design better protocols for CRT optimization in different patient populations.

\section{Resynchronization versus filling}

The present study demonstrates that changing AV-intervals in hearts with LBBB can change the degree of electrical and mechanical resynchronization. In hearts with complete AV-block, resynchronization can only result from biventricular pacing whereas in LBBB hearts intrinsic conduction can deliver an alternative or additional wave front that contributes to resynchronization. 
Our results confirm previous data where it was shown that the "effective" VVinterval, correcting for the contribution by intrinsic conduction, predicts the hemodynamic response during LV, simultaneous and sequential biventricular pacing. ${ }^{12}$ The "leftward curves" accentuate the importance of recognizing the contribution of intrinsic conduction to individual optimization. The close relation between maximal resynchronization and optimal hemodynamic effect in the AV-block and LBBB model strongly support the role of resynchronization as general concept.

The present study also indicates that CRT optimization is not notably determined by modification of ventricular filling. In hearts with complete AV-block the AVinterval was varied over a wide range and very little changes were noted in ventricular filling volume or pressure. Similarly, in LBBB hearts maximal values of $\mathrm{LVd} P / \mathrm{d} t_{\max }$ were achieved despite minor changes in ventricular filling. Although the degree of dilatation is undoubtedly more pronounced in CRT patients than in the dog models used in this study, also clinical studies have indicated that AV-intervals influence ventricular filling only to a limited amount. This has been demonstrated by acute studies using PV-loop analysis in CRT patients ${ }^{13}$ and measurements of LV enddiastolic pressure. ${ }^{14}$ In addition, a recent sub-analysis of the MADIT-CRT trial revealed that the lowest incidence of heart failure events and mortality (combined endpoint) and largest echocardiographic response was found in patients with programmed AV-interval between 80 and $99 \mathrm{~ms}$, which is shorter than commonly found for achieving optimal E-A wave separation. ${ }^{15}$

\section{Hemodynamic effects of CRT Optimization}

The observation that optimization leads to an additional relative increase in LVdP/ $\mathrm{dt}_{\text {max }}$ of approximately $50 \%$ on top of that achieved by "out-of-the-box" CRT (from $\approx 10 \%$ to $\approx 15 \%$ above baseline LBBB), is in agreement with clinical data. ${ }^{16}$ Interestingly, the surface plots do not show a "steep peak" of a single optimum but rather a "ridge" of multiple optima, matching with findings from Zuber et al. who showed that in most of twenty matrix-optimized patients no global optimum was seen but rather several optimal AV/VV interval combinations. ${ }^{17}$ More abrupt peaks, as shown by other studies, may have been caused by variability in the measurement of $\mathrm{LVd} P / \mathrm{d} t_{\max }$ which we accounted for by quadratic fitting of relative changes.

A recent study shows that stroke work is a better predictor of long term CRT response than $\mathrm{LVdP} / \mathrm{dt}_{\max }{ }^{18}$ In the present study we found that the optimal 
pacemaker settings for $\mathrm{LVdP} / \mathrm{dt}_{\text {max }}$ closely matched those for optimal stroke work. The differences in the patterns of optimization between the two hemodynamic parameters may be due to the fact that $\mathrm{LVdP} / \mathrm{dt}_{\max }$ reflects only the isovolumic contraction of cardiac systole, while LV SW comprises the full systolic phase and incorporates both pressure and volume changes, and that catheter movement artifacts add to the variability of this measurement. ${ }^{19}$

\section{Potential clinical implications}

Extrapolation of data from the experimental to the clinical situation should always be done with care. However, the canine models of AV-block and LBBB have been shown to provide data that apply quite well to the human situation, due to the similarities in anatomy and conduction system. ${ }^{20} \mathrm{~A}$ first important potential implication is that CRT can provide similar hemodynamic benefit in hearts with LBBB and hearts with AV-block or in those with chronic atrial fibrillation and slow ventricular conduction requiring continuous pacing. The latter condition is present in patients with AV-block (intrinsic or after His-ablation) receiving a de novo implant or who are upgraded to CRT. It has been shown in single-center studies and the BLOCK-HF study that CRT preserves LV function better and reduces mortality and heart failure events than RV-pacing in patients with AV-block. ${ }^{6}{ }^{21}$ Furthermore, for these patients the present data imply that a proper setting of $\mathrm{VV}$-interval appears more critical than that of AV-interval.

For LBBB patients an implication of the present results is that optimization of the interventricular delay or allowing contribution of intrinsic conduction may improve the benefit of CRT as compared to "out-of-the-box" settings, as has been recognized earlier. ${ }^{22}$ As a consequence the present study provides a rationale for identifying and modifying the electro-mechanical substrate for CRT optimization. Evidence for this idea has already been observed in an analysis of data from the PATHCHF-I study, since MIVD could predict optimal increase in $\mathrm{LVd} P / \mathrm{d} t_{\text {max }}$ without changing LV EDP. ${ }^{14}$ Furthermore, the data show that LV "fusion" pacing may be at least as efficacious as BiV pacing, as also has been demonstrated by van Gelder et al. $^{22} \mathrm{~A}$ novel algorithm for automated optimization of AV- and VV-intervals uses information on the A-RV sensing interval to allow such RV-synchronized LV pacing. ${ }^{23}$ Summarizing, the present study indicates the value of the proper interplay of electrical wave fronts for the most effective application of CRT. 


\section{Limitations}

This animal study investigated the acute hemodynamic improvement by CRT without evaluation of its long-term benefit. Acute response may not always predict chronic outcome. ${ }^{24}$ Moreover, the dog models may not recapitulate all characteristics of dyssynchronous heart failure and/or LBBB occurring in patients. The canine model used is representative of non-ischemic LBBB hearts in patients, but may not reflect all abnormalities present in patients with ischemic hearts. However, previous studies from our laboratory showed that in dogs with myocardial infarction on top of LBBB a similar acute hemodynamic can be achieved as in LBBB dogs without infarction, albeit that more attention has to be paid to pacing site and $\mathrm{AV}$-interval. ${ }^{25}$

\section{Conclusions}

In canine hearts with LBBB and AV-block, optimal acute hemodynamic response during CRT is achieved at AV/VV settings that provide the best electro-mechanical resynchronization. In hearts with $\mathrm{LBBB}$ this optimum is reached by interplay of activation waves originating from pacing electrodes and from intrinsic conduction, whereas in hearts with AV-block resynchronization is governed entirely by VVinterval. Changes in ventricular filling do not seem to play a role in achieving the optimal acute hemodynamic effect.

\section{Funding Sources}

This research was performed within the framework of CTMM, the Center for Translational Molecular Medicine (www.ctmm.nl), project COHFAR (grant 01C-203), and supported by the Dutch Heart Foundation. 


\section{References}

1. Abraham WT, Fisher WG, Smith AL, Delurgio DB, Leon AR, Loh E, Kocovic DZ, Packer M, Clavell AL, Hayes DL, Ellestad M, Trupp RJ, Underwood J, Pickering F, Truex C, McAtee P, Messenger J, Evaluation MSGMIRC. Cardiac resynchronization in chronic heart failure. N Engl J Med. 2002;346:1845-1853.

2. Fantoni C, Kawabata M, Massaro R, Regoli F, Raffa S, Arora V, Salerno-Uriarte JA, Klein HU, Auricchio A. Right and left ventricular activation sequence in patients with heart failure and right bundle branch block: A detailed analysis using threedimensional non-fluoroscopic electroanatomic mapping system. J Cardiovasc Electrophysiol. 2005;16:112-119; discussion 120-111.

3. van Geldorp IE, Delhaas T, Hermans B, Vernooy K, Broers B, Klimusina J, Regoli F, Faletra FF, Moccetti T, Gerritse B, Cornelussen R, Settels JJ, Crijns HJ, Auricchio A, Prinzen FW. Comparison of a non-invasive arterial pulse contour technique and echo doppler aorta velocity-time integral on stroke volume changes in optimization of cardiac resynchronization therapy. Europace. 2011;13:87-95.

4. Raphael CE, Kyriacou A, Jones S, Pabari P, Cole G, Baruah R, Hughes AD, Francis DP. Multinational evaluation of the interpretability of the iterative method of optimisation of av delay for crt. Int J Cardiol. 2012

5. Ellenbogen KA, Gold MR, Meyer TE, Fernndez Lozano I, Mittal S, Waggoner AD, Lemke B, Singh JP, Spinale FG, Van Eyk JE, Whitehill J, Weiner S, Bedi M, Rapkin J, Stein KM. Primary results from the smartdelay determined av optimization: A comparison to other av delay methods used in cardiac resynchronization therapy (smart-av) trial: A randomized trial comparing empirical, echocardiography-guided, and algorithmic atrioventricular delay programming in cardiac resynchronization therapy. Circulation. 2010;122:2660-2668.

6. Curtis AB, Worley SJ, Adamson PB, Chung ES, Niazi I, Sherfesee L, Shinn T, Sutton MS, Biventricular versus Right Ventricular Pacing in Heart Failure Patients with Atrioventricular Block Trial I. Biventricular pacing for atrioventricular block and systolic dysfunction. N Engl J Med. 2013;368:1585-1593.

7. Strik M, van Middendorp LB, Vernooy K. Animal models of dyssynchrony. J Cardiovasc Transl Res. 2012;5:135-145.

8. Vernooy K, Verbeek XA, Peschar M, Crijns HJ, Arts T, Cornelussen RN, Prinzen FW. Left bundle branch block induces ventricular remodelling and functional septal hypoperfusion. Eur Heart J. 2005;26:91-98.

9. Strik M, Rademakers LM, van Deursen CJ, van Hunnik A, Kuiper M, Klersy C, Auricchio A, Prinzen FW. Endocardial left ventricular pacing improves cardiac resynchronization therapy in chronic asynchronous infarction and heart failure 
models. Circ Arrhythm Electrophysiol. 2012;5:191-200.

10. Mills RW, Cornelussen RN, Mulligan LJ, Strik M, Rademakers LM, Skadsberg ND, van Hunnik A, Kuiper M, Lampert A, Delhaas T, Prinzen FW. Left ventricular septal and left ventricular apical pacing chronically maintain cardiac contractile coordination, pump function and efficiency. Circ Arrhythm Electrophysiol. 2009;2:571-579.

11. Cleveland WS. Robust locally weighted regression and smoothing scatterplots. Journal of the American Statistical Association. 1979;74:829-836.

12. Vernooy K, Verbeek XA, Cornelussen RN, Dijkman B, Crijns HJ, Arts T, Prinzen FW. Calculation of effective vv interval facilitates optimization of av delay and vv interval in cardiac resynchronization therapy. Heart Rhythm. 2007;4:75-82.

13. Steendijk P, Tulner SA, Bax JJ, Oemrawsingh PV, Bleeker GB, van Erven L, Putter H, Verwey HF, van der Wall EE, Schalij MJ. Hemodynamic effects of long-term cardiac resynchronization therapy: Analysis by pressure-volume loops. Circulation. 2006;113:1295-1304.

14. Verbeek XA, Auricchio A, Yu Y, Ding J, Pochet T, Vernooy K, Kramer A, Spinelli J, Prinzen FW. Tailoring cardiac resynchronization therapy using interventricular asynchrony. Validation of a simple model. Am J Physiol Heart Circ Physiol. 2006;290:H968-977.

15. Brenyo A, Kutyifa V, Moss AJ, Mathias A, Barsheshet A, Pouleur AC, Knappe D, McNitt S, Polonsky B, Huang DT, Solomon SD, Zareba W, Goldenberg I. Atrioventricular delay programming and the benefit of cardiac resynchronization therapy in madit-crt. Heart Rhythm. 2013

16. Bogaard MD, Doevendans PA, Leenders GE, Loh P, Hauer RN, van Wessel H, Meine M. Can optimization of pacing settings compensate for a non-optimal left ventricular pacing site? Europace. 2010;12:1262-1269.

17. Zuber M, Toggweiler S, Roos M, Kobza R, Jamshidi P, Erne P. Comparison of different approaches for optimization of atrioventricular and interventricular delay in biventricular pacing. Europace. 2008;10:367-373.

18. de Roest GJ, Allaart CP, Kleijn SA, Delnoy PP, Wu L, Hendriks ML, Bronzwaer JG, van Rossum AC, de Cock CC. Prediction of long-term outcome of cardiac resynchronization therapy by acute pressure-volume loop measurements. Eur J Heart Fail. 2013;15:299-307.

19. Mafi Rad M, Blaauw Y, Prinzen FW, Vernooy K. The role of acute invasive haemodynamic measurements in cardiac resynchronization therapy: Looping towards prediction of long-term response and therapy optimization. European journal of heart failure. 2013 
20. Strik M, Regoli F, Auricchio A, Prinzen F. Electrical and mechanical ventricular activation during left bundle branch block and resynchronization. J Cardiovasc Transl Res. 2012;5:117-126.

21. van Geldorp IE, Vernooy K, Delhaas T, Prins MH, Crijns HJ, Prinzen FW, Dijkman B. Beneficial effects of biventricular pacing in chronically right ventricular paced patients with mild cardiomyopathy. Europace. 2010;12:223-229.

22. van Gelder BM, Bracke FA, Meijer A, Pijls NH. The hemodynamic effect of intrinsic conduction during left ventricular pacing as compared to biventricular pacing. J Am Coll Cardiol. 2005;46:2305-2310.

23. Krum H, Lemke B, Birnie D, Lee KL, Aonuma K, Starling RC, Gasparini M, Gorcsan J, Rogers T, Sambelashvili A, Kalmes A, Martin D. A novel algorithm for individualized cardiac resynchronization therapy: Rationale and design of the adaptive cardiac resynchronization therapy trial. Am Heart J. 2012;163:747-752 e741.

24. Bogaard MD, Houthuizen P, Bracke FA, Doevendans PA, Prinzen FW, Meine $\mathrm{M}$, van Gelder BM. Baseline left ventricular dp/dtmax rather than the acute improvement in $\mathrm{dp} / \mathrm{dtmax}$ predicts clinical outcome in patients with cardiac resynchronization therapy. Eur J Heart Fail. 2011;13:1126-1132.

25. Rademakers LM, van Kerckhoven R, van Deursen CJ, Strik M, van Hunnik A, Kuiper M, Lampert A, Klersy C, Leyva F, Auricchio A, Maessen JG, Prinzen FW. Myocardial infarction does not preclude electrical and hemodynamic benefits of cardiac resynchronization therapy in dyssynchronous canine hearts. Circ Arrhythm Electrophysiol. 2010;3:361-368. 
Interplay of Electrical Wave Fronts 

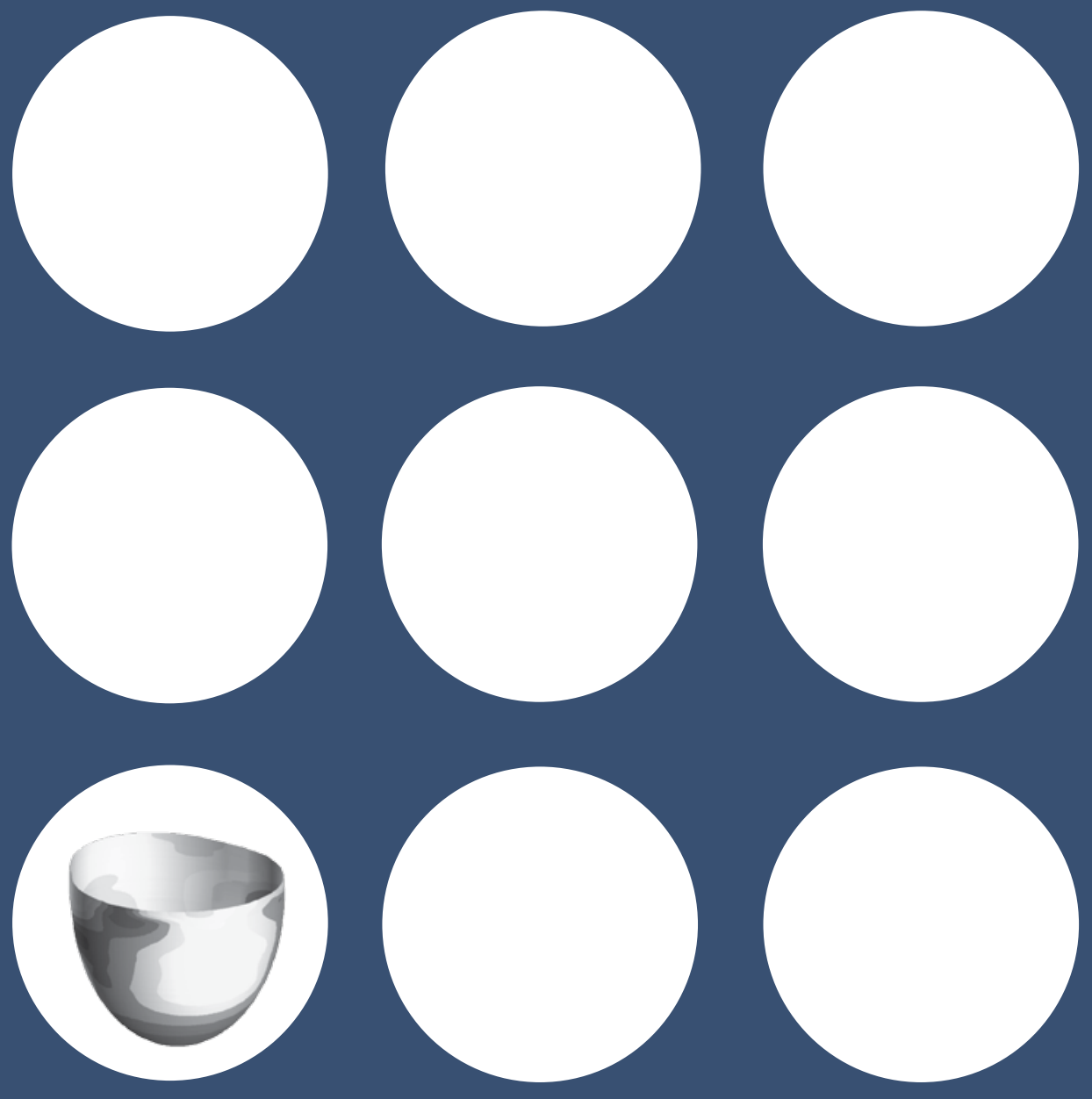

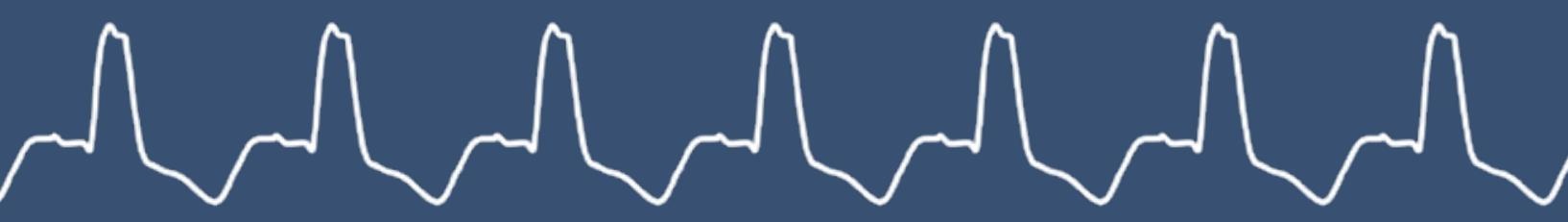

112 


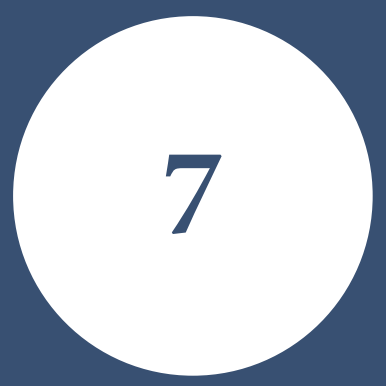

\section{Acute Electrical and Hemodynamic Effects of Multi- Left Ventricular Pacing for CRT in the Dyssynchronous Canine Heart}

Ploux S, Strik M, van Hunnik A, van Middendorp LB, Kuiper M and Prinzen FW

Heart Rhythm. 2013 Oct 9.

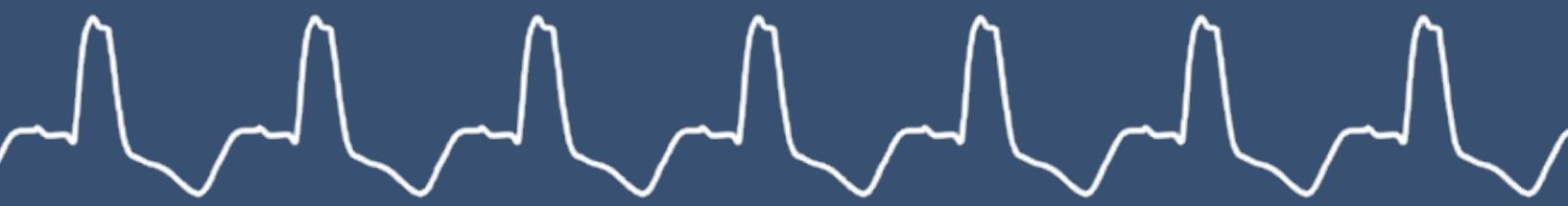


Chapter 7

\section{Abstract}

\section{Background}

Multisite left ventricular (multi-LV) epicardial pacing has been proposed as an alternative to conventional single-site LV (single-LV) pacing to increase efficacy of cardiac resynchronization therapy. We compared the effects of multi- versus single-LV pacing in dogs with left bundle branch block (LBBB).

\section{Methods}

Studies were performed in nine anaesthetized dogs with chronic LBBB using seven LV epicardial electrodes. Each electrode was tested alone and in combination with 1, 2, 3, and 6 other electrodes, the sequence of which was chosen based on practically real time electrical mapping to determine the site of latest activation. LV total activation time (LVTAT) and dispersion of repolarization (DRep) were measured using $\approx 100$ electrodes around the ventricles. LV contractility was assessed as $\mathrm{LVd} P / \mathrm{d} t_{\text {max }}$.

\section{Results}

Single-LV pacing provided on average a $-4.0 \pm 9.3 \%$ change in LVTAT and $0.2 \pm 13.7 \%$ change in DRep. Multi-LV pacing markedly decreased both LVTAT and DRep in a stepwise fashion to reach $-41.3 \pm 5 \%$ ( $p<0.001$ for overall comparison) and $-14.2 \pm 19.5 \% \quad(p<0.02$ for overall comparison) in the septuple-LV pacing configuration, respectively. Single-LV pacing provided a mean $10.7 \pm 7.7 \%$ increase in $\mathrm{LVd} P / \mathrm{d} t_{\max } . \mathrm{LVd} P / \mathrm{d} t_{\text {max }}$ incrementally increased by addition of pacing electrodes to $+16.4 \pm 8.7 \%$ ( $\mathrm{p}<0.001$ for overall comparison). High response to single site-LV pacing could not further be improved during multi-LV pacing.

\section{Conclusion}

Compared to single-LV pacing, multi-LV pacing can considerably reduce both LVTAT and DRep in dogs with LBBB, but the improvement in contractility is limited to conditions where single LV-pacing provides suboptimal improvement. Further studies are warranted to determine if these acute effects translate in antiarrhythmic properties and better long-term outcomes. 


\section{Introduction}

Cardiac Resynchronization Therapy (CRT) is an established treatment for patients with symptomatic heart failure, severely impaired left ventricular (LV) function and conduction disorders, most often in the form of left bundle branch block (LBBB). Large randomized trials have demonstrated that CRT improves quality of life, symptoms, and reduces heart failure related hospitalizations as well as mortality. However, approximately one-third of patients appear not to respond significantly to CRT. ${ }^{1}$

Because CRT is a relatively expensive and invasive technique, requiring virtually irreversible device implantation, there is considerable interest in attempts to improve the response rate. While most attention has been focused on criteria for patient selection, an at least equally important approach is to improve therapy delivery. As the benefits of CRT are particularly thought to result from improved electrical resynchronization of the $\mathrm{LV}$, multi-site $\mathrm{LV}$ pacing has arisen as an alternative strategy for improving the success rate of CRT. Based on this concept, adding more LV pacing sites (multi-LV) would improve the intra-LV synchrony. However thus far this question has not been specifically addressed. Human data are restricted to LV pacing at two sites (triventricular pacing) ${ }^{2,3}$ and acute hemodynamic studies evaluating the role of triventricular pacing have shown conflicting results., ${ }^{4}$

The hypothesis of the present study was that both electrical resynchronization and hemodynamic improvement in function with the number of the LV pacing sites. In order to investigate this hypothesis, experiments were performed in dogs with chronic LBBB. In this well-established animal model of dyssynchrony it was possible to perform almost real time detailed electrical mapping to add the latest activated of seven pre-determined LV pacing electrodes to simultaneous stimulation, resulting in at maximum seven LV pacing sites and thus providing the best possible scenario for achieving optimal resynchronization. This design allows an extensive comparison of many pacing sites and invasive hemodynamic measurements.

\section{Methods}

Animal handling was performed according to the Dutch Law on Animal Experimentation and the European Directive for the Protection of Vertebrate Animals Used for Experimental and Other Scientific Purposes. The protocol was approved by the Animal Experimental Committee of Maastricht University. 


\section{Experimental setup}

The experiments were performed on 9 adult mongrel dogs of either sex and unknown age, weighing $22.0 \pm 0.5 \mathrm{~kg}$. After pentothal induction, anesthesia was maintained by infusion of midazolam $(0.25 \mathrm{mg} / \mathrm{kg} / \mathrm{h} \mathrm{IV})$ and sufentanyl $(3 \mu \mathrm{g} /$ $\mathrm{kg} / \mathrm{h} \mathrm{IV}$ ). Left bundle-branch block (LBBB) was created by radiofrequency ablation 16 weeks before the acute experiment, allowing for ventricular remodeling to occur.

Surface ECGs were recorded from the limb lead electrodes. LV pressure and volume were measured using a 7F combined catheter-tip manometer and conductance catheter, and RV pressure with a $7 \mathrm{~F}$ catheter-tip manometer (CD-Leycom, Zoetermeer, The Netherlands). These catheters were introduced into the carotid artery and jugular vein, respectively. After thoracotomy, two multi-electrode bands for recording and pacing were positioned around the heart, one approximately $1 \mathrm{~cm}$ below the base and the other around the mid level. Each of these customized bands contained two rows of electrodes $(2 \times 30$ and $2 \times 22$, respectively), approximately 1 $\mathrm{cm}$ apart. To measure electrical activation of the septum, an 8-pole multi-electrode catheter (Daig Livewire TC, Minnetonka, Minnesota) was placed through the jugular vein in contact with the RV septum. Temporary myocardial pacing leads (Medtronic, type 6500, Minneapolis, Minnesota) were sutured to the epicardial surface of the roof of right atrium ( 1 to $2 \mathrm{~cm}$ from the sinus node) and to the LV apex. Seven predefined epicardial electrodes were used for the pacing protocol: at the anterior, lateral and posterior walls of the basal and the mid level of the LV wall (from the bands), and at the LV apex (lead). After instrumentation and hemodynamic stabilization, electrical mapping and hemodynamic measurements were acquired simultaneously. For all 7 epicardial electrodes the pacing threshold was determined. Each LV electrode was first used for single-LV pacing, the order of which was randomized per dog. Subsequently, a second LV electrode was added, being the one located in the latest activated region during single-LV pacing, as assessed by epicardial mapping (Figure 1). The same procedure was repeated for the $3^{\text {rd }}$ and $4^{\text {th }}$ LV electrode (Figure 1). Finally, all seven LV electrodes were paced together. The ventricular pacing mode was DOO, $10 \mathrm{bpm}$ above the sinus rhythm. Baseline atrial pacing measurements were repeated at each pacing site in AOO mode at the same rate. The paced $\mathrm{AV}$-interval was set at $70 \mathrm{~ms}$ and full capture was confirmed by cardiac mapping (absence of early activation at the level of the RV septum). The ventricular electrodes used for multi-LV pacing were paced simultaneously. Recording of measurements started 30 seconds after initiation of pacing to achieve hemodynamic stability and lasted 20 seconds to include four respiratory cycles. 


\section{Data analysis}

Data analysis was performed using custom MATLAB software (MathWorks, Natick, MA). From the LV and RV pressure signals, the following parameters were derived: systolic and end-diastolic pressure, $\mathrm{d} P / \mathrm{d} t_{\max }$, and $\mathrm{d} P / \mathrm{d} t_{\min } . L V$ volume was determined using the conductance data, recorded on a Leycom Sigma 5DF signal conditioner processor (CDLeycom, Zoetermeer, the Netherlands). For all cardiac mapping electrodes, activation times were calculated as the time difference between onset of the $\mathrm{Q}$ wave (during baseline LBBB) or pacing artefact (during ventricular pacing) and the time of steepest negative deflection in the depolarization part of the electrogram. LV total activation time (LVTAT) was calculated as the maximal difference in activation time between all LV electrodes. Repolarization times were estimated as the time difference between onset of the $\mathrm{Q}$ wave or the pacing artifact and the time of steepest positive deflection in the repolarization part of the electrogram. Total dispersion of repolarization was quantified as the maximum time difference in repolarization from the electrode bands. ${ }^{6}$

\section{Statistical analysis}

Statistical analyses were performed using the SPSS software, version 18.0 (SPSS Inc., Chicago, IL). All values are presented as mean \pm SD. For all pacing conditions the hemodynamic or electrical results are expressed as a percentage of the corresponding baseline. Changes in hemodynamics and electrical parameters were compared among the different pacing configurations using repeated measures ANOVA. Greenhouse Geisser correction was applied in case of violation of the sphericity assumption. Bonferroni correction was used for post hoc comparisons. The relationship between $\mathrm{LVd} P / \mathrm{d} t_{\text {max }}$ and LVTAT changes was assessed using the Pearson (for normally distributed data) or the Spearman correlation coefficients. Statistical significance was assumed at $\mathrm{p}<0.05$.

\section{Results}

\section{Effects of multi-LV pacing on electrical activation/repolarization}

In each of the 9 experiments, single, dual, triple and quadruple LV pacing configurations were tested at each of the $7 \mathrm{LV}$ segments except for one dog that had partly missing data for both triple and quadruple LV pacing. Neither single-LV pacing nor multi-LV pacing induced ventricular arrhythmias even when seven sites were stimulated at an output up to 10 Volts. 


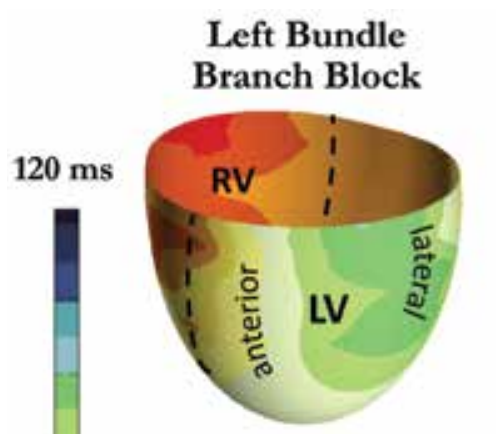

1 LV Pacing Site

$\mathrm{LV} \mathrm{dP} / \mathrm{dt}_{\max }+10 \%$

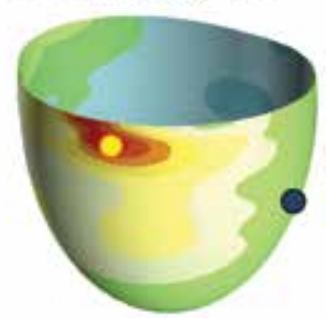

3 LV Pacing Sites

$\mathrm{LV} \mathrm{dP} / \mathrm{dt}_{\max }+19 \%$

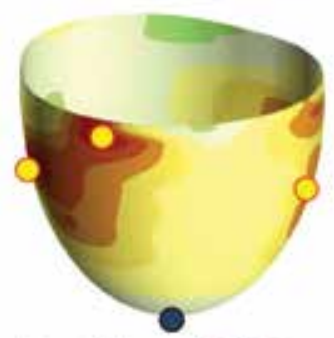

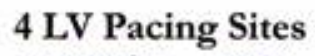

$\mathrm{LV} \mathrm{dP} / \mathrm{dt}_{\max }+19 \%$

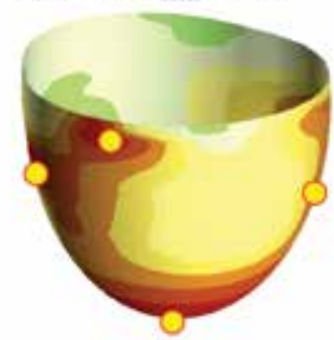

2 LV Pacing Sites

$\mathrm{LV} \mathrm{dP} / \mathrm{dt}_{\max }+15 \%$

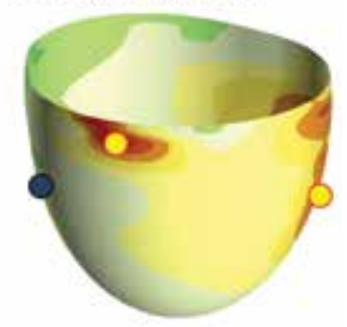

7 LV Pacing Sites

$\mathrm{LV} \mathrm{dP} / \mathrm{dt}_{\max }+25 \%$

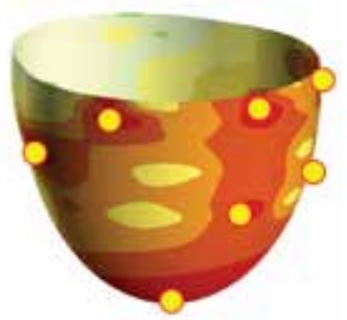

\section{Pacing Site Latest Activation Region}

Figure 1: Overview of the pacing protocol. 3D epicardial activation maps of both ventricles during $\mathrm{LBBB}$ activation, single, dual, triple, quadruple and septuple-LV pacing configurations in the same dog. In this example, single-LV pacing started with the basal-anterior LV electrode (center panel, top row). During single-LV pacing, the latest remaining electrode was middle-posterior (blue dot) and was thereby used for the dual LV-pacing configuration (right panel, top row). Each time the latest activated electrode was added to achieve triple and quadruple-LV pacing. Finally, the seven electrodes were paced together.

Figure 1 shows electrical maps during baseline (LBBB) and during LV pacing at an incremental amount of simultaneously stimulated electrodes. In this example, single-site anterobasal LV pacing did not resynchronize the LV as the area of latest activation shifted from the LV lateral wall (during LBBB) towards the midposterior region with even increased electrical asynchrony (evidenced by the dark-blue color contour and LVTAT?). Simultaneously stimulating the second LV electrode closest to midposterior region eradicated the area of delayed activation and clearly resynchronized the LV. Adding more pacing sites further resynchronized the LV, as areas of latest activation were selected to undergo stimulation simultaneously with the electrodes selected in previous settings. 


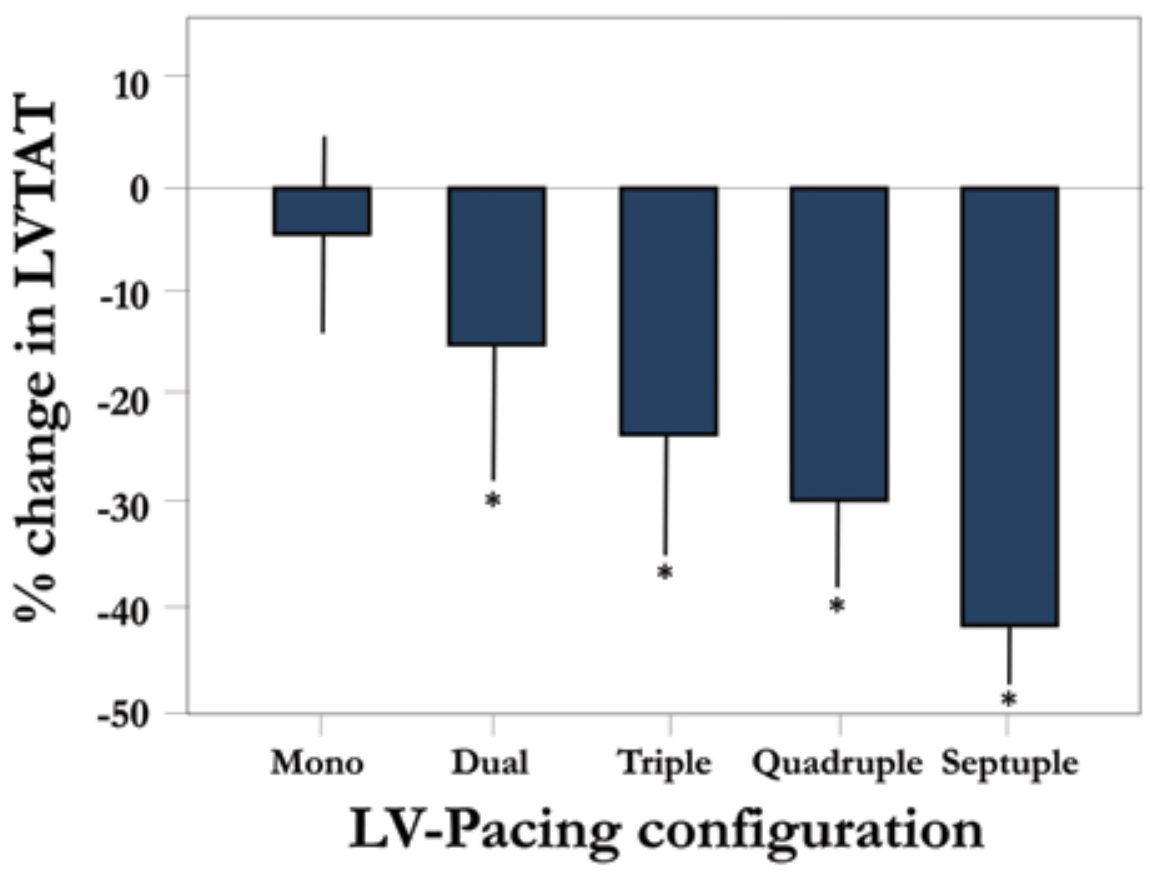

Figure 2. Percent changes in LVTAT during single, dual, triple, quadruple and septuple-LV pacing compared with baseline atrial pacing in the LBBB heart. Presented are mean values $+/-1$ standard deviation. $\mathrm{p} \leq 0.001$ for differences among all pacing configurations. *:p $\leq 0.01$ vs single-site $L V$ pacing.

On average, single-LV pacing did not change LVTAT as compared with intrinsic LV activation (AAI pacing) in the LBBB hearts $(-4.0 \pm 9.3 \%, \mathrm{p}=\mathrm{N} . \mathrm{S}$.). In contrast multi-LV pacing markedly and significantly decreased the LVTAT in a stepwise manner: $-14.3 \pm 13 \% ;-22.9 \pm 11.5 \% ;-29.2 \pm 8.2 \%$ and $-41.3 \pm 5 \%$ for dual, triple, quadruple and septuple LV pacing, respectively ( $\mathrm{p} \leq 0.001$ for differences among all pacing configurations; Figure 2). Table 1 shows absolute values for electrocardiographic and hemodynamic parameters for all pacing modes where similar reductions were observed for QRS duration and total activation time.

Single-LV pacing yielded a non-significant $0.2 \pm 13.7 \%$ change in dispersion of repolarization (as compared with baseline LBBB). Adding more pacing sites progressively decreased the dispersion of repolarization: $-2.5 \pm 17.8 \%,-6.3 \pm 17.4 \%$, $-9.7 \pm 15.9$ and $-14.2 \pm 19.5 \%$ for dual, triple, quadruple and septuple LV pacing, respectively ( $\mathrm{p} \leq 0.02$ for differences among all pacing configurations; Figure 3 ) and QTc time was reduced similarly (Table 1). 


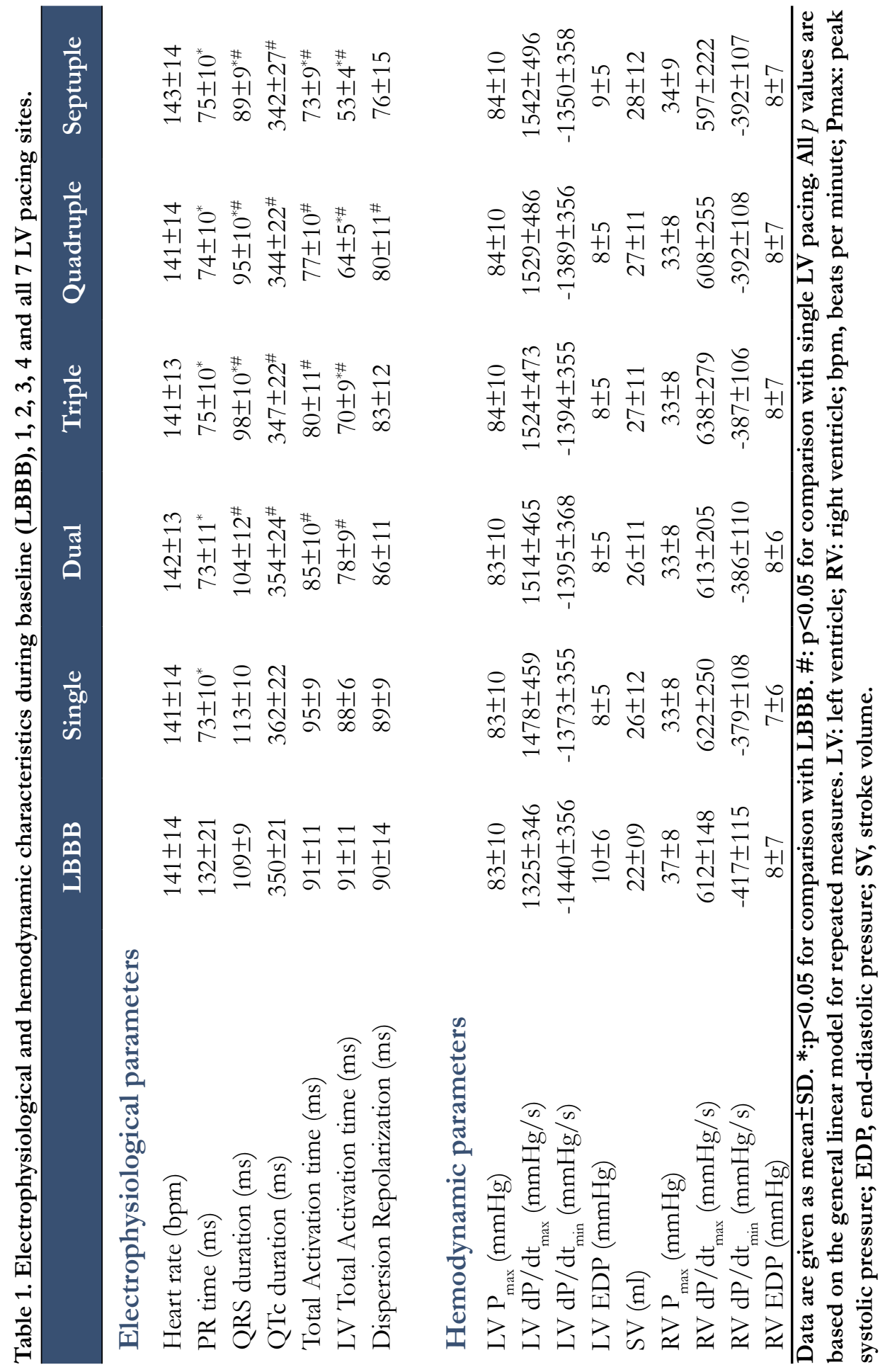




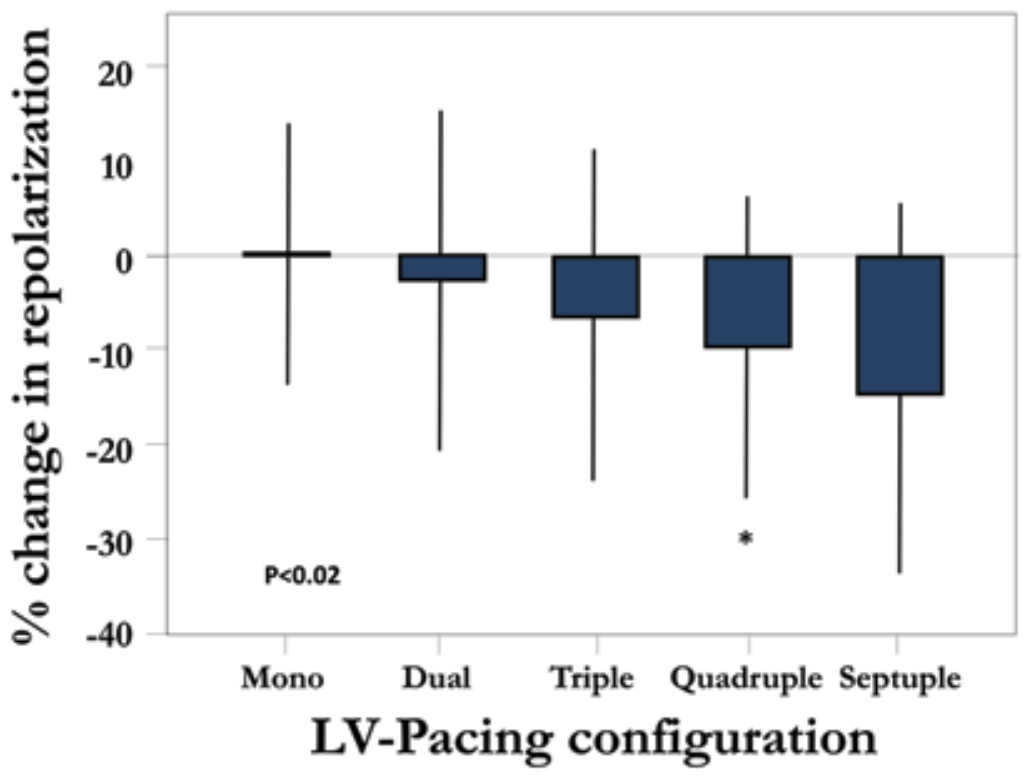

Figure 3. \% change in dispersion of repolarization during single, dual, triple, quadruple and septuple-LV pacing compared with baseline atrial pacing in LBBB hearts. Presented are mean values \pm S.D. $\mathrm{p}<0.02$ for differences among all pacing configurations. ${ }^{*}$ : $\leq 0.03$ vs single-site $\mathrm{LV}$ pacing.

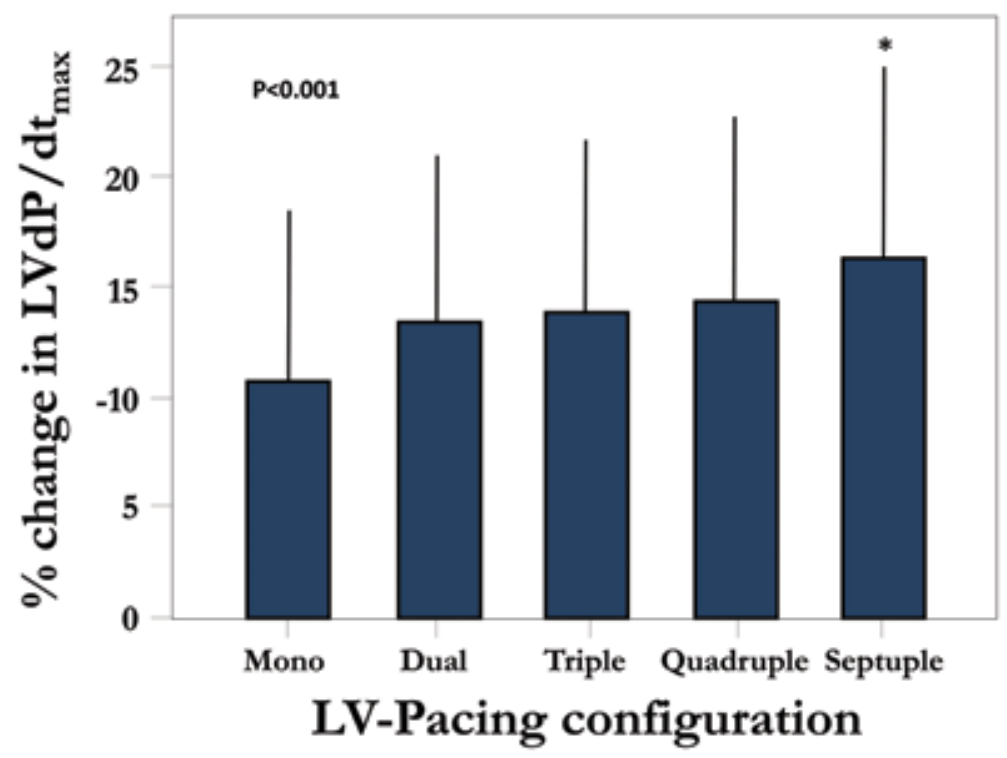

Figure 4. Percent changes in $\mathrm{LVdP} / \mathrm{dt}_{\text {max }}$ during single, dual, triple, quadruple and septuple-LV pacing compared with baseline atrial pacing in the LBBB heart. Presented are mean values \pm S.D. $\mathrm{p} \leq 0.001$ for differences among all pacing configurations. .*:p $\leq 0.03$ vs single-site $L V$ pacing. 


\section{Effects of multi-LV pacing on hemodynamic performance}

Single-LV pacing provided a mean $10.7 \pm 7.7 \%$ increase in $\mathrm{LVd} P / \mathrm{d} t_{\max }$. The optimal single-LV pacing site was dog-specific. On average pacing the anterior, lateral and posterior base increased $\mathrm{LVd} P / \mathrm{d} t_{\max }$ by $6.6 \pm 6.9 \%, 9.2 \pm 10 \%$ and $12.9 \pm 7.9 \%$, respectively. Pacing the anterior, lateral, and posterior faces of the LV middle segment yielded $14.3 \pm 9.4 \%, 9.8 \pm 7.9 \%$ and $8.5 \pm 13 \%$ increase in $\mathrm{LVd} P / \mathrm{d} t_{\max }$, respectively, while the apex was associated with a mean $14.1 \pm 7.8 \%$ increase.

Table 2. Relation between changes in $\mathrm{LVdP} / \mathrm{dt}_{\text {max }}$ and changes in LVTAT

\begin{tabular}{cccc} 
& \multicolumn{3}{c}{ Correlation } \\
\hline subject \# & $\mathrm{n}$ & $\mathrm{r}$ & $\mathrm{p}$ \\
\hline 1 & 28 & -0.04 & 0.8 \\
2 & 14 & 0.06 & 0.8 \\
3 & 28 & -0.36 & 0.06 \\
4 & 28 & 0.06 & 0.8 \\
5 & 27 & -0.40 & 0.04 \\
6 & 27 & -0.50 & $<0.01$ \\
7 & 28 & -0.29 & 0.1 \\
8 & 28 & -0.10 & 0.6 \\
9 & 27 & -0.41 & 0.03 \\
\hline
\end{tabular}

n: number of points; r: correlation coefficient

The anterior and lateral base were found to be the worst site three and two times respectively; the posterior base was the best site in two dogs, the mid-anterior region was the best in two cases, the worst in one; the mid-lateral region was the best in one dog and the worst in another; the mid-posterior region was the best in two dogs and the worst in two others; the apex was the best site in two dogs.

Adding more pacing sites provided a gradual increase in $\mathrm{LVd} P / \mathrm{d} t_{\text {max }}$, reaching $+16.4 \pm 8.7 \%$ for the septuple configuration ( $\mathrm{p} \leq 0.001$ for differences among all pacing configurations, Figure 4). Correlations between $\mathrm{LVd} P / \mathrm{d} t_{\text {max }}$ and LVTAT changes from the different pacing configurations are presented in table 2 for each dog. Interestingly, a modestly significant correlation was found in three dogs and no correlation in the remaining six dogs. 


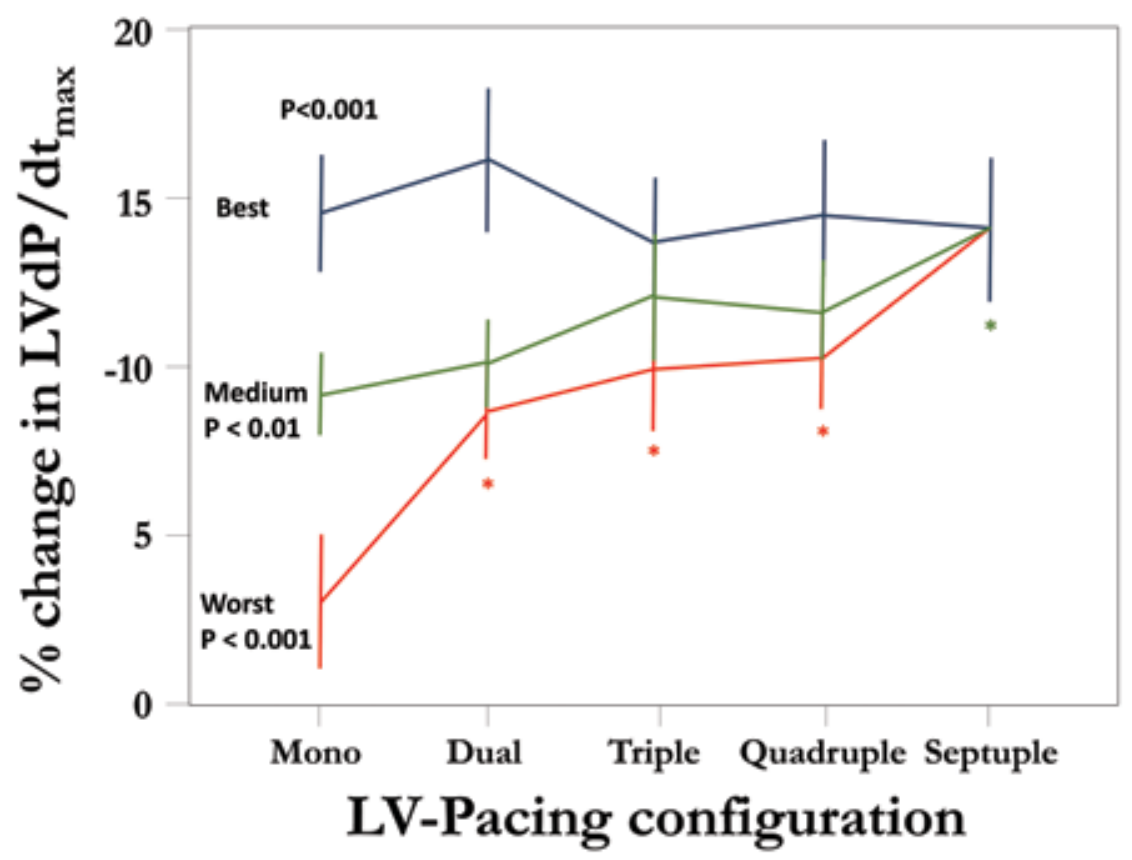

Figure 5. Percentages increase in $\mathrm{LVdP} / \mathrm{dt}_{\max }$ versus baseline during single, dual, triple, quadruple and septuple-LV pacing according to the hemodynamic improvement provided by single-site LV pacing (seven modalities for each $\operatorname{dog}(n=8)$ ). In blue: pooled data for the two best hemodynamic single-site LV pacing ("best"; no significant differences between the different pacing configurations). In red: pooled data for the two worst hemodynamic single-site LV pacing ("worst", $p<0.001$ for differences among all pacing configurations). In green: pooled data for the 3 remaining single-site LV pacing, providing thus intermediate results ("medium", $\mathrm{p}<0.01$ for differences among all pacing configurations). ${ }^{*} \mathrm{p} \leq 0.05$ vs single-site $L V$ pacing.

\section{Effect of multi-LV pacing according to the single-LV pacing effect}

Figure 5 shows the hemodynamic responses on the different multi-LV configurations, distinguishing between scenarios with the two single-LV sites that, within each experiment, provided the largest increase in $\mathrm{LVd} P / \mathrm{d} t_{\text {max }}$ ("best" sites), the two "worst" sites, and the three sites which yielded "intermediate" hemodynamic improvement. When a single-LV pacing site provided a "poor" or "intermediate" hemodynamic response, adding more electrodes resulted in additional improvement. When the hemodynamic response was "best" with a single-LV pacing site, no further improvement occurred with the addition of pacing site(s). Noteworthy, the pacing location during single-LV pacing were highly variable among the 3 groups whereas the mean local activation times in sinus rhythm were similar: $65 \pm 22 \mathrm{~ms}, 63 \pm 21 \mathrm{~ms}$ and $70 \pm 48 \mathrm{~ms}$ for the "best", "intermediate" and "worst" group, respectively ( $\mathrm{p}=\mathrm{ns})$. 


\section{Discussion}

In the present animal study we investigated a strategy for optimal delivery of CRT using real-time mapping and adding pacing sites at the latest activated regions. This study demonstrated that compared to single site-LV pacing, multi-LV epicardial pacing produced faster ventricular electrical depolarization and repolarization and some additional improvement in systolic LV pump function. While the electrophysiological effects were clearly proportional to the number of pacing sites, the hemodynamic improvement was poorly correlated to the reduction in LVTAT. Multisite LV pacing only caused a significant improvement in hemodynamic response if pacing at a single-LV site provided sub-optimal response.

\section{Electrical changes induced by multi-LV pacing}

LV pacing can improve the pump function of hearts with depressed ejection fraction and LBBB. In LBBB the loss of fast LV activation through the specialized conduction system leads to delayed and prolonged LV activation. Single site LV pacing does not reduce LVTAT while Multi-LV pacing can reduce it consistently and proportional to the number of electrodes used, reaching a maximal reduction in LVTAT of $\approx 41 \%$. In fact, total and LV activation time as well as QRS duration approach near-physiological values. ${ }^{7}$ This reduction is larger than that reported in dogs with normal atrio-ventricular conduction $(25 \%$ QRS width reduction with multi-LV pacing using four electrodes as compared with single-site LV apex pacing). ${ }^{8}$

Similarly in heart failure patients, dual-LV pacing shortened QRS duration by $22 \%$, whereas single site posterior base and lateral LV wall pacing increased it significantly by 2 and $12 \% .{ }^{4}$ In our study, the reduction in LVTAT coincided with a reduction in the dispersion of repolarization, a combination that may confer antiarrhythmic properties. ${ }^{9}$ Multi-LV pacing has been suggested as a method for reducing the possibility of reentry based on the premise that synchronous activation should reduce the dispersion of recovery of excitability and thus the probability that reentry will occur. ${ }^{10,11}$

\section{Hemodynamic effect of multi-LV pacing}

Overall, multi-LV pacing also provided a significant increase in $\mathrm{LVd} P / \mathrm{d} t_{\max }$ over single site-LV pacing. However, the relationship between reduction in LVTAT and a hemodynamic benefit is not straightforward. There hardly exists a correlation between changes in LVTAT and $\mathrm{LVd} P / \mathrm{d} t_{\text {max }}$. 
This lack of correlation shows that the hemodynamic benefit by multi-LV pacing does not exclusively hinge on the degree of absolute electrical asynchrony.

The present study demonstrates, in agreement with earlier studies, that the site of LV pacing is a primary determinant of the hemodynamic response to CRT, even though the physiological process by which one site surpasses another are not well understood. ${ }^{8,12}$ Furthermore, it is unknown what the effects of the interaction between a "optimal" and a "sub-optimal" LV pacing spot are.

In this study the addition of electrodes was beneficial as long as the hemodynamic improvement was suboptimal. Conversely, when a large $\mathrm{LVd} P / \mathrm{d} t_{\text {max }}$ increase was achieved (even with a single electrode), the addition of pacing sites was not detrimental. These observations suggest that the hemodynamic improvement of a given pacing configuration is mostly driven by the best of the pacing electrodes used and may explain why on average, dual-LV is better than single-LV, triple-LV better than dual-LV pacing and so on: the likelihood of getting a favorable pacing site in the pacing set increases with the number of electrodes used. Our findings are supported by an acute hemodynamic study in 12 heart failure patients where the benefit of biventricular pacing using two LV leads was not superior to conventional biventricular pacing using the best of two LV leads with an optimized AV delay. ${ }^{5}$

Human experience of multi-LV pacing is also restricted to biventricular pacing using one RV and two LV leads (triventricular pacing). Two randomized trials with small sample-size have shown triventricular pacing to be associated with a higher reduction in LV end-systolic volume than conventional biventricular pacing while the 6 min walk distance did not significantly differ between the two groups. ${ }^{2,3}$ In these studies only one biventricular configuration (out of two) was tested against triventricular pacing. Bordachar et al. recently compared triventricular pacing (one $\mathrm{RV}+$ two LV electrodes) to conventional biventricular pacing in dogs with ischemic heart-failure and LBBB and did not find any significant difference between the 2 pacing modes. ${ }^{13}$ Differences of this canine study with ours are that we studied LV pacing instead of biventricular pacing, that we extended the concept of multi-LV pacing to $7 \mathrm{LV}$ electrodes, and that additional pacing sites were chosen based on near real-time electrical mapping, thus providing the best possible scenario for reducing electrical asynchrony. 


\section{Clinical implications}

This study holds two possible clinical implications. First, Multi-LV pacing appears to be effective in maximizing the hemodynamic benefit without requiring any optimization of the pacing site. Also interesting is the potential effect in preventing ventricular arrhythmias. Indeed, single-site LV pacing has been suspected to be proarrhythmic by increasing transmural heterogeneity of repolarization intrinsic to ventricular myocardium. ${ }^{14}$ Sudden death may occur in heart failure patients even when implanted with an ICD. Shock delivery has been proven to be associated with death. Therefore any strategy that prevents the occurrence of ventricular arrhythmias is welcome. ${ }^{15}$

Multi-LV pacing is nowadays restricted to triventricular pacing due to technical limitations. Accumulation of pacing leads has evident limitation transvenously as well as pericardially. Current devices provide only two ventricular ports, adding ports will drain the battery and capacity would be too low to chronically supply more than three ventricular exits. In the light of the foregoing results, research in the development of dedicated materials may be considered. In that respect, multi electrodes leads and wireless pacing systems may offer potential advantages.

\section{Experimental model and limitations}

The present study was performed in the established model of experimental LBBB in the canine heart. Even in the absence of other heart disease, chronic LBBB leads to ventricular dilation and asymmetric hypertrophy and decrease in $\mathrm{LVd} P / \mathrm{d} t_{\max }{ }^{16}$ Results from this model have been shown to translate well to the clinical situation. ${ }^{17}$ CRT was achieved by pure LV pacing, which has been proven to be as effective as biventricular pacing. ${ }^{18,}{ }^{19} \mathrm{RV}$ pacing was not considered because its participation to the LV activation during biventricular pacing (through the septum) has been found to be limited in dogs, therefore the LV-pacing approach provides the most sensitive scenario to test the hypothesis that reduction in electrical activation leads to improvements in pump function.

A particular aspect of the present study was the strategy aiming to deliver the best possible electrical resynchronization using virtual real time electrical mapping for finding the latest activated region at each step in the protocol. Our results should be extrapolated to the human situation with caution because most of the CRT candidates have additional systolic impairment due to the underlying cardiomyopathy with 
possible areas of scar. Also, this study was conducted in isolated proximal LBBB, results for other conduction defects are not warranted. Finally, acute hemodynamic improvement may not predict chronic outcome. ${ }^{20}$

\section{Conclusion}

In dogs with chronic LBBB Multi-LV pacing reduces asynchrony of electrical activation and dispersion of repolarization compared to single-LV pacing in dogs with chronic LBBB. Reduction in LVTAT is probably not the mechanism by which multi-LV pacing improves the LV hemodynamic since its effect was similar to that observed for the best single-LV pacing sites. Multi-LV pacing was particularly effective in improving sub-optimal combination of pacing sites. Potential antiarrhythmic properties and superiority in terms of LV reverse remodeling have to be specifically investigated on long term studies.

\section{Funding}

S Ploux received a grant from «La Fédération Française de Cardiologie ». S Ploux was supported by the French government «l'Agence National de la Recherche au titre du programme Investissements d'Avenir », ref [ANR-10-IAHU-04]. This research was performed within the framework of CTMM, the Center for Translational Molecular Medicine (www.ctmm.nl), project COHFAR (grant 01C-203), and supported by the Dutch Heart Foundation. 


\section{References}

1. Auricchio A, Prinzen FW. Non-responders to cardiac resynchronization therapy: The magnitude of the problem and the issues. Circ J. 2011;75:521-527.

2. Leclercq C, Gadler F, Kranig W, Ellery S, Gras D, Lazarus A, Clementy J, Boulogne E, Daubert JC. A randomized comparison of triple-site versus dual-site ventricular stimulation in patients with congestive heart failure. J Am Coll Cardiol. 2008;51:14551462.

3. Rogers DP, Lambiase PD, Lowe MD, Chow AW. A randomized double-blind crossover trial of triventricular versus biventricular pacing in heart failure. Eur J Heart Fail. 2012;14:495-505.

4. Pappone C, Rosanio S, Oreto G, Tocchi M, Gulletta S, Salvati A, Dicandia C, Santinelli V, Mazzone P, Veglia F, Ding J, Sallusti L, Spinelli J, Vicedomini G. Cardiac pacing in heart failure patients with left bundle branch block: Impact of pacing site for optimizing left ventricular resynchronization. Italian heart journal : official journal of the Italian Federation of Cardiology. 2000;1:464-469.

5. Padeletti L, Colella A, Michelucci A, Pieragnoli P, Ricciardi G, Porciani MC, Tronconi F, Hettrick DA, Valsecchi S. Dual-site left ventricular cardiac resynchronization therapy. Am J Cardiol. 2008;102:1687-1692.

6. van Deursen C, van Geldorp IE, Rademakers LM, van Hunnik A, Kuiper M, Klersy C, Auricchio A, Prinzen FW. Left ventricular endocardial pacing improves resynchronization therapy in canine left bundle-branch hearts. Circ Arrbythm Electrophysiol. 2009;2:580-587.

7. Verbeek XA, Vernooy K, Peschar M, Cornelussen RN, Prinzen FW. Intra-ventricular resynchronization for optimal left ventricular function during pacing in experimental left bundle branch block. J Am Coll Cardiol. 2003;42:558-567.

8. Peschar M, de Swart H, Michels KJ, Reneman RS, Prinzen FW. Left ventricular septal and apex pacing for optimal pump function in canine hearts. J Am Coll Cardiol. 2003;41:1218-1226.

9. Acosta H, Pothula VR, Arter J, Antonio C, Ramadas S, Castellanos A. Transvenous dual site left ventricular pacing plus biventricular pacing for the management of refractory ventricular tachycardia. J Interv Card Electrophysiol. 2006;17:73-75.

10. Restivo M, Gough WB, el-Sherif N. Reentrant ventricular rhythms in the late myocardial infarction period: Prevention of reentry by dual stimulation during basic rhythm. Circulation. 1988;77:429-444.

11. Okishige K, Ohkubo T, Goseki Y, Matsubara T, Hiejima K, Ibukiyama C. Experimental study of the effects of multi-site sequential ventricular pacing on the prophylaxis of ventricular fibrillation. Jpn Heart J. 2000;41:193-204. 
12. Derval N, Steendijk P, Gula LJ, Deplagne A, Laborderie J, Sacher F, Knecht S, Wright M, Nault I, Ploux S, Ritter P, Bordachar P, Lafitte S, Reant P, Klein GJ, Narayan SM, Garrigue S, Hocini M, Haissaguerre M, Clementy J, Jais P. Optimizing hemodynamics in heart failure patients by systematic screening of left ventricular pacing sites: The lateral left ventricular wall and the coronary sinus are rarely the best sites. J Am Coll Cardiol. 2010;55:566-575.

13. Bordachar P, Grenz N, Jais P, Ritter P, Leclercq C, Morgan JM, Gras D, Yang P. Left ventricular endocardial or triventricular pacing to optimize cardiac resynchronization therapy in a chronic canine model of ischemic heart failure. American journal of physiology. Heart and circulatory physiology. 2012;303:H207-215.

14. Fish JM, Di Diego JM, Nesterenko V, Antzelevitch C. Epicardial activation of left ventricular wall prolongs qt interval and transmural dispersion of repolarization: Implications for biventricular pacing. Circulation. 2004;109:2136-2142.

15. Poole JE, Johnson GW, Hellkamp AS, Anderson J, Callans DJ, Raitt MH, Reddy RK, Marchlinski FE, Yee R, Guarnieri T, Talajic M, Wilber DJ, Fishbein DP, Packer DL, Mark DB, Lee KL, Bardy GH. Prognostic importance of defibrillator shocks in patients with heart failure. N Engl J Med. 2008;359:1009-1017.

16. Vernooy K, Cornelussen RN, Verbeek XA, Vanagt WY, van Hunnik A, Kuiper M, Arts T, Crijns HJ, Prinzen FW. Cardiac resynchronization therapy cures dyssynchronopathy in canine left bundle-branch block hearts. European heart journal. 2007;28:2148-2155.

17. Vernooy K, Verbeek XA, Peschar M, Crijns HJ, Arts T, Cornelussen RN, Prinzen FW. Left bundle branch block induces ventricular remodelling and functional septal hypoperfusion. European heart journal. 2005;26:91-98.

18. Blanc JJ, Etienne Y, Gilard M, Mansourati J, Munier S, Boschat J, Benditt DG, Lurie KG. Evaluation of different ventricular pacing sites in patients with severe heart failure: Results of an acute hemodynamic study. Circulation. 1997;96:3273-3277.

19. Thibault B, Ducharme A, Harel F, White M, O'Meara E, Guertin MC, Lavoie J, Frasure-Smith N, Dubuc M, Guerra P, Macle L, Rivard L, Roy D, Talajic M, Khairy P. Left ventricular versus simultaneous biventricular pacing in patients with heart failure and a qrs complex $>/=120$ milliseconds. Circulation. 2011;124:2874-2881.

20. Bogaard MD, Houthuizen P, Bracke FA, Doevendans PA, Prinzen FW, Meine M, van Gelder BM. Baseline left ventricular dp/dtmax rather than the acute improvement in $\mathrm{dp} / \mathrm{dtmax}$ predicts clinical outcome in patients with cardiac resynchronization therapy. Eur J Heart Fail. 2011;13:1126-1132. 

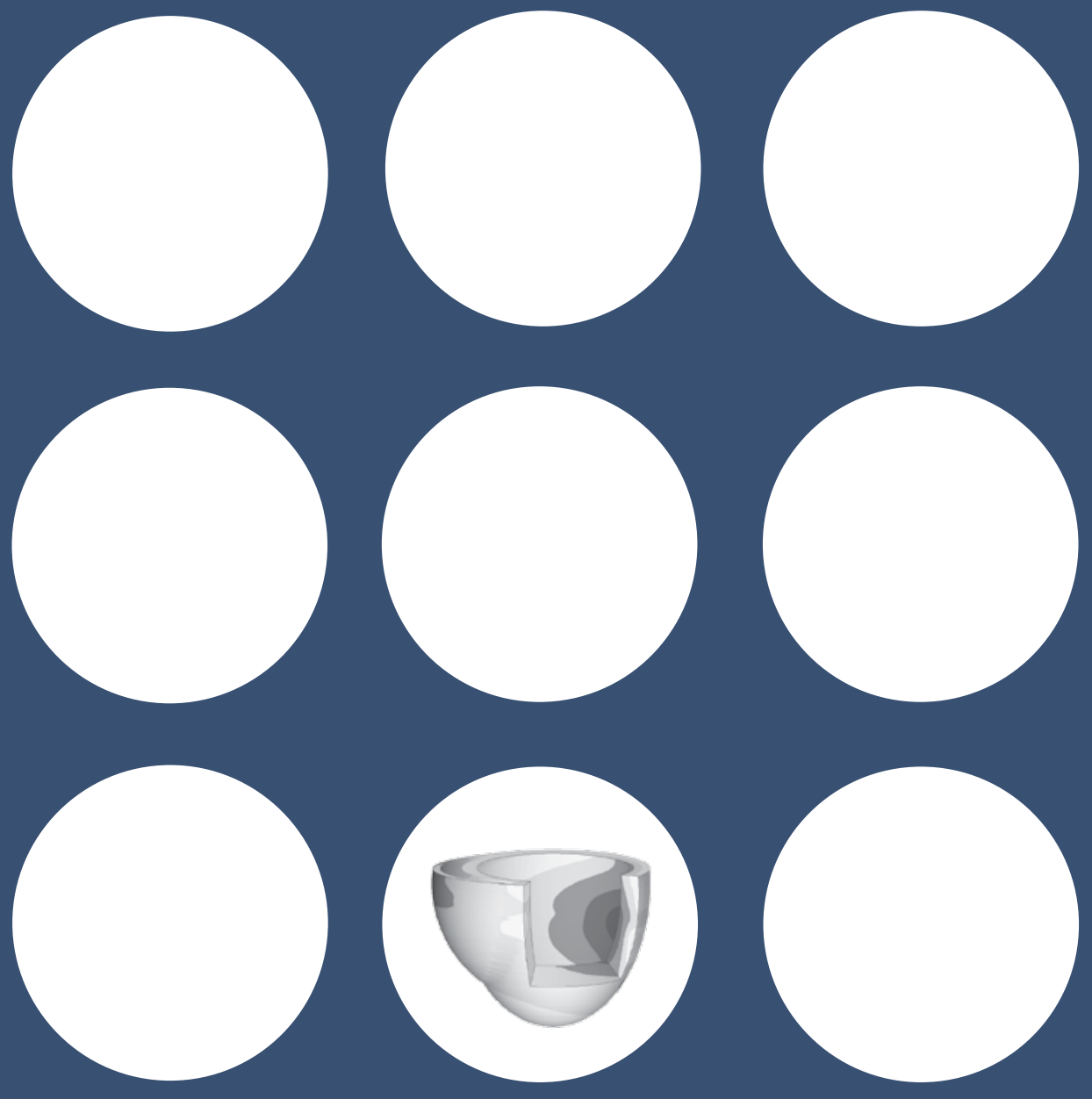

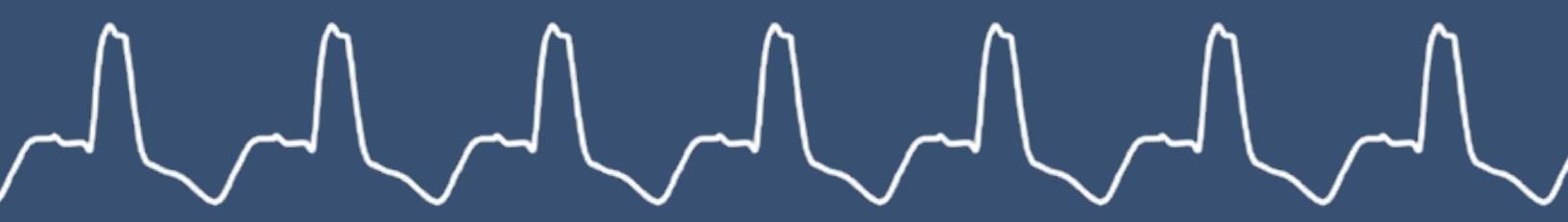




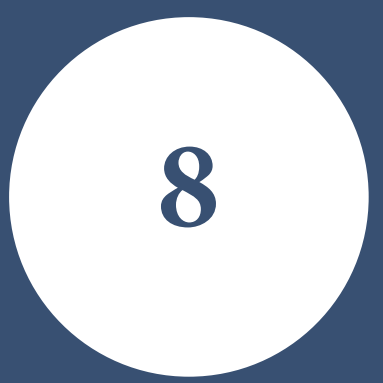

\section{Endocardial Left Ventricular Pacing Improves Cardiac Resynchronization Therapy in Chronic Asynchronous Infarction and Heart Failure Models}

Strik M, Rademakers LM, van Deursen CJ, van Hunnik A, Kuiper M, Klersy C, Auricchio A, Prinzen FW.

Circ Arrhythm Electrophysiol. 2012 Feb;5(1):191-200

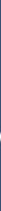




\section{Abstract}

\section{Introduction}

Studies in canine hearts with acute left bundle branch block (LBBB) showed that endocardial left ventricular (LV) pacing improves efficacy of Cardiac Resynchronization Therapy (CRT) as compared to conventional epicardial LV pacing. The present study explores the efficacy of endocardial CRT in more compromised hearts and the mechanisms of such beneficial effects.

\section{Methods}

Measurements were performed in 22 dogs, 9 with acute LBBB, 7 with chronic LBBB combined with infarction (embolization; $\mathrm{LBBB}+\mathrm{MI}$, concentric remodeling) and 6 with chronic LBBB and heart failure (rapid pacing, LBBB+HF, eccentric remodeling). Head-to-head comparison was performed of the effects of endocardial and epicardial LV pacing at 8 sites. LV activation times were measured using $\approx 100$ endocardial and epicardial electrodes and non-contact mapping. Pump function was assessed from right ventricular and LV pressures.

\section{Results}

Endocardial CRT resulted in better electrical resynchronization than epicardial CRT in all models, though the benefit was larger in concentrically remodeled LBBB+MI than in eccentrically remodeled $\mathrm{LBBB}+\mathrm{HF}$ hearts (19 vs. $10 \%$, respectively). In $\mathrm{LBBB}$ and $\mathrm{LBBB}+\mathrm{HF}$ animals, endocardial conduction was $\approx 50 \%$ faster than epicardial conduction and in all models transmural impulse conduction was $\approx 25 \%$ faster when pacing from the endocardium than from the epicardium. Hemodynamic effects were congruent with electrical effects.

\section{Conclusions}

Endocardial CRT improves electrical synchrony of activation as well as LV pump function compared to conventional epicardial CRT in compromised canine LBBB hearts. This benefit can be explained by shorter path length along the endocardium and by faster circumferential and transmural impulse conduction during endocardial LV pacing. 


\section{Introduction}

Cardiac Resynchronization Therapy (CRT) is an established treatment for patients with moderate-to-severe heart failure and a wide QRS complex. ${ }^{1}$ However, the amount of reverse remodeling and clinical improvement is highly variable and a considerable amount of patients respond poorly to the therapy. ${ }^{1}$ In conventional CRT, the left ventricular (LV) lead is transvenously positioned in a coronary vein, which results in epicardial (EPI) LV pacing. As a consequence, the initiated electrical wave front propagates over the epicardium and through the LV wall towards the endocardium. Under physiological conditions, electrical activation of the LV initiates at the endocardium. ${ }^{2}$ Endocardial (ENDO) LV pacing results in less asynchronous activation of the LV free wall than EPI LV pacing. ${ }^{3}$ In dogs with acute left bundle branch block (LBBB), ENDO LV pacing during CRT (ENDO-CRT) has indeed been shown to increase the benefits of CRT as compared to EPI-CRT. ${ }^{4}$ Three possible mechanisms explaining the more rapid electrical activation during ENDO-CRT were proposed: 1) shorter path length of conduction, 2) faster endocardial than epicardial conduction as well as 3) faster conduction from endocardium to epicardium than vice versa. While all three factors may contribute in the setting of acute LBBB in otherwise healthy canine hearts, several factors may potentially diminish the benefit of ENDO-CRT in patients. Firstly, the influence of an infarct on impulse conduction in asynchronous hearts is not understood and may differ between myocardial layers. ${ }^{4}$ Secondly, ventricular dilatation and wall thinning would reduce the difference in conduction path length between endocardium and epicardium, potentially reducing the advantage of ENDO-CRT in patients with dilated cardiomyopathy. In addition, Spragg et al showed that in canine hearts with chronic LBBB, impulse conduction was reduced especially in the endocardium of the late activated regions, exactly the region where one would position the ENDO LV pacing lead. ${ }^{5}$ Better understanding of the various factors determining the benefits of ENDO-CRT in animal models with compromised hearts are warranted also to better understand the ambivalent results reported from the few small clinical studies on endocardial CRT.6. ${ }^{6-9}$

To this purpose we investigated the efficacy of ENDO-CRT in three animal models: canine hearts with acute LBBB and in chronic LBBB in combination with myocardial infarction (LBBB+MI, induced by coronary embolization) or with dilated cardiomyopathy ( $\mathrm{LBBB}+\mathrm{HF}$, induced by rapid pacing). In order to better understand the mechanisms of ENDO-CRT we also performed more detailed electrophysiological measurements as compared to our earlier studies. ${ }^{4}$ 


\section{Methods}

Animal handling was performed according to the Dutch Law on Animal Experimentation and the European Directive for the Protection of Vertebrate Animals used for Experimental and Other Scientific Purposes (86/609/EU). The protocol was approved by the Experimental Animal Committee of Maastricht University.

\section{Experimental models}

Twenty-two adult mongrel dogs of either sex and unknown age, weighing $29.5 \pm 2.0 \mathrm{~kg}$, were divided into three groups; acute $\mathrm{LBBB}(\mathrm{n}=9$, of which some data were already reported previously $\left.{ }^{4}\right), \mathrm{LBBB}+\mathrm{MI}(\mathrm{n}=7)$ and $\mathrm{LBBB}+\mathrm{HF}(\mathrm{n}=6)$. Animals were induced by intravenous Pentothal administration and anesthetized by continuous infusion of midazolam $(0.25 \mathrm{mg} / \mathrm{kg} / \mathrm{h} \mathrm{IV})$ and sufentanyl $(3 \mu \mathrm{g} / \mathrm{kg} / \mathrm{h}$ IV). In the $\mathrm{LBBB}+\mathrm{MI}$ group, transmural infarction was created by embolization of the LCX $(n=3)$ and LAD $(n=4)$ artery using a suspension of $\approx 1$ cc dry volume polyvinyl alcohol foam particles and four weeks later, LBBB was induced. ${ }^{10}$ Infarct size (\% LV mass) and transmurality was determined by triphenyltetrazolium chloride staining postmortem. ${ }^{10}$ In the LBBB $+\mathrm{HF}$ group, LBBB was created and, during the same procedure, a standard pacing lead was placed in the apex of the right ventricle (RV) and connected to a pacemaker (Medtronic InSync ${ }^{\circledR}$ III). After a week of recovery, the heart was paced at a rate of 220 beats per minute for 4 weeks to induce systolic LV dysfunction, as described by other groups. ${ }^{11,12}$ In both models, M-mode recordings of 2D echocardiography measurements from the mid ventricular papillary muscle level were obtained at baseline and just before the final measurements.

\section{Cardiac Resynchronization Therapy studies}

Five weeks after creating the infarction $(\mathrm{LBBB}+\mathrm{MI})$ or four weeks after turning on the pacemaker $(\mathrm{LBBB}+\mathrm{HF})$, the animals were anesthetized again, as described above, for the acute CRT studies. RV and LV pressure catheters were positioned as reported earlier. ${ }^{4}$ After opening the chest, two multi-electrode arrays holding 102 contact electrodes were placed around the heart, which measured epicardial electrical potentials (Figure 1). Additional EPI LV electrodes were placed at the apex and lateral apex. 
An octapolar electrode catheter (Daig Livewire TC, Minnetonka, MN) was positioned against the RV-septum. Eight LV EPI electrodes were selected for pacing at various wall regions; anterior base, lateral base, posterior base, mid anterior, mid lateral, mid posterior, lateral apex and apex. For a paired comparison between EPI and ENDO LV pacing, custom-made plunge electrodes were inserted at these exact sites to enable ENDO-CRT and endocardial LV mapping (Figure 1).

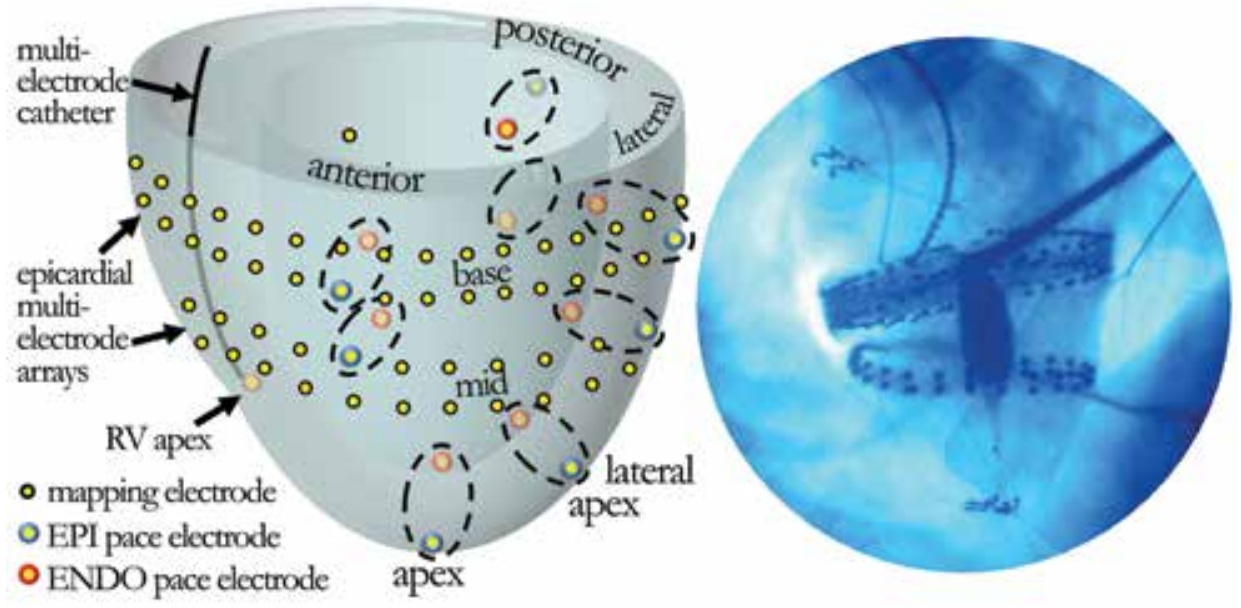

Figure 1: Schematic set-up of the experiment (left panel) with mapping electrodes depicted as yellow dots; The 8 pacing electrodes have an additional blue (EPI) or red (ENDO) border. The fluoroscopic image (right panel) shows the mapping electrodes and multi-electrode array in place.

\section{Pacing protocol}

All pacing was performed in D00 mode, using atrial pacing at approximately 10 beats per minute above intrinsic rate. Between each switch of LV pacing site (8 EPI and 8 ENDO), baseline atrial pacing measurements were made during three respiratory cycles. During biventricular (BiV) pacing, the RV apex was stimulated simultaneously with the selected EPI or ENDO LV electrode, using the longest atrioventricular (AV) interval that ensured complete biventricular capture. After hemodynamic measurements in the LBBB and LBBB+HF dogs, a non-contact multi-electrode array (EnSite $3000 \AA$, Figure 1) was introduced into the LV to enable localization of the LV endocardium and plunge electrodes. ${ }^{13}$ Subsequently, the pacing protocol was repeated while deriving 2048 virtual electrograms around the endocardial LV simultaneously and storing them for offline analysis. 


\section{Data analysis}

From the surface ECG, QRS-width and time from T-peak to T-end were determined. ${ }^{4}$ For all electrodes, depolarization times were calculated as the time difference between onset of the $\mathrm{Q}$ wave (during baseline) or ventricular pacing artifact (during CRT) and the time of steepest deflection in the electrogram (-dV/ $\left.d t_{\max }\right)$. Three-dimensional depolarization time maps were created by plotting the depolarization times on epicardial and endocardial models using custom MATLAB software (MathWorks, Natick, MA). ${ }^{14}$ Activation times (AT) were defined as the maximum depolarization time difference and were calculated for specific LV layers (endocardium, epicardium and transmural) and of the total LV. LV EPI electrodes were considered to be the band electrodes on the LV wall, the LV apical plunge electrodes and the RV septal electrodes.

Since endocardial LV AT was derived from a small amount of plunge electrodes, the 2048 virtual electrograms as derived from the multi-electrode array (EnSite $3000 \AA)$ were used to calculate endocardial LV AT in an alternative way to compare with the plunge electrode measurements. Conduction velocities were calculated in the acute $\mathrm{LBBB}$ and $\mathrm{LBBB}+\mathrm{HF}$ groups for anterior, lateral and posterior regions between the paced electrode and their neighboring electrodes in the same myocardial layer by dividing the inter-electrode distance by the difference in AT. For epicardial conduction velocity, this distance was equal to the interelectrode distance on the epicardial bands. For the endocardial conduction velocity, the endocardial interelectrode distance was derived from the shortest path length between these electrodes over the endocardial contour as calculated by the EnSite ${ }^{\circledR}$ system. Hemodynamic data analysis was performed as described previously. ${ }^{4}$

\section{Statistical analysis}

Continuous data are presented as mean \pm standard deviation, and discrete variables as counts and percentage. A series of general linear regression models were used to compare pacing sites and experimental models for the several endpoints, with identity or logistic link function according to the dependent variable assessed. To account for intra-individual correlation of measurements (panel data), Huber-White robust standard-errors were calculated. No missing data imputation was performed. Stata 10 (StataCorp, College Station, TX, USA) was used for computation. A two-sided $P$-value $<0.05$ was considered statistically significant. The Bonferroni correction was used for post-hoc comparisons. 


\section{Results}

In all 22 experiments, 8 EPI-ENDO pairs of LV pacing sites were evaluated during BiV pacing. Due to occasional misplacement of the endocardial electrode or unstable hemodynamic conditions, 151 out of the possible 176 paired datasets were successfully acquired.

Table 1: Baseline electrocardiography, echocardiography and hemodynamic characteristics of the LBBB group, LBBB+MI group and LBBB +HF group.

$\mathrm{LBBB} \quad \mathrm{LBBB}+\mathrm{MI} \quad \mathrm{LBBB}+\mathrm{HF}$

$$
(\mathrm{n}=9) \quad(\mathrm{n}=7) \quad(\mathrm{n}=6)
$$

Electrocardiography parameters

Heart rate $(b p m)$

$\begin{array}{lll}117 \pm 11 & 125 \pm 16 & 135 \pm 10^{*} \\ 116 \pm 8 & 106 \pm 9 & 123 \pm 10\end{array}$

QRS width (ms)

(16+8

Echocardiography parameters

LV end-diastolic diameter (cm)

$\begin{array}{ccc}3.97 \pm 0.45 & 4.09 \pm 0.37 & 4.90 \pm 0.36^{*} \\ 1.14 \pm 0.18 & 1.41 \pm 0.12^{*} & 0.90 \pm 0.11^{*} \\ 1.31 \pm 0.09 & 1.53 \pm 0.16^{*} & 0.86 \pm 0.12^{*} \\ 54 \pm 8 & 53 \pm 9 & 15 \pm 2^{*}\end{array}$

LV posterior wall thickness $(\mathrm{cm})$

LV septum wall thickness $(\mathrm{cm})$

LV Ejection Fraction (\%)

$54 \pm 8$

$1554 \pm 249$

$1409 \pm 282$

$842 \pm 82 *$

$\mathrm{LV} \mathrm{dP} / \mathrm{dt}_{\max }(m m H g / s)$

$1383 \pm 266 \quad 1495 \pm 344 \quad 976 \pm 175^{*}$

$\mathrm{LV}-\mathrm{dP} / \mathrm{dt}_{\min }(m m H g / s)$

$91 \pm 11$

$87 \pm 13$

$76 \pm 10^{*}$

LV EDP $(m m H g)$

$6 \pm 3$

$13 \pm 9 *$

$18 \pm 11 *$

$\mathrm{SV}(m L)$

$32 \pm 8$

$26 \pm 7$

$15 \pm 5 *$

$\mathrm{SW}(m m H g / m L)$

$1700 \pm 94$

$1208 \pm 593 *$

1044+434*

$\mathrm{RV} \mathrm{dP} / \mathrm{dt}_{\text {max }}(m m H g / s)$

$512 \pm 82$

$489 \pm 129$

$426 \pm 125$

$\mathrm{RV} \mathrm{dP} / \mathrm{dt}_{\min }(m m H g / s)$

$-264 \pm 36$

$-279 \pm 75$

$-388 \pm 165 *$

$\mathrm{RV}$ PSP $(m m H g)$

$24 \pm 9$

$30 \pm 5$

$30 \pm 10$

RV EDP $(m m H g)$

$0 \pm 7$

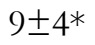

$8 \pm 5^{*}$

Mech.InterVentr.Asynch. (ms)

$-27 \pm 7$

$-22 \pm 7$

$-23 \pm 11$

Mech.InterVentr.Asynch.: mechanical interventricular asynchrony. ${ }^{*} \mathrm{p}<0.05$ compared to LBBB group, using a general linear model for repeated measures and Bonferoni correction for post-hoc comparisons. 


\section{Experimental models}

Table 1 summarizes baseline characteristics of hearts with acute LBBB, $\mathrm{LBBB}+\mathrm{MI}$ and $\mathrm{LBBB}+\mathrm{HF}$ during the CRT protocol. All infarctions were transmural and infarct size accounted for $20 \pm 16 \%$ (range 14-32\%) of LV mass. As compared to the acute LBBB group, LV function was depressed in the LBBB+MI group, as indicated by lower stroke work and elevated LV and RV end-diastolic pressures. Echocardiographically, LV end-diastolic diameter remained constant while wall thickness increased.

\section{LBBB}

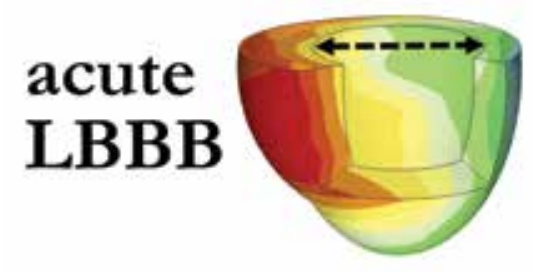

\section{LBBB $\stackrel{+}{\text { MI }}$}

\section{LBBB $+$ HF}
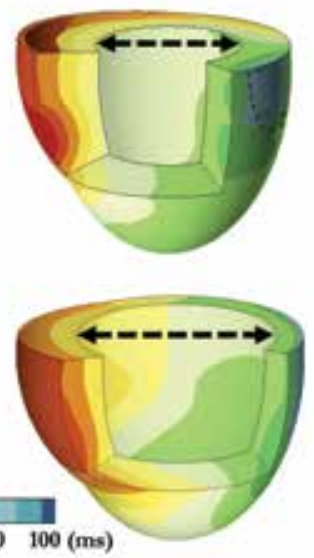

EPI CRT ENDO CRT
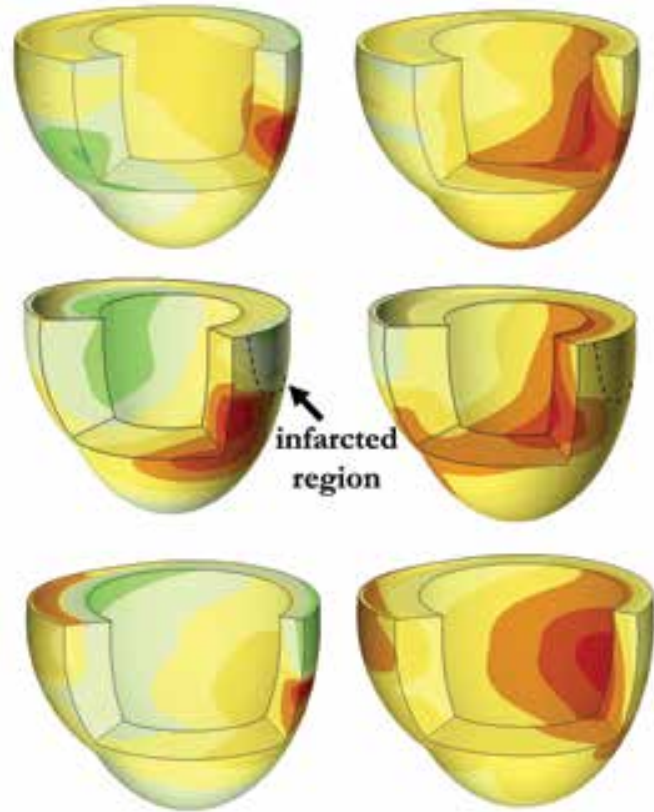

Figure 2: Typical examples of 3D electrical activation in the LBBB group, LBBB+MI group and LBBB+HF group during baseline LBBB (left panels), CRT with EPI LV pacing (middle panels) and ENDO LV pacing (right panels). In both modes of CRT the $L V$ pacing lead was positioned at the mid-level of the $L V$ wall. The size of cavity and the wall thickness correspond with the echocardiographic measurements.

Consequently, the ratio of outer to inner LV radius was higher in the $\mathrm{LBBB}+\mathrm{MI}$ group as compared with the acute LBBB group (1.88 versus 1.61, respectively, general linear model (post-hoc comparison) $\mathrm{p}=<0.05$ ), indicating concentric remodeling. In the LBBB+HF group, four weeks of rapid pacing induced an increase in LV end-diastolic diameter and a decrease in LV wall thickness. In this model, the ratio of outer $L V$ radius and inner $L V$ radius was decreased to 1.36 (general linear 
model (post-hoc comparison) $\mathrm{p}<0.05$ ), reflecting eccentric remodeling, which was accompanied by severe systolic dysfunction as evidenced by an LV ejection fraction of $\approx 15 \%$ in combination with $\approx 50 \%$ reduction of $\mathrm{LV} \mathrm{d} P / \mathrm{d} t_{\text {max }}$, and elevated LV EDP (Table 1).

\section{Effects of ENDO-CRT on impulse conduction}

Typical examples of electrical activation in the ventricles for all three groups are shown in Figure 2. During baseline LBBB (left panels), the electrical wave front initiated at the RV endocardium and gradually spread through the interventricular septum towards the latest activated LV lateral wall, consistent with electrical maps from an earlier high-resolution mapping study. ${ }^{15}$ During conventional EPI-CRT, activation wave fronts (red-yellow) generated in the RV and LV merged near the septum and anterior wall (green), thus resynchronizing the ventricles as compared to baseline LBBB. ENDO-CRT (right panels) resulted in more pronounced resynchronization than EPI-CRT, as is depicted by a more homogeneous color pattern and less crowding of isochrone lines.

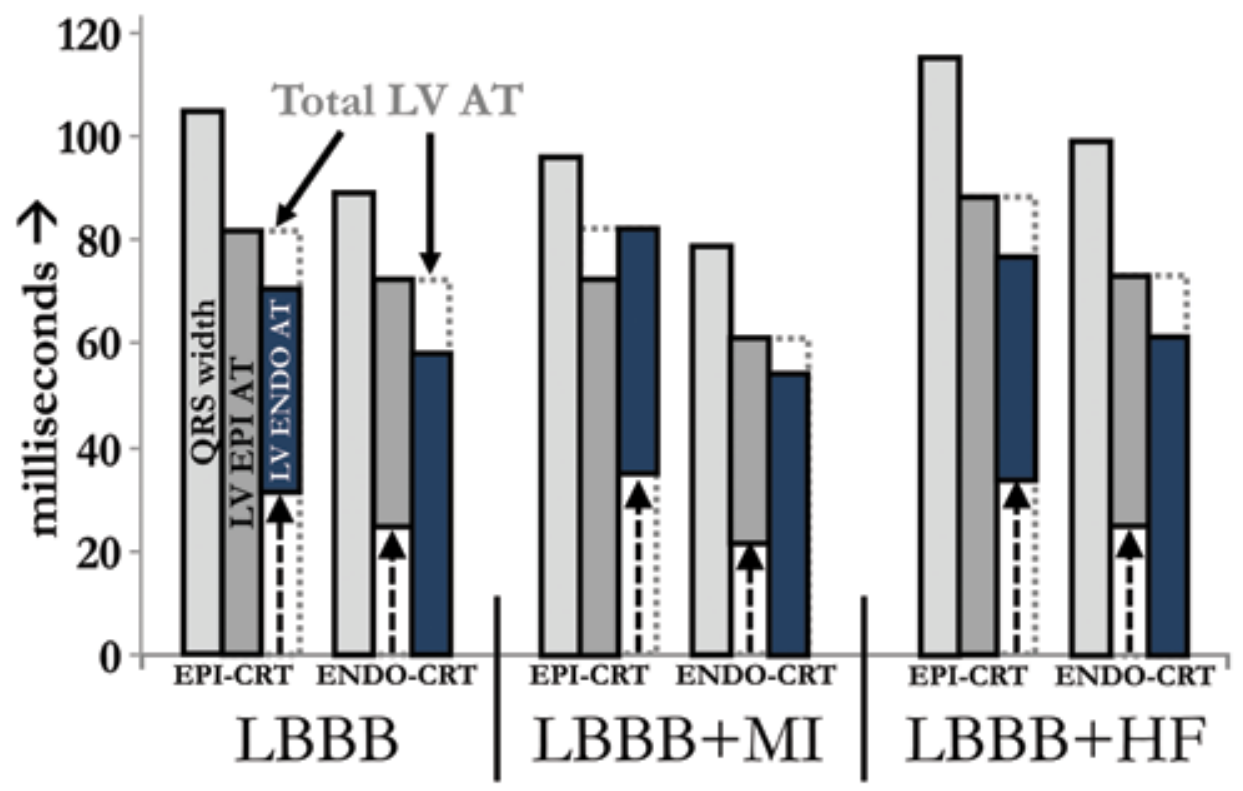

Figure 3: Overview of mean QRS duration, epicardial LV AT (activation time) and endocardial LV AT during EPI versus ENDO-CRT in dogs with LBBB, LBBB+MI and LBBB+HF. Dashed bars indicate total LV AT and dashed arrows show transmural LV AT. All EPI-ENDO comparisons are statistically significant $(\mathrm{p}<0.01)$, see Table 2 for absolute values and p-values (all p-values are based on the general linear model for repeated measures). 
The mapping studies revealed that in all models, ENDO-CRT significantly reduced total LV AT as compared with EPI-CRT ( $p<0.05$ for all comparisons). In concordance with the data acquired from invasive mapping, the QRS duration was also reduced in all dyssynchronous models (Figure 3 and Table 2). The shorter total LV AT during ENDO-CRT was caused by shorter epicardial LV AT as well as shorter transmural LV AT. The latter is depicted in Figure 3 by the dashed arrow lines as the time to the first endocardial activation during EPI-CRT and time to first epicardial activation during ENDO-CRT.
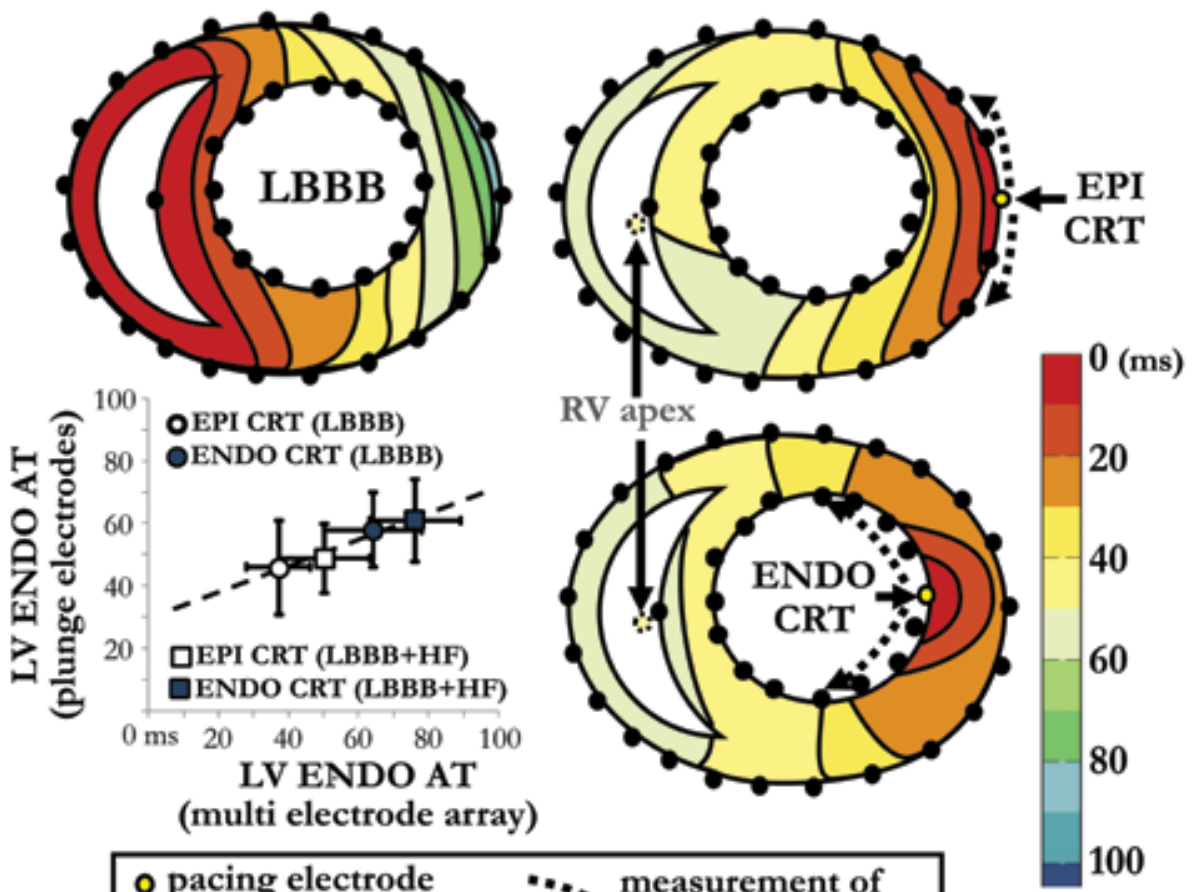

(multi electrode array)

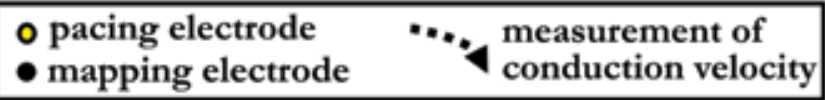

Figure 4: Typical examples of short-axis electrical activation during baseline LBBB (left), EPI-CRT (top right) and ENDO-CRT (bottom right), obtained by electrode band and multi-electrode array mapping. Transmural and epicardial isochrone broadening during ENDO-CRT indicate faster depolarization but the endocardium is depolarized later than during EPI-CRT as indicated by the isochrone narrowing. Dotted lines indicate the electrodes from which activation times were derived and divided by their distance to the pacing electrode to obtain conduction velocity. The graph plot shows the correlation between ENDO AT derived by the plunge electrodes and by the multi-electrode array during EPI and ENDO-CRT in the LBBB and $\mathrm{LBBB}+\mathrm{HF}$ groups. 
A detailed indication of the spread of activation in the short axis is provided by Figure 4. This figure also explains why endocardial LV AT was paradoxically increased by ENDO-CRT as compared to EPI-CRT in Figure 3. During EPI-CRT, a broad wave front slowly approached the endocardium but caused almost simultaneous activation of a large part of the LV endocardium, whereas during ENDO-CRT the earliest endocardial activation occurred in a small region that took time to spread to more remote areas of the LV endocardium. The endocardial LV AT as derived from the LV contact electrodes corresponded closely with those derived from multi-electrode array mapping (plot in Figure 4), albeit that the plunge electrodes underestimated endocardial LV AT at higher values, presumably because the multielectrode array is more likely to include small late activated regions.

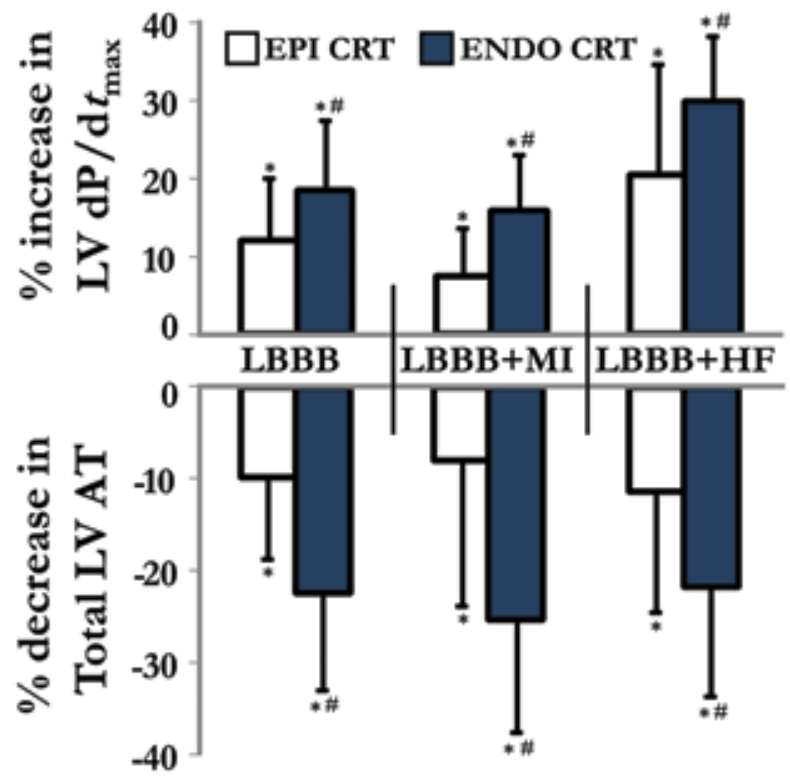

Figure 5: Percent change in LV $\mathrm{dP} / \mathrm{dt}_{\text {max }}$ (top panel) and during LV total activation duration (LV AT, bottom panel) during EPI versus ENDO-CRT in dogs with $\mathrm{LBBB}, \mathrm{LBBB}+\mathrm{MI}$ and LBBB+HF. $*_{\mathrm{p}}<0.05$ compared with baseline atrial pacing. \# $\mathrm{p}<0.05$ comparing ENDO-CRT with EPI-CRT. (all p-values are based on the general linear model for repeated measures).

Comparing all measurements to baseline LBBB, ENDO-CRT reduced total LV AT significantly more than EPI-CRT in all three models (bottom panel of Figure 5). The improved resynchronization during ENDO-CRT was associated with approximately $50 \%$ higher circumferential conduction velocities at the endocardium than at the epicardium (Figure 6A). This difference was consistent for all LV segments and was observed in hearts with acute LBBB and in the LBBB $+\mathrm{HF}$ hearts. The added benefit of ENDO-CRT to resynchronize was larger in concentrically remodeled hearts $(\mathrm{LBBB}+\mathrm{MI})$ and least (19 vs. $10 \%$, respectively) in eccentrically remodeled hearts $(\mathrm{LBBB}+\mathrm{HF}$; Figure $6 B)$, indicating that smaller path length along the endocardium partly explains the benefit of endocardial CRT on electrical resynchronization. 


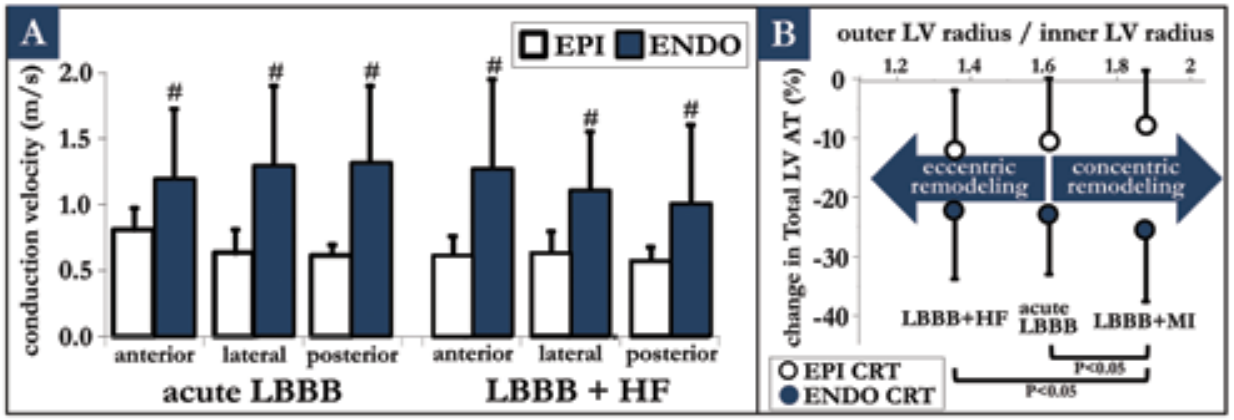

Figure 6: A: Means ( $\pm S D)$ of conduction velocities (in $\mathrm{m} / \mathrm{s}$ ) of the epicardium and endocardium in anterior, lateral and posterior regions in dogs with acute LBBB and chronic LBBB+HF. ${ }^{*} \mathrm{p}<0.05$ EPI versus ENDO. B: Percent change in total LV AT during EPI versus ENDO-CRT as a function of the ratio of outer $L V$ radius to inner $L V$ radius in the three experimental groups. P-values signify a statistical difference in ENDO-EPI difference between groups.

\section{Effects of ENDO-CRT on hemodynamic performance}

The superior electrical resynchronization by ENDO-CRT coincided with larger increases in $\mathrm{LV} \mathrm{dP} / \mathrm{d} t_{\text {max }}$ than during EPI-CRT and the absolute increase was similar for the three models $(\approx 10 \%$ on top of EPI-CRT effect; upper panel in Figure 5). Larger LV contractility improvement during ENDO-CRT was consistent for all paced regions and groups (with the exception of apicolateral pacing in the $\mathrm{LBBB}+\mathrm{HF}$ group, Figure 7 ). Defining $\geq 10 \%$ increase in $\mathrm{LV} \mathrm{d} P / \mathrm{d} t_{\max }$ as acute hemodynamic response to CRT, ENDO-CRT resulted in a hemodynamic response in $90 \%$ cases, whereas EPI-CRT only resulted in a 59\% response rate.

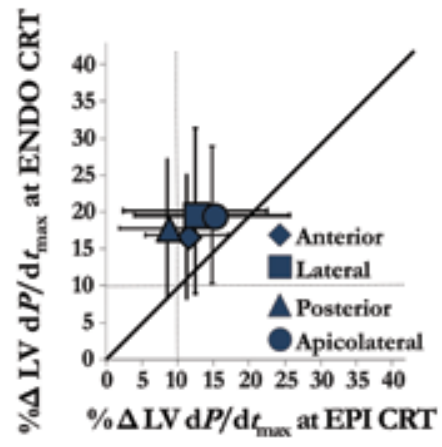

LBBB

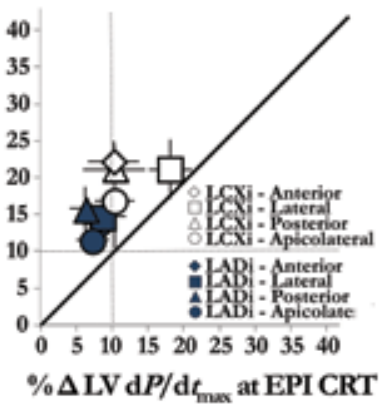

LBBB+MI

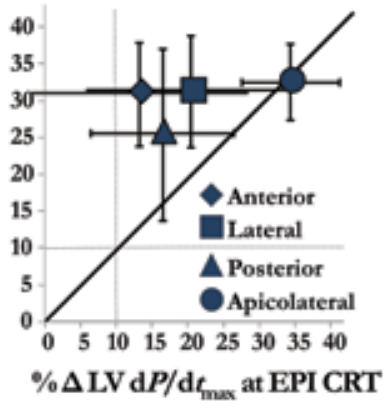

$\mathbf{L B B B}+\mathbf{H F}$

Figure 7: Increase in $\mathrm{LV} \mathrm{dP/dt}{ }_{\max }$ (mean values and S.D., pooled by regions, as compared to baseline) during ENDO-CRT as a function of the \% increase in LV dP/ $\mathrm{dt}_{\text {max }}$ during EPI-CRT in dogs with LBBB, LBBB+MI and LBBB+HF. 
Generally, the optimal sites during ENDO-CRT were located at the same wall regions as the optimal sites during EPI-CRT (Figure 8). However, endocardial sites providing a significant effect, encompassed a larger LV area and magnitude of improvement was larger than for epicardial sites, as indicated by the more intense red colors. In LBBB hearts with LAD infarction the best pacing sites were the basolateral LV wall, whereas in LBBB hearts with LCX infarction, LV mid-lateral to apicolateral wall sites provided the best results. In the acute $\mathrm{LBBB}$ and $\mathrm{LBBB}+\mathrm{HF}$ group, lateral and apicolateral pacing sites tended outperform anterior and posterior sites but there was not an identifiable 'optimal' pacing site (Figure 8). ENDO-CRT tended to increase stroke work as compared to EPI-CRT and in the LBBB+HF group, ENDO-CRT resulted in larger decreases in $\mathrm{LV} \mathrm{d} P / \mathrm{d} t_{\min }$ than EPI-CRT (Table 2).

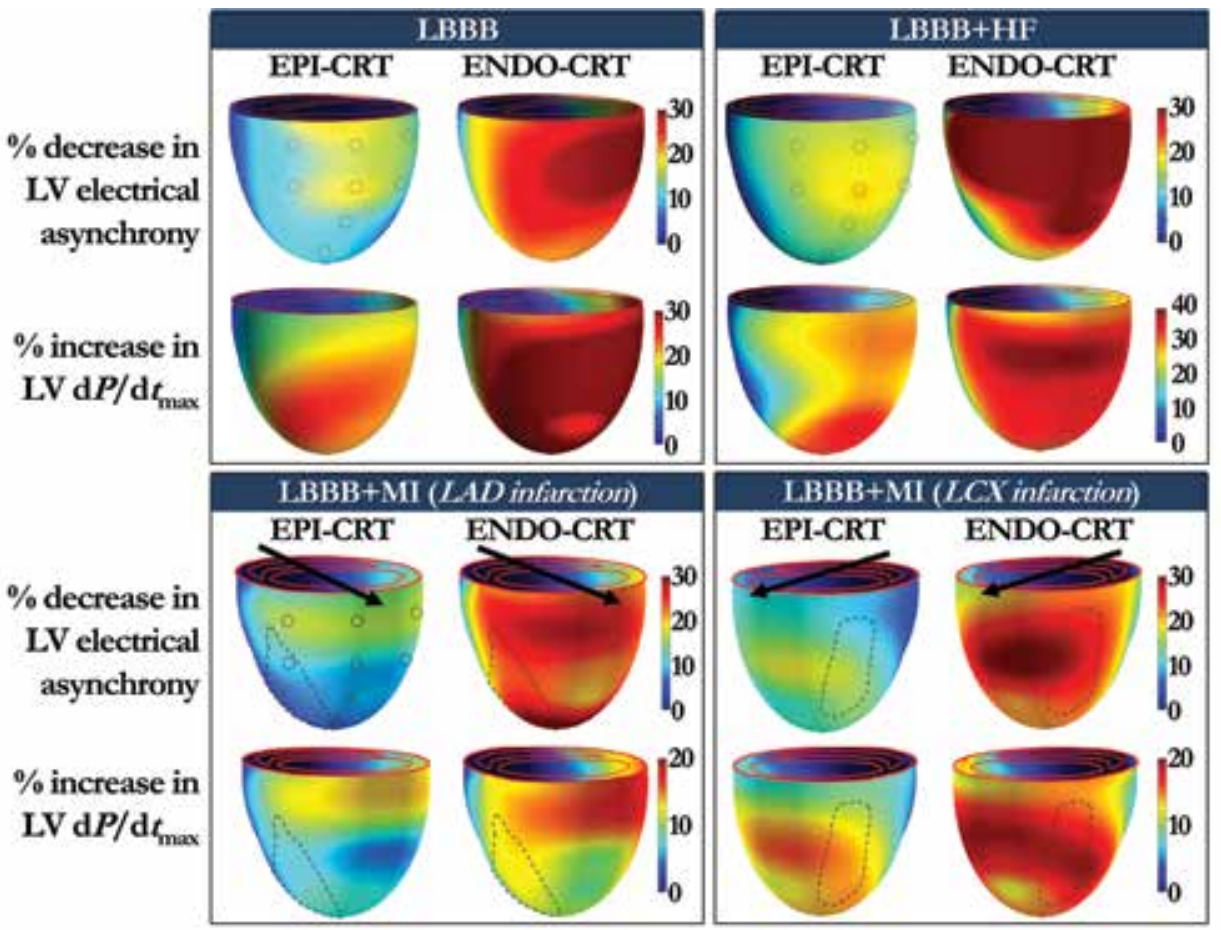

Figure 8: Distribution of pacing sites (grey circles) that provide a certain \%increase in LV electrical resynchronization and $\mathrm{LVdP} / \mathrm{dt}_{\text {max }}$ during EPI-CRT and ENDOCRT as compared to baseline. Plots are based on mean values from 6 LBBB hearts (top left panels), $6 \mathrm{LBBB}+\mathrm{HF}$ hearts (top right), $4 \mathrm{LBBB}+\mathrm{MI}$ with LAD infarction (bottom left) and 3 LBBB+MI hearts with LCX infarction (bottom right). Dashed lines indicate region of infarction and arrows indicate rotation of LAD versus LCX. 
Table 2A: Electrophysiological and hemodynamic variables during baseline LBBB conduction and during epicardial and endocardial CRT in dogs with LBBB and myocardial infarction. Corresponding data for the acute LBBB group have been published previously. ${ }^{4}$

\begin{tabular}{|c|c|c|c|c|}
\hline & $\begin{array}{c}\text { Baseline } \\
\mathrm{LBBB}+\mathrm{MI}\end{array}$ & $\begin{array}{l}\text { EPI- } \\
\text { BiV }\end{array}$ & $\begin{array}{l}\text { ENDO- } \\
\text { BiV }\end{array}$ & $\begin{array}{l}\Delta \text { EPI vs } \\
\Delta \text { ENDO }\end{array}$ \\
\hline & mean $\pm \mathrm{SD}$ & $m e a n \pm S D$ & $m e a n \pm \mathrm{SD}$ & p-value \\
\hline $\operatorname{HR}(b p m)$ & $125 \pm 16$ & $124 \pm 17$ & $124 \pm 18$ & 0.486 \\
\hline QRS width (ms) & $106 \pm 9$ & $96 \pm 17 *$ & $79 \pm 12 *$ & $<0.001$ \\
\hline Total LV AT (ms) & $88 \pm 7$ & $81 \pm 16^{*}$ & $66 \pm 12 *$ & $<0.001$ \\
\hline Epicardial LV AT (ms) & $88 \pm 7$ & $81 \pm 16^{*}$ & $40 \pm 11 *$ & $<0.001$ \\
\hline Endocardial LV AT (ms) & $52 \pm 16$ & $47 \pm 15$ & $54 \pm 10$ & 0.003 \\
\hline Transmural AT (ms) & & $36 \pm 21$ & $21 \pm 11$ & $<0.001$ \\
\hline $\mathrm{T}_{\text {peak }}-\mathrm{T}_{\text {end }}(m s)$ & $63 \pm 4$ & $52 \pm 12$ & $49 \pm 11$ & 0.358 \\
\hline Tau (ms) & $43 \pm 6$ & $45 \pm 5$ & $45 \pm 5$ & 0.017 \\
\hline $\mathrm{LV} \mathrm{P}_{\max }(m m H g)$ & $87 \pm 12$ & $88 \pm 12$ & $88 \pm 13$ & 0.183 \\
\hline $\mathrm{LV} \mathrm{d} P / \mathrm{d} t_{\max }(m m H g / s)$ & $1410 \pm 282$ & $1527 \pm 320^{*}$ & $1673 \pm 382^{*}$ & 0.005 \\
\hline $\mathrm{LV} \mathrm{d} P / \mathrm{d} t_{\min }(m m H g / s)$ & $-1495 \pm 344$ & $-1550 \pm 340$ & $-1551 \pm 375$ & 0.711 \\
\hline LV EDP (mmHg) & $13 \pm 7$ & $14 \pm 8$ & $14 \pm 7$ & 0.362 \\
\hline $\mathrm{SV}(m l)$ & $20 \pm 7$ & $21 \pm 8$ & $21 \pm 8$ & 0.384 \\
\hline $\mathrm{SW}\left(m m H g^{*} m l\right)$ & $1208 \pm 594$ & $1403 \pm 692 *$ & $1586 \pm 775^{*}$ & 0.074 \\
\hline $\mathrm{RV} \mathrm{P}_{\max }(m m H g)$ & $30 \pm 5$ & $28 \pm 4$ & $26 \pm 4$ & 0.011 \\
\hline $\mathrm{RV} \mathrm{d} P / \mathrm{d} t_{\max }(m m H g / s)$ & $490 \pm 129$ & $531 \pm 148$ & $517 \pm 139$ & 0.066 \\
\hline $\mathrm{RV} \mathrm{d} P / \mathrm{d} t_{\min }(m m H g / s)$ & $-280 \pm 75$ & $-272 \pm 69$ & $-288 \pm 90$ & 0.351 \\
\hline RV EDP (mmHg) & $9 \pm 4$ & $10 \pm 4$ & $9 \pm 3$ & 0.408 \\
\hline Mech.InterVentr.Async. (ms) & $-22 \pm 7$ & $-16 \pm 9$ & $-9 \pm 10$ & 0.052 \\
\hline
\end{tabular}

Mech.InterVentr.Asynchr: mechanical interventricular asynchrony; data from 51 paired measurements in 7 experiments. ${ }^{*} \mathrm{p}<0.05$ compared to baseline LBBB. In the last column, p-values are presented for the differences in relative change $(\Delta)$ by EPI-CRT versus ENDO-CRT. All p-values are based on the general linear model for repeated measures. 
Table 2B: Electrophysiological and hemodynamic variables during baseline LBBB conduction and during epicardial endocardial CRT in dogs with LBBB and dilated cardiomyopathy.

\begin{tabular}{|c|c|c|c|c|}
\hline & $\begin{array}{c}\text { Baseline } \\
\text { LBBB+HF }\end{array}$ & $\begin{array}{l}\text { EPI- } \\
\text { CRT }\end{array}$ & $\begin{array}{c}\text { ENDO- } \\
\text { CRT }\end{array}$ & $\begin{array}{l}\triangle E P I \text { vs } \\
\triangle E N D O\end{array}$ \\
\hline & mean \pm SD & mean $\pm S D$ & mean $\pm S D$ & p-value \\
\hline $\mathrm{HR}(\mathrm{bpm})$ & $135 \pm 10$ & $135 \pm 9$ & $135 \pm 9$ & 0.175 \\
\hline QRS width (ms) & $123 \pm 10$ & $116 \pm 16$ & $99 \pm 20 *$ & 0.005 \\
\hline Total LV AT (ms) & $97 \pm 16$ & $87 \pm 13 *$ & $76 \pm 17 *$ & $<0.001$ \\
\hline Epicardial LV AT (ms) & $97 \pm 16$ & $85 \pm 12 *$ & $49 \pm 16^{*}$ & $<0.001$ \\
\hline Endocardial LV AT (ms) & $37 \pm 10$ & $42 \pm 11$ & $61 \pm 13^{*}$ & $<0.001$ \\
\hline Transmural AT (ms) & & $35 \pm 11$ & $26 \pm 9$ & 0.002 \\
\hline Tpeak-Tend (ms) & $56 \pm 8$ & $44 \pm 13^{*}$ & $45 \pm 18^{*}$ & 0.883 \\
\hline Tau (ms) & $57 \pm 20$ & $49 \pm 22$ & $46 \pm 21$ & 0.297 \\
\hline $\mathrm{LV} \mathrm{P}_{\max }(\mathrm{mmHg})$ & $76 \pm 10$ & $78 \pm 9$ & $78 \pm 10$ & 0.87 \\
\hline $\mathrm{LV} \mathrm{dP} / \mathrm{dt}_{\max }(\mathrm{mmHg} / \mathrm{s})$ & $842 \pm 82$ & $1009 \pm 153^{*}$ & $1090 \pm 221 *$ & 0.106 \\
\hline $\mathrm{LV} \mathrm{dP} / \mathrm{dt}_{\max } / \mathrm{P}_{\text {norm }}(\mathrm{mmHg} / \mathrm{s})$ & $22.3 \pm 5$ & $26.9 \pm 7 *$ & $29 \pm 7 *$ & 0.002 \\
\hline $\mathrm{LV} \mathrm{dP} / \mathrm{dt}_{\min }(\mathrm{mmHg} / \mathrm{s})$ & $-976 \pm 175$ & $-1091 \pm 241 *$ & $-1177 \pm 281 *$ & 0.039 \\
\hline LV EDP $(\mathrm{mmHg})$ & $18.3 \pm 11$ & $18.3 \pm 14$ & $17.7 \pm 15$ & 0.386 \\
\hline $\mathrm{SV}(\mathrm{ml})$ & $15 \pm 5$ & $20 \pm 9 *$ & $20 \pm 10$ & 0.556 \\
\hline $\mathrm{SW}\left(\mathrm{mmHg}{ }^{*} \mathrm{ml}\right)$ & $1088 \pm 398$ & $1363 \pm 644^{*}$ & $1467 \pm 767^{*}$ & 0.170 \\
\hline $\mathrm{RV} \mathrm{P}_{\max }(\mathrm{mmHg})$ & $30 \pm 10$ & $28 \pm 9 *$ & $28 \pm 9 *$ & 0.640 \\
\hline $\mathrm{RV} \mathrm{dP} / \mathrm{dt}_{\max }(\mathrm{mmHg} / \mathrm{s})$ & $426 \pm 125$ & $442 \pm 102$ & $437 \pm 142$ & 0.823 \\
\hline $\mathrm{RV} \mathrm{dP} / \mathrm{dt}_{\min }(\mathrm{mmHg} / \mathrm{s})$ & $-388 \pm 165$ & $-384 \pm 172$ & $-412 \pm 176$ & 0.001 \\
\hline RV EDP (mmHg) & $8 \pm 5$ & $8 \pm 7$ & $8 \pm 7$ & 0.662 \\
\hline Mech.InterVentr.Async. (ms) & $-23 \pm 11$ & $-16 \pm 9$ & $-9 \pm 10 *$ & 0.008 \\
\hline
\end{tabular}

Mech.InterVentr.Asynchr: mechanical interventricular asynchrony; data from 48 paired measurements in 6 experiments. ${ }^{*} \mathrm{p}<0.05$ compared to baseline LBBB. In the last column, p-values are presented for the differences in relative change $(\Delta)$ by EPI-CRT versus ENDO-CRT. All p-values are based on the general linear model for repeated measures. 


\section{Discussion}

The present study shows that endocardial CRT produces more uniform ventricular depolarization as well as larger hemodynamic benefit as compared to conventional epicardial CRT in three models of experimental dyssynchrony: acute LBBB and chronic LBBB in combination with heart failure and with myocardial infarction. The advantage of endocardial over epicardial CRT can to a large extent be understood from higher endocardial impulse conduction velocities, shorter transmural activation times and shorter conduction path length, the latter explaining the less pronounced resynchronization in eccentrically remodeled LBBB+HF.

\section{Improved electrical resynchronization by endocardial CRT}

From the data of our previous study ${ }^{4}$ in canine hearts with acute LBBB we suggested that the electrical benefits of endocardial CRT could be explained by three factors: (i) a shorter path length for the depolarization wave to reach all regions of the ventricles, (ii) more rapid impulse conduction in the endocardium than in the epicardium, (iii) a more rapid transmural conduction from endocardium to epicardium than in the opposite direction. ${ }^{4}$ The present study extends these observations and provides more robust and more detailed evidence for these mechanisms.

While obviously the path for impulse conduction is always shorter along the endocardium than along the epicardium, the difference depends on the eccentricity of ventricular remodeling. The finding that the added benefit of endocardial over epicardial CRT on electrical resynchronization was greater in hearts with concentric than with eccentric remodeling supports the idea of a role for the shorter path length in the benefits of endocardial CRT. However, even in the most eccentrically remodeled hearts a clear benefit remained, indicating important roles for other factors. The most predominant factor in respect to the added benefit of endocardial pacing appears to be the faster impulse conduction in the endocardial layers. This fast conduction was even observed in the chronically dyssynchronous failing hearts and without regional differences. These results seem to contradict results from in vitro mapping studies by Spragg et al, who showed endocardial conduction slowing in lateral regions of chronically dyssynchronous canine hearts. ${ }^{5}$ These contradictory findings might be explained by the difference in setup (perfused wedge preparations versus in vivo). Factors like hypoxia, tissue damage during isolation of the wedge and perfusion with crystalline medium may have influenced the in vitro measurements. On the other hand, distance along the endocardium may have been assessed less accurately in our in vivo preparation. Finally, Spragg et al measured along the main 
axis of a diagonally propagating wave front, whereas we selectively measured velocity in circumferential direction. Beside a faster endocardial than epicardial impulse conduction we also consistently found that impulse conduction across the LV wall was $\approx 25 \%$ faster when pacing the LV endocardium than pacing the LV epicardium, thus adding to the more rapid total LV resynchronization. This difference in transmural conduction velocity is not well understood, because it would be expected that the conduction path is the same. Interestingly, this effect was observed even in the LBBB + HF group, even though LV wall thickness was decreased by $\approx 21 \%$, thus contributing to the better electrical resynchronization during endocardial CRT.

\section{Comparison with clinical studies}

LV endocardial pacing in humans can be established through an atrial transseptal approach. ${ }^{6-8}$ The results of our study are, at least in part, supported by a few small observational studies in human CRT patients where such approach has been followed. In these clinical studies, $\mathrm{LV} \mathrm{dP} / \mathrm{dt}_{\text {max }}$ at the best $\mathrm{LV}$ endocardial site was significantly greater than that with device pacing via the coronary sinus. ${ }^{7-9}$ Recently, these findings were debated to be subjected to statistical bias as the best LV ENDO site was selected among many (up to 51) LV endocardial sites, which were compared to a single LV EPI site (via the coronary sinus). ${ }^{16}$ Using this method, a relatively small measurement error could project into a rather wide range of extreme results. ${ }^{16}$ In contrast, in our study we used 8 sites, evenly spread over the LV free wall, and used back-to-back comparison of endocardial and epicardial CRT, thus eliminating these site-specific biological pacing effects and statistical bias. In the clinical studies that compared the effect of pacing the coronary sinus electrode with the corresponding, immediately opposite LV endocardium the statistical significance was lost, but the trend still was towards a better effect of endocardial CRT. ${ }^{7,8}$ A possible explanation for the lack of statistical significance in the clinical studies may be the fact that one study only investigated single-site LV pacing ${ }^{7}$, which in the present canine study also did not result in significant $\mathrm{LV} \mathrm{d} P / \mathrm{d} t_{\text {max }}$ differences when using short $\mathrm{AV}$-intervals (data not shown). In another study ${ }^{8}$ the direct comparison could only be made in 7 patients, which resulted in very low statistical power. An additional advantage of our animal experiment may have been the higher accuracy of positioning the pacing leads at directly opposite sides of the LV wall because of the direct access to the heart. Clearly, a more systematic study is required to certify the benefit of endocardial over epicardial CRT in patients. 
Most clinical studies used either QRS duration or solely epicardial or endocardial activation time to assess electrical asynchrony while few studies measured total (epicardial and endocardial activation time). Like in our study, Ginks et al employed multi-electrode array (EnSite $\left.{ }^{\circledR}\right)$ measurements of endocardial LV AT and found no reduction in this variable when moving from epicardial to endocardial CRT.' This observation was also made in our study, actually demonstrating an increase of endocardial LV AT upon endocardial CRT. However, this paradoxical increase was inconsequential, due to the reduction in epicardial LV as well as transmural AT, such that total LV AT was reduced. Comparable to our results achieved in canine hearts, Ginks et al found that endocardial LV AT encompassed $\approx 40 \%$ of the QRS duration. ${ }^{9}$ Therefore, endocardial conduction velocity is most likely similarly higher than epicardial conduction in patients, which is an important factor in the mechanism of endocardial CRT.

The present study shows one possible reason why endocardial CRT may be less beneficial in patients with dilated heart failure. The smaller endocardial to epicardial path length difference in patients with dilated hearts could preclude the better resynchronization but the hemodynamic benefits remain in favor of endocardial CRT, presumably due to the role of faster transmural and endocardial conduction. In the latter respect Ginks et al made an important observation, in that they observed smaller benefits at endocardial sites with slow conduction, possibly related to scar or hypoperfusion. This observation may seem in contradiction with our observation that the benefit of endocardial pacing was largest in the LBBB+MI group. However, it should be kept in mind that in our study we avoided to pace inside the infarcted area. In fact, myocardial infarction does not preclude benefits of CRT, but the efficacy is more dependent on location and timing of stimulation, as has also been shown in a previous report. ${ }^{10}$ Also, a recent publication provides evidence that pacing in the scar strongly reduces the benefit of CRT. ${ }^{17}$ Therefore, it is still plausible that ENDO-CRT can increase therapy response in ischemic patients. In this respect an important benefit of endocardial CRT is that more pacing sites can be reached than usually with coronary venous implants. Exploring the sites appears important in the light of the findings of Ginks et al as well as of our finding that there was no single optimal endocardial pacing site that showed consistently better hemodynamics. Helm et al investigated over one hundred pacing sites in failing and non-failing asynchronous canine hearts and found, in agreement with our results, that average CRT response was excellent in a fairly broad range of the LV lateral wall. Individual tailoring of endocardial CRT by searching 
the optimal pacing site within the endocardium is thus warranted. The fact that endocardial CRT provides consistently better electrical resynchronization as well as hemodynamic improvement in the three different animal models further supports the idea that endocardial CRT is the ultimate preference in a wide variety of patients with dyssynchrony. This benefit may be enhanced by the larger range of accessible locations at the endocardium.

\section{Endocardial CRT in specific LBBB models}

It was interesting to observe that despite all differences between the three models, CRT resulted in a similar absolute increase in $\mathrm{LV} \mathrm{d} P / \mathrm{d} t_{\text {max }}$ (all $\approx 150 \mathrm{mmHg} / \mathrm{s}$ with EPI-CRT and $\approx 250 \mathrm{mmHg} / \mathrm{s}$ with endocardial CRT). Because baseline $\mathrm{LV} \mathrm{d} P / \mathrm{d} t_{\max }$ was considerably lower in the $\mathrm{LBBB}+\mathrm{HF}$ group, this translated to higher relative increases in $\mathrm{LV} \mathrm{d} P / \mathrm{d} t_{\text {max }}$ during CRT, relative increases that are similar to those found in patients. ${ }^{18}$ Interestingly, in CRT patients, a wide range of baseline LV dP/ $\mathrm{d} t_{\text {max }}$ is observed, yet the increase in $\mathrm{LV} \mathrm{dP/d} t_{\text {max }}$ upon CRT is also $\approx 200 \mathrm{mmHg} / \mathrm{s}$. This indicates that there is an almost fixed increase in this parameter by CRT, which, as we show, can be increased by using a better (endocardial) pacing site.

\section{Limitations}

Even though current chronic animal models resemble CRT candidates better than the acute LBBB model, our data should be extrapolated to patients with care. The LBBB+MI model has been introduced in a previous publication. ${ }^{10}$ It is characterized by preserved LV ejection fraction, but elevated LV and RV filling pressures and reduced stroke work. It should be realized that in this model, LBBB was induced by ablation of the proximal left bundle branch. The thus induced conduction abnormality may differ from that in patients with ischemic etiology of heart failure, where the ischemia may be the underlying cause of the conduction abnormality. The LBBB+HF model has been used before by other groups. Even in these 'chronic' animal models the disease history is shorter than in patients, and in addition, fibrosis and molecular remodeling may differ between animals and patients. Furthermore, the present study investigated the acute hemodynamic response, whereas the long term response, reverse remodeling and survival are more relevant. Long term follow up of patients with endocardial CRT is limited to a small study, comparing 8 patients with endocardial CRT with 17 conventional (epicardial) CRT patients. ${ }^{6}$ This study found a more homogenous intraventricular resynchronization, better LV filling and increased systolic performance after 6 months. Clearly, larger long term follow up of endocardial CRT in patients is indicated. 
Chapter 8

\section{Conclusions}

In the canine model of chronic LBBB combined with myocardial infarction or dilated cardiomyopathy, endocardial CRT improves electrical synchrony of activation as well as LV function as compared with conventional epicardial CRT. The extent of additional electrical resynchronization by endocardial CRT is dependent on cardiac remodeling but the functional response is not. Therefore, this study further emphasizes the relevance of investigating the benefits of endocardial LV stimulation in CRT patients.

\section{Acknowledgements}

The authors are indebted to the continuous scientific interest of Dr. Debra S. Echt (EBR Systems Inc., Sunnyvale, CA).

\section{Funding Sources}

This work was supported by EBR Systems Inc., Sunnyvale, CA. 


\section{References}

1. Rossi A, Rossi G, Piacenti M, Startari U, Panchetti L, Morales MA. The current role of cardiac resynchronization therapy in reducing mortality and hospitalization in heart failure patients: A meta-analysis from clinical trials. Heart Vessels. 2008;23:217223.

2. Durrer D, van Dam RT, Freud GE, Janse MJ, Meijler FL, Arzbaecher RC. Total excitation of the isolated human heart. Circulation. 1970;41:899-912.

3. Frazier DW, Krassowska W, Chen PS, Wolf PD, Danieley ND, Smith WM, Ideker RE. Transmural activations and stimulus potentials in three-dimensional anisotropic canine myocardium. Circulation research. 1988;63:135-146.

4. van Deursen C, van Geldorp IE, Rademakers LM, van Hunnik A, Kuiper M, Klersy C, Auricchio A, Prinzen FW. Left ventricular endocardial pacing improves resynchronization therapy in canine left bundle-branch hearts. Circ Arrbythm Electrophysiol. 2009;2:580-587.

5. Spragg DD, Akar FG, Helm RH, Tunin RS, Tomaselli GF, Kass DA. Abnormal conduction and repolarization in late-activated myocardium of dyssynchronously contracting hearts. Cardiovasc Res. 2005;67:77-86.

6. Garrigue S, Jais P, Espil G, Labeque JN, Hocini M, Shah DC, Haissaguerre M, Clementy J. Comparison of chronic biventricular pacing between epicardial and endocardial left ventricular stimulation using doppler tissue imaging in patients with heart failure. Am J Cardiol. 2001;88:858-862.

7. Derval N, Steendijk P, Gula LJ, Deplagne A, Laborderie J, Sacher F, Knecht S, Wright M, Nault I, Ploux S, Ritter P, Bordachar P, Lafitte S, Reant P, Klein GJ, Narayan SM, Garrigue S, Hocini M, Haissaguerre M, Clementy J, Jais P. Optimizing hemodynamics in heart failure patients by systematic screening of left ventricular pacing sites: The lateral left ventricular wall and the coronary sinus are rarely the best sites. J Am Coll Cardiol. 2010;55:566-575.

8. Spragg DD, Dong J, Fetics BJ, Helm R, Marine JE, Cheng A, Henrikson CA, Kass DA, Berger RD. Optimal left ventricular endocardial pacing sites for cardiac resynchronization therapy in patients with ischemic cardiomyopathy. $\mathrm{J}$ Am Coll Cardiol. 2010;56:774-781.

9. Ginks MR, Lambiase PD, Duckett SG, Bostock J, Chinchapatnam P, Rhode K, McPhail MJ, Simon M, Bucknall C, Carr-White G, Razavi R, Rinaldi CA. A simultaneous $\mathrm{x}$-mri and non contact mapping study of the acute hemodynamic effect of left ventricular endocardial and epicardial cardiac resynchronization therapy in humans. Circulation. Heart failure. 2011;4:170-179.

10. Rademakers LM, van Kerckhoven R, van Deursen CJ, Strik M, van Hunnik A, 
Kuiper M, Lampert A, Klersy C, Leyva F, Auricchio A, Maessen JG, Prinzen FW. Myocardial infarction does not preclude electrical and hemodynamic benefits of cardiac resynchronization therapy in dyssynchronous canine hearts. Circ Arrbythm Electrophysiol. 2010;3:361-368.

11. Helm RH, Byrne M, Helm PA, Daya SK, Osman NF, Tunin R, Halperin HR, Berger RD, Kass DA, Lardo AC. Three-dimensional mapping of optimal left ventricular pacing site for cardiac resynchronization. Circulation. 2007;115:953-961.

12. Prabhu SD, Freeman GL. Effect of tachycardia heart failure on the restitution of left ventricular function in closed-chest dogs. Circulation. 1995;91:176-185.

13. Gornick CC, Adler SW, Pederson B, Hauck J, Budd J, Schweitzer J. Validation of a new noncontact catheter system for electroanatomic mapping of left ventricular endocardium. Circulation. 1999;99:829-835.

14. Mills RW, Cornelussen RN, Mulligan LJ, Strik M, Rademakers LM, Skadsberg ND, van Hunnik A, Kuiper M, Lampert A, Delhaas T, Prinzen FW. Left ventricular septal and left ventricular apical pacing chronically maintain cardiac contractile coordination, pump function and efficiency. Circ Arrbythm Electrophysiol. 2009;2:571579 .

15. Taccardi B, Punske BB, Macchi E, Macleod RS, Ershler PR. Epicardial and intramural excitation during ventricular pacing: Effect of myocardial structure. American journal of physiology. Heart and circulatory physiology. 2008;294:H1753-1766.

16. Wichterle D, Vancura V. Statistical bias in seeking the left ventricular endocardial sweet spot for cardiac resynchronization therapy. J Am Coll Cardiol. 2011;57:1000.

17. Leyva F, Foley PW, Chalil S, Ratib K, Smith RE, Prinzen F, Auricchio A. Cardiac resynchronisation therapy guided by late gadolinium-enhancement cardiovascular magnetic resonance. J Cardiovasc Magn Reson. 2011;13:29.

18. Bogaard MD, Houthuizen P, Bracke FA, Doevendans PA, Prinzen FW, Meine M, van Gelder BM. Baseline left ventricular dp/dtmax rather than the acute improvement in $\mathrm{dp} / \mathrm{dtmax}$ predicts clinical outcome in patients with cardiac resynchronization therapy. Eur J Heart Fail. 2011;13:1126-1132. 
Endocardial CRT 

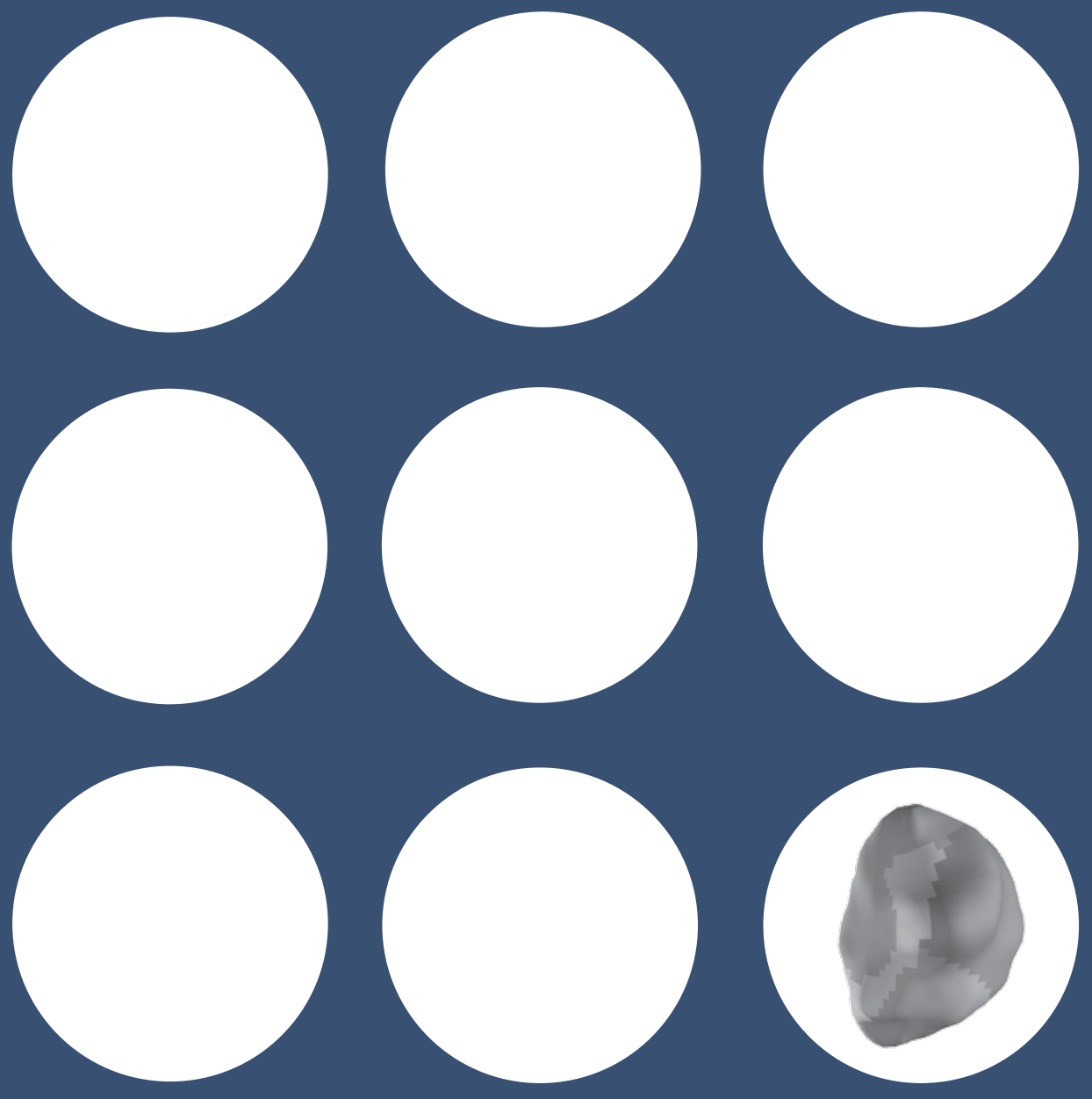

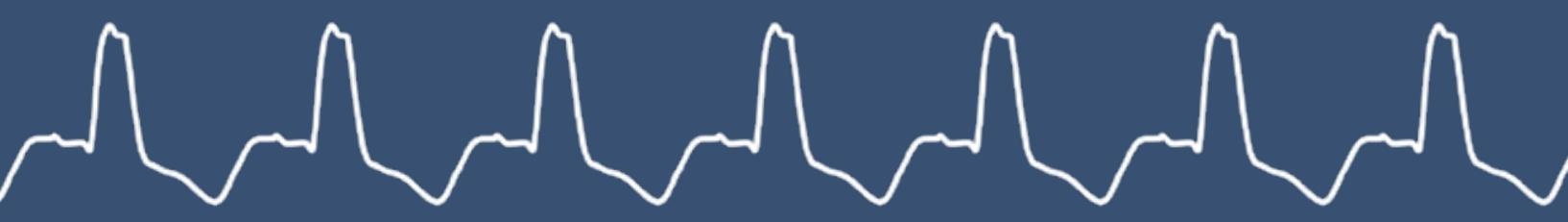




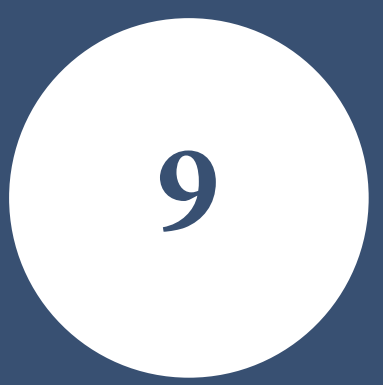

General Discussion

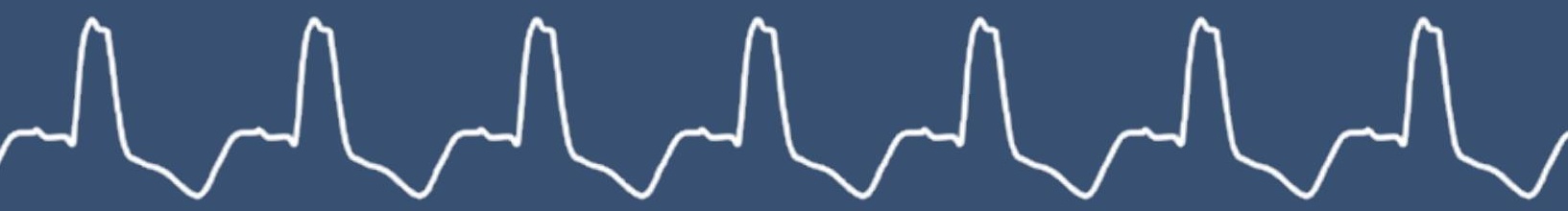




\section{Introduction}

The general aims of the research presented in this thesis were:

1. To improve understanding of electrical activation of the asynchronous heart, in particular during left bundle branch block (LBBB), and resynchronized heart.

2. To deliver tools for better treatment of the asynchronous heart.

To investigate these aims, extensive ventricular stimulation and mapping studies were performed. The canine LBBB model can be considered highly suitable for this purpose, as alluded to in chapter 3. The two aims of this thesis intertwine because improved understanding feeds back on improved therapy, and vice versa. After all, when the electrical abnormality is known, the best therapy is likely the one that returns electrical activation towards the physiological, synchronous activation. For example, even though the studies described in chapter 4, 5 and 6 were specifically designed with the purpose of increasing understanding in asynchrony and resynchronization, chapters $\mathbf{7}$ and $\mathbf{8}$ are also of value in this regard, because performing novel therapies with the intention of optimizing treatment can bring important insights into mechanisms.

In this general discussion, the results of the studies presented in this thesis are linked and put in broader perspective. First, CRT in the modern era is described, focusing on why electrical substrate is both essential and sufficient for CRT efficacy. The study findings described in this thesis are then put in perspective to reach an improved understanding and treatment of the electrical substrate.

\section{CRT in the modern era}

As its name suggests, CRT is designed to treat the electrical substrate in symptomatic heart failure patients with reduced LV ejection fraction and wide QRS complex. A recent meta-analysis pooled more than 3000 CRT patients from six trials and reported a reduction in all-cause mortality of $29 \%$ and a reduction of new hospitalizations for worsening heart failure of $37 \% .{ }^{1}$ Nevertheless, a QRS duration $\geq 120 \mathrm{~ms}$ has proven to be a moderate predictor of CRT efficacy, since $30-50 \%$ of implanted patients do not respond to the therapy. ${ }^{2-4}$ The amount of non-responders has sparked major efforts into identifying patients who benefit from CRT by investigating mechanical dyssynchrony. Since echocardiography is non-invasive and relatively affordable, multiple echocardiography-based mechanical indices have been proposed. 
Despite promising results from single-center studies, none of these parameters have yet shown to adequately classify response in prospective multi-center trials. ${ }^{5,6} \mathrm{On}$ the other hand, the duration of the QRS complex is also a rudimentary reflection of the electrical substrate. As will be mentioned below, a more precise impression of the electrical substrate can be achieved by observing QRS morphology or by more detailed mapping studies.

\section{Electrical substrate is essential and sufficient for effective CRT}

Recent attention to the electrical substrate for CRT relates to the questions whether a higher cut-off for QRS duration (150 instead of $120 \mathrm{~ms}$, associated with severe QRS broadening) should be adopted and whether morphology of the QRS complex can help to predict CRT response ${ }^{7-9}$, as alluded to in more detail in chapter 2 . The reason why $150 \mathrm{~ms}$ might be a better cut-off value is still matter of dispute, but an important factor may be that using this cut-off value, predominantly patients with LBBB will be selected. This is important, because studies that focused on the morphology of the QRS complex showed that LBBB is a very strong predictor of CRT response.

Although our canine studies are performed using proximal and complete LBBB, clinical studies have typically used inclusion criteria of a QRS duration of at least 120 ms which implies that patients with right bundle branch block or other conduction disease were also included. ${ }^{3,4,8,10}$ In addition, the duration threshold might be too lenient since a recent electrical mapping study showed that 'true LBBB' was only seen in patients with a QRS duration exceeding $130 \mathrm{~ms}$ (female) or $140 \mathrm{~ms}$ (male). ${ }^{11}$ As expected from the animal experiments, patients with QRS duration $>150 \mathrm{~ms}$ and LBBB morphology consistently showed the highest response rates in large multicenter trials ${ }^{12,13}$ (see chapter 2). It becomes increasingly clear that LBBB is the hallmark conduction disease, which is treatable by CRT, as evidenced by CRT efficacy in canine hearts with isolated LBBB and in CRT candidates with LBBB, irrespective of the degree of heart failure.

The exact natural history of LBBB in patients is poorly understood because onset of LBBB is a silent event and, consequently, it is not known when LBBB started and whether it is cause or consequence of worsening heart function. Transcatheter aortic valve implantation (TAVI) is a novel less-invasive treatment for patients with severe aortic stenosis who cannot undergo surgery. ${ }^{14}$ 
During the TAVI procedure, pressure of the implanted device on the interventricular septum and the nearby left bundle branch may cause LBBB in approximately one third of patients. ${ }^{15,16}$ From our point of view, the relatively high occurrence of this unfortunate side-effect establishes the first human model of LBBB. Despite the existence of significant co-morbidities in this group of patients, comparing post-TAVI patients with LBBB versus post-TAVI patients without LBBB enables further comprehension of the possible significance of LBBB in humans. By multivariate regression analysis, TAVI-induced LBBB was an independent predictor of all-cause mortality (hazard ratio 1.54). A likely cause for the higher mortality is progression of heart failure as a consequence of LV remodeling induced by the abnormal conduction pattern. This is further supported by a recent report that TAVI-induced LBBB reduced LV function. ${ }^{17}$

In our canine studies, immediately upon inducing $\mathrm{LBBB}, \mathrm{LV} \mathrm{d} P / \mathrm{d} t_{\max }$ decreases by $\approx 22 \%$ and adverse effects as described in earlier animal models of pacing induced dyssynchrony are reproduced. ${ }^{18}$ Biventricular pacing in the otherwise healthy LBBB heart immediately increases $L V \mathrm{~d} P / \mathrm{d} t_{\text {max }}$ to $86 \pm 5 \%$ of pre-LBBB followed by a slight further improvement to $89 \pm 5 \%$ of pre-LBBB values after eight weeks of CRT. ${ }^{18}$ These data indicate that CRT clearly improves cardiac pump function in LBBB hearts, even in the absence of heart failure, but does not return it completely to pre-LBBB values. The lack of complete return to baseline could be explained by the fact that the physiological sequence of activation and contraction are never completely restored during CRT, because electrical conduction remains less efficient than activation through the Purkinje system. ${ }^{19}$ Even though it might appear obvious, these results indicate that lack of electrical substrate renders CRT ineffective, or even detrimental. This idea is further supported by observations in canine hearts with normal conduction and a narrow QRS complex. In these hearts biventricular pacing resulted in better LV pump function than RV pacing, but this was still less than during normal conduction. ${ }^{19}$ Also in heart failure patients with narrow QRS duration, CRT is not effective and may even be harmful. ${ }^{20}$

The aforementioned findings give rise to the notion that an 'adequate amount' of conduction delay needs to be present for CRT to be efficient. Whether additional factors such as LV systolic dysfunction need to co-exist with electrical asynchrony for CRT to be successful, is important for understanding the therapy and better selection of CRT candidates. 
In healthy canine hearts with isolated LBBB, CRT largely reversed global and regional function and structural abnormalities, indicating that LBBB as electrical substrate is sufficient for acute and long-term response to CRT. ${ }^{18}$ As described in this thesis (chapter 7), the increase in absolute $\mathrm{LVd} P / \mathrm{d} t_{\max }$ (in terms of $\mathrm{mmHg} / \mathrm{s}$ ) caused by CRT was similar between non-failing and failing dogs. Therefore a positive response to CRT does not require overt heart failure, although the relative effect is larger in patients with lowest starting values. Multiple trials have shown comparable CRT efficacy in patients who were not severely symptomatic (NYHA I-II) compared to those with severe symptoms (NYHA III-IV)., 21, 22

The mentioned findings support the idea that the underlying electrical substrate in the form of LBBB is both essential and sufficient for successful treatment with CRT and guidelines are changing accordingly. For example in 2011, the Heart Rhythm Society updated its 2010 indications for patients with a QRS interval of $\geq 120 \mathrm{~ms}$ to $<150 \mathrm{~ms}$ from "recommended" to "may be considered" (along essential) and extended multiple recommendations to patients with less overt heart failure (along sufficient). ${ }^{23}$ Although LBBB often provides good CRT response, this thesis shows several novelties about the LBBB heart and how it can be resynchronized better.

\section{Improving understanding of the electrical substrate}

\section{Functional lines of conduction block}

The need for combined endocardial and epicardial three-dimensional mapping inspired us to perform a validation study (described in chapter 4) comparing novel endocardial non-contact mapping (using the EnSite ${ }^{\circledR}$ system) with the golden standard, endocardial contact mapping. Non-contact mapping allowed creation of high-resolution endocardial activation time maps which revealed lines of conduction block during the LBBB situation, even in dogs where LBBB was created on the same day as the measurements. Similar to what has been first described by Auricchio et al in 2004, the virtual electrograms in the vicinity of block in our dog studies showed typical signs such as split potentials and emergence of an R' wave. ${ }^{24}$ Figure 1 shows four virtual electrograms with their locations around the line of conduction block (dashed line over anterior wall). The top left electrogram is measured away from the line of block with a typical unipolar complex without fractionation. Moving closer to the line of conduction block, an R' wave emerges (compare top left to bottom left panels) and is responsible for a jump in depolarization time (right panels). 
The majority of CRT candidates presented lines of conduction block during LV endocardial non-contact mapping ${ }^{25,26}$ which was in fact shown to be predictive for CRT response in a small observational study. ${ }^{27}$ Obviously, these patients suffer from heart failure with dilated and/or infarcted ventricles. This is why we were intrigued to find lines of conduction block not only in the failing LBBB hearts, but also in dogs immediately after induction of isolated LBBB. In most dogs, these lines of block seemed to be located along the junction of the right and left ventricle. However, the lines of conduction block shifted in size and location when the ventricle was paced, indicating a functional rather than an anatomical nature. Since in the dogs LBBB is created by a proximal ablation, CRT candidates who show functional lines of block might in fact also suffer from a proximal type of LBBB.
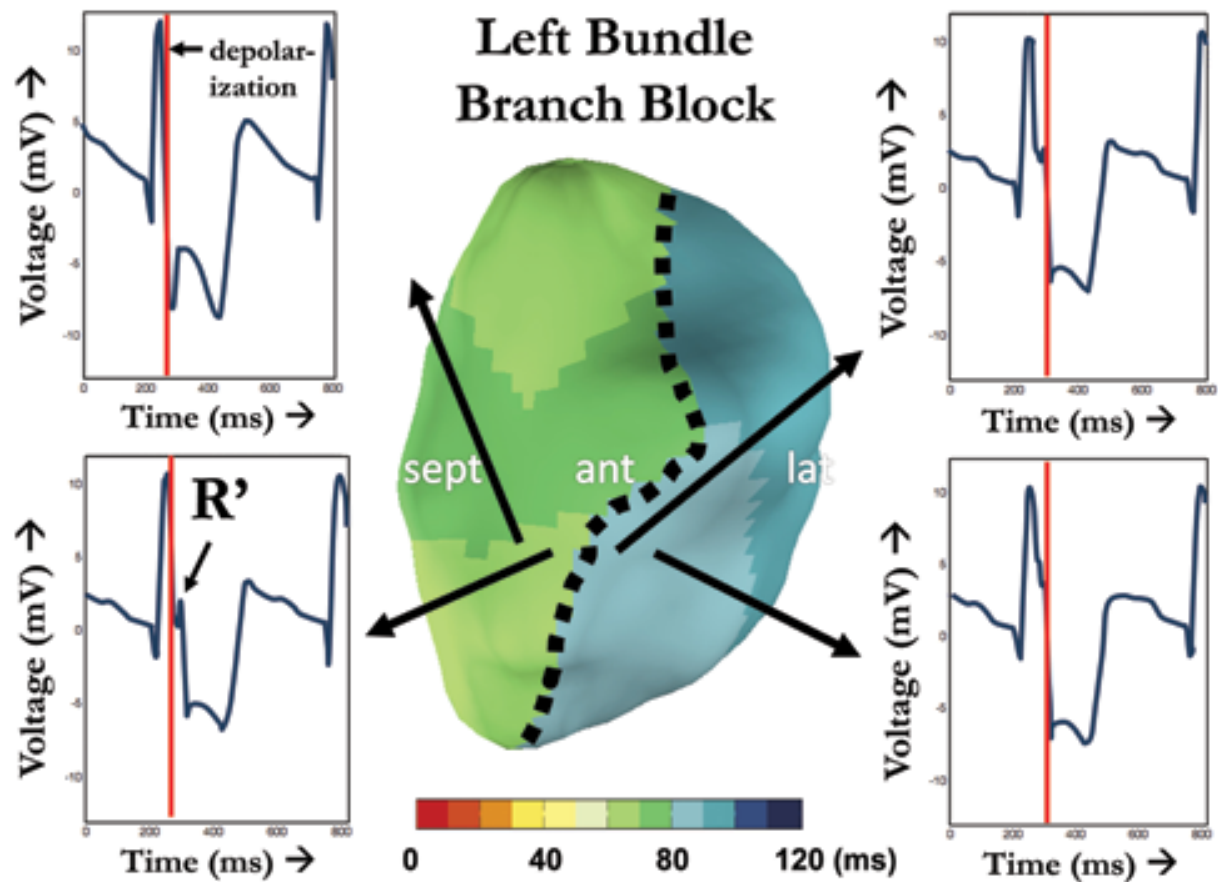

Time (ms) $\rightarrow$

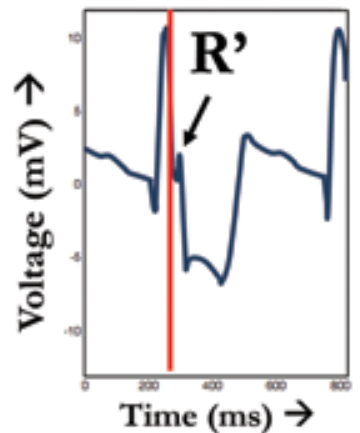

40

80

$120(\mathrm{~ms})$

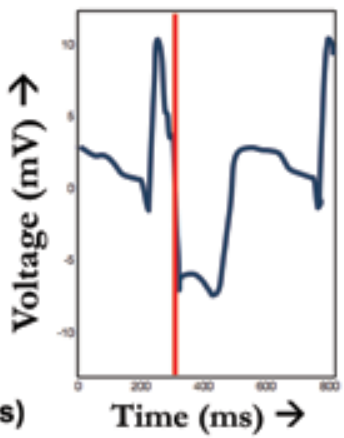

Figure 1. Endocardial activation time map (referenced to onset QRS) derived during non-contact mapping in a dog with acute LBBB. Electrograms surrounding the line of conduction block (indicated by the dotted line) are shown with emergence of $\mathbf{R}^{\text {' }}$ wave and split potentials.

While we attempted to quantify the amount of block by measuring the length of the block lines, no correlation was found with acute hemodynamic effects. This is perhaps caused by the fact that all dogs with LBBB are acute responders and in 
patients, these lines of block are only part of the underlying substrate. Interestingly, the only other technique to show functional lines of block in LBBB patients is ECG-imaging, of which an example is shown in chapter 2. ECG-imaging is a novel non-invasive non-contact epicardial mapping system which is also based on the principles of solving the inverse problem to calculate non-contact electrograms in a similar way as the EnSite ${ }^{\circledR}$ system, but now from the body surface. ${ }^{28}$ This observation raises the important question whether these lines of conduction block could be an artifact, created by the method of calculation of non-contact electrograms from their reference electrodes. Could this result in wrongful emergence of R' wave when calculating a single virtual electrograms based on multiple reference electrograms with varying morphologies? We concluded from our validation study (described in chapter 4) that the virtual electrograms derived from non-contact mapping represented endocardial potentials. However, we could not investigate wrongful emergence of $\mathrm{R}^{\prime}$ waves in our dog studies due to the limited spatial resolution of our endocardial contact mapping. Clinical CARTO measurements have yet failed to reproduce functional lines of block that has been attributed to noncontact mapping system actually measuring subendocardial potentials. ${ }^{24}$ Perhaps an epicardial or transmural approach is warranted, where block lines seen during ECG-imaging could be searched using epicardial/transmural contact mapping. Since epicardial contact mapping is highly invasive and simultaneous measurements during an extensive pacing protocol would be required to carefully investigate this phenomenon, this could be tested using ECG imaging in a canine model.

\section{Transseptal conduction as an important determinant for CRT}

In chapter 5 we performed extensive simultaneous epicardial and endocardial mapping to show when and where the opposing electrical wave fronts, induced by CRT, collide in the heart. The need for this mapping study was sparked by recent findings from clinical studies. LV pacing alone in the absence of fusion is known to induce electrical asynchrony but paradoxically leads to benefits that are comparable to those by biventricular pacing in large randomized clinical trials. ${ }^{29-33}$ In conflict with these observations, beneficiary effects of CRT are considered to act through decreasing the amount of electrical asynchrony generating "fusing" activation wave fronts that migrate from the LV and RV pacing electrodes.

We investigated the idea that the benefit of LV pacing might be due to disproportionally slow conduction through the interventricular septum. In agreement with mentioned clinical studies, our first observation was that, in failing 
hearts, single-site LV pacing indeed resulted in similar increases in contractility as biventricular pacing. Interestingly, even in hearts with isolated LBBB, the pacinginduced wave front from the RV apex electrode did not propagate through the interventricular septum fast enough to deliver a considerable contribution to resynchronize LV endocardial activation. In the hearts with chronic $\mathrm{LBBB}$ combined with dilated heart failure, this phenomenon was even more evident in concordance with further transseptal conduction slowing. For the first time, it is shown that LV endocardial conduction is similar during single-site LV pacing and biventricular pacing and that $L V$ endocardial conduction is not decreased compared with the LBBB situation. From these observations it can be learned that not the amount of endocardial conduction delay is important to create an improvement in pump function by CRT, but rather the direction. These data may explain why also in clinical studies similar effects are seen on cardiac function, mortality and hospitalization during single-site LV pacing as compared with biventricular pacing. ${ }^{31-36}$

Simply reversing the direction of endocardial conduction may improve hemodynamics, but this does not mean it is the optimal situation. We altered the timing of RV and/or LV lead stimulation to result in pre-excitation of the RV which indeed shortened LV endocardial conduction time by compensating for slow transseptal conduction. However, $\mathrm{RV}$ pre-excitation is known to result in diminished CRT efficacy in the clinical situation. ${ }^{37}$ In the canine hearts, the optimal setting was indeed not found during RV pre-excitation. In contrast, the best improvement in hemodynamics was actually found during optimal resynchronization of the total activation, rather than solely the endocardium. At these settings, endocardial conduction was dominated by the activation wave front originating from the LV electrode. Endocardial conduction is after all, only a fraction of total activation and increases can be compensated by decreases in epicardial and transmural conduction delay, as shown later in this chapter.

Observations from clinical trials and from our canine studies give rise to the notion that the RV lead might actually be considered obsolete. The RV lead need not to be added during implantation of the CRT device or a regular pacemaker could be implanted with insertion of the LV lead in the port where traditionally the RV lead is connected. The heart could then be stimulated at a short AV-interval or for better effect, at optimized LV lead-stimulation timing. ${ }^{38}$ There are situations when implantation of an RV lead is warranted such as during implantation of a defibrillator, but in that case this electrode does not need to be paced. 
Despite compelling evidence against the usefulness of an RV lead, many cardiologists will still implant one, because they fear LV-lead failure during highgrade AV-conduction disease. However, evidence that such precautions need to be taken is thin, because chronic LV lead performance is shown to be comparable with that of right atrial and RV leads. ${ }^{39,40}$

\section{Improved resynchronization optimizes CRT}

We learnt from chapter 5 that intrinsic conduction (through the right bundle branch) plays a critical role on optimization and therefore renders differentiation between importance of filling and resynchronization during varying $A V$-delays difficult. For this reason we performed the pacing protocol in dogs with LBBB as well as in dogs who lacked right bundle branch conduction by creating complete AV-block. The results of our extensive study on the optimization of the timing of RV and LV electrode in dogs with LBBB or AV-block are discussed in chapter $\mathbf{6}$, where acute response during a one-hundred setting approach was compared to changes in epicardial resynchronization and filling parameters.

Concordant with the optimization results from chapter 5, changes in electrical epicardial resynchronization induced changes in mechanical interventricular asynchrony and coincided with behavior in $\mathrm{LVd} P / \mathrm{d} t_{\max }$. In chronic LBBB $\mathrm{dogs}$, pacing at longer AV-delays enabled pacing-induced wave fronts to fuse with the intrinsic wave front and at even longer AV-delays, ventricular capture was lost. These variations in activation patterns changed acute response while LV end-diastolic volume did not change significantly. In dogs with complete AV-block, up to ten AV-delays could be tested while keeping the activation pattern identical and during these settings, changes in $\mathrm{LVd} P / \mathrm{d} t_{\text {max }}$ were small and changes in $\mathrm{LV}$ end-diastolic volume were even negligible.

Our results are in keeping with Verbeek et al who showed that during AV-optimization interventricular mechanical dyssynchrony was significantly reduced during the optimal AV-interval (maximal $\mathrm{LVd} P / \mathrm{d} t_{\max }$ ) while EDP remained unchanged. ${ }^{30}$ The PATH-CHF (Pacing Therapies for Congestive Heart Failure) trial was an early CRT study where it was already shown that the AV delay was a significant determinant of changes in $\mathrm{LVd} P / \mathrm{d} t_{\text {max }}$ and $\mathrm{LV}$ pulse pressure. ${ }^{41}$ Studies have since then more often used echocardiography-derived parameters (aortic outflow or mitral inflow patterns) to optimize AV-delay based on the idea that LV filling required optimization by altering timing of atrial contraction in the cardiac cycle. ${ }^{42-45}$ 
The results from these studies are contradictory and have not created consensus on how to optimize a CRT patient or even to optimize at all. ${ }^{42,46,47}$ The results described in chapter 6 indicate that the electrical fusion is the dominant driver for CRT response while LV filling by altering atrial pump timing does not appear to play a major role.

Even though only dogs with isolated conduction disease (LBBB or AV-block) were investigated, infarction or heart failure are not expected to change this phenomenon in an important manner. Preliminary results in dogs with myocardial infarction on top of LBBB indeed show similar results as dogs with LBBB. Figure 2 depicts electrical resynchronization (percent decrease in total activation time using epicardial mapping) in a dog with LBBB and a dog with LBBB and myocardial infarction $(\mathrm{LBBB}+\mathrm{MI})$ where electrical resynchronization is seen during biventricular pacing at short AV-delay and LV-pacing at longer AV-delay (fusion pacing) for both dogs. The ridge of highest electrical resynchronization, showing a leftward turn, is also seen for $\mathrm{LVd} P / \mathrm{d} t_{\max }$, indicating that the ideas proposed in chapter 6 might also hold true for dogs with additional underlying substrate.
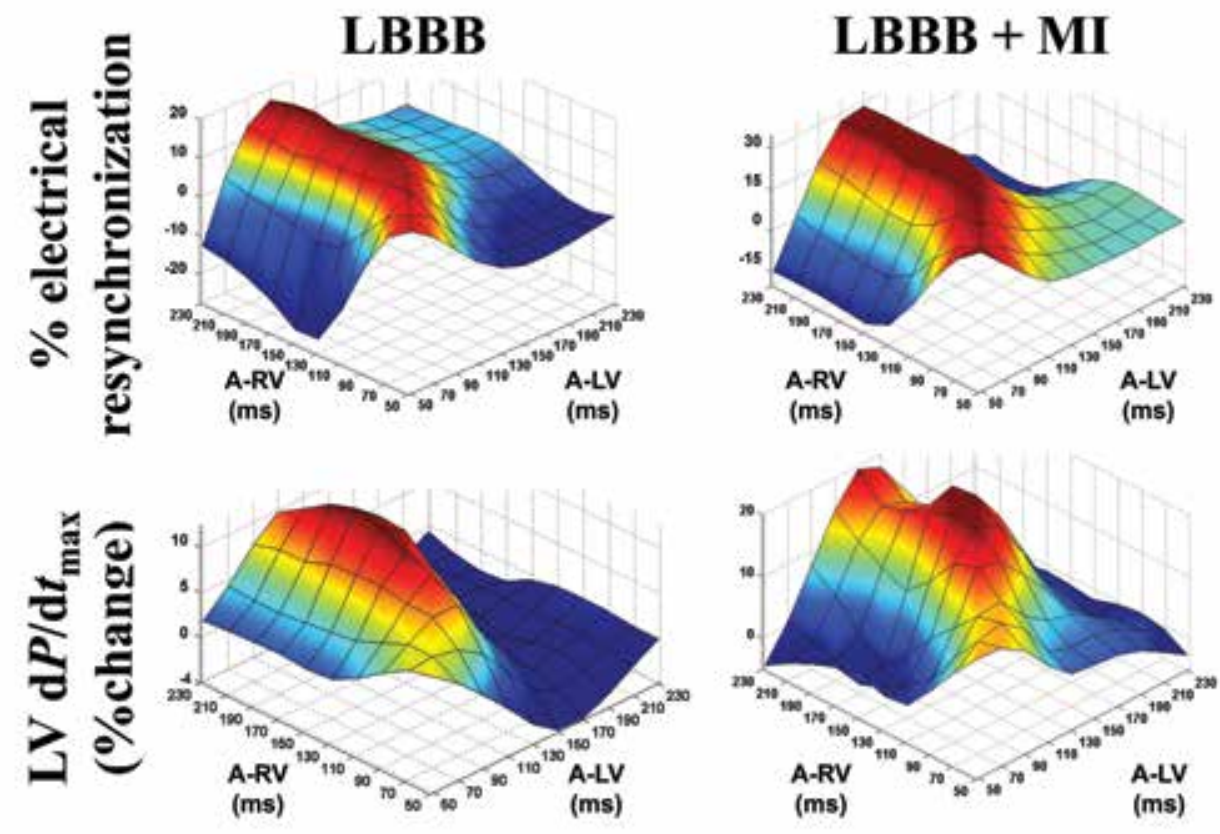

Figure 2. Electrical resynchronization (top panels) and \%change in $\mathrm{LVdP} / \mathrm{dt}_{\max }$ during one hundred AV/VV delays in a dog with chronic LBBB (left panels) and one with chronic LBBB+MI (right panels). 
The re-programming of atrioventricular (AV) and interventricular (VV) delays aims at increasing the hemodynamic improvement and the long-term benefit induced by CRT. The optimal delays are thought to be different among patients because the underlying substrate varies, warranting an individualized approach. Even in dogs with isolated chronic LBBB but otherwise healthy hearts, the hemodynamic response to altering lead-stimulation timings was heterogeneous. Since optimization of these settings may increase the individual benefit of CRT, it may also increase the amount of patients responding to the therapy. Therefore, the present study warrants to increase efforts in improving protocols for optimization of CRT by using parameters reflecting resynchronization, either electrical or mechanical.

\section{Tools for improved treatment of the electrical substrate}

\section{In search for the optimal LV pacing site(s)}

Theoretically, the sites of pacing that may be considered optimal are those that establish the greatest reduction in activation time. The benefit of multi-site LV pacing may involve two mechanisms; 1) by increasing the number of pacing sites, the probability of reaching a more efficient site may be increased and 2) additional electrical wave fronts could provide a faster and more physiological LV activation.

\section{Single-site LV pacing}

By using extensive epicardial mapping and magnetic resonance imaging strain analysis, Helm et al. demonstrated that in canine LBBB hearts the exact LV site of pacing is not very critical, as a good ( $>70 \%$ of maximum) increase in LV dP/ $\mathrm{d} t_{\max }$ was achieved by pacing in $43 \%$ of the $\mathrm{LV}$ wall. ${ }^{48}$ The latter region included the LV apex, which also was shown to provide excellent effects in other studies in canine hearts. ${ }^{49-51}$ In contrast to these findings, a recent publication about the MADIT-CRT study showed that LV apical pacing provided an inferior effect. ${ }^{52}$ A potential explanation for these contradictory findings may be that LV apex pacing requires a shorter AV-delay to be optimal in canine hearts. ${ }^{49}$ Indeed, in CRT patients the increase in $\mathrm{LV} \mathrm{d} P / \mathrm{d} t_{\text {max }}$ during $\mathrm{LV}$ apex pacing is low when using an average AV-delay, but almost maximal when using the optimal AV-delay. ${ }^{53}$ Another explanation could be the definition of apical regions in clinical studies: the lower $1 / 3$. In the MADIT-CRT study it is mentioned that most of the apically located leads were in the posterior vein, most likely not the best position but certainly not comparable to the true LV apical position we tested in the animal model. 
Commonly, the LV lead is placed in the latest activated region, which in LBBB is usually the basal part of the posterolateral wall. ${ }^{24,54}$ Whether stimulating the latest activated region truly results in highest CRT efficacy, has not been systematically investigated in clinical trials. The extensive pacing protocol of twenty-two experiments used for chapters $4, \mathbf{5}$ and $\mathbf{8}$, allowed us to retrospectively analyze this hypothesis. During baseline atrial pacing (LBBB pattern) depolarization times were calculated for the eight candidate epicardial LV pacing sites. Biventricular pacing was then performed at all eight LV pacing sites and the changes in $L V \mathrm{~d} P / \mathrm{d} t_{\max }$ and LV electrical activation time were compared with pacing at the latest activated electrode.

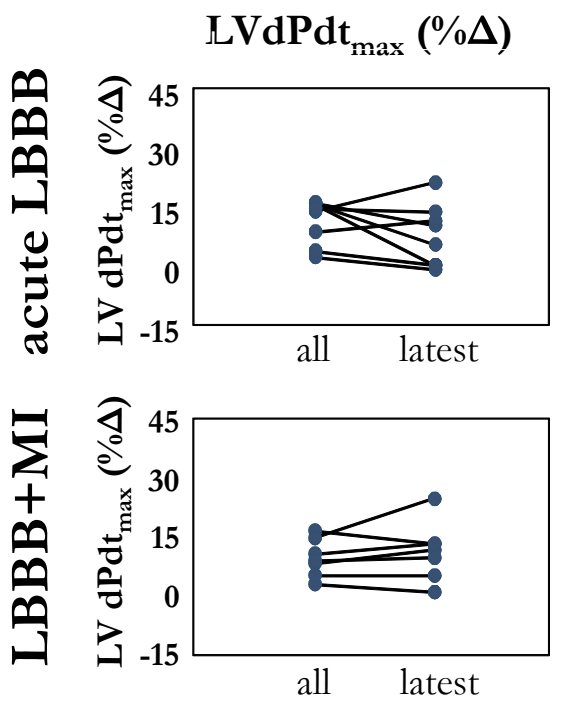

LV activation time $(\% \Delta)$
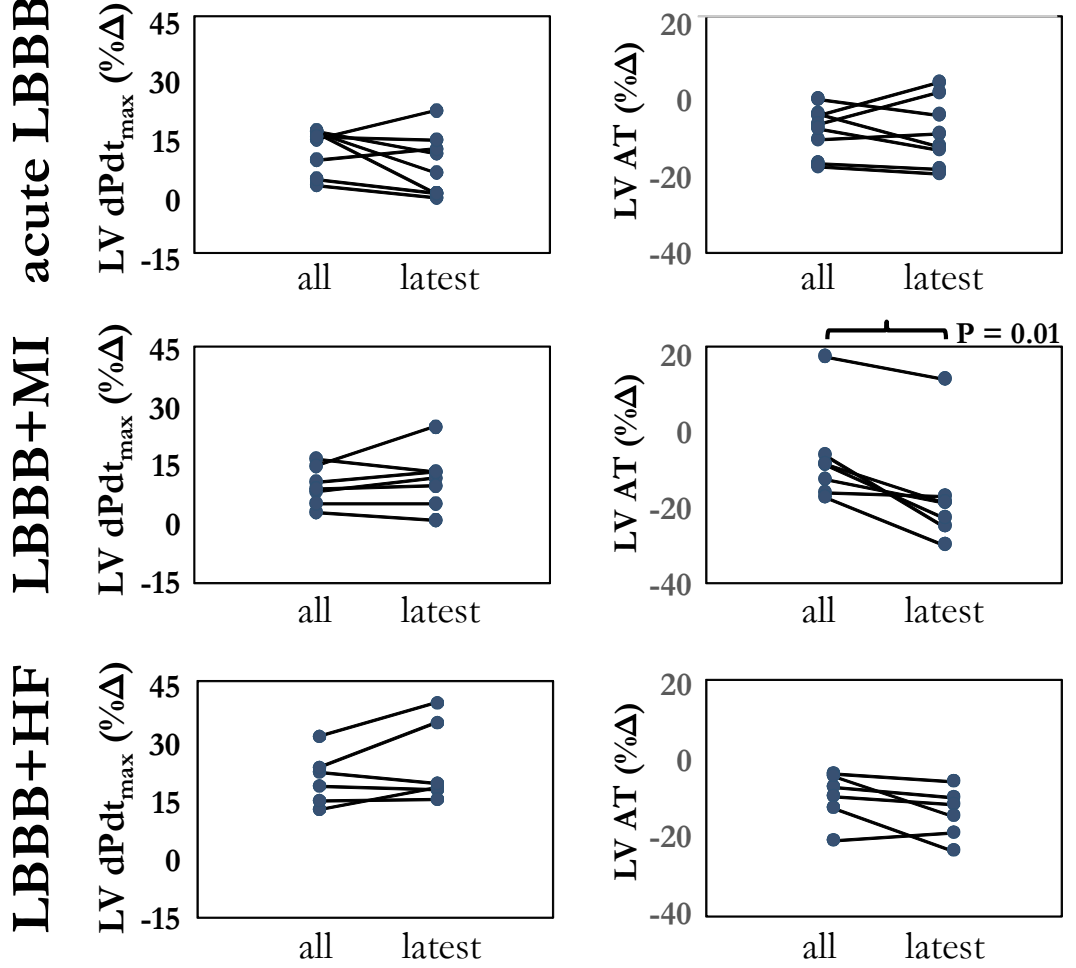

Figure 3. Average change (\%) in LV dP/dt ${ }_{\max }$ (left panels) and LV electrical activation time (LV AT) during simultaneous biventricular pacing at short AV delay as compared with baseline atrial pacing (LBBB). For dogs with LBBB (top), LBBB+MI (middle) and LBBB+HF (bottom), all eight epicardial LV pacing sites were averaged per subject ("all") and compared to the pacing site which was activated last during baseline atrial pacing ("latest"). 
Figure 3 shows that for all dog models (acute LBBB, chronic LBBB with infarction and chronic $\mathrm{LBBB}$ with heart failure) pacing the latest activated area does not increase $L V \mathrm{~d} P / \mathrm{d} t_{\text {max }}$ compared with the average response of all eight electrodes. For LV activation time, only in the infarcted dogs pacing at the latest activated region significantly improved electrical resynchronization.

\section{Multi-site LV pacing}

To investigate the potential benefits of pacing the latest activation region further, we performed an experiment (described in chapter 7) aiming at the best possible "treatment" of the latest activated area. First, we measured systolic function and electrical asynchrony during LBBB and then we progressively added the latest activated LV region to ventricular stimulation; 1, 2, 3, 4 and finally $7 \mathrm{LV}$ pacing sites were stimulated simultaneously. We found that adding LV pacing sites consistently decreases $L V$ activation time, but $\mathrm{LVd} P / \mathrm{d} t_{\max }$ did not increase further after pacing from two LV sites. Whether the added beneficiary effect of adding an additional LV pacing site is to be attributed to improved resynchronization through the added activation wave front or simply to inadequate response from the initial pacing site is uncertain even though results from our multi-LV study suggest the latter. Peschar et al. did not observe benefits (in terms of $\mathrm{LV} \mathrm{d} P / \mathrm{d} t_{\text {max }}$ and stroke work) of biventricular pacing or multi-site LV pacing (up to four sites) as compared to LV apex alone in eleven healthy dogs. ${ }^{55}$ Stimulating the latest activated region may appear to be the most suitable site to compensate for asynchronous activation but our experimental results show this is hypothesis is flawed. Possible factors that may play a role are regional differences in conduction velocity, electromechanical coupling or contraction. In the clinical setting, stimulating the $L V$ at a region with limited delay may indicate inadequate underlying electrical substrate (no true LBBB), rather than simply not having found the latest activated region. It appears that the sequence of electrical activation is a stronger determinant of ventricular function than the synchrony of activation. ${ }^{56}$ Even though the added benefits of multi-site LV pacing may be limited, it may be an important treatment option for the subgroup of CRT patients that do not respond to the therapy. Since current CRT devices hold three ports (atrial, RV and LV), multi-site LV pacing in patients could be accomplished by 1) connecting two LV-leads to the LV port using a parallel Y-connector or by 2) connecting one LV lead which holds multiple electrodes, for example a quadripolar lead. Implanting a second LV lead has been reported to improve CRT efficacy in non-responders. ${ }^{57,58}$ 
Pappone et al. investigated fourteen CRT candidates and found that dual-LV pacing increased $\mathrm{LV} \mathrm{d} P / \mathrm{d} t_{\text {max }}$ significantly more than posterior base and lateral wall pacing alone. ${ }^{59}$ The TRIP-HF (Triple Resynchronization in Paced Heart Failure Patients) study is the only prospective, randomized study comparing the effects of dual-site LV pacing versus conventional CRT. ${ }^{60}$ In this study, 40 patients were enrolled and successful implantation of an additional LV lead in the anterior region occurred in 34 patients $(85 \%)$. After a follow-up period of 3 months in a cross-over design the patients with dual-site $L V$ pacing experienced further LV reverse remodeling as assessed by LV end-systolic and -diastolic volumes and ejection fraction. However, the level of post-procedural complications was significant because five patients had phrenic nerve stimulation (requiring lead repositioning in four) and two patients underwent explantation due to infection. ${ }^{60}$ The ongoing V3 Trial will randomize half of 84 traditional CRT non-responders to receive an additional LV lead and compare them to the other half of (control) patients after 12 months. ${ }^{61}$ The alternative multisite LV approach through implantation of a single multi-electrode lead may hold additional benefits such as decreases in loss of capture, unexplained increased LV pacing threshold, or phrenic nerve stimulation. ${ }^{62}$ These benefits are attributed to the increased bipolar pacing configurations; up to ten have been described by using a combination of an LV electrode with another LV electrode or the RV coil. ${ }^{62}$,

63 In a prospective comparison with conventional implant $(n=23)$, patients with quadripolar leads ( $\mathrm{n}=22)$ experienced significantly less LV lead failure. In the more recent prospective multicenter study with 154 implanted patients and a follow-up time of 191 patient years, nine episodes of clinical phrenic nerve stimulation occurred, all of which could be solved by reprogramming of the quadripolar lead. ${ }^{64}$ Benefits of multi-electrode LV leads towards improved pump function of survival are yet to be investigated.

\section{Endocardial versus epicardial LV pacing in CRT}

For optimal LV function the selection of an optimal single pacing site is more important than pacing from multiple sites. This is perhaps shown most clearly by the endocardial pacing study where we performed a back-to-back comparison of LV endocardial versus epicardial pacing during CRT, discussed in chapter 8.Previous work from our lab has shown that endocardial LV pacing during CRT improved LV pump function, reduced electrical dyssynchrony and decreased dispersion of repolarization, as compared to epicardial LV pacing at the same site (conventional CRT). ${ }^{51}$ However, whether endocardial CRT would also outperform conventional CRT in hearts with additional substrate such as infarction or dilation 
was not known. In chapter 8 we investigated endocardial versus epicardial CRT in infarcted and failing dyssynchronous hearts with even more extensive electrical mapping than in the previous study. Indeed we found that endocardial CRT was superior to epicardial CRT without considerable differences between groups when regarding the added benefit (LBBB: $\approx 19 \%$ versus $\approx 11 \%$, LBBB + MI: $\approx 16 \%$ versus $\approx 7 \%$, LBBB $+\mathrm{HF}: \approx 30 \%$ versus $\approx 20 \%$ ). These effects coincided with improved electrical resynchronization and decreases in dispersion of repolarization.

\section{epicardial CRT}

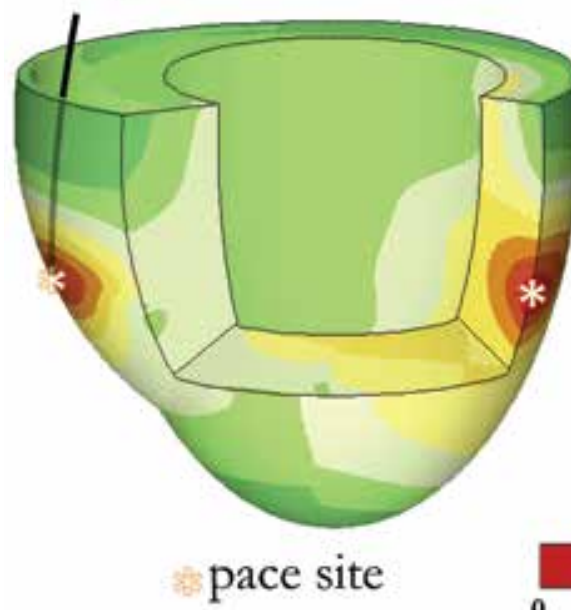

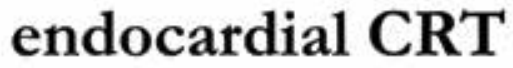

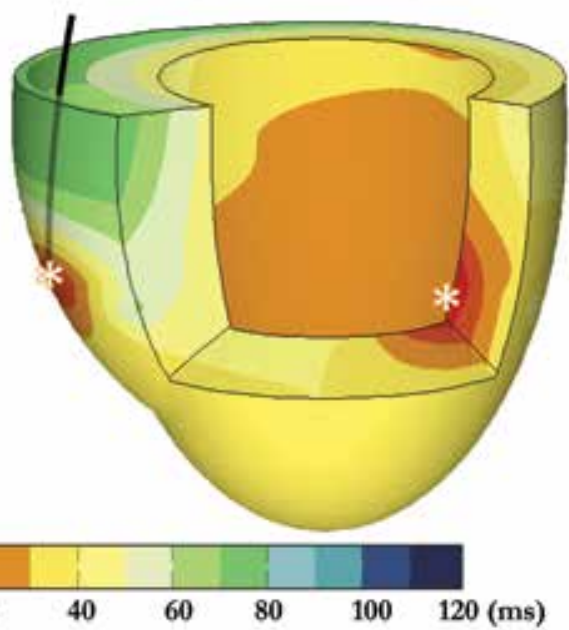

Figure 4. Three-dimensional electrical activation time maps during epicardial CRT (left panel) and endocardial CRT (right panel) in acute LBBB. Asterisk-symbols show pacing sites.

Although we found that endocardial CRT indeed resulted in improved acute CRT response when compared with conventional (epicardial) CRT, this effect coincided with paradoxical increases in endocardial conduction delay. In Figure 4 typical examples are shown of electrical maps where the heart clearly appears more resynchronized during endocardial CRT as compared with epicardial CRT. Looking closer at the electrical maps one notices that improved resynchronization might hold true for the epicardium, but indeed not for the LV endocardium since three contour lines are shown during epicardial CRT while four contour lines are shown during endocardial CRT. We hypothesize that while an activation wave front with epicardial onset might need time to reach the endocardium, when finally endocardial breakthrough is established, the rest of the endocardium is quickly depolarized by the transmural wave front(s). 
Despite increases in endocardial delay, endocardial CRT consistently decreased QRS duration and total electrical asynchrony more than epicardial CRT through reductions in epicardial and transmural conduction delay. Similar to what we observed in the studies explained in chapter $\mathbf{5}$, improved hemodynamics did not coincide with improved endocardial conduction but rather with total conduction. These findings might be interpreted as a blessing in disguise, as endocardial potentials are difficult to measure and total asynchrony could be evaluated more easily using body surface techniques such as ECG or ECG imaging.

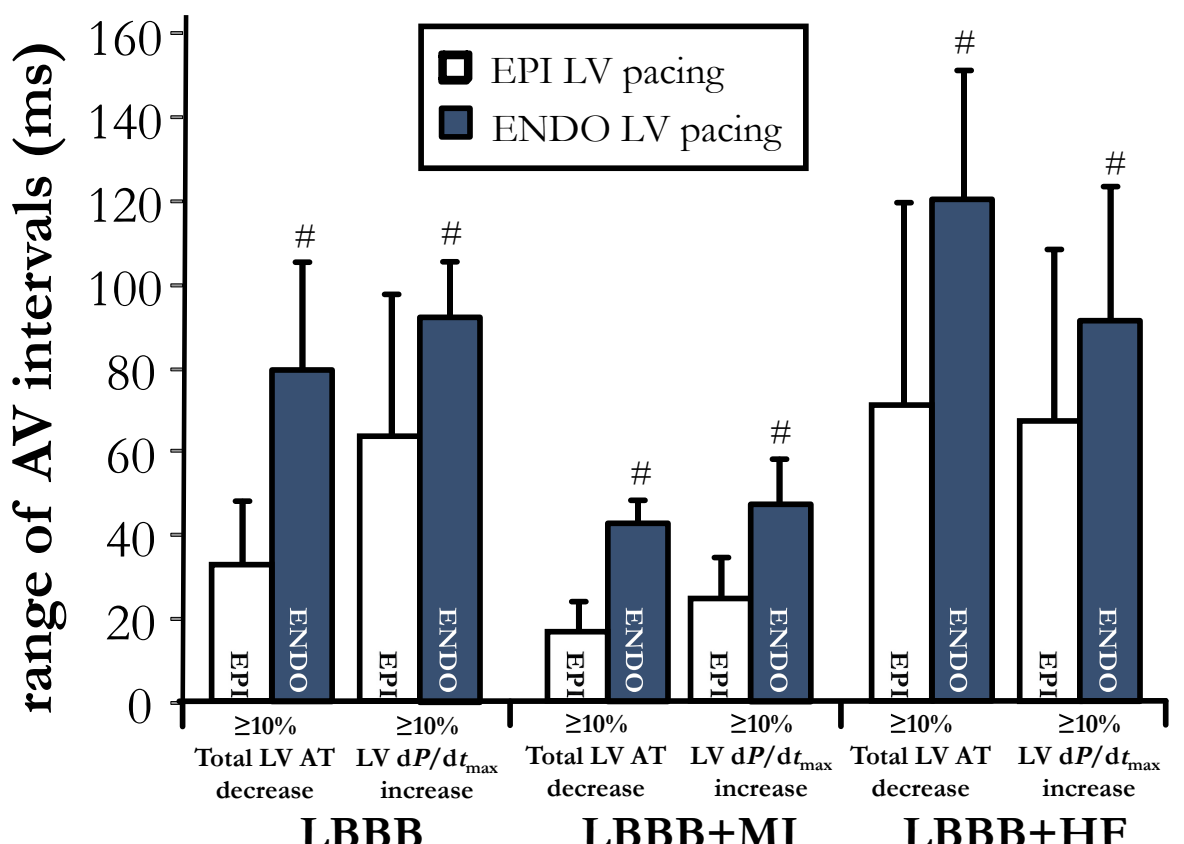

Figure 5. Range of AV intervals during which single-site LV pacing results in (i) $\geq 10 \%$ decrease in total activation delay or (ii) $\geq 10 \%$ increase in $\mathrm{LVdP} / \mathrm{dt}_{\max }$ in dogs with $\mathrm{LBBB}, \mathrm{LBBB}+\mathrm{MI}$ and $\mathrm{LBBB}+\mathrm{HF}$. \#p $<0.05$ as compared with EPI LV pacing.

Even though chapter 8 solely describes biventricular pacing, single-site LV pacing was also performed in the light of the ongoing biventricular versus LV pacing discussion (chapter 5). Pacing the LV at a short AV delay increased LVdP/dtmax as compared with baseline LBBB; a trend was seen in favor of endocardial LV pacing as compared to epicardial LV pacing but the difference did not reach significance in any group $(\mathrm{LBBB}: \approx 13 \%$ versus $\approx 9 \%, \mathrm{LBBB}+\mathrm{MI}: \approx 10 \%$ versus $\approx 7 \%, \mathrm{LBBB}+\mathrm{HF}$ : $\approx 27 \%$ versus $\approx 25 \%$ ). When increasing the $\mathrm{AV}$-intervals in order to allow fusion 
between activation waves from the LV electrode and the right bundle branch, the range at which total $\mathrm{LV}$ activation time decreased by at least $10 \%$ as compared to baseline was significantly larger during endocardial than epicardial LV pacing (Figure 5). Similarly, an LVdP/dtmax increase by at least $10 \%$ (often used as an index for acute hemodynamic response) was seen during a larger range of $\mathrm{AV}$-intervals during endocardial LV pacing than epicardial LV pacing. The maximal LVdP/dtmax during single-site $L V$ pacing at increasing AV-intervals was significantly higher during endocardial than during epicardial LV pacing (LBBB: $\approx 22 \%$ versus $\approx 17 \%$, $\mathrm{LBBB}+\mathrm{MI}: \approx 15 \%$ versus $\approx 7 \%, \mathrm{LBBB}+\mathrm{HF}: \approx 43 \%$ versus $\approx 32 \%, \mathrm{p}<0.001)$.

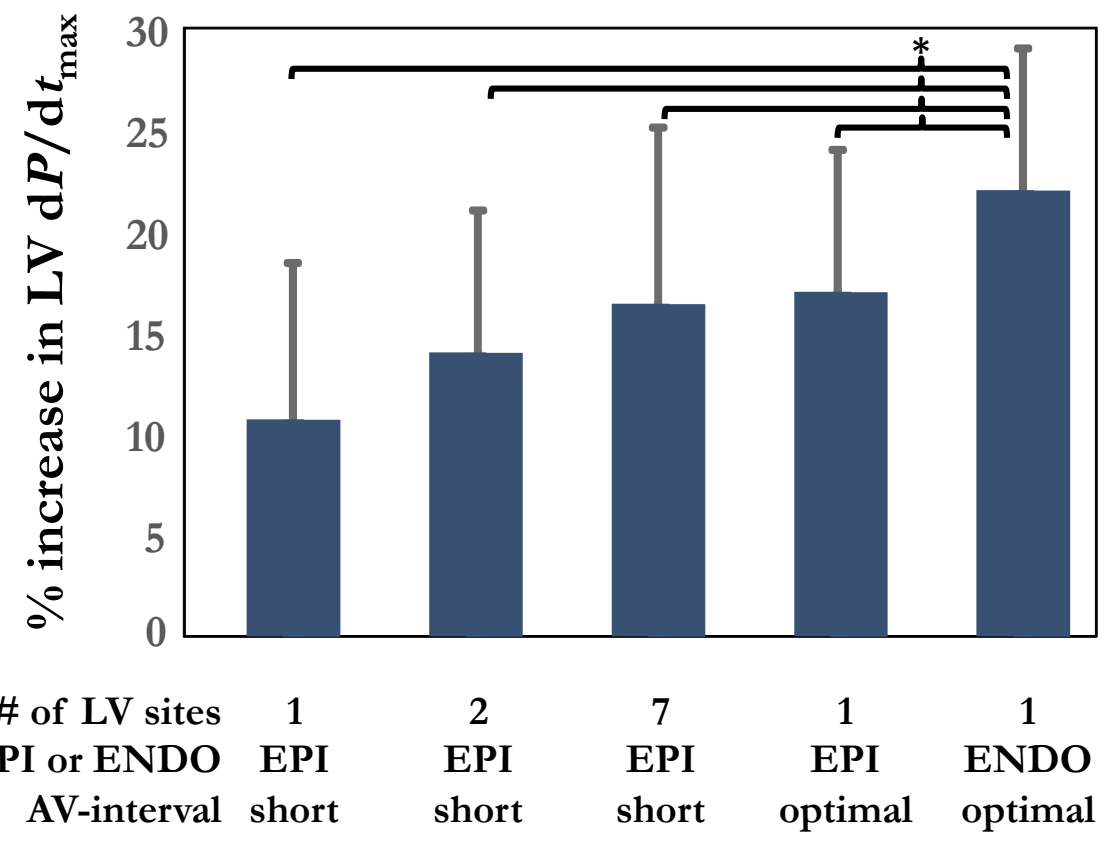

Figure 6. Average increase in $\mathrm{LVdP} / \mathrm{dt}_{\text {max }}$ in dogs with isolated LBBB during LV pacing at 1, 2 or 7 sites, epicardial or endocardial pacing and at short or optimal AVinterval. ${ }^{*} \mathrm{p}<0.05$ using Mann-Whitney $U$ test.

These data indicate that the added benefit of endocardial LV pacing over epicardial LV pacing does not only hold true for "out-of-the-box" CRT but also for optimized pacing. In fact, optimized endocardial LV pacing not only outperforms epicardial single-site $\mathrm{LV}$ pacing, but also multi-site $\mathrm{LV}$ pacing up to seven simultaneously stimulated electrodes (see Figure 6 for comparison between studies). Meanwhile several small clinical studies have been published that at least partly confirm our canine data concerning the beneficial effects of endocardial CRT. Spragg et al investigated 7 
ischemic cardiomyopathy patients and CRT systems where LV endocardial and epicardial pacing at immediately transmural sites gave equivalent $\mathrm{LV} \mathrm{d} P / \mathrm{d} t_{\max }$ values. ${ }^{65}$ However, $\mathrm{LV} \mathrm{dP} / \mathrm{dt}_{\max }$ at the best $\mathrm{LV}$ endocardial sites was greater than conventional CRT. Similarly, Derval and colleagues investigated up to eleven LV pacing sites (ten endocardial sites and one epicardial coronary sinus site) in 35 nonischemic dilated cardiomyopathy patients. ${ }^{66}$ When comparing the effect of pacing the endocardium with that of the immediately opposite coronary sinus electrode, no statistically significant increase in $L V \mathrm{~d} P / \mathrm{d} t_{\max }$ was observed although $\mathrm{LV} \mathrm{d} P /$ $\mathrm{d} t$ max tended to be higher during endocardial CRT. However, single-site LV pacing at the optimal endocardial site doubled $\mathrm{LV} \mathrm{d} P / \mathrm{d} t_{\max }$ as compared to conventional CRT. The superior effect of the optimal endocardial site over conventional CRT on contractility was recently confirmed by Ginks et al who investigated LV endocardial CRT in fifteen CRT candidates. ${ }^{67}$ In agreement with the earlier studies, the optimal endocardial pacing site was heterogeneous between patients. Given individual variations in etiology, severity, patterns of delayed ventricular activation, location of regions of scar, and extent of mitral regurgitation in heart failure, it seems indeed unlikely that one pacing site will "fit all". Individual tailoring of endocardial CRT by searching the optimal pacing site within the endocardium is warranted.

LV endocardial pacing in humans can be established through an atrial transseptal approach, which is shown to be technically feasible and effective during acute and mid-term follow-up. ${ }^{68-71}$ Alternatively a left trans-apical approach can be used ${ }^{72}$. However, these approaches have their limitations and disadvantages and are currently only used as last resource. The ultimate method to pace the LV endocardium would require (1) flexibility in placing the electrode as the optimal site may differ between patients and (2) absence of a pacing lead in the LV cavity to minimize risk of thromboembolic events. One approach would be leadless pacing, by implanting an electrode at the desired endocardial location followed by retraction of the lead and stimulation of the implanted electrode through ultrasound ${ }^{73}$ or magnetic stimulation $^{74}$. EBR systems ${ }^{\circledR}$ is currently engaged in the WiSE-CRT Study, a 100 patient feasibility, safety, and CE-Mark trial in Europe demonstrating biventricular capture in heart failure patients. Sixteen patients have been enrolled in the study at this time with promising results. Patients successfully treated to date include those with acutely failed coronary sinus (CS) lead placement, chronically failed CS leads, patients "upgraded" from dual-chamber defibrillators and patients who have not yet responded to traditional cardiac resynchronization therapy (CRT). 


\section{Conclusions}

For optimal CRT, it is imperative that the correct electrical substrate exists, preferably in the form of true LBBB, and that it is treated as such. With the aid of endocardial LV pacing, with- or without RV pacing, pacing a single LV site or multiple, patientspecific tailoring of pacing lead position and AV- and VV-interval can boost CRT efficacy to new levels. These recommendations are schematically shown in Figure 7.

\section{tools for improving CRT efficacy}

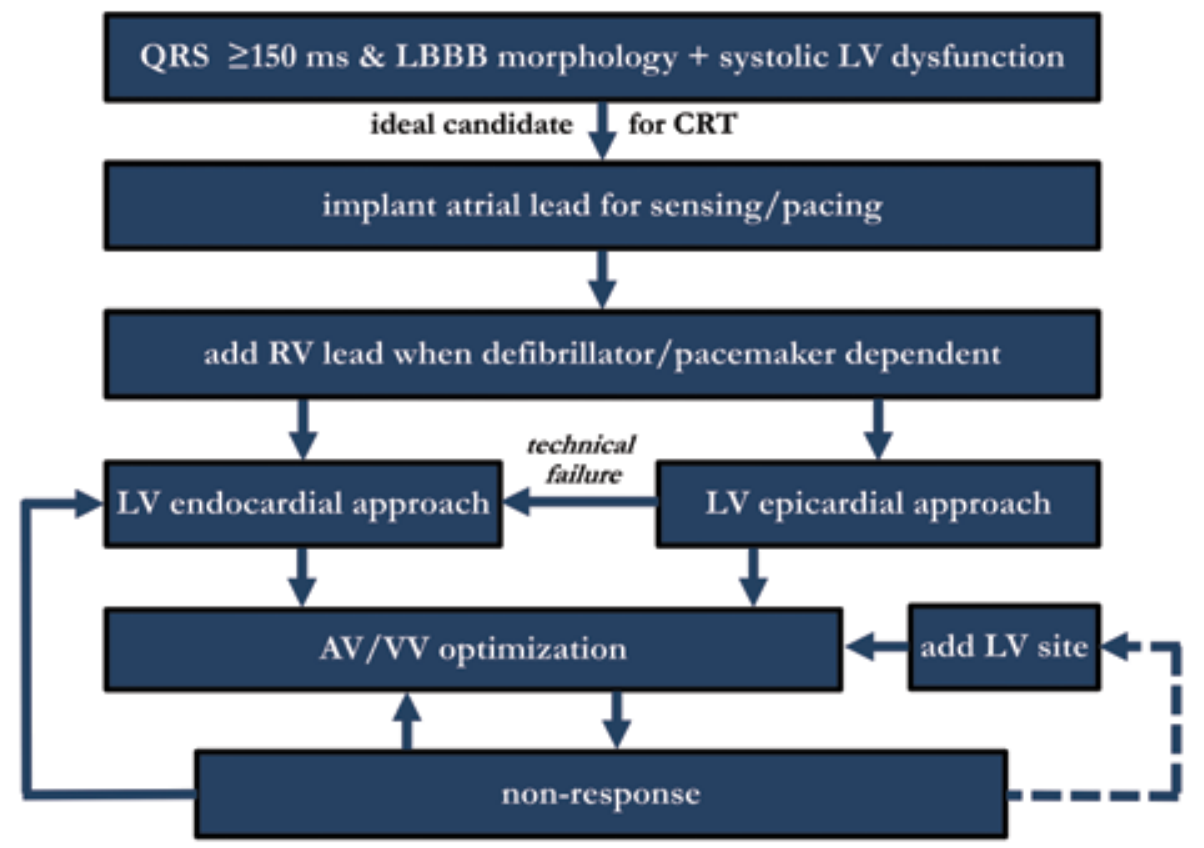

Figure 7. The schematic step-by-step diagram is based on the results from clinical trials and from studies described in this thesis. When a CRT candidate is identified (with systolic LV dysfunction and preferably with severely widened QRS with LBBB morphology) an atrial lead can be implanted for sensing/pacing. Even though implantation of an RV lead is not required for optimal CRT efficacy, it will most often be implanted for defibrillation purposes and because of fear of LV lead failure during pacemaker dependency. An LV endocardial approach can be considered as first option, but because of practical reasons LV epicardial approach remains the norm. An endocardial approach can be reconsidered after technical failure of the epicardial approach. If no AV/VV optimization is performed, a standard AV-interval of 90 $\mathrm{ms}$ is recommended with an interventricular offset of $0 \mathrm{~ms}$. When the patient does not respond, AV/VV optimization of endocardial approach may be (re)considered or more LV pacing sites could be added (to enable multi-site LV pacing or singlesite pacing at an alternative LV location). 


\section{References}

1. Rossi A, Rossi G, Piacenti M, Startari U, Panchetti L, Morales MA. The current role of cardiac resynchronization therapy in reducing mortality and hospitalization in heart failure patients: A meta-analysis from clinical trials. Heart Vessels. 2008;23:217223.

2. Abraham WT, Fisher WG, Smith AL, Delurgio DB, Leon AR, Loh E, Kocovic DZ, Packer M, Clavell AL, Hayes DL, Ellestad M, Trupp RJ, Underwood J, Pickering F, Truex C, McAtee P, Messenger J, Evaluation MSGMIRC. Cardiac resynchronization in chronic heart failure. The New England journal of medicine. 2002;346:1845-1853.

3. Bristow MR, Saxon LA, Boehmer J, Krueger S, Kass DA, De Marco T, Carson P, DiCarlo L, DeMets D, White BG, DeVries DW, Feldman AM. Cardiacresynchronization therapy with or without an implantable defibrillator in advanced chronic heart failure. The New England journal of medicine. 2004;350:2140-2150.

4. Cleland JG, Daubert JC, Erdmann E, Freemantle N, Gras D, Kappenberger L, Tavazzi L. The effect of cardiac resynchronization on morbidity and mortality in heart failure. The New England journal of medicine. 2005;352:1539-1549.

5. Chung ES, Leon AR, Tavazzi L, Sun JP, Nihoyannopoulos P, Merlino J, Abraham WT, Ghio S, Leclercq C, Bax JJ, Yu CM, Gorcsan J, 3rd, St John Sutton M, De Sutter J, Murillo J. Results of the predictors of response to crt (prospect) trial. Circulation. 2008;117:2608-2616.

6. Seo Y, Ito H, Nakatani S, Takami M, Naito S, Shiga T, Ando K, Wakayama Y, Aonuma $\mathrm{K}$. The role of echocardiography in predicting responders to cardiac resynchronization therapy. Circ J. 2011

7. Zareba W, Klein H, Cygankiewicz I, Hall WJ, McNitt S, Brown M, Cannom D, Daubert JP, Eldar M, Gold MR, Goldberger JJ, Goldenberg I, Lichstein E, Pitschner H, Rashtian M, Solomon S, Viskin S, Wang P, Moss AJ. Effectiveness of cardiac resynchronization therapy by qrs morphology in the multicenter automatic defibrillator implantation trial-cardiac resynchronization therapy (madit-crt). Circulation. 2011;123:1061-1072.

8. Tang AS, Wells GA, Talajic M, Arnold MO, Sheldon R, Connolly S, Hohnloser SH, Nichol G, Birnie DH, Sapp JL, Yee R, Healey JS, Rouleau JL. Cardiacresynchronization therapy for mild-to-moderate heart failure. The New England journal of medicine. 2010

9. Bilchick KC, Kamath S, DiMarco JP, Stukenborg GJ. Bundle-branch block morphology and other predictors of outcome after cardiac resynchronization therapy in medicare patients. Circulation. 2010;122:2022-2030.

10. Linde C, Abraham WT, Gold MR, St John Sutton M, Ghio S, Daubert C. Randomized 
trial of cardiac resynchronization in mildly symptomatic heart failure patients and in asymptomatic patients with left ventricular dysfunction and previous heart failure symptoms. J Am Coll Cardiol. 2008;52:1834-1843.

11. Strauss DG, Selvester RH, Wagner GS. Defining left bundle branch block in the era of cardiac resynchronization therapy. Am J Cardiol. 2011;107:927-934.

12. Sipahi I, Carrigan TP, Rowland DY, Stambler BS, Fang JC. Impact of qrs duration on clinical event reduction with cardiac resynchronization therapy: Meta-analysis of randomized controlled trials. Arch Intern Med. 2011

13. Hsing JM, Selzman KA, Leclercq C, Pires LA, McLaughlin MG, McRae SE, Peterson BJ, Zimetbaum PJ. Paced left ventricular qrs width and ecg parameters predict outcomes after cardiac resynchronization therapy: Prospect-ecg sub-study. Circ Arrbythm Electrophysiol. 2011

14. Leon MB, Smith CR, Mack M, Miller DC, Moses JW, Svensson LG, Tuzcu EM, Webb JG, Fontana GP, Makkar RR, Brown DL, Block PC, Guyton RA, Pichard AD, Bavaria JE, Herrmann HC, Douglas PS, Petersen JL, Akin JJ, Anderson WN, Wang D, Pocock S, Investigators PT. Transcatheter aortic-valve implantation for aortic stenosis in patients who cannot undergo surgery. The New England journal of medicine. 2010;363:1597-1607.

15. Sinhal A, Altwegg L, Pasupati S, Humphries KH, Allard M, Martin P, Cheung A, Ye J, Kerr C, Lichtenstein SV, Webb JG. Atrioventricular block after transcatheter balloon expandable aortic valve implantation. JACC. Cardiovascular interventions. 2008;1:305309.

16. Houthuizen P, Van Garsse LA, Poels T'T, de Jaegere P, van der Boon RM, Swinkels BM, Ten Berg JM, van der Kley F, Schalij MJ, Baan J, Jr., Cocchieri R, Brueren GR, van Straten AH, den Heijer P, Bentala M, van Ommen V, Kluin J, Stella PR, Prins MH, Maessen JG, Prinzen FW. Left bundle-branch block induced by transcatheter aortic valve implantation increases risk of death. Circulation. 2012;126:720-728.

17. Tzikas A, van Dalen BM, Van Mieghem NM, Gutierrez-Chico JL, Nuis RJ, Kauer F, Schultz C, Serruys PW, de Jaegere PP, Geleijnse ML. Frequency of conduction abnormalities after transcatheter aortic valve implantation with the medtroniccorevalve and the effect on left ventricular ejection fraction. Am J Cardiol. 2011;107:285-289.

18. Vernooy K, Cornelussen RN, Verbeek XA, Vanagt WY, van Hunnik A, Kuiper M, Arts T, Crijns HJ, Prinzen FW. Cardiac resynchronization therapy cures dyssynchronopathy in canine left bundle-branch block hearts. European heart journal. 2007;28:2148-2155.

19. Wyman BT, Hunter WC, Prinzen FW, Faris OP, McVeigh ER. Effects of single- and 
biventricular pacing on temporal and spatial dynamics of ventricular contraction. American journal of physiology. Heart and circulatory physiology. 2002;282:H372-379.

20. Thibault B, Harel F, Ducharme A, White M, Ellenbogen KA, Frasure-Smith N, Roy D, Philippon F, Dorian P, Talajic M, Dubuc M, Guerra PG, Macle L, Rivard L, Andrade JG, Khairy P, Investigators E. Cardiac resynchronization therapy in patients with heart failure and a qrs complex <120 ms: The lesser-earth trial. Circulation. 2013

21. Daubert C, Gold MR, Abraham WT, Ghio S, Hassager C, Goode G, Szili-Torok T, Linde C. Prevention of disease progression by cardiac resynchronization therapy in patients with asymptomatic or mildly symptomatic left ventricular dysfunction: Insights from the european cohort of the reverse (resynchronization reverses remodeling in systolic left ventricular dysfunction) trial. J Am Coll Cardiol. 2009;54:1837-1846.

22. Solomon SD, Foster E, Bourgoun M, Shah A, Viloria E, Brown MW, Hall WJ, Pfeffer MA, Moss AJ. Effect of cardiac resynchronization therapy on reverse remodeling and relation to outcome: Multicenter automatic defibrillator implantation trial: Cardiac resynchronization therapy. Circulation. 2010;122:985-992.

23. Stevenson WG, Hernandez AF, Carson PE, Fang JC, Katz SD, Spertus JA, Sweitzer NK, Tang WH, Albert NM, Butler J, Westlake Canary CA, Collins SP, Colvin-Adams M, Ezekowitz JA, Givertz MM, Hershberger RE, Rogers JG, Teerlink JR, Walsh MN, Stough WG, Starling RC. Indications for cardiac resynchronization therapy: 2011 update from the heart failure society of america guideline committee. J Card Fail. 2012;18:94-106.

24. Auricchio A, Fantoni C, Regoli F, Carbucicchio C, Goette A, Geller C, Kloss M, Klein H. Characterization of left ventricular activation in patients with heart failure and left bundle-branch block. Circulation. 2004;109:1133-1139.

25. Auricchio A, Prinzen FW. Update on the pathophysiological basics of cardiac resynchronization therapy. Europace. 2008;10:797-800.

26. Fung JW, Yu CM, Yip G, Zhang Y, Chan H, Kum CC, Sanderson JE. Variable left ventricular activation pattern in patients with heart failure and left bundle branch block. Heart. 2004;90:17-19.

27. Fung JW, Chan JY, Yip GW, Chan HC, Chan WW, Zhang Q, Yu CM. Effect of left ventricular endocardial activation pattern on echocardiographic and clinical response to cardiac resynchronization therapy. Heart. 2007;93:432-437.

28. Jia P, Ramanathan C, Ghanem RN, Ryu K, Varma N, Rudy Y. Electrocardiographic imaging of cardiac resynchronization therapy in heart failure: Observation of variable electrophysiologic responses. Heart Rhythm. 2006;3:296-310.

29. Verbeek XA, Vernooy K, Peschar M, Van Der Nagel T, Van Hunnik A, Prinzen FW. 
Quantification of interventricular asynchrony during lbbb and ventricular pacing. American journal of physiology. Heart and circulatory physiology. 2002;283:H1370-1378.

30. Verbeek XA, Auricchio A, Yu Y, Ding J, Pochet T, Vernooy K, Kramer A, Spinelli J, Prinzen FW. Tailoring cardiac resynchronization therapy using interventricular asynchrony. Validation of a simple model. American journal of physiology. Heart and circulatory physiology. 2006;290:H968-977.

31. Rao RK, Kumar UN, Schafer J, Viloria E, De Lurgio D, Foster E. Reduced ventricular volumes and improved systolic function with cardiac resynchronization therapy: A randomized trial comparing simultaneous biventricular pacing, sequential biventricular pacing, and left ventricular pacing. Circulation. 2007;115:2136-2144.

32. Auricchio A, Stellbrink C, Sack S, Block M, Vogt J, Bakker P, Huth C, Schondube F, Wolfhard U, Bocker D, Krahnefeld O, Kirkels H. Long-term clinical effect of hemodynamically optimized cardiac resynchronization therapy in patients with heart failure and ventricular conduction delay. J Am Coll Cardiol. 2002;39:2026-2033.

33. Thibault B, Ducharme A, Harel F, White M, O'Meara E, Guertin MC, Lavoie J, Frasure-Smith N, Dubuc M, Guerra P, Macle L, Rivard L, Roy D, Talajic M, Khairy P. Left ventricular versus simultaneous biventricular pacing in patients with heart failure and a qrs complex $>=120$ milliseconds. Circulation. 2011;124:2874-2881.

34. Boriani G, Kranig W, Donal E, Calo L, Casella M, Delarche N, Lozano IF, Ansalone G, Biffi M, Boulogne E, Leclercq C. A randomized double-blind comparison of biventricular versus left ventricular stimulation for cardiac resynchronization therapy: The biventricular versus left univentricular pacing with icd back-up in heart failure patients (b-left hf) trial. American heart journal. 2010;159:1052-1058 e1051.

35. Gasparini M, Bocchiardo M, Lunati M, Ravazzi PA, Santini M, Zardini M, Signorelli S, Passardi M, Klersy C. Comparison of 1-year effects of left ventricular and biventricular pacing in patients with heart failure who have ventricular arrhythmias and left bundle-branch block: The bi vs left ventricular pacing: An international pilot evaluation on heart failure patients with ventricular arrhythmias (believe) multicenter prospective randomized pilot study. American heart journal. 2006;152:155 e151-157.

36. Kass DA, Chen CH, Curry C, Talbot M, Berger R, Fetics B, Nevo E. Improved left ventricular mechanics from acute vdd pacing in patients with dilated cardiomyopathy and ventricular conduction delay. Circulation. 1999;99:1567-1573.

37. Bogaard MD, Meine M, Tuinenburg AE, Maskara B, Loh P, Doevendans PA. Cardiac resynchronization therapy beyond nominal settings: Who needs individual programming of the atrioventricular and interventricular delay? Europace. 2012;14:1746-1753.

38. van Gelder BM, Bracke FA, Meijer A, Pijls NH. The hemodynamic effect of intrinsic 
conduction during left ventricular pacing as compared to biventricular pacing. J Am Coll Cardiol. 2005;46:2305-2310.

39. Ahsan SY, Saberwal B, Lambiase PD, Chaubey S, Segal OR, Gopalamurugan AB, McCready J, Rogers DP, Lowe MD, Chow AW. An 8-year single-centre experience of cardiac resynchronisation therapy: Procedural success, early and late complications, and left ventricular lead performance. Europace. 2013

40. Johnson WB, Abraham W'T, Young JB, Wheelan K, Smith AL, Chang Y, Brinkman P. Long-term performance of the attain model 4193 left ventricular lead. Pacing Clin Electrophysiol. 2009;32:1111-1116.

41. Auricchio A, Stellbrink C, Block M, Sack S, Vogt J, Bakker P, Klein H, Kramer A, Ding J, Salo R, Tockman B, Pochet T, Spinelli J. Effect of pacing chamber and atrioventricular delay on acute systolic function of paced patients with congestive heart failure. The pacing therapies for congestive heart failure study group. The guidant congestive heart failure research group. Circulation. 1999;99:2993-3001.

42. Ellenbogen KA, Gold MR, Meyer TE, Fernndez Lozano I, Mittal S, Waggoner AD, Lemke B, Singh JP, Spinale FG, Van Eyk JE, Whitehill J, Weiner S, Bedi M, Rapkin J, Stein KM. Primary results from the smartdelay determined av optimization: A comparison to other av delay methods used in cardiac resynchronization therapy (smart-av) trial: A randomized trial comparing empirical, echocardiography-guided, and algorithmic atrioventricular delay programming in cardiac resynchronization therapy. Circulation. 2010;122:2660-2668.

43. Sawhney NS, Waggoner AD, Garhwal S, Chawla MK, Osborn J, Faddis MN. Randomized prospective trial of atrioventricular delay programming for cardiac resynchronization therapy. Heart Rhythm. 2004;1:562-567.

44. van Geldorp IE, Delhaas T, Hermans B, Vernooy K, Broers B, Klimusina J, Regoli F, Faletra FF, Moccetti T, Gerritse B, Cornelussen R, Settels JJ, Crijns HJ, Auricchio A, Prinzen FW. Comparison of a non-invasive arterial pulse contour technique and echo doppler aorta velocity-time integral on stroke volume changes in optimization of cardiac resynchronization therapy. Europace. 2011;13:87-95.

45. Boriani G, Muller CP, Seidl KH, Grove R, Vogt J, Danschel W, Schuchert A, Djiane P, Biffi M, Becker T, Bailleul C, Trappe HJ, Resynchronization for the HemodYnamic Treatment for Heart Failure Management III. Randomized comparison of simultaneous biventricular stimulation versus optimized interventricular delay in cardiac resynchronization therapy. The resynchronization for the hemodynamic treatment for heart failure management ii implantable cardioverter defibrillator (rhythm ii icd) study. American heart journal. 2006;151:1050-1058.

46. Raphael CE, Kyriacou A, Jones S, Pabari P, Cole G, Baruah R, Hughes AD, Francis 
DP. Multinational evaluation of the interpretability of the iterative method of optimisation of av delay for crt. International journal of cardiology. 2012

47. Pabari PA, Willson K, Stegemann B, van Geldorp IE, Kyriacou A, Moraldo M, Mayet J, Hughes AD, Francis DP. When is an optimization not an optimization? Evaluation of clinical implications of information content (signal-to-noise ratio) in optimization of cardiac resynchronization therapy, and how to measure and maximize it. Heart Fail Rev. 2010

48. Helm RH, Byrne M, Helm PA, Daya SK, Osman NF, Tunin R, Halperin HR, Berger RD, Kass DA, Lardo AC. Three-dimensional mapping of optimal left ventricular pacing site for cardiac resynchronization. Circulation. 2007;115:953-961.

49. Verbeek XA, Vernooy K, Peschar M, Cornelussen RN, Prinzen FW. Intra-ventricular resynchronization for optimal left ventricular function during pacing in experimental left bundle branch block. J Am Coll Cardiol. 2003;42:558-567.

50. Rademakers LM, van Kerckhoven R, van Deursen CJ, Strik M, van Hunnik A, Kuiper M, Lampert A, Klersy C, Leyva F, Auricchio A, Maessen JG, Prinzen FW. Myocardial infarction does not preclude electrical and hemodynamic benefits of cardiac resynchronization therapy in dyssynchronous canine hearts. Circ Arrbythm Electrophysiol. 2010;3:361-368.

51. van Deursen C, van Geldorp IE, Rademakers LM, van Hunnik A, Kuiper M, Klersy C, Auricchio A, Prinzen FW. Left ventricular endocardial pacing improves resynchronization therapy in canine left bundle-branch hearts. Circ Arrbythm Electrophysiol. 2009;2:580-587.

52. Singh JP, Klein HU, Huang DT, Reek S, Kuniss M, Quesada A, Barsheshet A, Cannom D, Goldenberg I, McNitt S, Daubert JP, Zareba W, Moss AJ. Left ventricular lead position and clinical outcome in the multicenter automatic defibrillator implantation trial-cardiac resynchronization therapy (madit-crt) trial. Circulation. 2011;123:11591166.

53. Auricchio A, Klein H, Tockman B, Sack S, Stellbrink C, Neuzner J, Kramer A, Ding J, Pochet T, Maarse A, Spinelli J. Transvenous biventricular pacing for heart failure: Can the obstacles be overcome? Am J Cardiol. 1999;83:136D-142D.

54. Rodriguez LM, Timmermans C, Nabar A, Beatty G, Wellens HJ. Variable patterns of septal activation in patients with left bundle branch block and heart failure. $J$ Cardiovasc Electrophysiol. 2003;14:135-141.

55. Peschar M, de Swart H, Michels KJ, Reneman RS, Prinzen FW. Left ventricular septal and apex pacing for optimal pump function in canine hearts. J Am Coll Cardiol. 2003;41:1218-1226.

56. Prinzen FW, Van Oosterhout MF, Vanagt WY, Storm C, Reneman RS. Optimization 
of ventricular function by improving the activation sequence during ventricular pacing. Pacing Clin Electrophysiol. 1998;21:2256-2260.

57. Clementy N, Bernard-Brunet A, Pierre B, Saint-Etienne C, Babuty D. Successful 'quadrangular' pacing in a non-responder patient to cardiac resynchronization therapy. European heart journal. 2011;32:2215.

58. Ploux S, Barandon L, Ritter P, Bordachar P. Positive hemodynamic and clinical response to tri-left ventricular pacing in a nonresponder to traditional cardiac resynchronization therapy. Heart Rhythm. 2011;8:315-317.

59. Pappone C, Rosanio S, Oreto G, Tocchi M, Gulletta S, Salvati A, Dicandia C, Santinelli V, Mazzone P, Veglia F, Ding J, Sallusti L, Spinelli J, Vicedomini G. Cardiac pacing in heart failure patients with left bundle branch block: Impact of pacing site for optimizing left ventricular resynchronization. Italian heart journal : official journal of the Italian Federation of Cardiology. 2000;1:464-469.

60. Leclercq C, Gadler F, Kranig W, Ellery S, Gras D, Lazarus A, Clémenty J, Boulogne E, Daubert J-C. A randomized comparison of triple-site versus dual-site ventricular stimulation in patients with congestive heart failure. Journal of the American College of Cardiology. 2008;51:1455-1462.

61. Bordachar P, Alonso C, Anselme F, Boveda S, Defaye P, Garrigue S, Gras D, Klug D, Piot O, Sadoul N, Leclercq C. Addition of a second lv pacing site in crt nonresponders rationale and design of the multicenter randomized v3 trial. Journal of Cardiac Failure. 2010;16:709-713.

62. Wecke L, van Hunnik A, Thompson T, DiCarlo L, Zdeblick M, Auricchio A, Prinzen FW. Networked multielectrode left ventricular pacing lead for avoidance of phrenic nerve stimulation in a canine model. Heart Rhythm. 2012;9:789-795.

63. Forleo GB, Della Rocca DG, Papavasileiou LP, Molfetta AD, Santini L, Romeo F. Left ventricular pacing with a new quadripolar transvenous lead for crt: Early results of a prospective comparison with conventional implant outcomes. Heart Rhythm. 2011;8:31-37.

64. Forleo GB, Mantica M, Di Biase L, Panattoni G, Della Rocca DG, Papavasileiou LP, Santamaria M, Santangeli P, Avella A, Sergi D, Santini L, Tondo C, Natale A, Romeo F. Clinical and procedural outcome of patients implanted with a quadripolar left ventricular lead: Early results of a prospective multicenter study. Heart Rhythm. 2012;9:1822-1828.e1823.

65. Spragg DD, Dong J, Fetics BJ, Helm R, Marine JE, Cheng A, Henrikson CA, Kass DA, Berger RD. Optimal left ventricular endocardial pacing sites for cardiac resynchronization therapy in patients with ischemic cardiomyopathy. $\mathrm{J}$ Am Coll Cardiol. 2010;56:774-781. 
66. Derval N, Steendijk P, Gula LJ, Deplagne A, Laborderie J, Sacher F, Knecht S, Wright M, Nault I, Ploux S, Ritter P, Bordachar P, Lafitte S, Reant P, Klein GJ, Narayan SM, Garrigue S, Hocini M, Haissaguerre M, Clementy J, Jais P. Optimizing hemodynamics in heart failure patients by systematic screening of left ventricular pacing sites: The lateral left ventricular wall and the coronary sinus are rarely the best sites. J Am Coll Cardiol. 2010;55:566-575.

67. Ginks MR, Lambiase PD, Duckett SG, Bostock J, Chinchapatnam P, Rhode K, McPhail MJ, Simon M, Bucknall C, Carr-White G, Razavi R, Rinaldi CA. A simultaneous $\mathrm{x}$-mri and non contact mapping study of the acute hemodynamic effect of left ventricular endocardial and epicardial cardiac resynchronization therapy in humans. Circulation. Heart failure. 2011;4:170-179.

68. Jais P, Takahashi A, Garrigue S, Yamane T, Hocini M, Shah DC, Barold SS, Deisenhofer I, Haissaguerre M, Clementy J. Mid-term follow-up of endocardial biventricular pacing. Pacing Clin Electrophysiol. 2000;23:1744-1747.

69. van Gelder BM, Scheffer MG, Meijer A, Bracke FA. Transseptal endocardial left ventricular pacing: An alternative technique for coronary sinus lead placement in cardiac resynchronization therapy. Heart Rhythm. 2007;4:454-460.

70. Pasquie JL, Massin F, Macia JC, Gervasoni R, Bortone A, Cayla G, Grolleau R, Leclercq F. Long-term follow-up of biventricular pacing using a totally endocardial approach in patients with end-stage cardiac failure. Pacing Clin Electrophysiol. 2007;30 Suppl 1:S31-33.

71. Morina-Vazquez P, Roa-Garrido J, Fernandez-Gomez JM, Venegas-Gamero J, Pichardo RB, Carranza MH. Direct left ventricular endocardial pacing: An alternative when traditional resynchronization via coronary sinus is not feasible or effective. Pacing Clin Electrophysiol. 2013

72. Kassai I, Foldesi C, Szekely A, Szili-Torok T. Alternative method for cardiac resynchronization: Transapical lead implantation. Ann Thorac Surg. 2009;87:650-652.

73. Echt DS, Cowan MW, Riley RE, Brisken AF. Feasibility and safety of a novel technology for pacing without leads. Heart Rhythm. 2006;3:1202-1206.

74. Wieneke H, Konorza T, Erbel R, Kisker E. Leadless pacing of the heart using induction technology: A feasibility study. Pacing Clin Electrophysiol. 2009;32:177-183. 


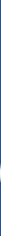

182 
Summary

hantantarb 
Summary

184 
Under normal conditions, ventricular depolarization occurs very fast, often within one hundred milliseconds. A near synchronous activation is considered imperative to maintain normal cardiac pump function. In the presence of conduction abnormalities ventricular activation occurs slower and in a dyssynchronous manner; during left bundle branch block (LBBB) from the right to the left ventricle. LBBB is associated with impairment of pump function, adverse structural remodeling, and increased risk for heart failure. As its name suggests, cardiac resynchronization therapy (CRT) aims to restore synchronous electrical activation of the ventricles, commonly by simultaneous biventricular (BiV) pacing. In the past 15 years, CRT has become an important treatment for symptomatic heart failure patients with reduced LV ejection fraction and increased QRS duration. However, up to half of patients do not show clinical and/or echocardiographic signs of response. A need exists for increased understanding of the detrimental effects of electrical asynchrony and beneficial effects of resynchronization as both aspects have been oversimplified in the past.

The general aims of the research presented in chapter 1 are twofold:

1) To improve understanding of electrical activation of the dyssynchronous and resynchronized heart.

2) To apply newly gained insights in order to deliver tools for increasing the efficacy of CRT.

Theoretical and clinical studies show that CRT is predominantly effective in patients with LBBB. The electrical activation patterns during LBBB and CRT in humans are discussed in chapter 2. Point-by-point contact mapping or single beat non-contact mapping studies show considerable differences in activation patterns between patients. These heterogeneous activation patterns might in part explain why the benefit of CRT leads to a varying amount of response. Furthermore, not all patients receiving CRT may have LBBB. This is because the key clinical investigational technique to detect and evaluate the extent of ventricular conduction delay remains the surface electrocardiogram (ECG). Clinical studies have typically implanted CRT device in patients with a QRS duration of at least $120 \mathrm{~ms}$. The application of this criterion implies that many patients with right bundle branch block or other conduction disease are also implanted with a CRT device. On top of that, one third of patients diagnosed with LBBB by conventional electrocardiographic criteria may not have true complete LBBB. 
It is becoming increasingly clear that the right electrical substrate (LBBB morphology on ECG or severely widened QRS duration) is required for CRT to be effective. Another finding supporting this idea is the observation from recent clinical trials that CRT efficacy is not dependent on severity of heart failure symptoms.

Presence of comorbidities and the lack of knowledge concerning the duration and extent of the lesion (or lesions) limits the use of clinical data to investigate the pathophysiology of electrical asynchrony. These limitations stimulated us to specifically investigate the effects of isolated LBBB and pacing therapies in animal models, as discussed in chapter 3. After ablating the proximal left bundle branch, a typical LBBB activation pattern appears which leads to acute decrease in pump function by redistribution of mechanical work, perfusion and oxygen demand. In the long-term, LBBB leads to structural remodeling with dilatation and asymmetrical hypertrophy. BiV pacing in the canine heart with isolated LBBB immediately causes an almost normalization of the strain patterns while cardiac pump function approaches but never returns to pre-LBBB values. Apparently, the physiological sequence of activation and contraction are never completely restored during CRT.

In later experiments, the dyssynchronous canine model was extended by the addition of transmural myocardial infarction through embolization of a coronary artery using foam particles. Achieving the maximal benefit in infarcted dyssynchronous hearts required positioning of the LV pacing lead distant from the infarction and more precise timing of LV stimulation. These data indicate that animal models are of great importance in understanding the events and consequences of dyssynchrony and resynchronization.

Throughout the thesis, we performed extensive cardiac mapping studies by placing a large amount of contact electrodes on the epicardium. To measure endocardial potentials, we introduced multiple transmural plunge electrodes and in addition, performed high-resolution non-contact mapping. Epicardial and endocardial potentials were matched successfully and three-dimensional activation time maps were created for the purpose of increased understanding of dyssynchrony and resynchronization. In chapter 4 , we investigated the accuracy of non-contact mapping by comparing it with direct contact mapping in ten dyssynchronous canine hearts with or without concomitant tachypacing-induced heart failure. During atrial pacing and $\mathrm{LV}+\mathrm{BiV}$ pacing at eight $\mathrm{LV}$ sites, up to eight non-contact/contact 
electrode pairs were compared by calculating morphology cross-correlation and activation time difference. We found that regardless of the existence of dilated cardiomyopathy, non-contact mapping adequately registered endocardial potentials. Based on these results, we utilized non-contact mapping to investigate asynchronous activation and resynchronization in subsequent chapters.

Multiple clinical trials reported that in CRT-patients, single-site LV pacing (with full biventricular capture) resulted in similar mid-term beneficial effects when compared with simultaneous BiV pacing. These results were very surprising, since the beneficial effects of CRT are thought to be the result of the fusing opposing activation wave fronts from the RV- and LV-lead. Simultaneous non-contact and contact mapping allowed us to investigate the underlying electrical mechanisms of resynchronization in unprecedented detail in chapter 5. Simultaneous BiV pacing was compared with single-site LV pacing in the canine model of acute LBBB $(n=10)$ and in the canine model of chronic LBBB and tachypacing-induced heart failure $(\mathrm{n}=6)$. We indeed found similar response in $\mathrm{LV} \mathrm{dP} / \mathrm{dt}_{\text {max }}$ during $\mathrm{LV}$-pacing and $\mathrm{BiV}$ pacing in the failing hearts. Interestingly, non-contact and contact mapping showed very similar LV endocardial activation patterns during both pacing modalities, while epicardial and total activation showed significant changes. In addition, similarities in LV endocardial conduction between pacing modalities were most apparent in failing hearts.

We hypothesized that the activation wave front propagating from the RV apical pacing-lead was not able to cross the interventricular septum in due time to induce significant LV endocardial depolarization. Transmural conduction measurements confirmed that transseptal conduction was indeed slow as compared with transmural conduction of the LV free wall. In addition, transseptal conduction was even slower in the failing hearts, despite thinning of the interventricular septum. Compensating slow transseptal conduction was possible through RV pre-excitation, by pre-stimulating the RV lead or by allowing the right bundle branch to dominate LV depolarization. RV pre-excitation indeed minimized LV endocardial asynchrony but this condition did not coincide with optimal $\mathrm{LVdP} / \mathrm{dt}_{\max }$. Since epicardial or total asynchrony (assessed from vectors of epicardial activation times or surface ECG amplitudes) did predict optimal acute hemodynamic response, we concluded that epicardial or total electrical asynchrony, and not endocardial asynchrony, are predictive of acute CR'T response. 
The idea that epicardial asynchrony matches acute CRT response was further evaluated for conditions related to optimization of $\mathrm{AV}$ - and $\mathrm{VV}$-intervals in eight dogs with chronic LBBB, described in chapter 6 . One hundred randomized settings were tested with varying atrioventricular (AV) intervals for $\mathrm{LV}$ and RV pacing, interrupted only by 25 baseline atrial pacing settings. The relative changes in LV pump function $\left(\mathrm{d} P / \mathrm{d} t_{\max }\right.$, stroke work) during the tested settings were related to baseline values and plotted in surface plots. Changes in $\mathrm{LV} \mathrm{dP} / \mathrm{dt}_{\max }$ indeed matched with changes in electrical resynchronization and mechanical interventricular dyssynchrony. Clinical studies focus primarily on optimizing LV filling parameters (such as separation of Doppler E and A waves) by altering lead-stimulation timings. For this purpose, we also performed optimization in 6 dogs with complete AV-block which allowed us to investigate effects of changing AV-timings while keeping the electrical activation pattern constant. This combination is impossible in dogs with LBBB because of intrinsic conduction through the right bundle branch at longer AV-intervals. During varying $\mathrm{AV}$-intervals with fixed electrical activation patterns we found no significant changes in $\mathrm{LVdP} / \mathrm{dt}_{\max }$ or $\mathrm{LV}$ end-diastolic volumes.

These findings indicate that it is the electromechanical fusion rather than filling which dictate acute hemodynamic response in CRT optimization. We believe that future studies should focus on finding reliable electrophysiological parameters to optimize CRT in patients.

In order to increase electrical resynchronization, multiple LV-pacing sites could be stimulated instead of only one. A limited amount of small clinical studies have shown promising results which gave rise to the question whether there is a linear relation between the amount of pacing sites and electrical resynchronization and acute hemodynamic response. We investigated this research question in nine dogs with chronic LBBB in chapter 7 . We performed almost real time detailed electrical mapping to add the latest activated of seven pre-determined LV pacing electrodes to simultaneous stimulation, resulting in a maximum of seven $L V$ pacing sites and thus providing the best possible scenario for achieving optimal resynchronization. This design allowed an extensive comparison of many pacing sites and invasive hemodynamic measurements. Compared to single-LV pacing, multi-LV pacing reduced LV asynchrony of activation and dispersion of repolarization in a stepwise fashion. However, the improvement in contractility was limited to conditions where single LV-pacing provided suboptimal improvement. 
We concluded from this study that the better response to CRT by multisite pacing is due to the compensation of poorly performing previously stimulated LV-pacing electrodes rather than the addition of another LV-pacing electrode or further reduction of the absolute electrical dyssynchrony.

It remains unknown what renders an LV pacing-site as being "optimal" or "suboptimal" but earlier studies from our laboratory and small clinical trials have shown that LV endocardial pacing-sites often perform better than conventional LV epicardial sites. In chapter $\mathbf{8}$ we greatly extended these observations by performing extensive pacing and mapping studies comparing LV endocardial versus LV epicardial pacing in novel models of chronic LBBB with added myocardial infarction (induced by injection of foam particles in a coronary artery, $n=7$ ) or dilated cardiomyopathy (induced by tachypacing, $n=6$ ). Using a back-to-back comparison with up to eight LV pacing-sites we showed that in all models endocardial CRT outperformed epicardial CRT by the same added percentage $\mathrm{LVdP} / \mathrm{dt}_{\max }$ increase. Paradoxically, endocardial CRT increased endocardial asynchrony but important decreases in transmural and epicardial asynchrony resulted in a net decrease in total asynchrony during endocardial CRT as compared with conventional CRT. An important mechanism of the better electrical resynchronization of endocardial CRT appears to be the fast (sub)endocardial impulse conduction, which was observed in all models.

\section{Conclusions}

The electrical substrate is both essential and sufficient for CRT efficacy. LBBB appears to be the correct electrical substrate. When applying CRT, the largest hemodynamic benefit can be achieved by using endocardial LV pacing, alone or in combination with RV-pacing. When using (conventional) epicardial CRT, patient-specific tailoring of pacing lead position and AV-and VV-interval can also boost CRT efficacy to new levels. 


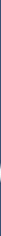


Samenvatting

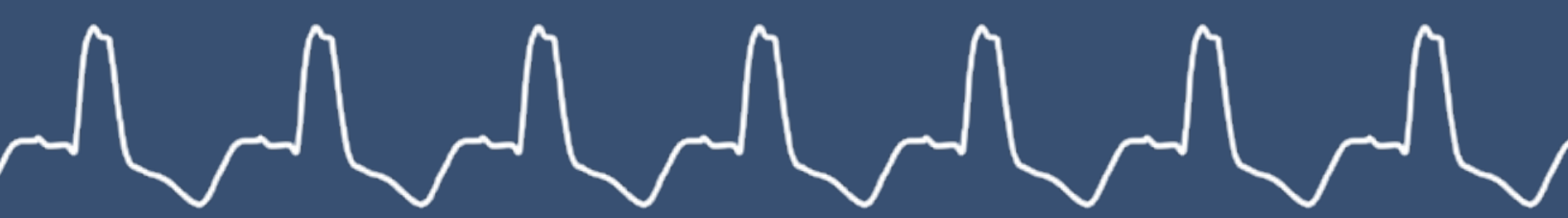


Samenvatting 
In een gezond hart worden beide ventrikels via de snel geleidende purkinje vezels (waaronder de rechter- en linkerbundel) gedepolariseerd, meestal binnen honderd milliseconden. Om een normale pompfunctie te bewerkstelligen is een nagenoeg synchrone activatie dan ook essentieel. Bij een geleidingsstoornis wordt ventriculaire activatie trager en asynchroon. Zo vindt tijdens linkerbundeltakblok (LBTB) de depolarisatie plaats van de rechter naar de linker ventrikel (LV) en ook de LV zelf wordt langzaam gedepolariseerd; van het septum naar de laterale wand. LBTB wordt geassocieerd met een verminderde pompfunctie, ongunstige structurele remodelering, en een toegenomen kans op hartfalen.

Zoals de naam suggereert, streeft cardiale resynchronisatie therapie (CRT) naar herstel van de synchrone elektrische activatie van de ventrikels, meestal door simultaan biventriculair (BiV) pacen. In de afgelopen 15 jaar is CRT uitgegroeid tot een belangrijke behandeling voor patiënten met symptomatisch hartfalen met verminderde LV ejectiefractie en toegenomen QRS duur. Toch laat tot de helft van de patiënten geen klinische en/of echocardiografische tekens van respons zien. Er bestaat een behoefte om de schadelijke effecten van elektrische asynchronie en de gunstige effecten van resynchronisatie beter te begrijpen, aangezien beide aspecten onvoldoende zijn onderzocht in het verleden.

De doelstelling van dit proefschrift (uiteengezet in hoofdstuk 1) is tweeledig:

1) Het beter begrijpen van de elektrische activatie van het asynchrone en geresynchroniseerde hart, en

2) De toepassing van de nieuwe inzichten om zodanig handvaten te leveren om de effectiviteit van CRT te vergroten.

Theoretische en klinische studies hebben laten zien dat CRT vooral effectief is in patiënten met LBTB. De elektrische activeringspatronen tijdens LBTB en CRT in mensen worden besproken in hoofdstuk 2. Elektrische mapping studies (puntvoor-punt contact mapping of enkele-hartslag non-contact mapping) laten zien dat er aanzienlijke verschillen zijn in activeringspatronen tussen patiënten. Deze heterogeniteit in activeringspatronen zou deels kunnen verklaren waarom het gunstige effect van CRT kan verschillen en de mate van respons variabel is. 
Daarnaast hebben niet alle patiënten die CRT krijgen LBTB, deels verklaart doordat de belangrijkste onderzoekstechniek om ventriculaire geleidingsvertraging vast te stellen en te evalueren nog steeds het oppervlakte elektrocardiogram (ECG) is. Klinische studies hanteren meestal het minimum van een QRS breedte van $120 \mathrm{~ms}$ voor patienten bij wie een CRT pacemaker wordt geïmplanteerd. De toepassing van dit criterium betekent dat ook veel patiënten met een rechterbundeltakblok of andere geleidingsstoornis een CRT pacemaker geïmplanteerd krijgen. Bovendien heeft een-derde van de patiënten, die gediagnosticeerd zijn met LBTB door conventionele ECG criteria, waarschijnlijk geen compleet LBTB. Het wordt steeds duidelijker dat het correcte elektrische substraat (LBTB morfologie of een ernstig verbreed QRS) essentieel is voor effectieve CRT. Deze veronderstelling wordt onderbouwd door de waarneming, tijdens recente klinische studies, dat de effectiviteit van CRT niet afhankelijk is van de mate van aan hartfalen gerelateerde klachten.

De aanwezigheid van co-morbiditeit en de onzekerheid over de duur en de mate van de laesie (of laesies) beperkt de toepasbaarheid van klinische gegevens om de pathofysiologie van elektrische asynchronie te onderzoeken. Deze beperking stimuleerde ons om de effecten van pacemaker therapieën specifiek te onderzoeken bij geïsoleerde LBTB in diermodellen, zoals uiteengezet in hoofdstuk 3. $\mathrm{Na}$ ablatie van de proximale linker bundeltak ontstaat een typisch LBTB activeringspatroon dat leidt tot een plotse daling in de pompfunctie door herverdeling van mechanische arbeid, perfusie, en zuurstofbehoefte. Op de lange termijn leidt LBTB tot structurele remodelering met dilatatie en asymmetrische hypertrofie. BiV stimuleren van een hondenhart met geïsoleerde LBTB resulteert in een onmiddellijke normalisatie van het contractiepatroon, terwijl de cardiale pompfunctie de normaalwaarde (van voor het LBTB) benadert, maar nooit helemaal bereikt. Blijkbaar wordt de fysiologische volgorde van activering nooit volledig bereikt door CRT.

In latere experimenten is het asynchrone hondenmodel uitgebreid met een transmuraal infarct door middel van een injectie in de kransslagader met schuim partikels. Om het optimale effect te behalen in geïnfarceerde asynchrone harten, is het belangrijk de LV electrode niet in de buurt van het geïnfarceerde weefsel te plaatsen en de LV op een preciezer tijdstip te stimuleren. Deze bevindingen tonen aan dat diermodellen zeer belangrijk kunnen zijn voor het begrijpen van de gevolgen van asynchronie en resynchronisatie. We beschrijven in dit proefschrift de uitgebreide cardiale mapping studies die we hebben verricht na het plaatsen van een groot aantal contact-elektrodes op het epicard. Om endocardiale potentialen te 
kunnen meten, hebben we meerdere transmurale electroden geplaatst en daarnaast hoge-resolutie non-contact mapping uitgevoerd. Epicardiale en endocardiale potentialen werden succesvol gepaard, waardoor het mogelijk was de elektrische activatie in kaart te brengen in een drie-dimensionele voorstelling.

In hoofdstuk 4 bespreken we de nauwkeurigheid van non-contact mapping die we hebben onderzocht door deze te valideren met directe contact mapping in tien honden met LBTB. Bij de helft van deze honden werd ook hartfalen geïnduceerd door snelle ventrikelstimulatie. Tijdens LV en BiV pacen op acht verschillende LV locaties en atriaal pacen, werden tot acht non-contact/contact electrode-paren vergeleken door berekening van het morfologische kruiscorrelatie coëfficiënt en het activatietijdsverschil. Onafhankelijk van de aanwezigheid van gedilateerde cardiomyopathie, registreerde non-contact mapping op een adequate wijze endocardiale potentialen. Gebaseerd op deze resultaten hebben we non-contact mapping in latere onderzoeken (hoofdstukken 5 en 8) gebruikt om asynchrone activatie en resynchronisatie te bestuderen.

Meerdere klinische studies rapporteren dat in CRT patiënten, LV-enkel pacen (waarbij vanaf één LV locatie beide ventrikels worden geactiveerd) vergelijkbare mid-termijn resultaten oplevert als simultaan BiV pacen. Deze resultaten waren verassend voor ons, omdat het gunstige effect van CRT wordt toegeschreven aan het fuseren van activerende golffronten vanuit de RV- en LV-electrode. Onze simultane non-contact en contact mapping methode gaf ons te mogelijkheid om de onderliggende elektrische mechanismen van resynchronisatie te onderzoeken, zoals beschreven in hoofdstuk 5. Simultaan BiV pacen werd vergeleken met LV-enkel pacen in het hondenmodel van acute LBTB $(n=10)$ en chronische LBTB en hartfalen (geïnduceerd door snelle ventrikelstimulatie, $n=6$ ). We vonden inderdaad vergelijkbare respons in $\mathrm{LVdP} / \mathrm{dt}_{\text {max }}$ tijdens $\mathrm{LV}$-pacen en BiV-pacen in de falende harten. Non-contact en contact mapping lieten sterk vergelijkbare LV endocardiale activeringspatronen zien bij beide pace-modi, terwijl epicardiale en totale activatie significant verschillend waren. In falende harten was de overeenkomst tussen LV-pacen en BiV-pacen het. We stelden de hypothese dat door langzame transseptale geleiding, het activerende golffront uit de RV apex elektrode niet snel genoeg door het interventriculaire septum geleidde om een belangrijke bijdrage te leveren aan LV endocardiale depolarisatie. Transmurale geleidingsmetingen bevestigden dat transseptale geleiding inderdaad langzaam was vergeleken met transmurale geleiding van de LV vrije wand. 
Daarnaast was de transseptale geleiding ook langzamer in de falende harten, ondanks verdunning van het interventriculaire septum in deze harten. RV pre-stimulatie maakt het mogelijk te compenseren voor langzame transseptale geleiding door pre-stimulatie van de RV electrode of door de rechter bundel tak een deel van de LV te laten depolariseren. RV pre-stimulatie resulteerde inderdaad in verminderde $\mathrm{LV}$ endocardiale asynchronie maar dit ging niet gepaard met optimale $\mathrm{LVdP} / \mathrm{dt}_{\text {max }}$. Omdat epicardiale of totale asynchronie (gemeten door gebruik van vectoren uit epicardiale activatie tijden of oppervlakte ECG amplitudes) wèl voorspellend was voor acute hemodynamische respons, concludeerden we dat epicardiale of totale elektrische asynchronie, en niet louter endocardial asynchronie, voorspellend was voor acute CRT respons.

De hypothese dat epicardiale asynchronie correleert met een acute CRT respons werd verder geëvalueerd door middel van uitgebreide optimalisatie van atrioventriculaire (AV) en ventriculoventriculaure (VV) intervallen in acht honden met chronische LBTB, zoals beschreven in hoofdstuk 6. Honderd gerandomiseerde instellingen werden getest met wisselende AV intervallen voor LV en RV stimulatie, slechts onderbroken door 25 controle metingen (atriaal pacen). De relatieve veranderingen in $\mathrm{LV}$ pompfunctie ( $\mathrm{dP} / \mathrm{dt}_{\max }$ en arbeid) tijdens gestimuleerde instellingen ten opzichte van de controlemetingen werden uiteengezet in oppervlakte grafieken. Veranderingen in $\mathrm{LVdP} / \mathrm{dt}_{\max }$ kwamen inderdaad overeen met veranderingen in elektrische resynchronisatie en mechanische interventriculaire dyssynchronie. Klinische studies richten zich vooral op het optimaliseren van LV vulling (door bijvoorbeeld separatie van de Doppler E en A golven) door het variëren van de elektrode-stimulatie tijden. Voor dit doel hebben we ook een optimalisatie uitgevoerd in zes honden met compleet AV-blok waardoor we konden onderzoeken wat het effect was van het aanpassen van AV-tijden terwijl het elektrische activeringspatroon identiek bleef. Deze combinatie is onmogelijk in honden met LBTB vanwege de intrinsieke geleiding via de rechter bundeltak tijdens langere AV intervallen. Tijdens het variëren van $\mathrm{AV}$ intervallen met identieke activeringspatronen vonden we geen significante verschillen in $\mathrm{LVdP} / \mathrm{dt}_{\text {max }}$ of $\mathrm{LV}$ end-diastolische volumes. Deze bevindingen tonen aan dat het de elektromechanische fusie is, en niet de $L V$ vulling, die de acute hemodynamische respons in CRT dicteert. Wij geloven dat toekomstige studies zich moeten richten op het vinden van betrouwbare elektrofysiologische parameters om CRT te optimaliseren in patiënten. 
Om elektrische resynchronisatie te verbeteren, zouden meerdere LV locaties gestimuleerd kunnen worden (multi-LV) in plaats van maar één. Enkele kleine klinische studies hebben een positief effect aangetoond waardoor de vraag naar boven komt of er een lineaire relatie bestaat tussen het aantal gestimuleerde locaties en elektrische resynchronisatie en acute hemodynamische respons. We onderzochten deze onderzoeksvraag in negen honden met chronische LBTB in hoofdstuk 7. We voerden gedetailleerde elektrische mapping uit waardoor het tijdens het experiment vrijwel direct mogelijk was om ook de laatst geactiveerde van de zeven vooraf bepaalde LV pacing elektrodes toe te voegen aan de gelijktijdige stimulatie. Dit protocol resulteerde uiteindelijk in een maximum van zeven simultaan gestimuleerde LV locaties waardoor een ideaal scenario ontstond om een optimale resynchronisatie te bereiken. Daarnaast was deze studie ontworpen om een uitgebreide vergelijking mogelijk te maken tussen het pacen van meerdere locaties en de effecten op elektrische asynchronie en hemodynamische status. Vergeleken met enkel-LV pacen, reduceerde multi-LV pacen stapsgewijs de LV asynchronie van depolarisatie en repolarisatie. De verbetering in contractiliteit werd echter alleen gevonden in situaties waarbij enkel-LV pacen resulteerde in een suboptimale verbetering. We concludeerden dat de betere respons op CRT door multi-LV pacen veroorzaakt wordt door de compensatie van slecht functionerende LV-pace elektrodes en niet zozeer door het toevoegen van LV electroden of verdere afname van absolute elektrische asynchronie.

Het is nog niet bekend welke aspecten een LV pace locatie "optimaal" of "suboptimaal" maken, maar eerdere studies van ons laboratorium en kleinschalige klinische studies hebben laten zien dat endocardiale LV pace-locaties vaak betere resultaten tonen dan conventionele epicardiale locaties (via de coronaire sinus). In hoofdstuk 8 hebben we deze observaties uitgebreid door uitvoerige pace- en mappingstudies te doen waarbij LV endocardiale CRT werd vergeleken met LV epicardiale CRT met aanvullende hondenmodellen van chronische LBTB met myocardinfarct (door injectie van schuim partikels in de kransslagaders, $n=7$ ) òf gedilateerde cardiomyopathie (geïnduceerd door snelle ventrikelstimulatie, $\mathrm{n}=6$ ). Door directe vergelijking van acht endocardiale LV pace-locaties versus epicardiale LV pace-locaties toonden we aan dat in alle nieuwe modellen endocardiale CRT betere resultaten gaf dan epicardiale CRT met vergelijkbare toename in percentage $\mathrm{LVdP} / \mathrm{dt}_{\max }$. 
Samenvatting

We zagen dat endocardiale CRT, daarentegen, resulteerde in toename van endocardiale asynchronie. Vergeleken met conventionele epicardiale CRT, resulteerde endocardiale CRT in belangrijke afnames in transmurale en epicardiale asynchronie met daardoor een netto afname in totale asynchronie. Een belangrijk mechanisme van de betere elektrische resynchronisatie van endocardiale CRT lijkt de snelle (sub)endocardiale voorgeleiding, die wij hebben gemeten in alle modellen.

\section{Conclusies}

Het elektrisch substraat is essentieel maar tegelijkertijd ook voldoende voor CRT om effectief te zijn. LBTB lijkt het correcte elektrisch substraat te zijn. Wanneer CRT uitgevoerd wordt, kan de beste hemodynamische verbetering behaald worden door endocardiaal LV-pacen, enkel-LV of samen met RV-pacen. Wanneer conventionele (epicardiale) CRT uitgevoerd wordt, zou patiënt-specifiek optimaliseren van AV en VV intervallen de CRT respons aanzienlijk kunnen verbeteren. 
Samenvatting 


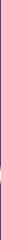




\section{Dankwoord \& Acknowledgements}

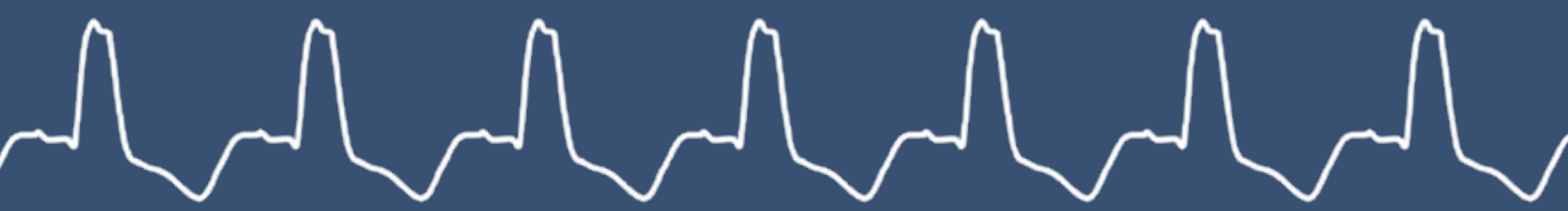


Dankwoord \& Acknowledgements 
Zonder de onvermoeibare inzet en kennis van vele anderen was dit proefschrift nooit tot stand gekomen.

Ik ben dan ook iedereen die op welke manier dan ook heeft bijgedragen aan dit werk, enorm dankbaar.

Mijn promotores prof. dr. Frits W. Prinzen en prof. dr. Angelo Auricchio wil ik allereerst bedanken voor hun begeleiding van mijn promotietraject. Beste Frits, dankzij jouw onuitputtelijke kennis en onvoorwaardelijke toegankelijkheid heb ik vanaf mijn geneeskunde opleiding een passie ontwikkeld voor onderzoek. Bedankt ook dat je het mij mogelijk maakte om vele congressen te bezoeken en nieuwe mensen te leren kennen. Het is dankzij jou dat ik met een goede basis van elektrofysiologie enthousiast kan beginnen aan mijn opleiding cardiologie. Angelo, I wish to thank you wholeheartedly for your commitment and eagerness to participate in our work, particularly by giving it much needed clinical focus.

Prof. dr. Uli Schotten, prof. dr. Harry J.G.M. Crijns, prof. dr. Hans-Peter Brunner-La Rocca, prof. dr. Tammo Delhaas, en prof. dr. Marc A. Vos, leden van de beoordelingscommissie, wil ik graag hartelijk bedanken voor de kritische beoordeling van mijn proefschrift.

De resultaten beschreven in dit proefschrift waren nooit verkregen zonder de expertise en toewijding van onze biotechnische collega's. Arne van Hunnik, bedankt voor je bereidheid om nieuwe technieken te implementeren en je passie waarmee je veel kennis hebt overgedragen zodat ik ook zelf aan de gang kon gaan. Marion Kuiper, dankzij jou bekwaamheid en toewijding was het mogelijk veel belangrijke data te vergaren. Bovendien is er niemand waarmee je heerlijker kan discussiëren dan met jou! Daarnaast wil ik ook de overige biotechnici bedanken die allen een essentiële bijdrage hebben geleverd: Sophie Bosch, Grace Croft, Goedele Verbakel en Anniek Lampert.

Daarnaast zijn er nog veel andere collegae op onze vakgroep Fysiologie die ik zou willen bedanken voor de positieve werksfeer en hun hulp bij het analyseren en interpreteren van de resultaten. Chantal Munts en Stijn Lumeij, bedankt voor het mij wegwijs maken in het lab wanneer ik verdwaald was. Frans van Nieuwenhoven, Ward Vanagt, Chantal Pöttgens, Ilka Lorenzen, bedankt voor jullie luisterend 
oor en kritische bijdrages tijdens de labmeetings. Richard Cornelussen, ik vond het geweldig dat je af en toe eens binnen kwam stormen met een vraag of opmerking, of soms alleen maar om te kijken hoe het met mij ging. Robert Mills, even though you are still considered the king of MATLAB, thanks to your guidance and code I have learned the basics and people can now turn to me for help. Nard Rademakers, bedankt voor het mij wegwijs maken van het analyseren van de vele typen signalen. Rob Wiegerinck, wat dapper van je dat je het MATLAB avontuur aangaat, ik wens je veel succes met het analyseren van de gegevens en bedankt voor de fijne samenwerking. Caroline van Deursen, ik hoop dat ons synergistisch effect ook in de toekomst nog door zal gaan, ik zie je graag weer binnenkort in de klinische setting. Patrick Houthuizen, ik heb altijd genoten van de interactie met jou over welk onderwerp dan ook, ik hoop ooit in jouw B\&B te mogen mopperen dat je eieren niet voldoende doorgekookt zijn. Sylvain Ploux, you might remember your year in Maastricht as the darkest you had ever had but for me it was a true joy to work together and to become friends with you and your family. I believe that we should continue to dig in each other's lives and I hope to spend some time in Bordeaux in the future. Joost Lumens, ik vond het fantastisch om jou te zien ontwikkelen de afgelopen jaren op allerlei vlakken, jij bent een groot voorbeeld voor mij en bedankt dat ik daar zo een belangrijke rol in mocht spelen! Lars van Middendorp, jij hebt enorm veel bijgedragen aan mijn promotietraject doordat je als kamergenoot als eerste de bevindingen kon beoordelen. Daarnaast heb je je enorm ingezet om het experimentele werk onder de knie te krijgen. Ik zal nooit vergeten dat jij ervoor gezorgd hebt dat ik in de laatste fase mij kon richten op het schrijven van de artikelen, bedankt!

Lieve Irene, wat vind ik het fantastisch dat ik onderdeel mocht zijn van jou eigen ontdekkingsreis en zelfs een belangrijke rol kreeg toebedeeld tijdens zowel je promotie als je huwelijk. Er was dan ook geen twijfel over dat jij mijn paranimf zou zijn en ik wil je bedanken voor jou investering in mij als onderzoeker en als persoon.

Beste mannen van E.R., ook jullie wil ik graag bedanken voor jullie vriendschap en bereidheid zo vaak naar Aubel af te reizen. Marc, Patrick, Giel, Sebas, Jakob en Martijn ik hoop ondanks de afstand en onze drukke agenda's jullie in de toekomst nog vaak te zien. Chrys, ik denk nog vaak aan je, speel de sterren van de hemel voor ons. 
Lieve mama en Bob, bedankt voor jullie interesse door de jaren heen en voor de revisie van de samenvatting. Lieve papa en Hanneke, bedankt voor de vele fijne momenten, door jullie gezelligheid kon ik de stress rondom het promoveren gemakkelijk vergeten. Lieve papa en mama, bedankt dat jullie mij vanaf kleins af aan alle kansen hebben gegeven mij te ontplooien. Zonder jullie immense toewijding en soms gênante trots had ik nooit het zelfvertrouwen gehad om dit te bereiken. Roy, bedankt voor mijn momenten in Tunesie nog plezieriger te maken, het ga je goed in het Midden-Oosten. "Kleintjes", Joep en Tim, ik ben zo trots op jullie ontwikkeling, wat fijn dat jullie zo een belangrijk onderdeel waren van de mijne. Hugo, bedankt dat je zoveel tijd hebt vrijgemaakt om mij te helpen in het ontwerpen van mijn proefschrift. Dankzij jou zal menig boekenkast er een stuk fraaier uitzien! Anna en Alex, ik ben blij dat jullie een onderdeel van mijn familie zijn geworden. Lieve Hans en Marja, jullie hebben ontzettend veel betekend voor mij de afgelopen jaren, bedankt voor mijn promotietijd zo aangenaam te maken en ervoor te zorgen dat mijn glas nooit leeg was! Beste Victor. het feit dat jij mijn getuige was wil al zeggen dat jij veel voor mij betekent. Ik vond het fantastisch dat ik mijn kennis met jou kon delen, al is het nooit verder gekomen dan "oesophagus".

Bijna de helft van mijn leven deel ik met jou, lieve Silvie, en ik kan me niet voorstellen dat iemand me meer zou kunnen steunen en liefhebben dan jij. Woorden schieten mij tekort om jou te bedanken voor je geduld en begrip van de afgelopen jaren en ook alvast voor de komende jaren. Wat een geluk hebben we dan ook dat onze liefde heeft geresulteerd in onze mooie blonde dochter. Lieve Adeline, ik zou willen dat je voor altijd een heerlijke kleine prinses blijft en ik jouw held. Bedankt dat je mijn leven zoveel meer inhoud hebt gegeven en ik kijk er naar uit om jou te zien opgroeien naar een fantastische vrouw, zoals je mama. Ook Iejoor mag ik niet vergeten want hij is onderdeel van ons gezin en mede verantwoordelijk voor heerlijke ontsnappingen naar de Hervense of Oostenrijkse bergen. 


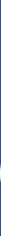

206 
About the Author

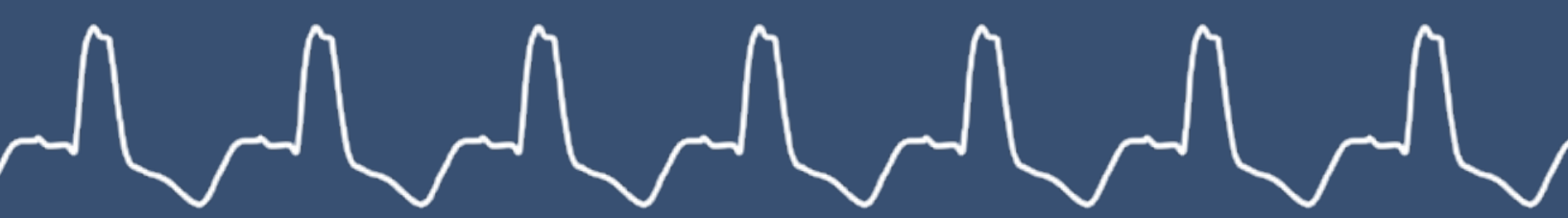


About the Author

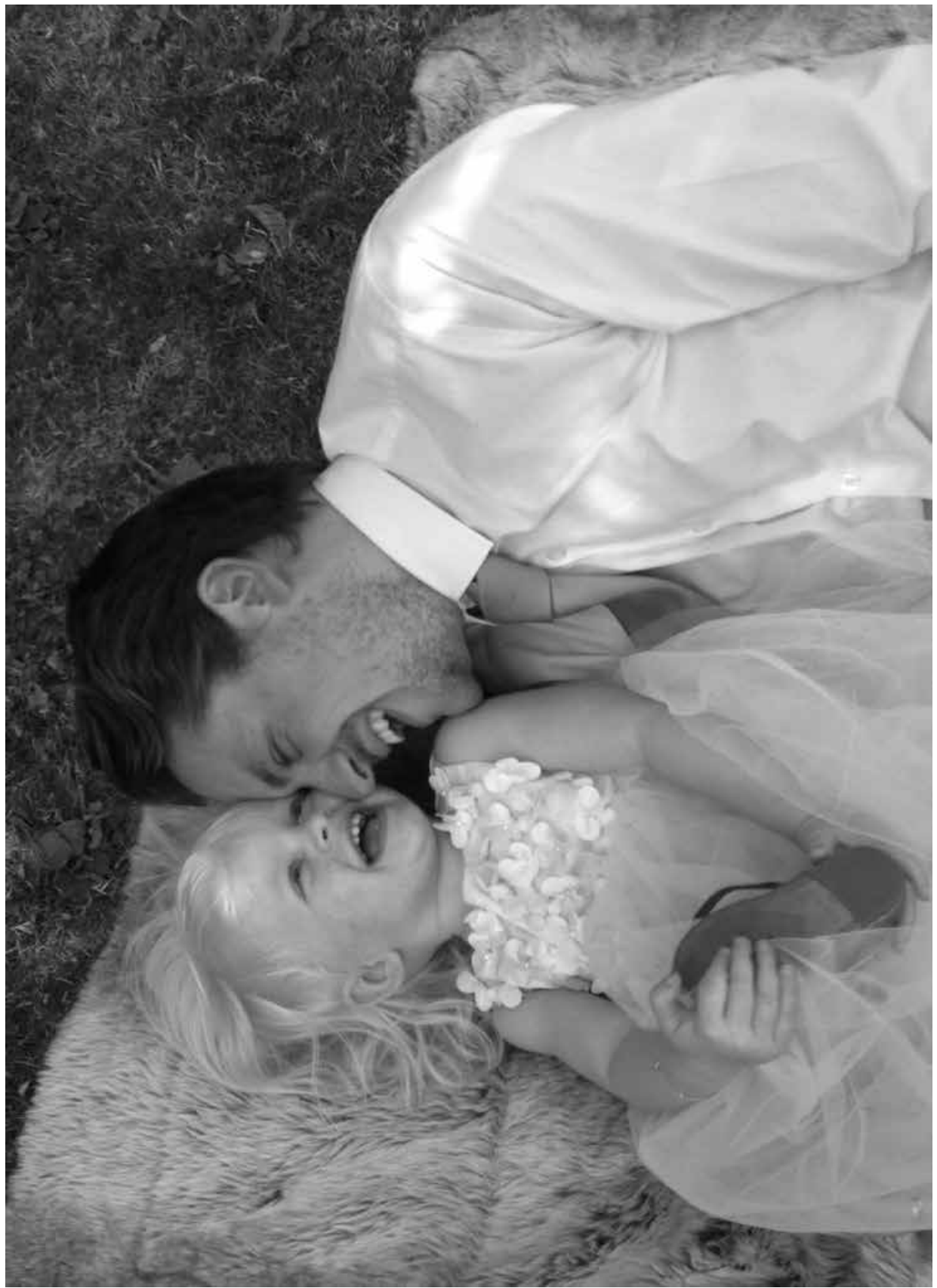




\section{Marc Oliver Strik}

was born on November 28, 1984 in Sousse, Tunisia.

From 1996 until 2002, he attended secondary education at the European School in Mol (Belgium) where he obtained his European Baccalaureate. In 2002, he started his medical training at the Faculty of Health and Life Sciences at Maastricht University. His passion for cardiology was sparked by his facultative cardiology internships at Maastricht University Medical Center in 2006 and in 2008. He became 'doctorandus' in Medicine (equivalent of Master of Science) in 2006 and graduated as Medical Doctor in July 2008 with cum laude distinction.

He was supervised by prof. dr. Frits Prinzen during his course "neurosciences" in 2004 and again during his research internship "electrical mapping" in 2008. These co-operations motivated him to pursue a PhD-track at the department of Physiology at Maastricht University under supervision of prof. dr. Frits Prinzen and prof. dr. Angelo Auricchio. Initiated in August 2008, the PhD-project aimed to optimize identification and treatment of the electrical substrate of cardiac resynchronization therapy. During this period he received the Young Physiologist Award for best poster presenter from the Dutch Society of Physiology three times.

From January to July 2012 he gained clinical experience in cardiology at Maastricht University Medical Center which enabled him to pursue a specialization tract from September 2013 to September 2019 at Maastricht University Medical Center, Orbis Medical Center (Sittard) and Atrium Medical Center (Heerlen). 


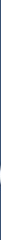




\section{List of Publications}

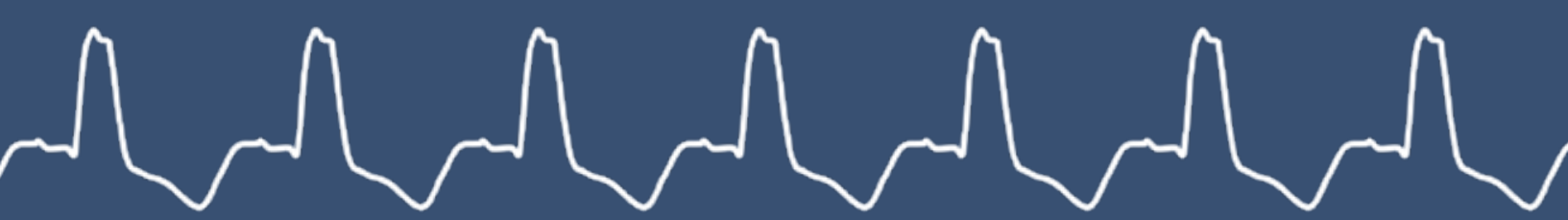


List of Publications

212 


\section{List of Publications}

Ploux S, Strik M, van Hunnik A, van Middendorp LB, Kuiper M, Prinzen FW.. Acute Electrical and Hemodynamic Effects of Multi-Left Ventricular Pacing for Cardiac Resynchronization Therapy in the Dyssynchronous Canine Heart. Heart Rhythm. 2013 Oct 9. [Epub ahead of print]

van Middendorp LB, Strik M, Houthuizen P, Kuiper M, Maessen JG, Auricchio A, Prinzen FW. Electrophysiological and Hemodynamic Effects of Vernakalant and Flecainide During Cardiac Resynchronization in Dyssynchronous Canine Hearts. J Cardiovasc Pharmacol. 2013 Sep 30. [Epub ahead of print]

Strik M, van Middendorp LB, Houthuizen P, Ploux S, van Hunnik A, Kuiper M, Auricchio A, Prinzen FW. The Interplay of Electrical Wave Fronts as Determinant of the Response to Cardiac Resynchronization Therapy in Dyssynchronous Canine Hearts. Circ Arrhythm Electrophysiol. 2013 Sep 18. [Epub ahead of print]

Lumens J, Ploux S, Strik M, Gorcsan III J, Cochet H, Derval N, Strom M, Ramanathan C, Ritter P, Haïssaguerre M, Jaïs P, Arts T, Delhaas T, Prinzen FW, Bordachar P. Comparative electromechanical and hemodynamic effects of left ventricular and biventricular pacing in dyssynchronous heart failure: electrical resynchronization versus left-right ventricular interaction. I Am Coll Cardiol. 2013 Aug 13. [Epub ahead of print]

Strik M, van Deursen CJ, van Middendorp LB, van Hunnik A, Kuiper M, Auricchio A, Prinzen FW. Transseptal conduction as an important determinant for cardiac resynchronization therapy, as revealed by extensive electrical mapping in the dyssynchronous canine heart. Circ Arrhythm Electrophysiol. 2013 Aug 1. 6(4): 682-9

van Deursen CJ, Strik M, Rademakers LM, van Hunnik A, Kuiper M, Wecke L, Crijns HJ, Vernooy K, Prinzen FW. Vectorcardiography as a tool for easy optimization of cardiac resynchronization therapy in canine left bundle branch block hearts. Circ Arrbythm Electrophysiol. 2012. 5:544-552. 
Strik M, Regoli F, Auricchio A, Prinzen F. Electrical and mechanical ventricular activation during left bundle branch block and resynchronization. J Cardiovasc Transl Res. 2012;5:117-126.

Strik M, van Middendorp LB, Vernooy K. Animal models of dyssynchrony. $J$ Cardiovasc Transl Res. 2012;5:135-145.

Strik M, Rademakers LM, van Deursen CJ, van Hunnik A, Kuiper M, Klersy C, Auricchio A, Prinzen FW. Endocardial left ventricular pacing improves cardiac resynchronization therapy in chronic asynchronous infarction and heart failure models. Circ Arrbythm Electrophysiol. 2012;5:191-200.

Prinzen F, Strik M, Regoli F, Auricchio A. Basic physiology and hemodynamics of cardiac pacing (chapter 9). In: Ellenbogen KA, ed. Clinical cardiac pacing, defibrillation, \& resynchronization therapy. $4^{\text {th }}$ edition. Saunders 2011.

Strik M, Ploux S, Vernooy K, Prinzen FW. Cardiac resynchronization therapy: Refocus on the electrical substrate. Circ J. 2011;75:1297-1304.

Rademakers LM, van Kerckhoven R, van Deursen CJ, Strik M, van Hunnik A, Kuiper M, Lampert A, Klersy C, Leyva F, Auricchio A, Maessen JG, Prinzen FW. Myocardial infarction does not preclude electrical and hemodynamic benefits of cardiac resynchronization therapy in dyssynchronous canine hearts. Circ Arrbythm Electrophysiol. 2010;3:361-368.

Mills RW, Cornelussen RN, Mulligan LJ, Strik M, Rademakers LM, Skadsberg ND, van Hunnik A, Kuiper M, Lampert A, Delhaas T, Prinzen FW. Left ventricular septal and left ventricular apical pacing chronically maintain cardiac contractile coordination, pump function and efficiency. Circ Arrbythm Electrophysiol. 2009;2:571579 . 


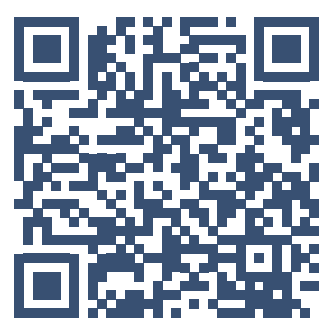


